\title{
Desarrollo de la
}

\section{alfabetización}

\section{en niños preescolares}

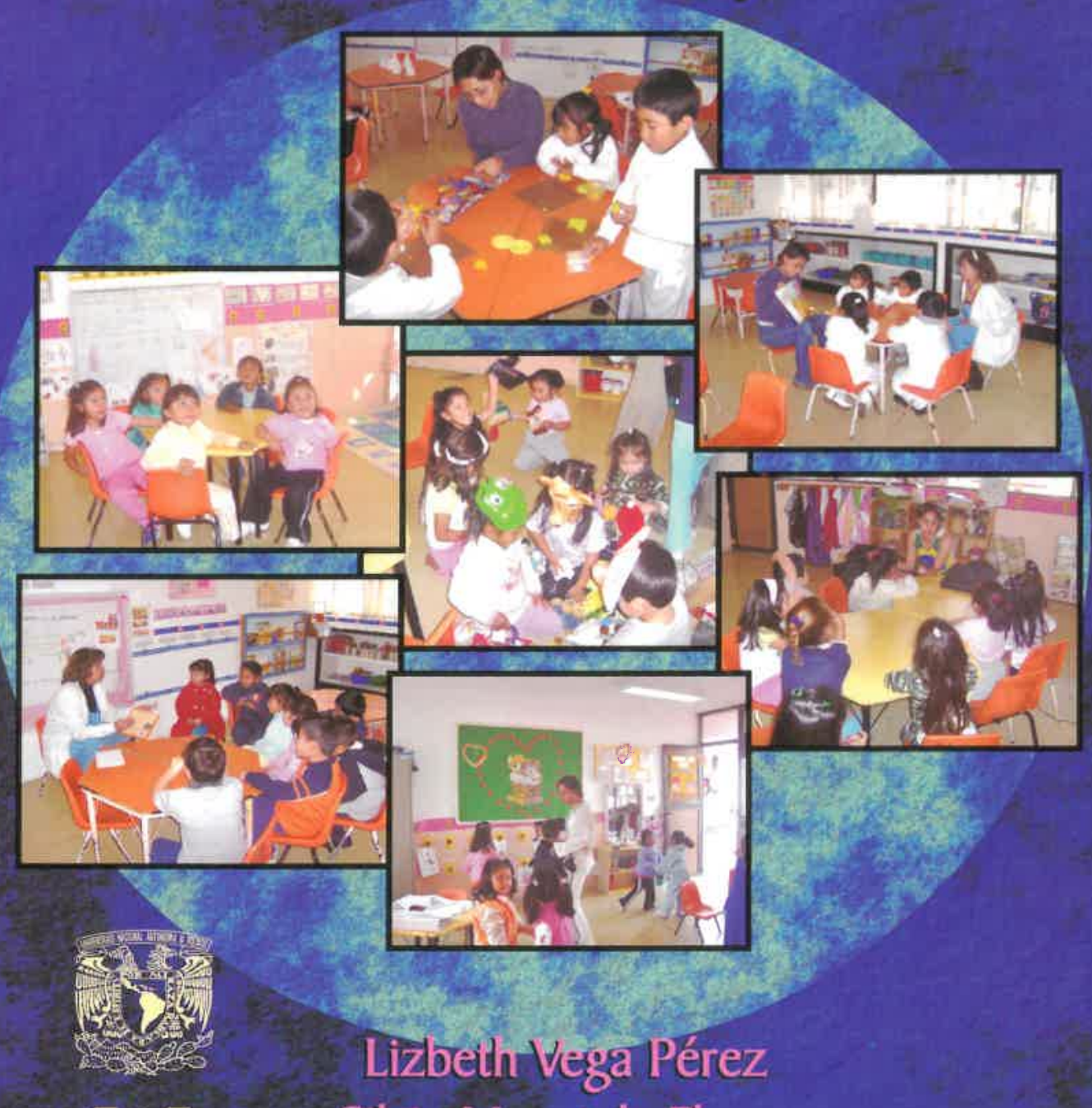

Z15

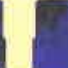

(e) Facultrad de psicologia

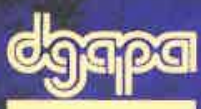

1. $\mathrm{N} A \mathrm{M}$
Silvia Macotela Flores

Facultad de Psicología Universidad Nacional Autónoma de México Esta publicación fue impresa con recursos del proyecto PAPIME EN 304004 
DESARROLLO DE LA ALFABETIZACIÓN EN NIÑOS PREESCOLARES 
FACULTAD DE PSICOLOGÍA, UNAM

Responsable de la edición Ma. Elena Gómez Rosales

Diseño por computadora

Nidia Irene Estudillo Montecillos

Diseño de portada Aurelio Jesús Graniel Parra

Revisión técnica Aurelio Jesús Graniel Parra 


\section{Desarrollo de la slitabetización en Niños Preescolares}

Lizbeth Vega Pérez

Silvia Macotela Flores †

FACULTAD DE PSICOLOGÍA

UNIVERSIDAD NACIONAL AUTÓNOMA DE MÉXICO

MÉXICO 2007 


\section{COMITÉ EDITORIAL}

Dra. Lucy María Reidl Martínez

Dra. Amada Ampudia Rueda

Dra. Rosa del Carmen Flores Macías

Lic. Silvia Teresa Lizárraga Rocha

Dra. Sofía Rivera Aragón

M. en C. Alfonso Salgado Benítez

Dr. Carlos Santoyo Velasco

Dr. Jesús Felipe Uribe Prado

Psic. Ma. Elena Gómez Rosales

Primera edición: 2007

D.R. (C) 2007. Universidad Nacional Autónoma de México

Ciudad Universitaria. 04510, México, D. F.

FACULTAD DE PSICOLOGÍA

Impreso y hecho en México

ISBN 978-970-32-4945-9 
A la memoria de la Dra. Silvia Macotela Flores. Lizbeth Vega Pérez 


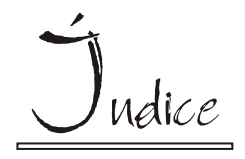

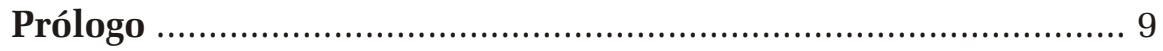

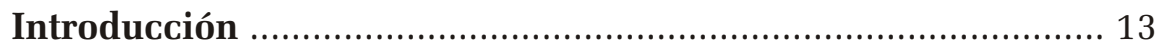

Capítulo 1. Aproximaciones teóricas ........................................... 17

Concepciones del desarrollo de la alfabetización .................... 17

Perspectivas teóricas que explican el desarrollo de la alfabetización .................................................................. 25

Capítulo 2. Lenguaje oral y escrito: Semejanzas, relaciones y diferencias .......................................... 35

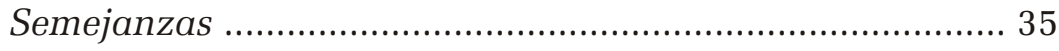

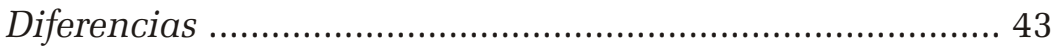

Capítulo 3. Papel de los padres en el desarrollo de la alfabetización ....................................................... 47

Ambiente familiar ........................................................... 47

Programas de capacitación a padres ................................ 52

Capítulo 4. Papel de las maestras en el desarrollo de la alfabetización 
Capítulo 5. Papel de la lectura de cuentos en el desarrollo de la alfabetización

Fundamentos del presente trabajo

Capítulo 6. Descripción del estudio realizado

Objetivos 83

Variables 83

Método 90

Procedimiento 95

Capítulo 7. Resultados obtenidos 97

Análisis realizados 97

I. Resultados para el objetivo 1 98

II. Resultados descriptivos de las variables contextuales y lingüísticas orales

III. Resultados para el objetivo 2

Capítulo 8. Comentarios finales y conclusiones 149

Comentarios finales 149

Conclusiones 163

Referencias 169

Glosario 181

\section{Anexos}

Cuestionario de actividades relacionadas con la lectura en el hogar 191

Lista cotejable para la lectura de cuentos en el hogar. 195

Lista cotejable para la lectura de cuentos en la escuela 199

Contenido y características psicométricas del

Instrumento para evaluar habilidades precurrentes para la lectura, EPLE .

Contenido y características psicométricas del instrumento de observación de los logros de la lectoescritura inicial

Resultados del análisis de regresión por tareas de desarrollo de la alfabetización 


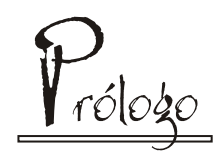

Un lector que lee atentamente, reflexiona, habla animadamente con otros lectores, recuerda, relee, puede volverse amigo de un millar de libros a lo largo de su vida (Zaid, 2004, p. 15). En una época en que se habla de crisis en las habilidades lectoras de los niños mexicanos, Desarrollo de la alfabetización en niños preescolares plantea posibilidades reales y contundentes, fundamentadas en investigación. Iniciar a los niños como amigos de los libros para el resto de sus vidas, como plantea Zaid, requiere de la mediación de los adultos.

Los planteamientos de Vega y Macotela en Desarrollo de la alfabetización en niños preescolares y los datos que arrojó la investigación, invitan a cuestionarnos el quehacer educativo con los niños y las niñas de edad preescolar para alfabetizarlos. Al respecto, Adelaida Nieto señala: Mañana es tarde para las niñas y para los niños porque sencillamente, mañana ya no serán niñas ni niños (Nieto, 2003, p. 9). Dado que mañana es muy tarde, en cuanto a la alfabetización se refiere, debemos iniciarlos como lectores ya, aunque sigue pendiente el gran cuestionamiento de cómo hacer para que se logre la meta con los efectos que señala Zaid.

En el libro, Vega y Macotela, hacen un recorrido por las diferentes perspectivas teóricas que históricamente han explicado los procesos lectores de los niños de edad preescolar y, por ende, han guiado las propuestas y acciones educativas. Como tal, el recorrido es una referencia importante para los interesados en el tema, además de profundizar en la perspectiva que respalda el trabajo y la que prevalece en la actualidad. 
Las autoras se propusieron: 1) Caracterizar el desarrollo de la alfabetización en una muestra de niños preescolares; 2) Presentar los resultados descriptivos de las habilidades lingüísticas orales y las variables contextuales; 3) Analizar la contribución de variables involucradas en el desarrollo de la alfabetización en niños preescolares. La investigación está lograda impecablemente en cuanto al empleo de instrumentos, pertinencia de análisis, descripciones detalladas, resultados estadísticos, tablas de datos y tablas comparativas del desempeño de los niños por edad.

El trabajo alude de manera explícita a aspectos del desarrollo alfabetizador que pocas veces se analizan y que son fundamentales para el éxito en la alfabetización escolar. Uno de ellos es el análisis comparativo de lo que hacen las madres y los padres cuando les leen cuentos a los niños y lo que hacen las docentes al realizar la misma actividad. [...] La mayor parte de la actividad por parte de las madres se presenta durante la lectura del cuento y está encaminada básicamente a lograr la comprensión de la historia, más que pretender que los niños conozcan los convencionalismos que se utilizan durante la lectura o intenten identificar palabras o leer por sí mismos, es decir, interactuar con el texto (p. 129). La mayor actividad de las maestras, al igual que la de las madres se llevó a cabo durante la lectura del cuento, sin embargo, a diferencia de las primeras, las maestras también tuvieron mucha actividad después de la lectura del mismo. En el caso particular de la lectura del cuento al grupo de niños, las experiencias y comentarios de unos y otros niños pueden ser aprovechadas para promover el conocimiento y comprensión del contenido del texto y de los convencionalismos del lenguaje escrito (p. 133-134).

Las autoras, con la sobriedad requerida para guiar una investigación, mantienen la discusión de los resultados dentro del ámbito de los objetivos, procedimientos y los datos, como es el caso de las citas anteriores. Sin embargo, los resultados son de una riqueza tal que permiten considerar otros aspectos del desarrollo alfabetizador, los cuales se mantienen en el ámbito de lo implícito a lo largo del documento. Uno de estos aspectos es lo que Barton (1994) analiza como las bases sociales del desarrollo alfabetizador y, la idea que él recalca, que para comprender lo que va aprendiendo el niño en su desarrollo alfabetizador se requieren interpretaciones sociales, psicológicas y culturales.

Desde una perspectiva que se aleja de lo escolar, cabe cuestionarse y resaltar la función diferenciada e igualmente importante de padres, madres y maestros para fomentar el desarrollo alfabetizador de las niñas y los niños. El análisis de las diferentes variables realizado por 
Vega y Macotela tiene implicaciones importantes relacionadas con los aspectos sociales, psicológicos y culturales del desarrollo alfabetizador. Por ejemplo, señalan que la escolaridad de los padres se relaciona también de manera significativa con la lectura de cuentos por las maestras, y a su vez esta última con las actividades de lectura que se realizan en los hogares, lo que puede querer decir que los padres de mayor escolaridad se interesan más en tener intercambios con las educadoras, que les permitan conocer las actividades que realizan sus hijos en la escuela y tratar de complementarlas mediante actividades relacionadas con la lectura en el hogar (p. 161).

Si bien no se trata de contra argumentar acerca del interés de los padres más escolarizados por mantener comunicación con la escuela, un argumento adicional es que los resultados ilustran las continuidades y discontinuidades entre escuela y hogar que se han detectado en diferentes estratos de escolaridad y por ende, socioeconómicos (Barton, 1994; Heath, 1983). Heath (1983), señaló que las familias de mayor escolaridad llevan a cabo acciones alfabetizadoras que emulan y preparan gradualmente a los niños para el lenguaje y las actividades escolares, mientras que los menos escolarizados, sin bien tenían una gran riqueza lingüística, ésta no emula la de la escuela.

La importancia del las prácticas alfabetizadoras del hogar y la comunidad son fundamentales en la vida de los individuos y para las maneras en que los mismos imparten sentido a las prácticas y experiencias alfabetizadas. Por ejemplo, las autoras señalan que los padres añadieron a la lista original materiales como: computadora, películas para niños, acuarelas, letras de plástico, pizarrón y libros de otros niveles educativos como primaria, secundaria, preparatoria y psicología (p. 123). Es probable que los padres consideran que la presencia de materiales en general contribuyen al éxito escolar y por tanto al desarrollo alfabetizador de los niños, aún cuando dichos materiales no sean propiamente para niños de edad preescolar.

En este sentido, uno de los aspectos implícitos del trabajo se relaciona con el sentido que les imparten los padres y madres a las prácticas y experiencias alfabetizadoras en los hogares y las que les imparten los maestros. Paradójicamente, el peso psicológico, social y cultural de la escuela frecuentemente interfiere con el ideal de formar lectores y escritores para el mañana, cuando los niños de hoy ya no serán niños (Nieto, 2003).

Argüelles (2003), señala que la herencia de los oficios familiares donde el hijo se vuelve aprendiz y luego maestro del oficio con sólo ver a su padre, e incluso puede llegar a superarlo en ese dominio al 
agregarle su propia imaginación. Otra prueba son los hijos que provienen de hogares donde la lectura es un hecho natural y cotidiano. El oficio de leer es un aprendizaje que puede ser tan natural como sumarse a una conversación, a un "diálogo de las personas de su ambiente", precisamente "metiendo la cuchara” (p. 89-90).

Los propósitos, resultados, análisis de resultados y discusión de Vega y Macotela, no sólo son una contribución de suma importancia en sí misma. Explícita e implícitamente ilustran la pertinencia y relevancia de variables fundamentales que abren camino para realizar más investigaciones en el campo de la psicología de la educación acerca del desarrollo alfabetizador de los niños y las niñas en México. Igualmente, los resultados y las variables detectadas son factores que potencian intervenciones encaminadas a promover la mediación efectiva de padres, madres, docentes y otros adultos para invitar a los niños a convertirse en amigos y recalco, amigos, de un millar de libros a lo largo de sus vidas.

Ileana Seda Santana Facultad de Psicología Universidad Nacional Autónoma de México

\section{Referencias}

Argüelles, J. D. (2003). ¿Qué leen los que no leen? México: Paidós.

Barton, D. (1994). Literacy, an introduction to the ecology of written language. Oxford, Reino Unido: Blackwell Publishing.

Heath, S. B. (1983). Ways with words. Cambridge, Reino Unido: Cambridge University Press.

Nieto, A. (2003). Mañana es muy tarde para las niñas y para los niños. Lecturas sobre Lecturas, 7, 9-18.

Zaid, G. (2004). El costo de leer y otros ensayos. México: Consejo Nacional para la Cultura y las Artes. 


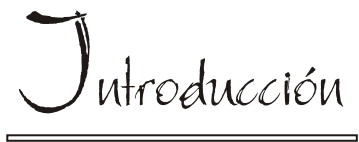

La Secretaría de Educación Pública (SEP, 2001) plantea entre sus metas lograr una educación básica de calidad. Definen a ésta como la que se obtiene al lograr en los educandos "el desarrollo de competencias cognoscitivas fundamentales de los alumnos, entre las que destacan las habilidades comunicativas básicas: lectura, escritura, comunicación verbal y el saber escuchar" (p. 123). En este sentido, el desarrollo de las habilidades comunicativas constituye una tarea prioritaria para la educación básica.

Por otra parte, el Programa de Educación preescolar (SEP, 2004) menciona que favorecer las competencias comunicativas básicas constituye una prioridad en la educación preescolar, no sólo en este campo formativo (lenguaje y comunicación) sino en todas las actividades escolares (p. 62).

Estas metas son congruentes con el concepto de desarrollo de la alfabetización que sirve de marco de referencia para el presente trabajo.

Este concepto enfatiza que el desarrollo de la alfabetización de los niños es un proceso gradual que se inicia muy temprano en la vida y se va construyendo a través de la participación activa en actividades cotidianas relacionadas con la lectura y la escritura. De hecho, ellos inician su vida como seres letrados mucho antes de que sean capaces de leer en el sentido convencional y esta alfabetización puede observarse a través de las actividades diarias que el niño realiza en relación con el lenguaje escrito (Valencia y Sulzby, 1991; Ferreiro, 1998; Morrow, 2001). 
Este desarrollo de la alfabetización, en particular en los años preescolares, se define como "todos los intentos de los niños por interpretar símbolos, así como para comunicarse mediante ellos, independientemente de que sean texto impreso, garabatos o dibujos" (Dixon-Krauss, 1997). Por su parte, Justice y Kadaraveck (2002, p. 12) lo definen como "el conocimiento y la conducta de los niños relacionados con la lectura y la escritura cuando aún no son alfabetizados convencionalmente."

Un aspecto muy importante de este desarrollo es que no se construye a partir de la instrucción directa, sino de la observación y participación en actividades cotidianas relacionadas con el lenguaje, la lectura y la escritura. Este conocimiento precede a la lectura y escritura convencionales y existe evidencia de que está íntimamente relacionado con ellas (Jordan, Snow y Porsche, 2000; Purcell, 1996; Sonnenschein, Baker, Sarpell y Schmidt, 2000). Asimismo, se ha enfatizado la relación estrecha que existe entre el desarrollo en el lenguaje oral y el de la alfabetización (Curtis, 1980; Glazer, 1989; Garton y Pratt, 1991; Fields y Spangler, 2000).

Por otra parte, este desarrollo se da en los ambientes cotidianos y personas con los que interactúa el niño (la casa y la escuela) y también se ha establecido su relación con estos ambientes (Tabors y Dickinson, 2001; Britto, 2001; Nielsen y Monson, 1996; Smith, 2001; Collins, Oakar y Hurt, 2002, Vega, 2006). Otro aspecto que se ha enfatizado dentro de estos ambientes, por considerarse de suma importancia, es el papel que juega la lectura de cuentos, por parte de padres y maestros, para promover el desarrollo de la alfabetización en niños preescolares (Strickland y Taylor, 1989; Rosenhouse, Feitelson, Kita y Goldstein, 1997; De Temple, 2001; Lozada y Vega, 2002; Rocha y Vega, 2002).

Existe evidencia empírica de la relación entre cada uno de los aspectos mencionados (lenguaje oral, materiales y actividades de lectura en el hogar, lectura de cuentos) y el desarrollo de la alfabetización.

Por tal motivo, el presente trabajo aporta elementos que permiten: 1) caracterizar el desarrollo de la alfabetización en niños preescolares y; 2) analizar la contribución de diversos aspectos involucrados en el desarrollo de la alfabetización en niños preescolares: habilidades lingüísticas orales, materiales de lectura al alcance del niño en el hogar, actividades relacionadas con la lectura en el hogar, la lectura de cuentos por parte de padres y maestros. Se consideró la contribución, tanto de manera conjunta como de cada uno por separado. 
El trabajo que se describe aporta elementos relevantes, que permiten identificar cuáles son los aspectos a enfatizar para promover el desarrollo de la alfabetización en los niños preescolares, abarcando tanto al propio niño como a sus padres y sus maestros. Los resultados del estudio realizado aportan evidencia empírica para esclarecer el proceso de desarrollo de la alfabetización que permitirá la realización de acciones efectivas encaminadas a su promoción.

Al considerar que la tarea prioritaria de las escuelas sigue siendo enseñar a leer (Gillet y Temple, 1994) y el desarrollo de las funciones comunicativas básicas (SEP, 2001); el estudio que se reporta tiene un valor preventivo importante pues permite aprovechar, al basarse en evidencia empírica, los conocimientos que los niños poseen respecto de la lectura y la escritura para que el acceso a la instrucción formal $^{1}$ tenga mayores probabilidades de ser exitosa.

En el primer capítulo se esclarece el concepto de desarrollo de la alfabetización y se describen dos perspectivas teóricas que explican los procesos que dan lugar a dicho desarrollo. En el segundo capítulo se presenta un análisis de los fundamentos teóricos y la evidencia empírica de las relaciones entre el lenguaje oral y el lenguaje escrito. En el tercero y cuarto capítulos se analizan los fundamentos teóricos y la evidencia empírica del papel que juegan el ambiente familiar y escolar como promotores del desarrollo de la alfabetización en niños preescolares. En el quinto capítulo, se analizan los fundamentos teóricos y la evidencia empírica del papel de la lectura de cuentos en la casa y en la escuela como promotora del desarrollo de la alfabetización. El capítulo concluye con la presentación de los fundamentos de la investigación que se reporta en este documento.

El capítulo seis describe el método seguido para el logro de los objetivos. Se incluye la presentación de los objetivos que guiaron la investigación y se definen las variables del estudio. Se describen las características de los participantes, escenarios, materiales e instrumentos utilizados. Se presenta el procedimiento seguido para la obtención de los datos.

El séptimo capítulo presenta los resultados. En primer lugar se presentan los resultados descriptivos y el análisis de los mismos, lo que permite cubrir el objetivo de caracterizar el desarrollo de la alfabeti-

\footnotetext{
${ }^{1}$ En el presente reporte se considera instrucción formal a aquella que se refiere a la instrucción directa sobre los convencionalismos del lenguaje escrito y que generalmente se imparte al ingreso a la escuela primaria.
} 
zación en una muestra de niños preescolares. Posteriormente, se describen las relaciones encontradas entre las variables con objeto de responder al objetivo de analizar la contribución de las variables del niño (edad y lenguaje oral) y del ambiente (materiales y actividades de lectura en el hogar, lectura de cuentos por madres y maestras) al desarrollo de la alfabetización.

El último capítulo discute los resultados obtenidos a la luz de los fundamentos teóricos y las implicaciones de dichos resultados. En este capítulo se presentan también las conclusiones del estudio, discutiendo tanto los hallazgos, como las aportaciones y limitaciones. 


\section{. capículo 1}

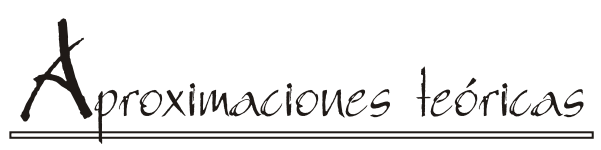

\section{Concepciones del Desarrollo de la Alfabetización}

\section{Concepto de aprestamiento}

Durante décadas diversos investigadores y pensadores se han interesado en el proceso de alfabetización y las variables involucradas. Uno de los primeros aspectos considerados consistió en determinar el momento preciso en que un niño está listo para aprender a leer. Esto dio como resultado el interés por precisar qué es lo que un niño necesita para acceder con éxito al aprendizaje de la lectura.

Desde los años veinte se ha manejado el concepto de lo que un niño debe poseer para acceder con éxito al aprendizaje de la lectura, surgiendo en estos tiempos el concepto de "aprestamiento". Este concepto consideraba que el desarrollo se sucede en etapas que se siguen en un orden inevitable y que, el pasar de una etapa a otra es producto de la maduración (Gesell, 1928 cit. en Durkin, 1980). Dadas las consideraciones anteriores, lo que se requería para que un niño aprendiera a leer era simplemente esperar a que estuviera listo para iniciar la instrucción. Posteriormente (Murphet y Washborne, 1931 cit. en Durkin) se determinó que una edad mental de 6 a 6 años y medio era una buena edad para iniciar la instrucción en lectura. Algunos autores como Gates y Bond (1936, en Durkin) se opusieron a este concepto enfatizando la importancia de ajustarse a las necesidades y limitaciones del individuo. Estos autores consideraban que el aprestamiento se desarrolla y no es algo por lo que hay que esperar. Este aprestamiento no depende de la naturaleza del niño mismo sino de la naturaleza del programa de lectura. 
La noción de aprestamiento para la lectura dio origen a la elaboración de una gran cantidad de pruebas, así como de programas específicos. La idea original de estos desarrollos consistía en utilizar las pruebas en un sentido diagnóstico con el fin de basar en él la aplicación del programa de aprestamiento. Pero esto no ocurría en la realidad: Las pruebas se utilizaban en un sentido clasificatorio, los contenidos de los programas rara vez estaban relacionados con la lectura y era más raro aun que se ajustaran a las necesidades individuales del niño (Durkin, 1980).

Durkin (1980) basada en las ideas de Ausubel, plantea la necesidad de determinar el aprestamiento del niño en función no sólo de sus características o habilidades, sino considerando también las demandas que la instrucción en la lectura le presenta. Define el aprestamiento para la lectura de la siguiente manera: "El aprestamiento es la adecuación de las capacidades existentes con relación a las demandas de una tarea de aprendizaje dada" (Ausubel, 1959 cit. por Durkin, 1980, p. 66) por lo que aclara que la pregunta en realidad no deberá ser si el niño está listo para la instrucción en la lectura sino si el niño está listo para un programa de instrucción en particular. Durkin ofrece un elemento adicional al concepto tradicional de aprestamiento al enfatizar no sólo las habilidades del niño, sino además el ambiente de instrucción y las demandas de éste.

Durkin critica la práctica de evaluar el "aprestamiento" mediante la utilización de pruebas, ya que considera que una prueba de aprestamiento puede ser más difícil que la misma instrucción de la lectura. Afirma que además, existe el inconveniente de que la mayoría de los autores aún no se ponen de acuerdo respecto de lo que constituyen las habilidades esenciales para la lectura. Considera que la mejor manera de evaluar es dar al niño oportunidades variadas para empezar a leer y que la evaluación debe realizarse a diario en el momento mismo de la instrucción. La instrucción y la evaluación deben realizarse de manera paralela ya que la habilidad para leer es un proceso que se desarrolla poco a poco. El "aprestamiento" no es algo que ocurra de manera inmediata, sino que se va desarrollando día a día. Es algo que se va dominando paso a paso en un largo periodo de tiempo, por lo que no habría que preguntarse si el niño está listo para aprender a leer sino qué aspectos domina y cuáles no.

Como se verá más adelante, esta idea de Durkin respecto del proceso de desarrollo que siguen los niños en su aprestamiento para la lectura y la idea de que la evaluación debe realizarse proporcionando al niño oportunidades para leer y en el mismo momento de la instrucción serán retomadas por otros autores. 
El concepto tradicional de aprestamiento se refiere a "aquellas habilidades necesarias para que una persona inicie el proceso de aprender a leer" (Clay, 1991). Este concepto sugiere que existe un punto en el tiempo en que el niño está listo para aprender a leer y no se alcanza a describir realmente qué es lo que está sucediendo con la alfabetización en el niño.

En la concepción de aprestamiento se considera que los niños aprenden a leer una vez que han recibido instrucción formal en lectura, básicamente en primero de primaria, por lo que en preescolar se enfatizan una serie de habilidades en una secuencia formal.

Morrow (2001) afirma que existen por lo menos las siguientes suposiciones equivocadas en esta concepción:

$\boldsymbol{\nabla}$ Los niños no poseen conocimiento alguno respecto del lenguaje escrito cuando llegan a la instrucción formal.

$\boldsymbol{\nabla}$ Los niños necesitan un programa instruccional de aprestamiento que no incluye familiarizarse con el lenguaje escrito sino actividades para el desarrollo de habilidades motoras gruesas y finas y de discriminación auditiva y visual.

Teale y Sulzby, (1986 cit. en Nielsen y Monson, 1996) mencionan que el concepto de aprestamiento es un buen concepto que ha sido mal aplicado. Con este comentario enfatizan el hecho de que no hay desacuerdo entre los autores respecto de la necesidad de un conocimiento previo, así como de que el desarrollo del lenguaje y otros factores fortalecen el desarrollo lector de un niño. Pero estos autores afirman que las decisiones se han tomado desde un punto de vista adulto más que desde un punto de vista del desarrollo.

Otros autores (Clay, 1989) empezaron a considerar el papel del ambiente y el conocimiento que el niño posee al ingresar a la primaria respecto del lenguaje escrito, de tal suerte que desde los años sesenta se empezó a abandonar gradualmente este concepto de aprestamiento. Los padres, maestros e investigadores empezaron a observar que los niños escuchaban las historias, las discutían y más aun, generaban sus propias historias escribiendo e inventando letras y que además eran capaces de leerlas. A partir de estas observaciones, se encontró que la alfabetización era un conjunto de conocimientos y habilidades que iniciaban muy temprano en la vida de los niños, quienes aprendían todo esto a partir del ambiente cotidiano que existía en sus hogares. 
Las aportaciones de Durkin respecto de considerar el ambiente de instrucción en el desarrollo de la alfabetización en los niños y las observaciones hechas por ella y otros autores sobre el conocimiento previo que tiene el niño antes de ingresar a la primaria y recibir instrucción formal en lectura y escritura, dieron como resultado un cambio en la concepción de aprestamiento para la lectura. Del concepto de "aprestamiento" que consideraba sólo las habilidades presentes en el niño se pasó al concepto de "Desarrollo de la alfabetización” (Nielsen y Monson, 1996) el cual enfatiza mayormente el papel de la experiencia en la alfabetización de los niños.

\section{Concepto de Desarrollo de la Alfabetización (Emergent literacy) ${ }^{2}$}

Teale y Sulzby (1989) mencionan que quizá el aspecto más importante de la investigación que llevó a la creación del concepto de desarrollo de la alfabetización fue el centrar los esfuerzos en analizar dicho desarrollo desde el punto de vista del niño, y tratar de comprender qué es lo que ocurre en su mente y en su mundo. Estos estudios han observado a los niños involucrados en actividades de lectura y escritura. Los resultados se han interpretado a la luz de perspectivas multidisciplinarias basadas en la psicología cognoscitiva, la antropología, el desarrollo del niño y teorías de la interacción social.

Según Sulzby y Teale (1991 cit. en Saint-Laurent, Giasson y Couture, 1997, p. 7) el desarrollo de la alfabetización se refiere a "las primeras señales de habilidades y conocimiento relacionadas con el lenguaje escrito y abarcan el periodo entre el nacimiento y el momento en que los niños leen y escriben de una manera convencional".

Dixon-Krauss (1997, p. 18) define el desarrollo de la alfabetización como "un periodo continuo en el desarrollo del niño que incluye todos sus intentos por interpretar símbolos, así como para comunicarse mediante ellos, independientemente de que los signos sean texto impreso, garabatos o dibujos".

Por su parte, Justice y Kaderaveck (2002, p. 12) definen al desarrollo de la alfabetización como "el conocimiento y la conducta de los niños relacionados con la lectura y la escritura cuando aún no son alfabetizados convencionalmente".

\footnotetext{
2 Del inglés "emergent literacy". El término se ha traducido como "alfabetización emergente", "alfabetización precoz", "alfabetización en evolución” y "desarrollo de la alfabetización” Este último es el término que se utiliza en este trabajo.
} 
Clay (1989) afirma que la alfabetización es un conjunto de habilidades y conocimientos en desarrollo que se inicia muy temprano en la vida de los niños, quienes toman un poco de aquí y un poco de allá conforme interactúan con los escenarios preescolares.

Los niños no alcanzan un punto en el tiempo en el que automáticamente están listos para la lectura y la escritura. Cada niño avanza lenta y gradualmente agregando conocimientos acerca del lenguaje escrito antes de entrar a la escuela. Estos conocimientos son el punto de partida para iniciar la instrucción. Este es el concepto de desarrollo de la alfabetización (Clay, 1989, p.v).

Morrow (2001) por su parte, agrega que la alfabetización involucra todas las habilidades de comunicación y cada habilidad fortalece a la otra en la medida en que se aprenden de manera concurrente. Menciona que el término desarrollo de la alfabetización fue usado por primera vez por Clay en 1966 y que este concepto asume que el niño adquiere conocimiento acerca del lenguaje, la lectura y la escritura antes de su ingreso a la escuela. La alfabetización inicia su desarrollo muy temprano en la vida y continúa a lo largo de ésta.

"El desarrollo de la alfabetización se observa en los garabatos de un niño, aun cuando no existan letras claramente reconocibles. El niño que reconoce las diferencias entre los garabatos y el dibujo tiene nociones de la diferencia entre la escritura y las ilustraciones. De la misma manera, cuando un niño narra un libro de cuentos mientras ve las ilustraciones y el texto impreso y da la impresión de que está leyendo, esta actividad se considera alfabetizada, aun cuando no pueda llamarse lectura en un sentido convencional" (Morrow, 2001, p. 133).

El concepto de desarrollo de la alfabetización involucra los siguientes elementos (Teale y Sulzby, 1989; McGee y Richgels, 1990):

v Para la mayoría de los niños en una sociedad alfabetizada, aprender a leer y escribir inicia muy temprano en la vida. Desde la edad de 2 o 3 años los niños son capaces de identificar etiquetas, señales y logotipos en su casa y comunidad. Los niños de 4 años escriben ya, aunque de una manera diferente a la escritura convencional (Harste, Woodward y Burke, 1984).

v Las funciones del lenguaje escrito son parte integral del proceso de aprendizaje que se está llevando a cabo. La mayoría de las actividades relacionadas con la lectura en que se involucran los niños se dirigen a algún objetivo que va más allá del propio lenguaje escrito. 
$\boldsymbol{\nabla}$ El lenguaje oral, la lectura y la escritura se desarrollan de manera concurrente e interrelacionada. La competencia en el lenguaje oral está relacionada con el desarrollo de la lectura y la escritura, y las experiencias relacionadas con la lectura influyen en el lenguaje oral.

$\boldsymbol{\nabla}$ La lectura y la escritura de los niños pequeños puede ser diferente a la de los adultos, pero no es menos importante.

$\boldsymbol{\nabla}$ En la construcción del conocimiento del lenguaje escrito. El conocimiento de la función de lo escrito precede al conocimiento de la forma.

$\boldsymbol{\nabla}$ Aprender a leer y escribir es un proceso de desarrollo. Los niños pasan por los diferentes estadios de diferentes maneras y a diferentes edades. Existen diferentes estadios en la adquisición de la lectura (Mason, 1980), así como diferentes estadios en el desarrollo de la escritura (Sulzby, Barnhart y Hiesima, 1990).

$\boldsymbol{\nabla}$ En un ambiente rico en alfabetización, los niños crecen experimentando con la lectura y la escritura en muchos aspectos de su vida cotidiana y a partir de ello construyen su comprensión respecto del lenguaje escrito. Lo alfabetizado se desarrolla a partir de la interacción con otras personas en situaciones de la vida real en las que se utilizan la lectura y la escritura.

> Los niños aprenden a partir de la participación activa. Su participación como aprendices activos en situaciones significativas es un concepto central en el desarrollo de la alfabetización.

$\boldsymbol{\nabla}$ El papel de los padres y otras personas alfabetizadas es facilitar este aprendizaje temprano de la lectura y escritura.

El desarrollo de la alfabetización incluye el desarrollo de una actitud positiva hacia la lectura y la adquisición de habilidades y conocimiento respecto de:

$\boldsymbol{\nabla}$ Las diferencias entre el lenguaje oral y el escrito.

v La dirección de la lectura (de derecha a izquierda y de arriba hacia abajo).

$\boldsymbol{\nabla}$ La comprensión de lo que es una letra, una palabra y una oración.

$\nabla$ El uso adecuado de los libros.

$\boldsymbol{\nabla}$ Los usos diferentes del lenguaje escrito.

$\boldsymbol{\nabla}$ La búsqueda de significado en los textos.

$\nabla$ El reconocimiento de algunas palabras.

Estas conductas son aspectos legítimos del desarrollo de la lectura y la escritura; preceden y se desarrollan hasta convertirse en alfabetización convencional, (Morrow, Burks y Rand, 1992; Sulzby y Teale, 1991 cit. en Saint-Laurent, Giasson y Couture, 1997). 
Mc Gee y Richgels (1990) afirman que al desarrollarse como seres alfabetizados, los descubrimientos que los niños hacen respecto del lenguaje escrito antes de la instrucción, son los siguientes:

$\boldsymbol{\nabla}$ La habilidad del lenguaje escrito (sic) para comunicar significado.

$\boldsymbol{\nabla}$ Las formas del lenguaje escrito.

$\boldsymbol{\nabla}$ Las relaciones entre el lenguaje oral y el escrito.

$\boldsymbol{\nabla}$ Las funciones del lenguaje escrito.

Este conocimiento se construye entre el nacimiento y los seis años de edad aproximadamente, e incluye la etapa preescolar. No se construye a partir de la instrucción directa, sino de la observación y participación en actividades informales relacionadas con la lectura y la escritura y provee al niño los fundamentos de las habilidades posteriores de alfabetización.

Dahl y Freepon (1995) mencionan que en el aprendizaje de la lectura los niños son "transactivos", esto es, que el aprendizaje de la lectura y la escritura y el que los niños se involucren en él ocurre en un contexto dinámico. El sentido que los aprendices den a dicho aprendizaje depende de los contextos sociales y culturales de los salones de clase y la propia comprensión del niño respecto de la lengua escrita.

Estas autoras enfatizan el hecho de que los niños son conscientes del lenguaje escrito e inician sus jornadas como lectores y escritores participando en actividades relacionadas con la lectura en casa. El número y naturaleza de estas actividades afecta su desempeño posterior en el aprendizaje de la lectura. Las costumbres culturales permean las habilidades emergentes de lectura ya que informan al niño de la manera en que el lenguaje oral y escrito se usa en su comunidad.

Saint Laurent, Giasson y Couture (1997) mencionan que a través del modelamiento, la interacción y de un ambiente rico, los padres concientizan a los pequeños acerca de la importancia y utilidad de la lectura, así como de lo interesante que puede resultar. El desarrollo de la alfabetización ocurre en los contextos diarios del hogar, la escuela y la comunidad a través de experiencias funcionales y significativas que requieren el uso de la lengua escrita en ambientes naturales. Estos ambientes son sociales, con adultos y niños interactuando a través de la colaboración y tutoría.

Al respecto, Ferreiro (1998) explica que los niños inician su aprendizaje de la lectura y escritura en los contextos más variados, porque la escritura forma parte del paisaje urbano y la vida urbana solicita continuamente el uso de la lectura: los niños tratan de comprender desde edades muy tempranas información de distinta procedencia. 
Aun cuando el propósito de los adultos no sea informar al niño, recibe información a través de su participación en diversos actos relacionados con el lenguaje escrito, aunque esta participación sea solo como observador. La autora afirma que ningún niño urbano llega a la escuela primaria con total ignorancia respecto de la lengua escrita y esta ignorancia puede atribuirse a los niños rurales sólo si se concibe a la alfabetización como el conocimiento de las letras.

Las concepciones revisadas parten de supuestos diferentes respecto de cómo los niños se convierten en seres alfabetizados.

Mientras que para la concepción de aprestamiento existe un punto en el tiempo en que el niño está listo para recibir instrucción en lectura, en la concepción de desarrollo de la alfabetización, no se considera que existe este punto preciso, ya que los niños van construyendo su conocimiento respecto del lenguaje escrito de manera gradual y desde muy temprana edad, de tal manera que al acceder a la instrucción formal en lectura y escritura (generalmente cuando ingresan a la primaria) poseen ya un amplio bagaje de conocimientos respecto del lenguaje escrito.

Los conocimientos que posee el pequeño, son generalmente ignorados en la concepción de aprestamiento; en tanto que en al concepción de desarrollo de la alfabetización son precisamente ellos los que sientan las bases para la instrucción formal en lectura y escritura.

El concepto de aprestamiento considera que el acceso a la alfabetización debe basarse en una serie de habilidades previas que el niño debe dominar. En la concepción de desarrollo de la alfabetización efectivamente se considera una capacidad inicial (la propia capacidad de aprendizaje del niño) (Hall, 1987) que requiere de las condiciones apropiadas para desarrollarse. El acceso a la alfabetización se da desde temprana edad y se refiere a todas las conductas del niño con relación al lenguaje escrito, considerándose todas ellas conductas alfabetizadas aun cuando no representen alfabetización convencional, en tanto que el la concepción de aprestamiento las conductas alfabetizadas son aquellas que representan la alfabetización convencional que se adquiere a partir de la instrucción.

Otro aspecto que marca una diferencia importante entre estas dos concepciones lo constituye el hecho de que en la concepción de aprestamiento se considera de manera primordial aquello que ocurre dentro del niño, en tanto que en el concepto de desarrollo de la alfabetización efectivamente se considera lo que ocurre dentro del niño; pero con relación al ambiente en que se desenvuelve y a es a partir de la observación y de la participación activa en su interacción con este ambiente que va estructurando sus conductas y conocimientos respecto del lenguaje escrito. 
El presente trabajo retoma el concepto de desarrollo de la alfabetización, considerando que los niños preescolares poseen amplio conocimiento respecto del lenguaje escrito. Este conocimiento lo han ido construyendo sin recibir instrucción directa respecto de él sino a partir de la observación y de la participación activa en actividades relacionadas con la lectura y la escritura tanto en su casa como en la escuela.

Para fines de este estudio, el desarrollo de la alfabetización se define como las primeras habilidades y conocimiento relacionados con el lenguaje escrito y abarca desde el nacimiento hasta que los niños son alfabetizados convencionalmente (Teale y Sulzby, 1991 cit. en Saint-Laurent, Giasson y Couture, 1997, p. 7).

A continuación se describen dos perspectivas teóricas que explican los procesos que dan como resultado el desarrollo de la alfabetización.

\section{Perspectivas teóricas que explican el desarrollo de la alfabetización}

Phillips y Walker (1987) presentan un análisis de dos perspectivas teóricas que explican cómo se desarrolla la alfabetización.

\section{Perspectiva Psicolingüística}

La perspectiva psicolingüística surge de la lingüística generativa transformacional de Chomsky, la cual enfatiza los aspectos creativos del lenguaje, dando la posibilidad de generar un número infinito de oraciones a partir de un número finito de reglas. Adicionalmente, esta perspectiva está basada en las ideas de Piaget, en el sentido de que la lectura como todo objeto de conocimiento se va construyendo por el propio niño a partir de la generación de hipótesis respecto de su función y uso convencional. El conocimiento no es una simple reproducción de lo que se experimenta, sino una construcción activa que involucra elementos de lo que es previamente conocido, lo que se cree y lo que se espera.

El proceso de construcción de la lectura y la escritura en el niño constituye un desafío a través del cual se enfrenta al problema fundamental que consiste en comprender la estructura misma del sistema y reconstruirla. Esto ocurre a partir de la integración de las experiencias progresivas que va teniendo con la lectura y la escritura, que dan como resultado la formación de estructuras mentales (esquemas) cada vez más complejas. Estas estructuras lo capacitan para el acercamiento al conocimiento y dominio de la lengua escrita a través de la acción de las invariantes funcionales descritas por Piaget (organización y adaptación) que tienen un papel fundamental en el proceso de construcción del conocimiento (Pintado, 1999). 
Según Rumelhart "Un esquema es una estructura que permite representar los conceptos genéricos almacenados en la memoria, de tal manera que contiene la red de interrelaciones que subyacen al concepto en cuestión” (1980, p. 33).

De acuerdo a la postura de Rumelhart (1980) los esquemas permiten el dominio de cualquier objeto de conocimiento, en este caso la lengua escrita, a través de las siguientes características:

$\boldsymbol{\nabla}$ Están constituidos por variables que pueden asociarse a diferentes aspectos del ambiente en diferentes instancias del esquema.

$\boldsymbol{\nabla}$ Son como teorías, ya que su función principal es la construcción de la interpretación de un evento, objeto o situación, de tal manera que el proceso de comprensión es análogo a una prueba de hipótesis en la que se evalúa lo adecuado del ajuste y la estimación de parámetros.

S Son como procedimientos, ya que una vez que se ha constatado que sus conceptos subyacentes se ajustan a una situación particular, el esquema se convierte en una teoría prototipo de ella y a la vez en una teoría procedural.

จ Son como "supervisores" (parsers). El proceso de encontrar y verificar los esquemas apropiados consiste en un proceso de "supervisión" que trabaja con elementos conceptuales, en lugar de símbolos, encontrando los constituyentes apropiados para la situación particular.

Partiendo del hecho de que los niños son "solucionadores naturales de problemas" McGee y Richgels (1990) mencionan que gran parte del desarrollo intelectual y cognoscitivo de los niños se relaciona con dar sentido a sus experiencias, a partir de ellas se adquiere el conocimiento que es almacenado en esquemas, los cuales permiten un libre acceso al conocimiento almacenado. Los esquemas permiten cambios a través de complementos o reorganizaciones para establecer relaciones entre lo nuevo y lo conocido.

Los niños aprenden a través de la acción, a medida que se actúa se produce conocimiento y los esquemas se modifican a medida que el pequeño adquiere estrategias más efectivas para conocer su mundo.

Según Athey (1983) el lenguaje tiene una base cognoscitiva que es la misma para escuchar, hablar, leer o escribir. Athey sostiene que el lenguaje y el pensamiento tienen sus raíces en un origen común: el proceso simbólico. De acuerdo con esta autora, con el advenimiento de las operaciones concretas, el niño es capaz de realizar operaciones que antes no eran posibles como la conservación y la reversibilidad. Como resultado de ello, en esta etapa está listo para comprender la conservación del lenguaje, la cual sienta las bases de la conciencia metalingüística. 
Combinando los hallazgos de la psicología y la lingüística, la aproximación psicolingüística da un gran énfasis al significado. Este punto de vista proclama la validez de lo cotidiano como base para el desarrollo de la alfabetización. El lenguaje hablado es visto como ejecución visible de habilidades abstractas subyacentes que involucran componentes semánticos, sintácticos y fonológicos de la competencia lingüística (Vellutino y Scanlon, 1982). Aprender a leer y escribir consiste en emplear todos estos componentes en el procesamiento del significado para escribir o en el significado implícito en el lenguaje escrito. La lectura es mucho más que recodificar los símbolos visuales en sus equivalentes hablados. Involucra la utilización del conocimiento del lenguaje oral por parte de los lectores, y su conceptuación para derivar el significado a partir de lo impreso. El conocimiento del lenguaje por parte del lector incluye familiaridad con el orden sintáctico de los elementos lingüísticos y las relaciones semánticas entre ellos. La experiencia del lector con el lenguaje oral y escrito resulta un factor crítico para el desarrollo de la alfabetización.

En esta aproximación se toma mucho en cuenta la continuidad entre la casa y la escuela en la experiencia de los niños pequeños con el lenguaje. A los niños se les estimula a pensar en sí mismos como lectores y escritores desde el principio, también se estimulan sus deletreos iniciales y sus intentos para escribir. El lenguaje que el niño ha adquirido en la casa, en la escuela y en la comunidad es fundamental para el desarrollo de sus habilidades relacionadas con la lectura. En el enfoque psicolingüístico, el interés de análisis se centra en el lector y cómo éste establece un significado a partir del texto. El interés principal es el contexto intrapersonal, el conocimiento previo y las habilidades que el lector o escritor trae a la tarea de interpretar o componer un texto, así como las diferencias personales en conocimiento y habilidades.

En la aproximación psicolingüística, el contexto se concibe como aquellas dificultades que el sujeto tendrá que superar para encontrar soluciones a sus problemas y formas de conocimiento cada vez más complejas y válidas, tomando como prototipo el conocimiento científico (Gárate, 1994). En esta misma línea, algunos autores (Mugny y Doise, 1983; Clémont, 1984 cit. en Gárate) explican que el progreso en el conocimiento es el resultado de la participación en situaciones de interacción social que provocará la aparición de conflicto cognoscitivo.

Los autores que se basan en esta aproximación, conciben a la lectura como un proceso en el que el lector construye el conocimiento a partir de sus experiencias previas tanto con el contenido como con el conocimiento de las características del texto. En este proceso, el lector utiliza los esquemas que posee para dar significado al texto. 
Ferreiro (1998) afirma que el proceso de lectura debe concebirse como un proceso de coordinación de informaciones de diversa procedencia cuyo objetivo final es la obtención de significado expresado lingüísticamente.

Clay (1991) define a la lectura como un proceso de solución de problemas para obtener el mensaje en el texto, que aumenta en poder y flexibilidad entre mayor práctica se tenga. En este proceso se deben tomar en cuenta las convenciones del código escrito, se deben dirigir las conductas verbales y perceptuales para poder obtener las claves del texto impreso; y una vez obtenidas se deben relacionar con el fin de lograr una comunicación específica y significativa.

Goodman (1986a) explica algunas características del proceso de lectura:

El lenguaje escrito al igual que el oral es esencialmente una invención social. Sin embargo, existe un proceso único de lectura independiente de la lengua, las características del texto o los propósitos del lector. Este proceso tiene características que son invariables; debe comenzar con un texto expresado en forma gráfica, este texto debe ser procesado como lenguaje y el proceso termina con construcción de significado.

El aprendizaje de la lectura inicia con el desarrollo del sentido de las funciones del lenguaje escrito y para buscar significado se debe tener un propósito. Los niños deben desarrollar estrategias para obtener el significado del texto, basadas en esquemas relacionados con la información que se les presenta, por lo que los lectores principiantes deben leer textos que les sean significativos e interesantes.

Aprender a leer no es más difícil que aprender el lenguaje oral, sin embargo la enseñanza tradicional basada en aprender a identificar letras, sílabas y palabras dificulta el proceso. La enseñanza de la lectura debe basarse en una comprensión del proceso y el desarrollo natural del niño dentro de la lengua escrita.

\section{Filosofia del lenguaje integral}

Una parte importante de la aproximación psicolingüística la constituye la filosofía del lenguaje integral (Goodman, 1986a). Según Goodman, esta aproximación tuvo sus antecedentes en Huey, quien consideró a la lectura como una búsqueda de significado, siendo ésta básicamente constructiva (Huey, 1908 cit. en Goodman, 1986a). 
La postura de Huey tuvo gran influencia en el primer cuarto del presente siglo, sin embargo, la búsqueda de escuelas más eficientes hizo que esta visión fuera olvidada y sustituida por una que consideraba que el aprendizaje de la lectura consistía en la ejercitación de una serie de habilidades y que leer era identificar palabras y ponerlas juntas para lograr textos significativos.

Ante esta situación, la lingüística hizo importantes aportaciones al centrarse en la competencia lingüística y establecer un puente con la psicología cognoscitiva que permitió el estudio de la interacción entre el pensamiento y el lenguaje. Este fue el inicio de la perspectiva psicolingüística en general y de la filosofía del lenguaje integral.

Algunos de los puntos centrales que subyacen a la filosofía del lenguaje integral (Goodman, 1986a) son:

$\boldsymbol{\nabla}$ En una sociedad alfabetizada, el lenguaje oral y escrito son dos formas de lenguaje paralelas entre sí.

$\boldsymbol{\nabla}$ Lo que diferencia al lenguaje oral del escrito son las circunstancias de uso.

$\boldsymbol{\nabla}$ Cada forma de lenguaje tiene un proceso productivo y uno receptivo, pero en ambos procesos se intercambia activamente significado.

$\boldsymbol{\nabla}$ Al utilizar el lenguaje productiva o receptivamente, se producen transacciones entre el pensamiento y el lenguaje.

v Los procesos lingüísticos son tanto personales como sociales. Son personales porque se utilizan para satisfacer necesidades personales. Son sociales porque son utilizados para establecer comunicación entre personas.

จ El lenguaje escrito no es un modo de representación del lenguaje oral, es una forma alternativa y paralela del lenguaje oral, en tanto modos de representar significado.

A esta visión psicolingüística del proceso de lectura, se agregan ciertas premisas fundamentales, que le dan la visión de lenguaje integral. Seda (1996) abunda sobre ellas:

$\boldsymbol{\nabla}$ El lenguaje y el aprendizaje forman parte de la naturaleza humana y adquieren sentido porque en su contexto natural están repletos de significado.

$\boldsymbol{\nabla}$ Existen relaciones recíprocas entre el lenguaje oral y el escrito.

$\boldsymbol{\nabla}$ El aprendizaje del lenguaje (oral o escrito) ocurre dentro de contextos sociales que están repletos de eventos con un alto nivel de significado para los aprendices. 
$\boldsymbol{\nabla}$ Es necesario desarrollar habilidades de autoformación, de tal manera que las primeras aproximaciones que hacen los aprendices al lenguaje escrito deben aceptarse como actos de alfabetismo, dado que permiten generar y continuar su desarrollo, el cual continuará de por vida.

Para Morrow (op. cit.) en la filosofía del lenguaje integral el aprendizaje de la lectura y escritura se centra en el niño pues la función y el significado parten de las experiencias del niño en su casa y en la escuela. El aprendizaje es autorregulado e individualizado con selección de actividades por parte de los niños. Un objetivo principal en la instrucción basada en esta filosofía lo constituye el desarrollar en los aprendices el deseo de leer y escribir.

Dentro de la perspectiva psicolingüística, se han analizado tanto las habilidades lingüísticas que el niño va desarrollando al tener contacto con el lenguaje oral y escrito, como la construcción de significado que el pequeño realiza, por lo que aun cuando la competencia lingüística y los factores cognoscitivos considerados son fundamentales en esta aproximación, lo es también la experiencia previa del niño con el sistema de lectura y escritura, la cual permitirá que el pequeño acceda con mayor facilidad al aprendizaje formal de dicho sistema.

\section{Aproximación Sociolingüística}

La aproximación sociolingüística del lenguaje (Phillips y Walker, 1987) se basa en la sociolingüística y la etnografía de la comunicación. En esta concepción, la lectura y la escritura se ven no sólo como procesos cognoscitivos, sino también como procesos lingüísticos y sociales. Como proceso social, la lectura y la escritura se usan para establecer, estructurar y mantener las relaciones sociales entre la gente. Como proceso lingüístico, la lectura y la escritura se usan para comunicar intenciones y significados, no sólo entre el autor y el lector o escritor, sino también entre otros involucrados en ambos eventos.

En esta perspectiva, el análisis se centra en el contexto interpersonal, la organización de los eventos de lectura y escritura, la interacción de los participantes en ambos eventos, las influencias de la interacción en ambos procesos y de qué manera estos procesos influyen en la interacción.

Por otra parte, con base en la perspectiva socio cultural de Vigotsky (Gárate, 1994) se otorga un lugar privilegiado al contexto, ya que los procesos psíquicos superiores tienen un origen social. En este enfoque, el contexto está constituido tanto por el contexto histórico cultural, como por el contexto interactivo. Este último tiene que ver con todas las personas que interactúan con el niño y le proporcionan todos los elementos creados por la cultura para desenvolverse en el mundo. Este contexto produce desarrollo individual. 
Seda (1996) enfatiza la función social de la lectura. Afirma que el lenguaje y el aprendizaje adquieren sentido porque en su contexto natural están repletos de significado. El aprendizaje tanto del lenguaje oral como del escrito ocurre dentro de contextos que están repletos de eventos con un alto nivel de significado para los aprendices.

Barratt-Pugh (2000) pone énfasis en seis elementos que caracterizan a la perspectiva sociolingüística de la alfabetización:

1) Los niños aprenden acerca del lenguaje escrito participando en actividades en su familia y comunidad. Al participar en las actividades diarias que involucran a la lectura y la escritura, aprenden mucho acerca de las diferentes formas de lo alfabetizado.

2) Las prácticas alfabetizadas se ejecutan de maneras específicas culturalmente determinadas y contribuyen al desarrollo de un sentido de identidad. Las actividades relacionadas con el lenguaje escrito no sólo se construyen socialmente sino que además son especificadas por la cultura, en el sentido de que son mediadas por los valores, creencias y conductas en la cultura de los niños.

3) Los niños tienen concepciones diferentes acerca de lo que constituye lo alfabetizado y cómo se realiza. Lo que aprenden de la alfabetización depende de las interacciones en eventos relacionados con el lenguaje escrito que se llevan a cabo en sus casas, y estos difieren de familia a familia.

4) Las prácticas alfabetizadas se realizan de formas particulares para propósitos particulares, por ejemplo, un niño puede aprender que las prácticas alfabetizadas pueden servir para obtener información a través de periódicos, revistas, la televisión; con fines de entretenimiento a través de libros, revistas, periódicos y la televisión; con fines de interacción social a través de tarjetas; para el trabajo a través de reportes; para obtener mayor desarrollo profesional a través de programas de computación.

5) El patrón de aprendizaje de lo alfabetizado difiere entre los niños en la medida en que se convierten en expertos dentro de diferentes eventos alfabetizados. Mientras participan en diferentes eventos que involucran al lenguaje escrito, construyen gradualmente su conocimiento, habilidades y comprensión respecto del mismo. La velocidad y nivel del desarrollo de su competencia se ven influenciados por la interacción con los adultos y con otros niños, además de la actividad misma. 
6) Las prácticas de alfabetización se valoran diferencialmente en contextos sociales y educacionales diferentes. Los niños de diferentes contextos tienen experiencias diferentes que forman su visión del lenguaje escrito, por lo que llegan a la educación inicial o preescolar sabiendo cosas diferentes acerca del lenguaje escrito y aproximándose a él de diferentes maneras. En contraste, las prácticas relacionadas con el lenguaje escrito que se realizan en diferentes contextos educativos son más homogéneas (Breen y cols., 1994 cit. en Barrath-Pugh, 2000).

Por su parte, Göncü y Katsarou (2000) afirman que el enfoque sociolingüístico se centra en establecer cómo las relaciones de los niños con los miembros de sus comunidades guían colectivamente su desarrollo y educación. Cuando se aplica al desarrollo de la alfabetización este enfoque tiene tres implicaciones principales:

$\boldsymbol{\nabla}$ La comprensión de cómo es que los niños se convierten en seres alfabetizados implica el análisis de los objetivos de educación establecidos por su comunidad.

$\boldsymbol{\nabla}$ Los niños se benefician de la instrucción contenida en las actividades cotidianas que son significativas para ellos, por ejemplo, el juego.

$\boldsymbol{\nabla}$ Los niños se benefician de la instrucción que establece intersubjetividad (proceso de alcanzar comprensión compartida entre socios en una actividad) entre el niño y otras personas alfabetizadas acerca del significado y funciones de la alfabetización.

McGee y Richgels (1990) combinan los dos enfoques anteriores y desde una perspectiva que ellos llaman psicosociolingüística hacen algunas consideraciones acerca del aprendizaje de la lectura y escritura, el cual sigue un proceso de desarrollo; pero no en el sentido de una progresión irreversible. Ningún descubrimiento y conocimiento de los niños acerca del lenguaje escrito es exactamente igual al de otros niños. De hecho, las conductas alfabetizadas de cada niño varían en sofisticación dependiendo de la tarea y la situación.

Los niños aprenden a través de la acción. A medida que se actúa se produce conocimiento y los esquemas se modifican a medida que el pequeño adquiere estrategias más efectivas para conocer su mundo. Los padres transmiten al pequeño las funciones comunicativas y la intencionalidad del lenguaje. Los adultos proveen a los pequeños de acciones y objetos predecibles a partir de las rutinas diarias, de manera que el niño aprende las conductas apropiadas para cada situación y al mismo tiempo las palabras que forman parte de esa situación. 
Los autores enfatizan la rutina de leer cuentos a los niños como una oportunidad muy importante para el desarrollo del lenguaje. En este sentido, se enfatiza la importancia de la interacción social que se lleva a cabo mediante esta actividad, la cual no consiste únicamente en modelar al pequeño, sino que proporciona andamiaje. Esta actividad inicia con la mayor parte de la lectura por parte de la madre o padre y termina totalmente por parte del niño, hasta que este último lee de manera independiente. Los conceptos que el niño desarrolla acerca de la lectura y la escritura se basan en esta interacción no sólo durante la lectura de cuentos, sino a lo largo de todas las actividades cotidianas que tienen que ver con el lenguaje escrito.

La contribución de las perspectivas teóricas revisadas (psicolingüística y sociolingüística) es clara. Ponen énfasis en el contexto sociocultural con el cual interactúa el niño, siendo mayor el énfasis en el sujeto en la aproximación psicolingüística y en el entorno en la sociolingüística. Ambas perspectivas consideran muy importante el papel de la experiencia en la alfabetización del niño, la importancia de las actividades cotidianas y de la participación activa en estas actividades; así como la importancia de la continuidad entre la casa y la escuela.

Una diferencia importante son los aspectos en que cada una de ellas se centra para el estudio del desarrollo de los niños como seres alfabetizados. Mientras que la aproximación psicolingüística considera el contexto intrapersonal de los niños, centrándose en los procesos cognoscitivos que resulta de su interacción con los demás, la aproximación sociolingüística se centra en el contexto interpersonal y la interacción que ocurre en este contexto.

El concepto de desarrollo de alfabetización retoma las premisas tanto del enfoque psicolingüístico, como del sociolingüístico al considerar el desarrollo de los niños en el lenguaje en general (tanto oral como escrito) y los ambientes con los que el pequeño interactúa y que van moldeando su conocimiento respecto de la lectura y la escritura, considerando los procesos involucrados en la adquisición de este conocimiento.

Desde el enfoque psicolingüístico se considerarían, aparte de las habilidades de los niños en el lenguaje oral y su relación con el lenguaje escrito, las actividades en casa y en la escuela relacionadas con la lectura y cómo la interacción de estos dos componentes darían como resultado el desarrollo de la alfabetización en estos años preescolares y posteriormente en los escolares. 
El enfoque sociolingüístico se interesaría además, en los contextos en que se da esta interacción y las funciones a las que sirve. También se consideraría cómo es que la interacción del niño con los contextos sociales le permite ir teniendo conciencia de las prácticas relacionadas con la alfabetización que son valoradas en su contexto particular y cuyo conocimiento le permitiría formar parte de la sociedad alfabetizada.

La propuesta del presente trabajo se basó primordialmente en el enfoque psicolingüístico, considerando el papel que tiene el desarrollo del niño en el lenguaje oral, así como las actividades relacionadas con la lectura en el hogar y de manera importante, la lectura de cuentos por parte de madres y maestras en el desarrollo de la alfabetización de los niños preescolares de la muestra estudiada. Del enfoque sociolingüístico se retomó el interés en analizar la interacción que se presenta durante la lectura de cuentos por madres y maestras. 


\section{. capítzilo 2}

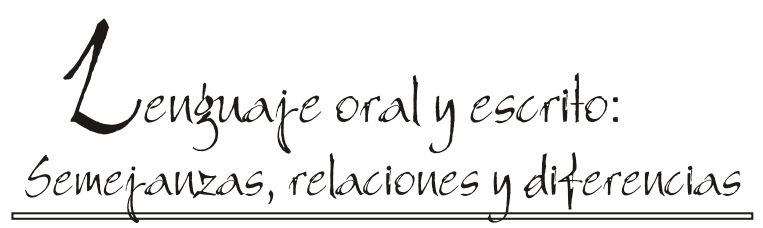

\section{Semejanzas}

Garton y Pratt (1991, p. 1) definen a la alfabetización como "el dominio del lenguaje hablado y la lectura y escritura". Con esta definición pretenden subrayar las continuidades entre el lenguaje oral y el lenguaje escrito. Según los autores, si bien es obvio que la alfabetización involucra al lenguaje escrito, también es claro que involucra al lenguaje oral ya que se espera que una persona alfabetizada hable con fluidez y demuestre dominio del lenguaje hablado.

Proponen que el lenguaje oral y el escrito se estudien de manera conjunta y esgrimen dos razones para ello:

Estos dos sistemas están interrelacionados. Aun cuando existe la idea de que el lenguaje oral precede al escrito, existe una fuerte interrelación entre ellos. El desarrollo del lenguaje escrito es una adquisición de segundo orden ya que está supeditado al desarrollo del lenguaje oral, por lo que el desarrollo de la alfabetización implica aprender a hablar, leer y escribir de manera competente.

Muchos de los procesos implicados en el aprendizaje del lenguaje oral y el escrito son similares. Tradicionalmente se considera que el aprendizaje del lenguaje oral es más natural y el del lenguaje escrito debe ser formal. Esta distinción es simplista pues en ambos sistemas el niño necesita ayuda, casi siempre de un adulto interesado, preparado para ayudarlo en su desarrollo del lenguaje oral y escrito inter- 
actuando con él. Tanto el desarrollo del lenguaje oral como el desarrollo del lenguaje escrito se ven facilitados por la interacción activa del niño con un adulto preparado para proporcionarle ayuda, guía y apoyo.

Fields y Spangler (2000) afirman que los niños adquieren el lenguaje escrito de la misma manera que adquieren el lenguaje oral en virtud de que ambos son lenguaje. Comprender cómo aprenden los niños a hablar ayuda a comprender cómo aprenden a leer y escribir: Los niños aprenden tanto el lenguaje oral como el escrito de la misma manera que, según Piaget aprenden muchas otras cosas, construyendo sus propias reglas y relaciones más que escuchándolas de otros. El papel del adulto consiste en promover que el niño experimente con el lenguaje (oral o escrito) proveerle modelos y promover su participación en actividades relacionadas con el lenguaje.

Glazer (1989) enfatiza que el lenguaje oral se desarrolla como resultado de factores tanto genéticos como ambientales. El niño nace con la capacidad para producir y aprender el lenguaje mediante la interacción con las personas a su cargo. Aprende el lenguaje para poder "funcionar" en su contexto, creando su propio lenguaje a través de la interacción de otras personas.

Este desarrollo del lenguaje oral es un vehículo para el desarrollo del lenguaje escrito. Hablar, leer y escribir son componentes funcionales en la vida de los niños. Padres y niños hablan acerca de las actividades que realizan, los padres leen a los niños ilustrando cómo es que el lenguaje oral sirve de compañía tanto para la lectura como para la escritura. Además, cuando los niños escuchan las historias aprenden tanto el lenguaje que se utiliza en ellas como su estructura. De igual forma, el lenguaje oral acompaña a la escritura de los niños cuando ellos dibujan o pintan.

El lenguaje oral, que ocurre de manera natural tanto dentro como fuera de la escuela, ayuda al niño a utilizar su conocimiento acerca del lenguaje en todas sus actividades relacionadas con la lectura y la escritura.

Goodman (1986b) afirma que el lenguaje oral y el lenguaje escrito son dos procesos lingüísticos paralelos y que el lenguaje escrito tiene todas las características del lenguaje oral, esto es, los símbolos y el sistema usados en el contexto de hechos lingüísticos significativos. La mayoría de las personas aprendemos a hablar antes que a leer y escribir y el aprendizaje del habla facilita al último; pero esto tiene que ver con la utilidad de ambos sistemas. Las personas aprenden primero las formas y procesos lingüísticos que más necesitan. 
Curtis (1980) señala que la comprensión de lo que se escucha sienta las bases para la adquisición de la habilidad de lectura. Los niños aprenden a comprender el lenguaje escrito igual que lo hacen con el lenguaje oral, en dos fases. En la primera fase aprenden a identificar en lo impreso las palabras que comprenden en el lenguaje oral. En la segunda fase desarrollan el mismo grado de eficiencia para comprender lo que leen a la que ya tienen al escucharlo. Curtis señala que la relación entre la comprensión de lo que se escucha y la comprensión de lo que se lee, se conserva desde los primeros estadios de adquisición hasta que los lectores son eficientes. De una serie de variables estudiadas por la autora, ésta fue la única variable que permaneció haciendo diferencia entre los buenos y malos lectores a través de la edad.

Dadas las relaciones estrechas entre el lenguaje oral y el escrito, diversos autores han enfatizado ciertos aspectos de la competencia lingüística en el lenguaje oral que están relacionados con el desarrollo del conocimiento del lenguaje escrito.

\section{Conciencia metalingüística}

Gartton y Pratt (1991, p. 152) mencionan la capacidad del niño para reflexionar sobre aspectos del lenguaje que se desarrolla antes de que se enfrente a la instrucción en la lectura. Esta capacidad de reflexión se conoce como conciencia metalingüística, y según estos autores se desarrolla a muy temprana edad. Cuando un niño comete un error al hablar y lo corrige, está realizando una acción consciente de reflexión sobre el lenguaje, aunque ella no sea deliberada. Esta reflexión espontánea sentará las bases para niveles de reflexión más controlados y deliberados que el niño seguirá desarrollando a medida que tenga mayor dominio sobre el lenguaje escrito.

Los autores mencionan tres aspectos del lenguaje a los que se aplica la conciencia metalingüística: Conciencia fonológica, conciencia de las palabras y conciencia sintáctica. Se describirá en qué consiste cada una de ellas:

1. Conciencia fonológica. Se refiere a la capacidad del niño para identificar los sonidos individuales del habla. Esto permitirá que posteriormente pueda asociarlos a los grafemas (las letras que representan estos sonidos). Aunque los sonidos son las unidades básicas del lenguaje, en la cadena hablada no se perciben como entidades separadas, por lo que centrar la atención en ellos resulta una tarea difícil para el niño. 
Jiménez (1992) define a la conciencia fonológica como la habilidad para analizar la estructura sonora del habla.

Soderman, Gregory y O’Neill (1999, p. 29) mencionan que la conciencia fonológica se refiere a la "habilidad para escuchar los sonidos y comprenderlos en el lenguaje oral".

Morrow (2000, p. 18) la define como el "conocimiento de que las palabras están formadas por sonidos individuales y la habilidad para segmentar las palabras en esos sonidos y juntarlos" y aclara que esto no implica asociar los símbolos visuales con los sonidos de las letras. Se relaciona únicamente con el lenguaje oral.

Rohl (2000, p. 58) define a la conciencia fonológica como la "habilidad para reconocer los sonidos individuales del lenguaje y manipularlos" y menciona que la conciencia fonológica incluye a la "conciencia fonética" (phonemic) que involucra la "habilidad para reconocer y manipular fonemas individuales".

Tummer, Herriman y Nasdale (1988) afirman que se requiere al menos un nivel mínimo de conciencia fonológica para poder realizar la correspondencia entre las letras y los sonidos en los niveles iniciales del desarrollo de la lectura.

Ball y Blachman (1991) realizaron un estudio que demostró la superioridad del entrenamiento en la conciencia fonética sobre el entrenamiento en el nombrar letras y asociarlas a sus sonidos sobre las habilidades de lectura y ortografía en niños de kindergarten.

Nation y Hulme (1997) evaluaron a niños de primero, tercero y cuarto grado de primaria comparando la habilidad para segmentar las palabras en fonemas y con base en su similitud al inicio y al final. Encontraron que la segmentación en fonemas es una buena predictora de las habilidades de lectura y escritura.

Vernon (1998) encontró en niños preescolares y de primer grado, que la conciencia fonológica tiene un desarrollo estrechamente relacionado con el desarrollo del conocimiento de la escritura. Los niños pasan de la segmentación de las palabras en sílabas, a la segmentación de la segunda sílaba de la palabra y finalmente a la segmentación de la palabra en fonemas.

Jacobo y cols. (2002) aplicaron un programa de entrenamiento en conciencia fonológica a niños preescolares, utilizando juegos que permitían realizar la segmentación del lenguaje hablado en palabras, sílabas y fonemas. Encontraron que el nivel léxico era el más fácil de lograr, seguido del silábico y finalmente el fonético, lo que 
apoya los hallazgos de Vernon (1998) citados anteriormente. Estos autores encontraron también que los niños que tuvieron un desempeño más alto en este programa accedieron con mayor facilidad al aprendizaje de la lectura y la escritura. Estos resultados coinciden con los encontrados por Favila y Seda en 2006.

Trabajando con niños de primaria que tenían problemas con la lectura, Hernández y Jiménez (2001) establecieron los efectos del entrenamiento en la conciencia fonológica sobre las habilidades de decodificación. Encontraron efectos positivos ya que los niños de los grupos experimentales mejoraron su desempeño en comparación con los controles. Por otra parte, los autores encontraron que los niños más pequeños se ven más beneficiados que los mayores y concluyen que el déficit fonológico se consolida con la edad por lo que hay que considerar este factor a la hora de realizar programas de tratamiento.

Una habilidad relacionada estrechamente con la conciencia fonológica es la habilidad de aparear símbolos alfabéticos al sonido. Esta habilidad ha sido denominada codificación fonética por Vellutino y Scanlon (1982) quienes encontraron a través de una revisión de diversos estudios que esta habilidad hace una diferencia importante entre los buenos y malos lectores.

Reitsma (1984) señala que los lectores iniciales requieren apoyarse en una representación fonológica familiar para acceder al significado a partir de la palabra impresa, en tanto que lectores más hábiles ya no requieren acceder a esta vía. Apoyando este hallazgo, Levin y Toklchinsky (1989) mencionan que a la edad de 5 ó 6 años, los niños se dan cuenta de que las diferencias relevantes representadas en la escritura son las fonéticas. Este hallazgo constituye un punto crítico, pues relacionarse con el factor fonético como una guía para producir e interpretar materiales escritos representa el descubrimiento de un marco de referencia estable para la ontogénesis y sociogénesis de la escritura.

Ehri y cols. (2001) realizaron un meta-análisis de la relación entre la capacitación en la conciencia fonológica y el aprendizaje de la lectura. Revisando 52 estudios, encontraron que los programas encaminados a promover esta habilidad tienen efectos fuertes y estadísticamente significativos sobre la adquisición de la conciencia fonética y moderada sobre el deletreo y la lectura, tanto en el reconocimiento de palabras como en la comprensión de la lectura. Estos resultados eran aplicables a niños con desempeño normal, con problemas de lectura, preescolares, de primer grado y de todos los niveles socioeconómicos, aunque el tamaño del efecto varió según las diferentes condiciones. 
2. Conciencia de las palabras. El segundo aspecto al que se aplica la conciencia metalingüística, según Garton y Pratt (1990) es la conciencia que los niños van adquiriendo respecto de las palabras como unidades lingüísticas diferentes a los fonemas y a las frases. Con el término palabra los niños no se centran en una unidad lingüística, en lugar de ello, centran su atención en el significado o la idea que la palabra representa.

Rohl (2000) proporciona un ejemplo de esta situación. Si a un niño preescolar se le pregunta por una palabra larga es bastante probable que conteste "tren" refiriéndose al tamaño del objeto representado, más que al sonido o forma escrita de la palabra.

Esta afirmación apoya los hallazgos de Ferreiro y Teberosky (1987) al analizar la evolución de la escritura en niños preescolares que no habían recibido instrucción en lectura y escritura.

Para la mayoría de los niños esta confusión continúa hasta que empiezan a leer y escribir. Sin embargo, se ha visto que aun cuando los pequeños confunden las propiedades del objeto con la palabra misma, tienen algún concepto de la entidad lingüística palabra y pueden reflexionar sobre él.

Tunmer, Herriman y Nesdale (1988) afirman que la conciencia de las palabras está inmersa en la conciencia fonológica, ya que reflexionar respecto de los sonidos presupone la habilidad para reflexionar sobre las palabras, pero no ocurre lo contrario.

Rohl (2000) concuerda con esta postura afirmando que el desarrollo de la conciencia de las palabras es esencial para el desarrollo de la conciencia fonológica, ya que esta última implica reflexionar sobre la estructura sonora de las palabras, independientemente de su significado.

Roberts (1992) hace una distinción entre el conocimiento tácito y el conocimiento explícito de las palabras. El primero es inconsciente, intuitivo y permite al usuario utilizar las reglas y convenciones del lenguaje. El segundo permite utilizar esas reglas deliberadamente y reflexionar sobre las unidades lingüísticas.

En un estudio realizado con niños preescolares y de los dos primeros grados de primaria, esta autora encontró que el conocimiento tácito de la palabra se desarrolla en edades muy tempranas en el lenguaje oral. Este concepto inicial se relaciona con los referentes de las palabras en la vida real. Después de los 5 años, los niños se fijan en las relaciones entre la extensión de las palabras impresas y el lenguaje oral. Esto les permite construir hipótesis acerca de las relacio- 
nes entre el lenguaje oral y el escrito. A medida que el niño avanza en la instrucción escolar se va desarrollando el concepto explícito de la palabra. La autora encontró que se desarrolla primero el conocimiento tácito en el lenguaje oral. Esto permite el desarrollo del conocimiento tácito en el lenguaje escrito, lo que lleva al conocimiento explícito en el lenguaje escrito. El último que se desarrolla es el conocimiento explícito en el lenguaje oral. Las fases de este desarrollo no son excluyentes, ya que el conocimiento tácito provee las bases para el conocimiento explícito; pero el primero sigue desarrollándose y estos dos tipos de conocimiento se traslapan con frecuencia.

Roberts concluye que el desarrollo del concepto de palabra está relacionado con el desarrollo cognoscitivo de los niños. En el periodo preoperacional los niños cambian rápidamente del conocimiento tácito al conocimiento explícito de la palabra, en tanto que en el periodo de operaciones concretas tienen una conciencia explícita de las palabras como unidades estables de significado.

3. El tercer aspecto al que se aplica la conciencia metalingüística según Garton y Pratt (1991) es la conciencia sintáctica, la cual consiste en la conciencia de la gramática de las oraciones. Sostienen que si bien los niños son capaces de emitir oraciones gramaticalmente correctas desde una edad relativamente temprana, sus producciones correctas resultan de un conocimiento tácito de la gramática y no son resultado de una reflexión consciente. Según estos autores, la habilidad para hacer juicios gramaticales independientemente del significado es poco práctica para los niños. Lo que es importante es que puedan evaluar los aspectos gramaticales de las oraciones. Esto les ayudará cuando están aprendiendo a leer, en conjunción con sus conocimientos semánticos, para la decodificación de palabras y cuando ya dominan el proceso les permitirá detectar errores en la comprensión.

Tunmer, Herriman y Nesdale (1988) encontraron que la conciencia sintáctica permite diferenciar a los buenos y malos lectores. Explican que esta habilidad puede influir en el desarrollo de la lectura al facilitar el desarrollo de habilidades fonológicas. Al combinar sus conocimientos respecto de la estructura de las oraciones con información fonológica incompleta, los niños podrán identificar palabras no familiares.

Tunmer y Chapman (1999 cit. en Rohl, 2000) encontraron que los niños que poseen conciencia sintáctica son capaces de usar su conocimiento 
del sistema gramatical para detectar si sus predicciones de palabras, hechas con base en conocimientos fonológicos incompletos son correctas. Tolchinsky y Levin (1987) han ubicado una secuencia de desarrollo en el dominio de estas tres grandes esferas de habilidades. Estas autoras afirman que en los primeros estadios de adquisición del lenguaje escrito, los lectores se apoyan más en los aspectos semánticos del lenguaje para la extracción del significado, y posteriormente, al adquirir más eficacia y experiencia se apoyan más en los aspectos fonéticos y finalmente en los sintácticos.

Por otra parte, Corley (1988) afirma que la transición de "aprendiendo a leer a leyendo para aprender" puede ocasionar muchos problemas a lectores pobres, quiénes se apoyan excesivamente en la información semántica para comprender las oraciones. Dicha comprensión requiere la integración de la información fonética, sintáctica y semántica de una oración y su recuperación en la memoria verbal. La instrucción debe encaminarse a enseñar a los niños a extraer el significado del texto, a través de una revisión minuciosa de las sutilezas semánticas transportadas por la información lingüística superficial dentro y fuera de las oraciones. Por ello recomienda poner al niño ejercicios que le permitan captar los aspectos estructurales del lenguaje.

Tunmer, Herriman y Nesdale (1988) analizaron la relación de las habilidades metalingüísticas, fonológicas y sintácticas, con las habilidades de prelectura y de lectura de 118 niños, a quienes evaluaron al inicio y final de primer grado y al final de segundo grado. Los autores encontraron que las habilidades metalingüísticas estaban significativamente correlacionadas con la codificación fonética y la comprensión de la lectura al inicio de la instrucción y que la conciencia fonológica y sintáctica juega un papel muy importante en los lectores iniciales, ya que ambas habilidades son esenciales para la adquisición de la correspondencia grafema-fonema.

Las habilidades metalingüísticas analizadas en el estudio de Tunmer, Herriman y Nesdale (1988) se relacionan con la codificación fonética (habilidad para aparear símbolos alfabéticos al sonido) y con la codificación sintáctica, que se refiere a la habilidad para obtener significado a través de las propiedades funcionales y formales de las palabras y su uso en un texto, enfatizadas por Vellutino y Scanlon en 1982, las cuales serían sus correspondiente en el lenguaje escrito.

Vellutino y Scanlon (1982) identificaron otra habilidad que hace diferencia entre los lectores novatos y expertos, así como entre los buenos y 
malos lectores y que se refiere a la codificación semántica, la cual consiste en el uso de las palabras, frases y oraciones para codificar información significativa y que es aplicable tanto al lenguaje oral como al escrito.

Hasta el momento se han descrito y analizado las semejanzas entre el lenguaje oral y el escrito así como las relaciones que existen entre ellos, Estas relaciones y semejanzas facilitan la adquisición del lenguaje escrito a partir del conocimiento del lenguaje oral. A continuación se procederá a analizar las diferencias entre estos dos sistemas del lenguaje.

\section{Diferencias}

Rubin (1980) divide las diferencias entre el lenguaje oral y el escrito en dos grandes esferas: a) las que tienen que ver con el medio comunicativo y b) las que tienen que ver con el mensaje.

Dentro del medio comunicativo señala que las diferencias se pueden referir a la modalidad, la interacción que se da entre hablante y escucha y escritor-lector, grado de involucramiento de los participantes, comunalidad temporal, referentes más o menos concretos, papeles que juega cada quién.

Dentro de la esfera del mensaje existen diferencias en el tema de la comunicación, su estructura y su función.

Garton y Pratt (1991) dividen estas diferencias en tres esferas: forma, función y modo de presentación.

En cuanto a la forma afirman que el lenguaje oral es transitorio y temporal y utiliza el sistema aural, lo que se relacionaría con las dimensiones de modalidad y comunalidad de Rubin. Las estructuras gramaticales son más elaboradas en el lenguaje escrito que en el lenguaje oral. La cohesión del discurso se consigue de manera diferente en ambos tipos de lenguaje, en el lenguaje oral se consigue mediante gestos y entonaciones, en tanto que en el lenguaje escrito se consigue a partir de los signos de puntuación.

En cuanto a la función, los autores afirman que el lenguaje oral se utiliza en la conversación cara a cara y generalmente es más coloquial y las diferencias funcionales se establecen con base en diferencias situacionales.

Con respecto de la función, Fields y Spangler (2000) mencionan que el lenguaje escrito se utiliza generalmente para dejar registro de eventos importantes o memorables, en tanto que el lenguaje oral se puede utilizar sólo para pasar el tiempo. 
Soderman, Gregory y O’Neill (1999) resumen las diferencias entre el lenguaje oral y el escrito en términos de su función:

El lenguaje oral tiene las siguientes funciones, que los autores retomaron de Halliday (1975): 1) Instrumental, para satisfacer necesidades y deseos; 2) Reguladora, para controlar a otros; 3 ) Personal, para expresar pensamientos y emociones; 4) Imaginativa, para crear mundos imaginarios; 5) Heurística, para obtener información e 6) Informativa, para comunicar información.

El lenguaje escrito tiene las siguientes funciones: 1) Recordar información; 2) Transmitir información en el tiempo y la distancia; 3) Comunicarse con gente que no nos es familiar; 4) Establecer identidad; 5) Registrar información; 6) Incrementar el conocimiento.

Dahl y Freepon (1995) mencionan que en el lenguaje escrito se depende exclusivamente del texto para construir el significado, en tanto que en el lenguaje oral se tienen claves adicionales. En el lenguaje escrito la estructura sintáctica es más formal, en tanto que la estructura de la oración es más sencilla que en el lenguaje oral.

Por su parte, Purcell Gates (1996) menciona que el lenguaje escrito al igual que el lenguaje oral sirve a funciones de comunicación. Sin embargo, señala las características del primero que le dan su propia identidad:

- Se utiliza para la comunicación a través del tiempo y el espacio.

$\checkmark$ El significado se trasmite en ausencia de un contexto físico compartido entre lector y escritor.

v Se utiliza para hacer permanentes nuestros pensamientos y emociones y al escribirlos tenemos más tiempo para codificar nuestro lenguaje que cuando hablamos.

v Utiliza vocabulario que puede llamarse "literario" y la sintaxis es más integrada y compleja.

v El lenguaje oral y el escrito constituyen dos puntos en el continuo entre el grado de involucramiento y distancia entre escritor y lector.

Según Sulzby (1985) las diferencias entre el lenguaje oral y el escrito pueden resumirse como sigue:

จ El lenguaje oral está diseñado para usarse en situaciones "cara a cara", altamente interactivas, en tanto que en el lenguaje escrito el emisor y receptor están lejanos en tiempo y espacio. 
จ El lenguaje oral depende en gran medida de un contexto inmediato, en tanto que en el lenguaje escrito la contextualización depende de qué tan especificado se encuentre el contexto dentro del texto, de tal manera que el lector pueda inferirlo.

v En el lenguaje oral existe un diálogo con mayor frecuencia que en el escrito, el cual se caracteriza básicamente por el monólogo, que es modelado por los adultos al leer en voz alta al niño.

De acuerdo a la información revisada se puede afirmar que los dos sistemas poseen muchas semejanzas: Ambos son sistemas de lenguaje, transmiten significado, se adquieren de manera paralela e interrelacionada y su conocimiento se construye a partir de la participación activa en situaciones cotidianas que los involucren a ambos. Sin embargo, existen diferencias de forma y función; y estas diferencias son precisamente las que los niños van aprendiendo en la medida en que van desarrollando su alfabetización, que como mencionaron Garton y Pratt (1991) involucra a ambos sistemas.

McGee y Richgels (1990) afirman que para tener una buena comprensión del texto impreso, los niños deben aprender que el lenguaje escrito transmite significado (contenido); cómo se estructura el texto impreso en una página o libro y las relaciones formales entre el habla y el texto impreso (forma); y las funciones del texto impreso en el mundo y en los juegos del niño (uso).

Schnikedanz (1989) menciona una serie de aspectos que los niños tienen que aprender respecto del lenguaje escrito a través de las actividades cotidianas que se realizan en el hogar y en los salones de clases:

จ Deben aprender que el lenguaje escrito es un sistema arbitrario para representar el lenguaje oral y que las palabras escritas no son representaciones físicas de personas y cosas.

v Deben aprender que el habla puede segmentarse en unidades pequeñas llamadas fonemas. Este aprendizaje se ve facilitado en la medida que el niño se involucra en situaciones en que el habla y el texto impreso se utilizan conjuntamente.

v Deben aprender a coordinar las claves contextuales y gráficas mientras leen. El contexto ayuda al niño a predecir qué palabras se incluyen en el texto y transformar la información grafofonética en palabras con significado.

v Deben aprender los nombres de las letras y los sonidos que estas letras representan. 
v Deben desarrollar un vocabulario rico y una comprensión profunda de los conceptos que representan las palabras.

จ Deben aprender los convencionalismos del texto impreso, tales como que éste se organiza de izquierda a derecha y de arriba a abajo y que se debe dejar espacio entre las palabras.

La autora afirma que si bien estos aspectos son importantes, no es suficiente centrarse en la enseñanza de ellos por separado. Los niños necesitan un ambiente rico en alfabetización, tanto en la casa como en la escuela, que les permita ir construyendo su aprendizaje en los años preescolares.

La estrecha interrelación entre el lenguaje oral y el escrito y las semejanzas tan importantes que poseen y que han sido mencionadas en este apartado permiten afirmar que el lenguaje oral sienta las bases para el aprendizaje de las características del lenguaje escrito que le dan su identidad y lo diferencian del primero y que son precisamente las que los niños tienen que ir descubriendo en los años preescolares y cuyo conocimiento les facilitará el acceso a la instrucción formal respecto de las características formales del lenguaje escrito.

Las aportaciones teóricas y la evidencia empírica revisadas permiten identificar habilidades de lenguaje oral que pueden facilitar el acceso al lenguaje escrito: tal es el caso de la conciencia metalingüística con sus componentes fonológicos y sintácticos descritos por Graton y Pratt (1991) así como de la codificación semántica identificada por Vellutino y Scanlon (1982).

En el estudio que aquí se reporta se retoma el papel de la conciencia fonológica y la codificación semántica de los niños como predictoras del desarrollo de la alfabetización.

A continuación se describe el papel de los padres en este desarrollo de la alfabetización. 


\section{. capículo 3}

\section{Papel de los padresenel desarrollo de la alfabetización}

\section{Ambiente familiar}

Soderman y cols. (1999) describen el papel que juegan los adultos en el desarrollo del lenguaje oral y escrito de los niños:

จ Modelan la estructura del lenguaje:

Al hablar con los niños pequeños, los adultos muestran cómo se estructuran las oraciones. Al leer y escribir enfrente de los niños, muestran las estructuras que adquiere el lenguaje escrito.

$\boldsymbol{\nabla}$ Usan el lenguaje para una variedad de propósitos:

A través de las actividades cotidianas, hablamos con los niños, de ellos y alrededor de ellos. Les damos instrucciones, cantamos y platicamos con ellos. De la misma manera, al realizar actividades con el lenguaje escrito les mostramos la variedad de usos que puede tener.

$\boldsymbol{\nabla}$ Esperan que los niños aprendan a hablar, leer y escribir.

Los adultos saben que los niños llegarán a ser eficientes con el lenguaje oral y a la vez les dan tiempo para realizarlo. En cuanto al lenguaje escrito, la certeza no es la misma: los adultos esperan, con cierto temor, que los niños lleguen a ser eficientes en su dominio y esta diferencia de actitud puede ser peligrosa, sobretodo en lo que se refiere a los niños que no avanzan al mismo ritmo que los demás.

$\boldsymbol{\nabla}$ Responden a los intentos de los niños con el lenguaje oral y escrito. 
Aceptan las aproximaciones de los niños en el lenguaje oral, modelando las formas correctas y reforzando sus intentos con sonrisas y atención. En el lenguaje escrito, existen quienes hacen lo mismo; pero también es frecuente responder a los intentos de los niños con frases como: "tú no sabes leer, sólo estás fingiendo".

Las diferencias en actitud de los adultos con respecto del aprendizaje del lenguaje oral y escrito hacen necesario que conozcan cuál es el proceso de desarrollo que siguen los niños en este aprendizaje y cuál es el papel que jugamos los adultos en él.

De acuerdo con Morrow (2001) las familias influyen en el desarrollo de la alfabetización de tres maneras diferentes:

1) A través de la interacción, que consiste en las experiencias compartidas por un niño con sus padres, hermanos y otras personas en el entorno familiar;

2) Mediante el ambiente físico, que incluye los materiales de lectura y escritura disponibles en el hogar y

3) Mediante el clima emocional y motivacional que comprende las relaciones entre las personas en la casa, principalmente las que reflejan las actitudes de los padres hacia la alfabetización y las aspiraciones referentes al desempeño de sus niños como seres alfabetizados.

Retomando el concepto de zona de desarrollo próximo de Vigotsky (1979) y el de participación guiada de Rogoff (1990), Neuman (2000) explica que los padres, como miembros más experimentados, guían la participación de los niños en las actividades cotidianas de la familia, para la comprensión de situaciones nuevas. Esta situación permite a los niños ir asumiendo cada vez mayor responsabilidad en la solución de problemas. Este proceso ocurre al crearse puentes de comprensión entre lo conocido y lo nuevo y estructurando la participación en actividades que desafían al niño.

McGee y Richgels (1990) afirman que los padres transmiten las funciones comunicativas del lenguaje y su intencionalidad, a través de las rutinas cotidianas que proveen al niño de acciones y objetos predecibles y les permiten aprender las palabras asociadas a estas rutinas.

La lectura de cuentos es una rutina que permite una buena oportunidad para el aprendizaje del lenguaje, ya que cada vez que padre y niño regresan a la actividad, el libro permanece siendo el mismo, independientemente de qué tantas veces se lea. Aun cuando se cambie el texto que se lee, la rutina continúa siendo la misma. Esta rutina inicia con la madre o padre llevando a cabo la mayor parte de la lectura; pero termina siendo el niño quien lee la mayor parte del cuento. 
Estas rutinas que se inician muy temprano en la vida de los niños continuarán influyendo en su desarrollo en los años escolares. En el salón de clases, los niños y los maestros negociarán patrones de interacción que utilizarán para el aprendizaje de diferentes tópicos. Aplebee y Langer, (1983 cit. en McGee y Richgels, 1990) llaman a este tipo de interacción "andamiaje instruccional".

Como se mencionaba al hablar del concepto de desarrollo de la alfabetización y de las teorías que lo explican, los padres juegan un papel muy importante en este desarrollo proveyendo un ambiente rico en alfabetización, promoviendo la participación activa del niño en actividades significativas, modelando las conductas y actitudes que se relacionan con el lenguaje escrito y guiando al niño a través de este desarrollo. Diversos investigadores han establecido la relación entre el ambiente en el hogar y el desarrollo de la alfabetización, tanto en los años preescolares como en los escolares. A continuación se presentan diversos estudios que aportan evidencia empírica para establecer esta relación.

Después de revisar el reporte de diversas instituciones gubernamentales (de Estados Unidos) Tabors y Dickinson (2001) concluyen que parece existir un consenso de que el ambiente ideal para los niños pequeños debe ser rico en lenguaje, utilizando muchas palabras durante conversaciones interesantes y debe enriquecerse con historias y narraciones. Afirman que el lenguaje más útil para promover el desarrollo de la alfabetización es el lenguaje extendido, el cual definen como "el habla que requiere de los participantes desarrollar comprensión más allá del aquí y ahora y que requiere el uso de diferentes enunciados y turnos para construir una estructura lingüística, como en las narraciones, explicaciones o dramatizaciones" (p. 2).

Apoyando estas conclusiones, Jordan, Snow y Porsche (2000) mencionan que los niños que provienen de familias que modelan actividades relacionadas con la lectura, que llevan a cabo actividades de alfabetización y que involucran a los niños en el uso de un discurso extendido, tienen mayores probabilidades de tener un mejor desempeño en la lectura y la escritura.

Con relación a la identificación de variables en el ambiente familiar y que contribuyen al desarrollo de la alfabetización Baker, Sonnenschein, Serpell y Scher (1996) realizaron un estudio longitudinal en escuelas publicas de Baltimore, indagando, a través de entrevistas y un diario de los padres, las actividades especificas encaminadas a promover el desarrollo de la alfabetización en esos hogares. Evaluaron también competencias de los niños tales como 
conocimiento acerca del texto impreso, conciencia fonológica y competencia narrativa.

Los padres que reportaban que la alfabetización es una fuente de entretenimiento tendían a reportar mayor involucramiento de sus hijos en actividades de alfabetización que los que reportaban que la alfabetización es un conjunto de habilidades que deben enseñarse propositivamente. Con respecto de las competencias, los hijos de los primeros se desempeñaban mejor en conceptos de texto impreso y comprensión de historias.

Los autores concluyen que los programas de intervención pueden ser más efectivos si son consistentes con las creencias de los padres.

Sonnenschein, Baker, Serpell y Schmidt (2000) complementan la información anterior al reportar un estudio acerca de la influencia de las creencias de los padres sobre las actividades en que se involucran los niños en casa y el desarrollo de la alfabetización de los niños. A través de una entrevista, un inventario y el diario de los padres encontraron dos perspectivas en la orientación de los padres. En la primera, llamada orientación de habilidades, la adquisición de la lectura se percibía como una tarea difícil de realizar y se concebía como la enseñanza de una serie de habilidades específicas. Los padres realizaban con los niños actividades de reconocimiento de letras, recitar el alfabeto, y aprender la relación letra sonido. En la segunda orientación, llamada de entretenimiento, los padres veían a la lectura como una fuente de recreación y para la vida cotidiana. Estos padres promovían que los niños leyeran o vieran libros en su tiempo libre.

Los autores encontraron que los niños que crecen en hogares con una orientación hacia el entretenimiento tienen mejor desempeño en el manejo de conceptos del texto impreso y comprensión de historias que los niños que crecen en hogares con la otra orientación. Concluyen que el desarrollo de la alfabetización se relaciona con las creencias de los padres y el apoyo que se dé a la alfabetización de los niños; que el ligar el juego con actividades de alfabetización puede ser una gran fuente de motivación para aprender a leer y escribir y; que el apoyo a las actividades de alfabetización en el hogar es responsable de gran parte de la varianza en la lectura cuando los niños se encuentran en los primeros grados de primaria.

Purcell-Gates (1996) realizó un análisis de la relación entre las actividades relacionadas con la lectura en el hogar y el conocimiento acerca del lenguaje escrito con que llegan los niños a la escuela. 
Después de un año de observación en los hogares de los pequeños (niños de clase baja y cuyas edades fluctuaban entre los 4 y 6 años) la autora llegó a varias conclusiones: 1) Los niños que aprenden más acerca del lenguaje escrito son aquellos en cuyos hogares se llevan a cabo más actividades relacionadas con el mismo, y quienes a su vez experimentan mayor interacción con sus madres acerca del texto impreso; 2) los niños aprenden acerca de la naturaleza y formas del texto escrito, así como su naturaleza alfabética, en aquellos hogares en que los padres y otros adultos interactúan con materiales impresos más complejos. También existe relación con la lectura sólo para esparcimiento; y 3) los padres se involucran más con las actividades alfabetizadas de sus hijos una vez que ellos ingresan a la primaria.

Purcell-Gates concluye también que la presuposición de que en los hogares de clase baja no se estimula el desarrollo de la alfabetización es falaz, ya que en muchos de estos hogares, todos ellos de clase baja, existían diferentes actividades cotidianas encaminadas a promover el desarrollo de la alfabetización.

En este mismo sentido, Bauman y Thomas (1997) presentan un estudio de caso en el que se describe la gran variedad de actividades que promueven la lectura y la escritura de una madre de raza negra, soltera y de bajo nivel socioeconómico, cuya hija preescolar tiene un gran desarrollo de la alfabetización, así como su hijo de primaria.

Britto (2001) investigó la relación de tres aspectos del ambiente familiar: 1) interacciones verbales; 2) clima de aprendizaje y; 3) clima social y emocional con el vocabulario receptivo y expresivo, la identificación de letras y palabras y habilidades de comprensión de 126 niños preescolares y escolares. Mediante un estudio longitudinal que inició cuando los niños tenían 7 meses y concluyó cuando tenían 7 años, la autora encontró que las habilidades de alfabetización de los niños preescolares están significativamente relacionadas con el clima de aprendizaje. La educación de las madres resultó ser una variable independiente que correlacionaba fuertemente con todas las habilidades de alfabetización de los niños, tanto preescolares como de primaria. La calidad de la interacción de madres y niños mientras leen cuentos se relaciona con la alfabetización de los niños.

La autora concluye que diferentes dimensiones del ambiente del hogar actúan en conjunto para producir una serie de actividades, experiencias y oportunidades que promueven el desarrollo de la alfabetización. El ambiente del hogar debe ser entendido dentro del contexto 
social y cultural en que reside la familia, y dada la complejidad del ambiente, los padres y maestros deben exponer a los niños a actividades diversas relacionadas con el lenguaje escrito que no se remitan exclusivamente a la lectura de cuentos.

Los estudios reportados hasta el momento han esclarecido la relación entre el ambiente familiar y el desarrollo de la alfabetización y apoyan lo afirmado por los autores presentados al inicio de este capítulo. Basados en los resultados de los estudios descriptivos y explicativos, otros autores se han avocado a la tarea de promover el desarrollo de la alfabetización mediante programas de intervención que involucran a padres y niños.

\section{Programas de capacitación a padres}

Sanders, Gershon, Huffman, y Mendoza (2000) aplicaron un programa de préstamo de libros con 122 familias inmigrantes de habla hispana. A 56 de ellas les proporcionaban libros para llevar a casa y a 66 no. Los autores pretendían determinar los efectos de prestar libros sobre la frecuencia de lectura compartida en el hogar, así como los efectos de una serie de variables sociodemográficas.

Mediante un análisis de frecuencias, encontraron diferencias significativas entre los padres de frecuencia alta de lectura compartida y los de frecuencia baja, en términos del país de origen, años de escolaridad, alfabetización y exposición al programa de préstamo de libros.

Los autores concluyen que el país de origen de los padres es una variable importante que ha sido pasada por alto, pues conlleva una serie de características sociales y culturales que pueden o no promover la lectura en el hogar (la autora del presente trabajo opina que esta puede ser una variable importante en Estados Unidos, no así en México; aunque las características socioculturales de la familia sí pueden serlo en ambos países).

Otra conclusión a que llegaron es que la alfabetización de los padres puede ser una buena predictora del desarrollo temprano de la alfabetización en los niños. Esto confirma los resultados de otros estudios en el sentido de que los padres con mayor grado de escolarización modelan a sus hijos las conductas de lectura y escritura. Los resultados de este estudio sugieren también que los padres que valoran leer libros pueden valorar también la lectura de libros para sus hijos y que el tener libre acceso a los libros incrementa la frecuencia de lectura compartida en familias inmigrantes de habla hispana. 
Con relación a los programas de capacitación para padres encaminados a promover el desarrollo de la alfabetización en niños preescolares, Saint Laurent, Giasson y Couture (1997) describen los aspectos esenciales en que debe centrarse la capacitación:

Lo primero que enfatizan es que un programa de este tipo debe ser flexible, de tal suerte que pueda adaptarse a las diferencias entre niños y familias. El programa debe incluir un ambiente tanto físico como humano, que tenga las siguientes características:

$\boldsymbol{\nabla}$ Debe proporcionar modelos, esto es, las personas que rodean al niño deben leer y escribir en su presencia, enfatizando los usos de la lectura y la escritura en situaciones cotidianas, por ejemplo, leer una receta, periódicos, hacer las listas del supermercado.

$\boldsymbol{\nabla}$ Debe mostrar que la lectura puede ser interesante, por ejemplo, mediante la lectura de libros, novelas o revistas.

$\boldsymbol{\nabla}$ El ambiente debe permitir la exploración mediante la manipulación de material escrito y mediante el acceso a toda clase de materiales, por ejemplo, libros, revistas, catálogos, circulares, periódicos, lápiz y papel, computadora y máquina de escribir.

$\boldsymbol{\nabla}$ Finalmente, debe incluir la interacción con los adultos, mediante la lectura de cuentos u otros materiales. Esta actividad debe hacerse en ambientes naturales, en los que los niños interactúan cotidianamente con sus padres, y todas estas actividades deben ser placenteras, evitando obligar al niño a realizarlas.

$\boldsymbol{\nabla}$ Aparte de los cuentos, los padres pueden leer cualquier material que ofrezca la oportunidad de que el niño comprenda que el lenguaje escrito está en todas partes, que transmite significado y que es importante.

Jordan, Snow y Porsche (2000) realizaron un análisis de las investigaciones que tratan de esclarecer la relación entre el ambiente familiar y la promoción de las habilidades de lenguaje y alfabetización de los niños, encontrando tres grupos de resultados:

$\boldsymbol{\nabla}$ El primer grupo sugiere que más que un constructo simple, la alfabetización es vista como una constelación de habilidades que tiene que ver tanto con el lenguaje oral como con el lenguaje escrito. Estas habilidades se ubican en dos dominios distintos: habilidades de decodificación y de comprensión del lenguaje. Durante los años preescolares, estos dominios corresponden a habilidades de reconocimiento de letras, reconocimiento del texto impreso en el ambiente, conciencia fonológica y habilidades de lenguaje. 
จ El segundo grupo de resultados aclara el papel de la familia en el desempeño alfabetizado del niño. La alfabetización es más fácil para aquellos niños cuyos hogares incluyen modelamiento de conductas alfabetizados, acciones para apoyar el desarrollo de la alfabetización y usos del lenguaje que preparan al niño para el discurso que se lleva a cabo en el salón de clases. Estos autores citan a Dickinson y Tabors (1991) quienes afirman que el tipo de conversación que favorece el desarrollo de la alfabetización es aquél en que los participantes son explícitos, se centran en el significado y hablan de tópicos más allá del aquí y ahora.

v El tercer grupo de resultados enfatiza el papel de la lectura de cuentos para promover el desarrollo de la alfabetización en los niños y en este aspecto se han considerado, tanto la frecuencia, como la calidad en la lectura de cuentos.

Los autores y estudios revisados han puesto de relieve el papel que juega la familia en el desarrollo de la alfabetización. Se ha enfatizado la importancia del ambiente tanto físico, como social y emocional; de las actitudes de los padres hacia la alfabetización; de la calidad de la interacción en las actividades cotidianas relacionadas con el lenguaje escrito y del nivel de involucramiento del niño en estas actividades. Los resultados de los estudios presentados son congruentes con las perspectivas teóricas que se describieron en el presente trabajo. El segundo ambiente con el que interactúa el pequeño es la escuela. A continuación se analizará el papel que juega el ambiente escolar en el desarrollo de la alfabetización de niños preescolares. 


\section{. capículo 4}

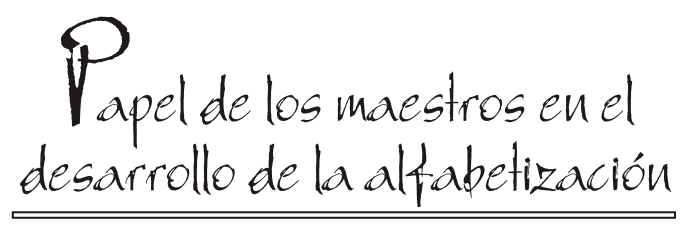

La Asociación Internacional de Lectura (IRA) y la Asociación Nacional para la Educación de los Niños Pequeños (NAEYC) ${ }^{3}$ publicaron en 1998, un comunicado conjunto. El objetivo del comunicado fue proporcionar una guía a los maestros sobre cómo promover el desarrollo de la lectura y la escritura en niños preescolares y de primero a tercero de primaria.

El documento inicia haciendo un resumen de los hallazgos de las investigaciones de los últimos treinta años. En este resumen se afirma lo que ya se ha tocado en este trabajo:

$\boldsymbol{\nabla}$ Mucho antes de que los niños sean capaces de mostrar habilidades de lectura y escritura, adquieren conceptos básicos acerca del lenguaje escrito y sus funciones.

$\boldsymbol{\nabla}$ La adquisición de la lectura y la escritura se conceptualiza como un continuo en el desarrollo, más que como un fenómeno de todo o nada.

$\boldsymbol{\nabla}$ La habilidad para leer y escribir no se desarrolla sin instrucción planeada y cuidadosa, los niños necesitan interacciones activas con el lenguaje escrito. Las habilidades específicas de lectura y escritura provienen de experiencias con el lenguaje oral y escrito.

${ }^{3}$ Ambas asociaciones tienen su sede en Estados Unidos de América por lo que las siglas representan sus nombres en inglés: International Reading Association (IRA) y National Association for the Education of Young Children (NAEYC). 
Una vez establecidos estos hechos, se hacen una serie de recomendaciones para la enseñanza de la lectura y escritura desde el nacimiento hasta la primaria.

Para los años preescolares, estas asociaciones recomiendan, basadas en los resultados de la investigación: leer en voz alta a los niños, exponerlos a los conceptos del lenguaje impreso, realizar juegos con el lenguaje que les permitan desarrollar la conciencia fonética y los principios alfabéticos y ofrecer oportunidades para que los niños puedan expresarse a través de la escritura.

Para los niños de kindergarten, que para nosotros continúan siendo preescolares, se recomienda: que los niños interactúen con un ambiente rico en texto impreso; capitalizar cualquier oportunidad para enriquecer el vocabulario; leer repetidamente los mismos textos para familiarizar a los niños con los diferentes géneros literarios; aprovechar las oportunidades para clarificar el concepto de palabra, así como conocer los nombres de las letras; instruirlos en la conciencia fonológica y la relación letra-sonido, y finalmente; involucrados en actividades de lectura y escritura que sirvan a propósitos múltiples.

La posición de estas dos asociaciones se resume de la siguiente manera:

$\boldsymbol{\nabla}$ La investigación apoya el hecho de que los niños son constructores activos de su aprendizaje y al mismo tiempo enfatiza el papel crítico de los adultos interesados e involucrados, apoyando este aprendizaje. Con base en ello, los objetivos para el desempeño de los niños como lectores y escritores deben ser apropiados a su nivel de desarrollo y deben constituir un reto que sea alcanzable con el apoyo del adulto.

จ Como otras habilidades complejas, la lectura y la escritura son logros que resultan del interjuego continuo entre el desarrollo y el aprendizaje y se espera que existan diferencias individuales en el desarrollo de estas habilidades. Los maestros deben entender el desarrollo de la lectura y la escritura y estar preparados con una variedad de estrategias para apoyar el desarrollo individual y el aprendizaje a través de este continuo.

$\boldsymbol{\nabla}$ El aprendizaje ocurre en contextos sociales y culturales por lo que los maestros deben respetar el lenguaje y la cultura de los hogares de los niños y tomarlos como base para construir las experiencias de lenguaje y aprendizaje. 
Rivalland (2000) apoya esta postura al afirmar que los maestros deben ser lo suficientemente sensibles para retomar las actividades y juegos de la casa con el fin de promover el desarrollo de la alfabetización en los niños preescolares. La misma autora ofrece una descripción de las estrategias que puede poner en juego un maestro para promover este desarrollo:

$\boldsymbol{\nabla}$ Los maestros deben ser capaces de detectar lo que los niños saben y aprenden. Para esto, pueden ser útiles las actividades en pequeños grupos que permitan a los niños mostrar lo que saben.

$\boldsymbol{\nabla}$ Los maestros proporcionan andamiaje a los niños en las rutinas de lenguaje oral y escrito que se utilizan comúnmente en los salones preescolares.

$\boldsymbol{\nabla}$ Con frecuencia ofrecen a los niños la oportunidad de participar espontáneamente compartiendo las experiencias vividas en su casa.

$\boldsymbol{\nabla}$ Ligar los juegos y actividades respecto del lenguaje escrito en la casa y en la escuela proporciona una buena oportunidad para aprender respecto del mismo.

$\boldsymbol{\nabla}$ Los intereses de los niños pueden utilizarse como fuente para aprender informalmente acerca de la lectura y escritura.

$\boldsymbol{\nabla}$ Los maestros proveen apoyo a los niños para moverse de las prácticas de alfabetización de la casa a las de la escuela y gran parte de su actividad se relaciona con proporcionar a los niños un ambiente rico en material impreso.

v El trabajo del maestro de preescolar debe inducir al niño en las prácticas alfabetizadas a través de un juicio sensitivo y un monitoreo riguroso.

$\boldsymbol{\nabla}$ Es importante enfatizar que no se debe confiar demasiado en las oportunidades informales para la intervención de los maestros. Es necesario proveer tanto oportunidades informales, como formales, así como experiencias planeadas que involucren a los niños en el aprendizaje del lenguaje en general y en particular del texto impreso, sus funciones y lo placenteras que pueden resultar las actividades alfabetizadas.

Las recomendaciones de esta autora están basadas en la concepción del desarrollo de la alfabetización. Sin embargo, en la práctica cotidiana la concepción de aprestamiento para la lectura aún sigue vigente entre muchos profesionales dedicados a la educación de los niños. Las aproximaciones a la enseñanza que se derivan de estas dos concepciones, por supuesto, son distintas. 
En la concepción de aprestamiento (Nielsen y Monson, 1996) se tiene la idea de que los niños aprenden la lectura y la escritura hasta que ingresan a la primaria y acceden a la instrucción formal, por lo que en preescolar se enfatiza la enseñanza de una serie de habilidades en una secuencia formal y el papel del sistema educativo consiste en proveer al niño de lecciones secuenciales que ponen énfasis en el reconocimiento del abecedario y las relaciones letra sonido.

Dahl y Freepon (1995) agregan que en esta concepción el lenguaje escrito se aprende a través de actividades secuenciales totalmente dirigidas por la maestra y se enfatizan criterios de desempeño y pulcritud mientras los niños realizan tareas de lectura y escritura.

Morrow (2001) menciona que en los salones preescolares que se guían por esta noción de los maestros dirigen la instrucción hacia el fortalecimiento del desarrollo físico, social, emocional e intelectual, lo que les permitirá tener un conjunto de competencias en estas áreas. Si el niño posee estas competencias estará listo para el aprendizaje de la lectura.

La segunda aproximación a la enseñanza se relaciona con la filosofía del lenguaje integral (Goodman, 1986a), derivada de la perspectiva psicolingüística y que fue descrita anteriormente. En esta aproximación, el lenguaje se aprende mediante actividades funcionales y centradas en el significado.

Goodman, (1986b) explica cómo se lleva a cabo la enseñanza de la lectura y la escritura en un programa basado en la filosofía del lenguaje integral:

En este programa se integra al lenguaje oral y al escrito y se comienza con el lenguaje cotidiano, útil, relevante y funcional a través de todas las variedades del lenguaje escrito, utilizando materiales reales en las lenguas de los aprendices. Los niños leen primero materiales predecibles que presentan conceptos y experiencias que ellos ya han vivido (empaques de cereal, carteles) y a partir de ellos empiezan a reconocer palabras familiares en otros materiales con los que no han interactuado y pronto estarán reconociendo palabras familiares.

El papel del maestro es servir como guía, facilitador y observador de los niños.

Morrow (2001) agrega que en la instrucción basada en este enfoque, los maestros requieren tener un conjunto de objetivos bien planeados que permitan a los estudiantes experimentar actividades que les faciliten desarrollar las habilidades necesarias para ser lectores y escritores competentes. 
Barratt-Pugh (2000) afirma que no existe un "mejor" método para enseñar a leer, ya que diferentes métodos moldean las prácticas sociales de diferente forma. Más que hablar de algún método en particular, para ser usuarios eficientes del lenguaje escrito, los niños y los adultos requieren una variedad de prácticas que los capaciten para:

$\boldsymbol{\nabla}$ Descifrar los códigos escritos, lo que involucra reconocer las relaciones entre sonidos y símbolos, así como las convenciones y los patrones de los textos.

Participar del significado del texto, lo cual implica el conocimiento y experiencias adquiridos a través de otros textos.

Usar los textos de una manera funcional, lo que significa saber para qué sirven.

$\nabla$ Analizar críticamente los textos.

Algunos autores han investigado los efectos de estas dos aproximaciones a la promoción del desarrollo de la alfabetización de los niños.

Dahl y Freepon (1995) realizaron una comparación entre dos ambientes alfabetizadores distintos (lenguaje integrado y aproximación de habilidades) y encontraron diferencias significativas en el sentido que los niños dan a la lectura a la luz de sus experiencias en el ambiente escolar. En un ambiente de lenguaje integrado, los niños generan más nociones sintácticas y léxicas del lenguaje, dan mayor aplicación a su conocimiento de la correspondencia letra sonido y adicionalmente obtienen una comprensión de sus limitaciones como lectores y escritores.

Estas autoras hacen una distinción entre las habilidades de alfabetización y las conductas alfabetizadas. Las primeras se refieren a los conceptos y conductas que usan los aprendices cuando leen y escriben. Las segundas tienen mayor amplitud, ya que incluyen las reflexiones del aprendiz acerca de su propia actividad alfabetizada, usando el lenguaje oral para interactuar con el escrito: reaccionando a una historia, elaborando un documento escrito o explicando su cuento favorito a otra persona.

Nielsen y Monson (1996) analizaron los efectos de la edad en que los niños ingresan al kinder y el curriculum (énfasis en desarrollo de la alfabetización y énfasis en aprestamiento) sobre el desarrollo de la alfabetización de 83 niños de dos grupos diferentes, a través de observaciones de los niños, entrevista a los maestros y medidas previas y posteriores del desempeño en alfabetización. Encontraron diferencias en términos del uso del tiempo, conteni- 
dos y conductas de las maestras en las dos aproximaciones comparadas. En el primer grupo, las maestras pasaban la mayor parte del tiempo en el desarrollo de conceptos y actividades relacionadas con la lectura de cuentos y la narración de historias. En el salón basado en la segunda aproximación, la maestra pasaba la mayor parte del tiempo en realizar ejercicios de cuadernos de trabajo $\mathrm{y}$ en dar instrucciones.

En cuanto a los niños, las autoras encontraron diferencias significativas en el tiempo que pasaban involucrados en actividades relacionadas con la lectura y la escritura (19\% en la postura de aprestamiento, contra $46 \%$ en la de desarrollo de la alfabetización).

No se encontraron diferencias significativas en el desempeño de los niños en medidas relacionadas con la alfabetización (repetición de historias, conceptos de texto impreso, relaciones símbolo-sonido, escritura, lectura de palabras).

Las autoras concluyen que sus resultados apoyan la noción de que no es la edad de entrada al kinder lo que hace diferencia en el desempeño de los niños en tareas de lectura y escritura, sino el curriculum en que se encuentren. En términos de ganancia, los niños del grupo de desarrollo de la alfabetización, que eran más pequeños tuvieron mejores resultados que los del grupo de aprestamiento que eran más grandes. Por ello es necesario realizar investigación encaminada a examinar más de cerca el ambiente de instrucción en que se desarrollan los pequeños.

Smith (2001) examinó las creencias pedagógicas de los maestros y sus prácticas instruccionales.

La autora explica que la mayor parte de los maestros de preescolar está altamente influenciada por la postura llamada "práctica apropiada en términos de desarrollo" (DAP)4, que está basada en la noción Piagetiana de que los niños aprenden a través de la manipulación de objetos e ideas y de la noción de que el papel de los maestros es construir un ambiente en que el niño pueda explorar de manera independiente y manipular objetos e ideas.

Smith (2001) analizó la relación entre los objetivos que los maestros expresan para sus estudiantes, su manera de organizar el ambiente de aprendizaje y el desarrollo del lenguaje y la alfabetización de los niños.

\footnotetext{
${ }^{4}$ Por su nombre en inglés: Developmentally Appropriate Practice (DAP).
} 
Analizando las respuestas a las entrevistas realizadas a maestras de preescolar, la autora encontró que las creencias de los maestros respecto de los objetivos se agrupan en cuatro dimensiones: 1) centradas en el desarrollo social; 2) centradas en habilidades preacadémicas; 3) centradas en el lenguaje y el uso de libros y; 4) centrados en el curriculum y su contenido. Al observar las actividades en el salón de clases encontró que el tiempo dedicado a cada una no correspondía al tiempo que las maestras reportaban dedicar, por ejemplo, al juego libre se dedicaba en promedio el $35 \%$ del tiempo y se reportaba el $20 \%$. La autora encontró que las variables que correlacionaron con el desempeño de los niños fueron, independientemente de que el maestro las hubiera reportado o se hubieran observado, la presencia de un programa de escritura y el tiempo que se dedicaba las actividades en grupos pequeños.

Collins, Oakar y Hurt (2002) realizaron un estudio para determinar las características que distinguen a los maestros efectivos para la enseñanza de la lectura y escritura desde preescolar hasta quinto de primaria.

El estudio constó de cuatro fases. En la primera de ellas, un grupo de supervisores observó a maestros de preescolar hasta quinto grado identificando 1294 categorías que distinguían a los profesores efectivos. En la segunda fase, estas categorías se redujeron a 475 por cuatro investigadores y se obtuvo la confiabilidad en las categorías resultantes. En la tercera fase, se intentó relacionar las categorías resultantes con los grados escolares y el grado de experiencia de los profesores. En la cuarta fase un grupo de jueces jerarquizó las categorías por su nivel de importancia para cada grado escolar.

Los autores encontraron que existen indicadores de eficiencia para cada grado escolar, que existió concordancia entre las características que definen a un buen maestro, detectadas por los profesionales en servicio (supervisores) y los expertos (jueces) y que la información obtenida puede utilizarse para la toma de decisiones.

Los autores encontraron que las características que definen a un buen maestro de preescolar son las siguientes:

Su papel predominante es el de guía, usan la exploración para promover la curiosidad acerca del lenguaje escrito y relacionan las experiencias de la casa con la escuela, permiten la manipulación de letras y palabras, convierten el salón en un segundo hogar agregando el texto impreso, relacionan el lenguaje oral de los niños con el lenguaje escrito. Usan gesticulaciones e inflexiones para mostrar a los niños la variabilidad del lenguaje. De todas estas características, según los expertos, la más importante es la última. 
Los autores concluyen que las características que definen a los maestros eficientes se pueden categorizar en seis dominios:

$\boldsymbol{\nabla}$ El primero de ellos se refiere a los roles que asumen los maestros con mayor frecuencia en la instrucción de lectura y escritura.

$\boldsymbol{\nabla}$ Los maestros efectivos utilizan diferentes estrategias para motivar a los estudiantes dependiendo del grado escolar.

$\boldsymbol{\nabla}$ El tercer dominio son las acciones que los maestros utilizan para volver a enseñar un tema que no ha sido los suficientemente comprendido.

$\boldsymbol{\nabla}$ El cuarto dominio se refiere a las técnicas que utilizan los maestros para establecer relaciones con los estudiantes.

$\boldsymbol{\nabla}$ El quinto se relaciona con la manera en que se imparten las clases.

$\boldsymbol{\nabla}$ El sexto dominio se relaciona con el ambiente del salón.

El quinto y sexto dominios probaron ser los más importantes en preescolar, kinder, segundo y quinto de primaria. Con relación al sexto dominio, Morrow (2001) describe las características que debe tener el ambiente de aprendizaje para estimular el desarrollo de la alfabetización. Este ambiente debe ofrecer una gran cantidad de material impreso que sea funcional: por ejemplo: etiquetas con los nombres de los niños, del mobiliario que hay en el salón, de las diferentes áreas de actividad; palabras de uso común en las paredes; materiales necesarios para que los niños dibujen y escriban. Este ambiente debe tener un área destinada a la biblioteca del salón y un espacio permanente de lectura, así como uno de escritura. Esta autora recomienda que los materiales y actividades de lectura y escritura se ajusten a las necesidades individuales de los niños.

La información revisada nos da una idea de cuáles son las características que debe tener un ambiente preescolar para estimular el desarrollo de la alfabetización según los teóricos y los investigadores. Este ambiente debe estar constituido de una gran cantidad de material de lectura y escritura que permita la exploración y la manipulación de materiales de lectura y escritura, así como la participación en actividades relacionadas con el lenguaje escrito que sirvan a propósitos múltiples. Los autores revisados señalan nuevamente la importancia de aprovechar las experiencias y conocimientos que el niño posee respecto del lenguaje escrito, señalando la necesidad de que exista una continuidad entre la casa y la escuela y de que se respeten y aprovechen las experiencias que el niño tiene en el hogar. 
También se señala que el papel del maestro debe ser de guía y facilitador, proporcionando una serie de actividades planeadas y organizadas para promover el desarrollo de a alfabetización.

Al hablar de actividades que promueven el desarrollo de la alfabetización en niños preescolares, un aspecto que ha sido recurrente lo constituye la lectura de cuentos por parte de padres y maestros, por lo que en el siguiente capítulo se analizará este tema. 


\section{. capículo 5}

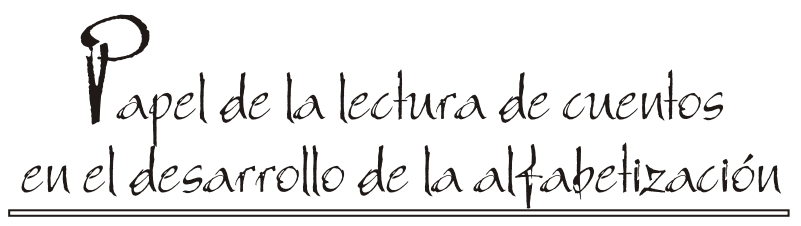

En 1966, Durkin realizó un estudio con niños que habían aprendido a leer y escribir antes de acceder a la instrucción formal. La investigadora encontró que existía una característica común entre estos niños: sus padres acostumbraban leerles cuentos en casa.

Desde entonces a la fecha ha existido mucha documentación empírica respecto de la relación entre la lectura de cuentos tanto en casa como en la escuela y el desarrollo de la alfabetización en los niños preescolares. También se ha investigado su relación con el desempeño posterior en la lectura y escritura convencionales.

En esta sección se describirá lo que aportan diversos autores e investigadores respecto de las características de la lectura de cuentos en el hogar y en la escuela, su relación con el aprendizaje del lenguaje escrito en niños preescolares y con el desempeño en la lectura y escritura convencionales.

Peters (1993, p. 2) define a la lectura de cuentos de la siguiente manera: "no es sólo el acto de sentarse y decir palabras a un niño que escucha. Esta actividad está inmersa en un diálogo entre el niño, el adulto y el libro en un contexto social y a través de la interacción social” y enfatiza que la lectura de cuentos no debe ser considerada como una preparación para construir el conocimiento de la lectura, sino como un vehículo de enseñanza a través del cual se adquiere, practica y aplica. A través de esta práctica el niño adquiere conocimiento de la función y usos del lenguaje escrito, conceptos del texto impreso, actitudes hacia la lectura y estrategias de lectura. 
Peters (1993) hace una serie de consideraciones respecto del papel de la lectura de cuentos:

La lectura de cuentos es el uso de lenguaje escrito, descontextualizado, cuyo significado depende de los aspectos léxicos y fonológicos, el significado es independiente del contexto. Debido a ello, leer a los niños los introduce en el lenguaje que es independiente de cualquier otro contexto que el mismo lenguaje.

Retoma a Vigotsky (1979) para aclarar que existen dos tipos de interacción en la lectura de cuentos: a) Las interacciones interpsicológicas, que involucran la negociación de significado entre adulto y niño. El papel mediador del adulto determina las ideas, habilidades y conceptos necesarios para desarrollar la alfabetización. b)Los aspectos intrapsicológicos en los que el niño internaliza las interacciones y esto le permite funcionar con independencia.

Strickland y Taylor (1989) identificaron los aspectos que hacen que la lectura de cuentos estimule el desarrollo el lenguaje en general y de la alfabetización en particular. Mencionan que los padres e hijos comparten la historia en una interacción centrada en el niño y personalizada, que permite que los padres ayuden a los niños a clarificar conceptos y relacionarlos con otros ya conocidos. En los hogares en que se realiza cotidianamente esta actividad, los padres la asumen y realizan como una actividad placentera y es esto lo que la hace tan importante.

A pesar de que no está considerada originalmente como una actividad para instruir a los pequeños en el lenguaje, en ella se aprende acerca del lenguaje en el momento en que los padres y los niños comparten el contenido del cuento y después, cuando platican acerca de él. La plática que se da alrededor del texto también amplía el vocabulario y los conceptos de los niños. Los padres hablan con los niños y tienden a seguir el liderazgo del niño más que dirigir la actividad.

Fields y Spangler (2000) afirman, apoyando lo dicho por Strickland y Taylor (1989), que a través de la lectura de cuentos transmitimos a los niños la idea de que esta actividad es placentera y gracias a ello les transmitimos el deseo de aprender a leer. Esta actividad constituye una rutina que forma parte de la vida diaria en el hogar, con rituales que satisfacen las necesidades de los miembros de la familia. La comunicación que se presenta alrededor de la lectura de cuentos constituye un medio para que las familias establezcan relaciones y un sentido de familia, ya que a través de ella, además de trasmitirse ideas se transmiten creencias y valores. 
McGee y Richgels (1990) afirman que esta rutina representa una de las mejores oportunidades para que los niños aprendan sobre el lenguaje y que la interacción que se presenta, aparte de incluir modelamiento e imitación es un proceso social complejo.

Morrow (2001) recomienda que esta actividad se convierta en un ritual, que se realice al mismo tiempo y en el mismo lugar todos los días. Al establecerse una rutina para los niños, eventualmente leerán por sí mismos antes de acostarse, por lo que la lectura individual que realicen también debe estimularse.

A través de esta rutina, les modelamos las conductas que se ejecutan en relación con el texto impreso, al mismo tiempo transmitimos el lenguaje que se utiliza cuando nos relacionamos con él. Esto les permite comprender y utilizar mejor el lenguaje ya que incrementa su vocabulario tanto receptivo como expresivo. Estas habilidades promueven tanto el lenguaje oral como el escrito y fortalecen el desempeño académico, pues les permite tomar claves de este conocimiento del lenguaje para comprender el significado que se expresa en los textos (Fields y Spangler, 2000).

Morrow (2001) afirma que el leer a los niños tiene beneficios sobre su adquisición de la lectura y la escritura; pero también fortalece la información que posee y los familiariza con el lenguaje de los libros. El escuchar historias también les permite crear y escribir sus propias historias.

La autora puntualiza que la lectura de cuentos fortalece el desarrollo de los niños básicamente en las siguientes áreas:

$\boldsymbol{\nabla}$ Fortalece su comprensión y su familiaridad con el vocabulario, la sintaxis y la estructura de los libros.

$\boldsymbol{\nabla}$ Le provee de modelos de lectura. De hecho, cuando empiezan a leer, los niños escogen libros que se les han leído previamente.

v Cuando se les ha leído, los niños desarrollan conocimiento de las funciones, forma y convenciones del texto impreso.

$\boldsymbol{\nabla}$ El que se les lea desarrolla en los niños actitudes positivas hacia la lectura ya que la calidez que generalmente acompaña a la lectura de cuentos involucra el compartir sensaciones agradables.

Sheridan (2000) aclara las razones por las que la lectura de cuentos es importante para los niños:

$\boldsymbol{\nabla}$ Primero, provee un camino para insertarse en la cultura de la comunidad, ya que se requiere un bagaje mínimo para la comunicación diaria y para ello es útil leerles historias tradicionales. 
- Segundo, las historias atrapan a los niños y una vez que han sido enganchados, sentirán la necesidad de aprender a leerlas por sí mismos.

$\boldsymbol{\nabla}$ Tercero, las historias proporcionan un marco de referencia para la experiencia. Al leerles una historia y leerla ellos mismos, aprenden, mediante aprendizaje vicario, experiencias que les serán útiles en su vida cotidiana, ya que los personajes actúan como modelos. Muchas experiencias en los libros ayudan a los niños a comprender sus propias reacciones.

Esta autora ofrece una serie de recomendaciones para la lectura de cuentos con los niños:

$\boldsymbol{\nabla}$ Es importante recordar que la literatura refleja la vida real; pero no es la vida real, por lo que no debe reemplazar a todas las experiencias multisensoriales que proveen las bases para la lectura y la escritura.

$\boldsymbol{\nabla}$ Los niños necesitan comprender los propósitos de la letra impresa, por lo que deben experimentar escribiendo diferentes textos para diferentes propósitos y audiencias.

$\boldsymbol{\nabla}$ Las experiencias con el texto impreso deben basarse en experiencias ricas con el lenguaje oral, por ejemplo, recitar y componer rimas que después escribirán o los adultos transcribirán por ellos.

Lozada y Vega (2002) proporcionan un ejemplo de las experiencias ricas con el lenguaje oral, que a la vez se relacionan de manera muy importante con el texto impreso en niños preescolares. Estas autoras realizaron un estudio que tuvo como objetivo promover el desarrollo del lenguaje oral a través de la narrativa infantil. Los niños elaboraban, mediante dibujos y texto inventado por ellos, cuentos, noticias, cartas, libros, historietas y periódicos murales que posteriormente narraban ante sus compañeros y la maestra. Las investigadoras transcribían estos mensajes para que quedaran registrados por escrito. Se evaluaron los efectos de este programa sobre las habilidades narrativas y el desarrollo del lenguaje oral de los niños, encontrándose diferencias significativas entre el inicio y el final de la aplicación del programa en ambas medidas.

Justice y Kaderaveck (2001) mencionan una serie de aspectos que se deben considerar cuando se leen cuentos a los niños y que hacen más probable que se promueva el desarrollo de la alfabetización:

$\boldsymbol{\nabla}$ Asegurarse de que el niño está involucrado activamente en la experiencia y que ella es atractiva. Esto se logra siendo menos directivo a la hora de leer y propiciando la colaboración entre niño y adulto. 
$\boldsymbol{\nabla}$ Otra cuestión que hay que considerar es el ser sensible al nivel de involucramiento e interés del niño, ya que para algunos niños resulta atractivo contestar preguntas durante la lectura, pero para otros no.

$\boldsymbol{\nabla}$ Para promover la conciencia respecto de los convencionalismos del texto impreso es conveniente utilizar lenguaje tanto verbal, como no verbal que enfatice estos aspectos, por ejemplo, hablar del texto impreso y señalarlo.

$\boldsymbol{\nabla}$ Padres y maestros pueden utilizar la lectura tanto para crear interacciones positivas con los niños como para desarrollar lectores iniciales motivados, involucrados y conocedores de la lectura y la escritura.

$\boldsymbol{\nabla}$ Un aspecto que es importante durante la lectura de cuentos es la interacción y la participación activa por parte del niño ya que fortalece su comprensión de la historia y su sentido de la estructura de la misma.

De Temple (2001) ofrece una serie de recomendaciones a los padres para la lectura de cuentos:

$\boldsymbol{\nabla}$ Escoger una variedad de libros que se asocien con comentarios de diferente tipo durante su lectura.

$\boldsymbol{\nabla}$ Leer los libros una y otra vez, ya que la familiaridad con ellos ofrece la oportunidad de una discusión más compleja.

$\boldsymbol{\nabla}$ Discutir algunos aspectos del libro antes y después de la lectura para explicar ideas, clarificar conceptos y vocabulario no usual.

- Variar la entonación para interesar al niño en la historia y facilitar la comprensión.

จ Usar gestos y señalar las ilustraciones para apoyar la comprensión del niño sin interrumpir la fluidez de la lectura.

$\boldsymbol{\nabla}$ Hacer que la experiencia de la lectura de cuentos se relacione con otras actividades de la vida diaria.

- Ser uno mismo, como padre, lector de libros.

Según Morrow (2001) uno de los objetivos principales de leer a los niños es la reconstrucción del significado a partir de la interacción entre adultos y niños. La interacción verbal entre niño y adulto tiene una influencia importante pues ofrece un canal de comunicación para el niño y apoya su desarrollo del lenguaje escrito. 
Las conductas que son útiles para desarrollar estos aspectos incluyen: promover que el niño responda, moldear y modelar las respuestas de los niños cuando no son capaces de responder, relacionar las respuestas a las experiencias cotidianas del niño, contestar sus preguntas y ofrecer reforzamiento positivo a sus respuestas.

Existe evidencia empírica que permite constatar la relación entre la lectura de cuentos en el hogar y el desarrollo del lenguaje oral y escrito. A continuación se presentan los resultados obtenidos en diversas investigaciones.

Neuman (2000) reportó un estudio realizado con madres adolescentes, encaminado a fortalecer la interacción entre las madres y los niños a través de actividades relacionadas con la lectura (lectura de cuentos, instrucción y juego). El programa constaba de tres fases: En la primera de ellas se instruía a las madres sobre cómo dar significado a la actividad, proporcionar andamiaje y transferir la responsabilidad de las madres a los niños; en la segunda fase, las madres llevaban a cabo actividades siguiendo estos principios y en la tercera se analizaba la actividad. La autora encontró que la lectura de cuentos proporciona mejores oportunidades para el desarrollo de relaciones entre objetos y experiencias, en tanto que el juego proporciona las mejores oportunidades para construir puentes entre lo conocido por los niños y lo que aún deben conocer. Concluye que se requiere una amplia gama de actividades en contextos variados para el desarrollo de la alfabetización y que es necesario considerar el ambiente particular en que estos conocimientos y habilidades se desarrollan.

Castillo y Luna (2002) reportan un estudio en el que observaron los hogares de 147 niños de 4 años; rurales de clase baja, y urbanos de clase media y baja, que se quedan al cuidado de algún adulto en el hogar. Les aplicaron un cuestionario para determinar los materiales relacionados con la lectura en el hogar y observaron la lectura de cuentos.

Los autores encontraron diferencias cualitativas entre los tres tipos de familias: en las familias de clase baja, tanto rural como urbana, los libros al alcance de los niños son primordialmente libros de texto y en las familias de clase media urbana hay mayor variedad: enciclopedias, libros para niños, revistas y periódicos. En lo que se refiere a la interacción durante la lectura de cuentos encontraron que en las familias de clase baja (urbanas y rurales) hay muchos adultos que silabean, cambian las palabras y no hacen entonaciones ni respetan la puntuación; los lectores de clase media tienen mejor desempeño y dramatizan los cuentos. 
Estos autores concluyen que existen diferencias cualitativas en la interacción que los adultos tienen con los niños durante la lectura de cuentos. Sugieren que existan programas gubernamentales encaminados a abatir el analfabetismo funcional de los adultos, a capacitarlos para tener materiales y actividades apropiados para estimular el desarrollo de la alfabetización en el hogar y para tener una interacción efectiva durante la lectura de cuentos.

Burges (2002) aclara que el ambiente de alfabetización en el hogar es una variable que muchas veces ha sido reducida a medidas como el ingreso, la ocupación o la escolaridad de los padres. Esta simplificación no toma en consideración los aspectos específicos que son importantes para el desarrollo del lenguaje y la alfabetización en sus diferentes estadios.

Este autor realizó una investigación para examinar las relaciones entre la lectura compartida y el lenguaje oral, específicamente el desarrollo de vocabulario y la conciencia fonológica. Participaron 97 niños de 4 y 5 años, de familias de clase media. Se evaluó el ambiente de alfabetización en el hogar y la frecuencia de la lectura compartida mediante un cuestionario que se aplicó a los padres.

Los resultados indicaron que la lectura compartida se relaciona con el desarrollo del lenguaje oral y la sensibilidad fonológica, que este estudio enriquece el cuerpo de conocimiento que relaciona el ambiente del hogar con el proceso educativo y que es necesario educar a los padres en métodos específicos para preparar a los niños para el proceso educativo.

Jordan, Snow y Porsche (2000) reportan un estudio realizado con 248 niños de kindergarten y sus padres, de los cuales 177 recibieron un programa para incrementar la frecuencia y calidad de la interacción con el lenguaje a través de la lectura de cuentos y 71 sirvieron como grupo control. El programa consistía en sesiones de orientación para los padres, modelamiento, práctica supervisada y actividades para realizar en el hogar.

Adicionalmente, se tomaron medidas del ambiente y las actividades relacionadas con la lectura en el hogar y se evaluó el lenguaje y las habilidades tempranas de lectura de los niños.

Los resultados mostraron diferencias significativas en las medidas de lenguaje y en algunas de las medidas de alfabetización (vocabulario, comprensión de historias, conciencia fonológica y conceptos de texto impreso). 
Al establecerse el poder predictivo de las variables se encontró que el ambiente familiar tiene una relación moderada con algunas medidas de alfabetización y con el desarrollo del lenguaje. Principalmente en lo que se refiere a las palabras supraordinadas, que han mostrado tener una relación importante con las habilidades de lectura en niños de primaria.

Estos autores concluyen que el desarrollar en los padres habilidades para involucrarse en conversaciones más complejas y desafiantes puede tener una contribución importante al desarrollo del lenguaje oral y de la alfabetización de los niños.

Otros autores han analizado el papel del tipo de interacción que se presenta entre los padres niños durante la lectura de cuentos. De Temple (2001) explica que hay muchas variaciones en la interacción cuando los padres leen libros a sus hijos. Esta interacción puede variar desde el padre leyendo "de corrido" el texto, sin comentario alguno, hasta platicar de las ilustraciones; desde contar una historia, sin leerla, hasta leer con una interacción extensa.

El tipo de comentarios que se hagan a los textos también puede variar. Pueden hacerse comentarios que se centren en la información inmediata que proveen las ilustraciones o comentarios que vayan más allá, promoviendo que el niño haga inferencias, provea interpretaciones y relacione el contenido del texto con su vida cotidiana.

La autora enfatiza que los comentarios que se hagan durante la lectura de cuentos son un vehículo excelente para fortalecer el desarrollo del lenguaje de los niños. El compartir la historia ofrece la oportunidad de que se presenten interacciones verbales más complejas, como explicaciones, definiciones y descripciones. También permite hablar de temas que no están presentes en el momento, mediante experiencias pasadas, predicciones e inferencias.

Esta investigadora realizó un estudio encaminado a establecer la relación entre el tipo de comentarios que emplean las madres cuando leen cuentos a sus hijos y el desarrollo del lenguaje oral y escrito de 54 niños preescolares. Realizando tres observaciones a niños de tres, cuatro y cinco años, identificó dos tipos de comentarios que realizan las madres durante la lectura de cuentos:

Comentarios inmediatos, que se refieren al aquí y ahora, que están totalmente ligados a las ilustraciones o palabras en el libro. Comentarios no inmediatos, que relacionan el contenido del texto con experiencias personales de los niños, comentarios acerca de conocimiento general o bien, la solicitud de elaboración de inferencias y predicciones. 
Como resultado de esta investigación, la autora concluyó que los aspectos de la lectura de cuentos en el hogar que más se relacionan con el desarrollo de la alfabetización son los siguientes:

El apoyo que se dé a la alfabetización en el hogar, que incluye el número de libros al alcance del niño, la frecuencia de su lectura y la variedad de actividades relacionadas con la lectura.

Todos los tipos de interacción están relacionados con el desarrollo de la alfabetización, pero, al menos en este estudio, sólo los comentarios no inmediatos correlacionan positivamente con el desempeño en la alfabetización. Los niños que tuvieron mayores puntajes en las medidas de alfabetización fueron aquellos niños cuyos hogares ofrecían mayor apoyo y cuyas madres utilizaban los comentarios no inmediatos con mayor frecuencia que los inmediatos.

Reese y Cox (1999) realizaron una investigación para determinar los efectos de diferentes estilos de interacción durante la lectura de cuentos, para promover el desarrollo de la alfabetización en los niños.

Los autores trabajaron con 50 niños de cuatro años de edad y sus madres. Se tomaron medidas del nivel educativo de los padres combinando el de ambos padres, así como medidas previas y posteriores al tratamiento, de vocabulario, conceptos de texto impreso, identificación de letras y palabras y comprensión de historias.

El programa consistió en la lectura de cuentos a los niños por estudiantes capacitados que desconocían los objetivos del estudio. Se capacitó a los estudiantes para leer a los niños en tres estilos diferentes: descriptivo, que consistía en describir y nombrar las ilustraciones constantemente; comprehensivo, centrado en el significado de la historia y con la realización de inferencias y predicciones y; orientado al desempeño, en el que no se interrumpe la lectura de la historia y hay mucha discusión antes y después de la lectura. Realizando análisis de regresión, los autores encontraron que los diferentes estilos de lectura predicen diferentes habilidades de lenguaje y alfabetización.

Los autores encontraron que en términos generales, el estilo descriptivo tiene mayores efectos sobre el vocabulario y las habilidades relacionadas con el texto impreso. Sin embargo, esos resultados deben analizarse a la luz de la interacción que se presenta entre el estilo de lectura y las habilidades previas de los niños. Por ejemplo, los niños que tenían un nivel de vocabulario mayor, se beneficiaron más con el estilo orientado al desempeño; mientras que los niños que tenían mejores habilidades de comprensión, se beneficiaron más con el estilo descriptivo. 
Las autoras concluyen que diferentes estilos en la lectura de libros benefician diferentes habilidades para niños de diferentes niveles, por lo que es necesario seguir investigando estos efectos para poder diseñar programas efectivos de intervención con niños preescolares.

De la misma manera que se ha investigado la relación entre la lectura de cuentos en el hogar y el desarrollo de la alfabetización, se ha investigado esta relación en los escenarios preescolares. Se presentan algunas investigaciones que ilustran los resultados obtenidos.

Dickinson (2001) afirma que la lectura de cuentos apoya el desarrollo de habilidades de comprensión de historias y fortalece al amor hacia los libros y la lectura, además de ser particularmente importante para desarrollar el tipo de lenguaje que se utiliza con el lenguaje escrito. La lectura de cuentos constituye uno de los pocos momentos en los salones preescolares en los que las palabras adquieren un papel protagónico. Los niños tienen que prestar atención al lenguaje del libro, integrarlo con la información que proviene de las ilustraciones y construir la comprensión de la historia.

Esta actividad puede ser difícil para los niños que tienen poca experiencia con la lectura de cuentos en sus hogares ya que no han tenido oportunidad de familiarizarse con los aspectos que la subyacen. Puede ser difícil también para los maestros, ya que es difícil involucrar a grupos de niños en conversaciones que sean a la vez desafiantes y comprensibles, si tienen diversos niveles de habilidades lingüísticas y de experiencia con los libros. Como resultado de ello, los maestros deben ser lo suficientemente hábiles para detectar los niveles de comprensión de los niños, para aclarar los aspectos confusos y para involucrar a los niños en conversaciones desafiantes; pero comprensibles. Los maestros deben ir más allá de la mera lectura, pidiendo a los niños que reconstruyan la historia mediante dramatizaciones, releyendo el libro solos o discutiéndolo con sus amigos o la maestra.

Basado en un estudio previo (Dickinson y Smith, 1994) Dickinson (2001) comparó 25 salones de clases de niños preescolares en términos del tiempo dedicado a la lectura de cuentos y el tipo de interacción que se presenta entre maestras y niños durante la lectura. Encontró que existían tres tipos de interacción:

Didáctica-interactiva, en la que las maestras solicitaban casi exclusivamente que los niños reprodujeran los nombres de los personajes o bien el texto que se acababa de leer. Este tipo de interacción estaba caracterizado también por el constante establecimiento de las reglas de participación. 
Co-constructiva, en la que había pocos comentarios durante la lectura y menos aun al final de la misma. Los contenidos de los comentarios se referían a esclarecer el vocabulario, las motivaciones de los personajes y a relacionar el contenido del libro con las experiencias cotidianas de los niños.

Orientada al desempeño, en la que la maestra leía la historia dramatizándola y ocasionalmente se detenía para hacer comentarios. El contenido de las conversaciones era similar a la co-constructiva, pero había mucha interacción al terminar la lectura con el fin de relacionar el contenido del cuento con las experiencias cotidianas de los niños, reflexionar sobre aspectos específicos de la historia o guiarlos en su reconstrucción.

Los resultados mostraron que los niños de los salones orientados al desempeño tuvieron mejores puntajes en vocabulario receptivo que los niños de los salones didáctico-interactivos, no habiendo diferencias significativas con el tipo co-constructivo. El autor concluye que aunque muchos maestros afirman que la lectura de libros es muy importante para desarrollar la alfabetización en los niños y es parte importante de las rutinas diarias en el salón, muy pocos de ellos se aproximan a esta tarea de una manera planeada e intencional. En algunos casos, los maestros son lectores eficientes, pero leen con muy poca frecuencia y en otros, los maestros leen con frecuencia pero son incapaces de involucrar a los niños en esta experiencia.

Rosenhouse, Feitelson, Kita y Goldstein (1997) investigaron los efectos de leer cuentos a los niños de primer grado sobre su desempeño en decodificación, comprensión lectora y narración de historias. También investigaron si leerles historias de un solo autor afecta su desempeño de manera diferente que leerles historias aisladas y cómo afectan diferentes tipos de libros la lectura voluntaria. Trabajaron con 16 grupos de niños (399 niños) de 5 a 7 años y sus maestras, con los que formaron 4 grupos experimentales. En el primer grupo se pidió a las maestras que leyeran historias de diferentes autores. En el segundo grupo, los niños escucharon historias aisladas de un mismo autor. En el tercer grupo, los niños escucharon historias del mismo autor que el segundo grupo, pero estas historias constituían una serie. El cuarto grupo, que era el grupo control, realizó las actividades cotidianas: cuadernos de trabajo y dibujos.

Los resultados mostraron diferencias estadísticamente significativas en la decodificación, comprensión de lectura y narración de historias. Los niños del grupo experimental tres fueron significativamente superiores al resto de los grupos. En cuanto a la lectura voluntaria, también hubo diferencias estadísticamente significativas a favor del tercer grupo. 
Las autoras concluyen que la lectura de cuentos por las maestras, y especialmente de ciertos tipos de literatura, afecta la comprensión de la lectura y también la habilidad de los escuchas para producir historias más largas. El exponer a los niños a la lectura diaria, afecta su motivación para la lectura voluntaria y esto se observó en mayor medida en los niños del grupo experimental tres. Esto se relaciona con lo que las autoras llaman "el secreto mágico" y que sugiere que a los niños que se encuentran en los niveles iniciales de lectura, leerles series de un mismo autor les proporciona una base familiar que facilita la comprensión del contenido de los libros, ya que los temas, estructura y patrones de lenguaje son familiares.

Morrow, O'Connor y Smith (1990) investigaron los efectos de un programa de lectura de cuentos en el desarrollo de la alfabetización de niños de kindergarten. Los niños provenían de ocho salones que fueron divididos aleatoriamente en cuatro grupos experimentales y cuatro controles. Los grupos experimentales recibieron un programa de lectura de cuentos, en tanto que los grupos controles llevaron un programa basado en la noción de aprestamiento para la lectura. Los componentes del programa experimental incluían lectura en silencio, actividad de lectura dirigida por la maestra, periodo recreativo de lectura y resumen del día.

Los resultados mostraron diferencias significativas a favor del grupo experimental en pruebas de comprensión e intentos de los niños de leer sus cuentos favoritos. No se encontraron diferencias estadísticamente significativas en los conceptos del texto impreso y en medidas tradicionales de aprestamiento para la lectura. Una cuestión importante a considerar es la forma como se conciba la lectura, pues de ello depende cómo se midan los efectos de un programa como el que se reporta, por lo que es necesario determinar qué experiencias tempranas llevan a las conductas alfabetizadas que queremos desarrollar.

Los autores concluyen que una estrategia instruccional efectiva debe incluir un programa de lectura de cuentos complementado con algunos elementos de la aproximación de aprestamiento y que el mejor programa no es uno u otro, sino una combinación que tome lo mejor de ambos.

Rocha y Vega (2002) realizaron una investigación que tuvo como objetivo capacitar a dos maestras en el uso de estrategias para promover el desarrollo de la alfabetización en niños preescolares mediante la lectura de cuentos. El programa constó de tres fases: modelamiento, ejecución guiada y ejecución independiente. 
Se formaron tres grupos, un grupo control y dos grupos experimentales: El grupo control siguió con sus rutinas normales, en el grupo experimental uno se enfatizó la interacción de la maestra y los niños durante la lectura del cuento, en el grupo experimental dos, además de la interacción, se capacitó a la maestra para activar los esquemas previos de los niños, captar su atención, organizar la información presentada y enlazar la información nueva con el conocimiento previo.

Los resultados mostraron diferencias significativas en el lenguaje oral a favor de los grupos experimentales sobre el grupo control, sin obtenerse diferencias entre los dos grupos experimentales. Por otro lado, la participación de los niños durante la lectura se incrementó como resultado del programa, siendo mayor en el grupo experimental dos.

En esta sección se han analizado las características de la lectura de cuentos que les permiten favorecer el desarrollo de los niños, así como los procesos que se llevan a cabo durante esta actividad y sus efectos sobre el lenguaje oral y escrito de los niños. Se ha evidenciado que la lectura de cuentos permite a los niños adquirir conocimiento respecto del los propósitos, función y características del lenguaje escrito, estimulando además su vocabulario receptivo y expresivo, así como moldeando sus actitudes respecto de la lectura.

La lectura de cuentos es además, un acto social, en el que se introduce al niño en la cultura de su comunidad a través de la interacción que se realiza entre adultos y niños. Como se ha mencionado, el tipo de interacción que se realice tiene efectos diferenciales sobre el desarrollo de la alfabetización, siendo mejor aquella que permita a los niños relacionar los acontecimientos del cuento con sus experiencias personales y producir conclusiones, predicciones e inferencias. En los escenarios preescolares además, los maestros pueden aprovechar las situaciones de grupo para fortalecer la comprensión, tanto de las historias como de las características del lenguaje escrito.

En la lectura de cuentos se pone de manifiesto el interjuego entre el contexto interpersonal analizado por la perspectiva sociolingüística y el contexto intrapersonal que es analizado por la perspectiva psicolingüística. Este interjuego da como resultado la cada vez mayor comprensión y el mayor conocimiento de los niños respecto del lenguaje escrito que se puede observar a través de su desempeño como lectores de cuentos. Sulzby (1985) ofrece una caracterización de las etapas por las que pasan los niños cuando pretenden leer sus cuentos favoritos a sus padres, hermanos o mascotas. 
Cuando los padres leen un cuento al niño, lo hacen de una manera interactiva, usualmente haciendo pausas para explicar o clarificar conceptos o bien para establecer relaciones entre el texto y las experiencias cotidianas de los niños. Posteriormente, en la medida en que el libro se convierte en familiar, los padres pueden leer mayores porciones del texto sin interrupciones. Después, los niños empiezan a leer segmentos del texto de manera independiente y antes de que sean capaces de leer o escribir de manera convencional, son capaces de recitar los libros con lenguaje que parece lectura y palabras que suenan como las de los textos. Conforme el niño avanza en estos intentos, su lectura se va haciendo más independiente de la interacción con el adulto y más consistente con los convencionalismos del texto impreso. Sulzby describe tres grandes estadios en esta sucesión:

$\boldsymbol{\nabla}$ Primero, los padres leen de una manera altamente interactiva que incluye características tanto de lenguaje oral, como de lenguaje escrito.

$\boldsymbol{\nabla}$ Segundo, en la medida en que el niño gana experiencia la lectura de cuentos se acerca más a las características del lenguaje escrito, con el adulto realizando un monólogo y el niño como escucha y observador.

$\boldsymbol{\nabla}$ Tercero, la lectura de cuentos se vuelve una actividad que el niño realiza para otra persona o para sí mismo y como lector independiente (sin leer convencionalmente) y cada vez más, el lenguaje que produce se parece al lenguaje escrito.

Sulzby ofrece una caracterización del desarrollo que siguen los niños en esta lectura independiente y conforme se avanza en evolución de este desarrollo, los niños van exhibiendo mayor conocimiento de las características del lenguaje escrito. Esta caracterización se retomó en el presente trabajo para analizar la lectura de cuentos por los niños, ubicándolos de acuerdo a las características de su lectura en cada uno de los niveles descritos por Sulzby. Cabe aclarar que estos niveles describen las características de la lectura de los niños cuando aún no lo hacen de manera convencional. 


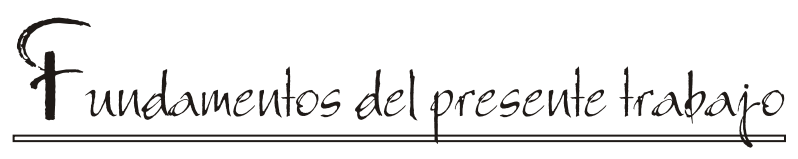

Con base en la revisión teórica realizada, el reporte de investigación que se presenta retomó el concepto de desarrollo de la alfabetización, considerando que los niños poseen un gran bagaje de conocimientos respecto del lenguaje escrito antes de que accedan a la instrucción en lectura y escritura convencionales, cuando ingresan a la primaria. Estos conocimientos son tan válidos como los convencionales y sientan las bases para ellos.

En este trabajo se considera que el niño aprende a partir de su participación en actividades relacionadas con la lectura y la escritura en el hogar y la escuela. Como resultado de ello va creando concepciones respecto de las características del lenguaje escrito que someterá a prueba e irá confirmando o rechazando conforme avanza en conocimiento. Este conocimiento se refleja en todas las conductas y actitudes que el niño manifiesta en relación con la lectura y la escritura y se va desarrollando de manera gradual en la medida en que adquiere experiencia con el lenguaje escrito.

Dadas las consideraciones anteriores, el concepto de aprestamiento, el cual ocurre en un punto fijo en el tiempo, no es aplicable a la presente investigación. Este concepto considera habilidades aisladas y enfatiza la instrucción en ellas, de manera descontextualizada, como requisito para el aprendizaje de la lectura y escritura.

El término utilizado, “desarrollo de la alfabetización”, pretende dar la idea de que efectivamente esta alfabetización se está desarrollan- 
do de manera continua y gradual, en la medida en que los niños van teniendo mayor relación con el lenguaje escrito, como resultado de su desarrollo general y de la participación en actividades de lectura y escritura. De tal suerte que se le concibe como un proceso que inicia muy temprano en la vida y aun cuando algunas definiciones marcan un punto en el tiempo (la instrucción convencional) para dar fin a este periodo, el aprendizaje informal de las características del lenguaje escrito continúa hasta la edad adulta.

Para el estudio de este desarrollo de la alfabetización se ha retomado principalmente la perspectiva psicolingüística que enfatiza el contexto intrapersonal de los niños en relación con el lenguaje escrito, considerando las aportaciones que tiene el ambiente con el que los niños interactúan. En el caso de la presente muestra, el ambiente está representado por sus casas y los escenarios de educación preescolar a que asisten.

Dentro del contexto intrapersonal, la perspectiva psicolingüística privilegia el desarrollo del lenguaje oral y la estrecha interrelación entre el lenguaje oral y el lenguaje escrito, señalando el papel de la conciencia metalingüística y de sus componentes (fonológica, de las palabras y sintáctica) en el desarrollo del lenguaje escrito. Se ha identificado también la relación entre la codificación semántica y el desarrollo del lenguaje escrito. Este trabajo retomó a la conciencia fonológica y la codificación semántica como variables a considerar en el desarrollo de la alfabetización. La selección de ellas está basada tanto en la revisión realizada para este estudio como en estudios previos (Vega y Reyes, 1998; Goldrine y Vega, 1999; Vega, Reyes y Azpeitia, 1999; Vega y Macotela, 2005).

En los fundamentos teóricos presentados, se ha enfatizado la importancia de los materiales y actividades relacionados con la lectura en el hogar para promover el desarrollo de la alfabetización. Se ha mencionado que un ambiente rico en alfabetización debe contener materiales diversos relacionados con en lenguaje escrito que faciliten la exploración y la manipulación del mismo, por lo que en este estudio se identificaron los materiales relacionados con el lenguaje escrito al alcance de los niños en el hogar. También se puso de manifiesto reiteradamente que la participación en actividades relacionadas con la lectura en el hogar promueve el desarrollo de conocimientos y habilidades relacionados con la alfabetización por lo que también se identificaron las actividades relacionadas con la alfabetización que se realizan en el hogar. 
De la aproximación sociolingüística se retoma el análisis de la interacción que se observa durante la lectura de cuentos, tanto por parte de madres como de maestras, considerando cómo promueve el desarrollo de la alfabetización en los niños. Los autores consultados privilegian a la lectura de cuentos como una actividad que de manera importante permite a los niños familiarizarse con las características del lenguaje escrito, así como desarrollar habilidades de lenguaje en general. La interacción que se presenta durante la lectura de cuentos proporciona una oportunidad para que el niño pueda generar y probar hipótesis respecto de las peculiaridades del lenguaje escrito que le dan su identidad.

Este conocimiento que los niños van adquiriendo a partir de la lectura de cuentos se refleja en su propio desempeño como lectores no convencionales por lo que se consideró esta actividad como parte de las tareas que los niños realizaron y que permitieron obtener datos para caracterizar su desarrollo de la alfabetización.

La observación de la lectura de cuentos por los niños aunada a la indagación de su conocimiento de los conceptos relacionados con el texto impreso, de las letras y palabras; así como el análisis de sus producciones escritas (Vukelich, 1997) permitió alcanzar el primer objetivo de este estudio: Caracterizar el desarrollo de la alfabetización en una muestra de niños preescolares. La evidencia que se obtuvo acerca del desarrollo de la alfabetización se logró utilizando indicadores múltiples. Seda y Pearson (1991) argumentan que para poder documentar las habilidades y desempeño de los estudiantes, es necesario considerar una variedad de medidas (tanto procedimientos como instrumentos) porque cada uno proporciona información específica.

Por otra parte, se ubicó el nivel de desarrollo de los niños a partir de la realización de tareas directamente relacionadas con la lectura y escritura, en el momento mismo en que el pequeño realizaba estas actividades. Este último planteamiento es consistente con el enfoque de la evaluación auténtica, que como menciona Valencia (1997) se lleva a cabo mediante actividades que son similares a las que ocurren en la vida real, tanto dentro como fuera de la escuela, de tal manera que el panorama del desarrollo de la alfabetización del niño sea preciso. La realización de estas tareas en tres momentos sucesivos (con diferencia de dos meses entre ellos) y por niños de edades diferentes en el mismo momento permitió tener una visión tanto longitudinal como transversal del desarrollo de los niños (Vega, 2002). 
El segundo objetivo de la investigación: Analizar la contribución de variables involucradas en el desarrollo de la alfabetización en niños preescolares se realizó desde una perspectiva multidimensional e interactiva (Coles, 1989) que consideró tanto el funcionamiento del niño como las diversas relaciones e interacciones a las que se enfrentaba.

Considerar únicamente las variables presentes en el niño, en términos de nivel de aprestamiento como se hacía anteriormente proporciona como resultado información inútil, ya que el niño es interactivo y transactivo (Dahl y Freepon,1995) y que esta interacción se traduce en un nivel de desarrollo, no fijo y estático, sino dinámico y en constante evolución. De tal suerte que la evaluación del desarrollo de la alfabetización en los preescolares requiere pasar del modelo de una evaluación única a un modelo ambiental diseñado para cada niño. En este modelo el niño es evaluado con los miembros de la familia presentes y tomando en consideración factores tanto de la casa como de la escuela (Vacc y Ritter, 1995).

En el caso de la presente investigación se consideraron, tanto el desempeño del propio niño en el lenguaje oral y escrito, como variables del entorno: el ambiente de alfabetización en el hogar y la lectura de cuentos por madres y maestras. Cada uno de estos aspectos se evaluó considerando los materiales y procedimientos que permitieran representar de una manera más fidedigna el desarrollo del niño en esta área de alfabetización, así como los aspectos en el ambiente que pueden tener relación con él (Vega, 2001). Esto permite ubicar el área específica en el contexto o en el propio niño, que requiere de intervención para su optimización.

Desde esta perspectiva, los problemas en la adquisición de la lectura no serían únicamente el resultado de áreas o procesos deficientes en el niño, sino que se ubicarían en un contexto más amplio considerando no solo sus capacidades y limitaciones, sino además y de manera muy importante, el ambiente de aprendizaje (en la escuela y el hogar) en el cual se desenvuelve así como sus interacciones recíprocas con ese ambiente y el papel que juegan todos los actores involucrados. De esta manera, la evaluación adquiere un sentido diferente y su utilidad en el nivel profiláctico se incrementa.

El conocer el papel de cada una de los factores involucrados permite una mejor comprensión del desarrollo de la alfabetización y de la adquisición de la lectura convencional y la realización de acciones para la optimización de estos procesos por parte de los pequeños. A continuación se presenta el método utilizado para la consecución de los objetivos. 

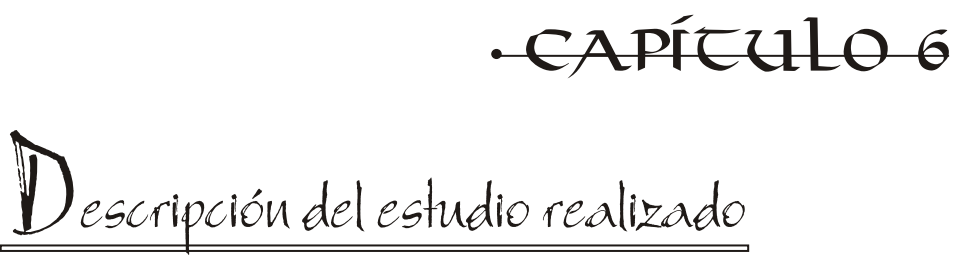

\section{Objetivos}

$\boldsymbol{\nabla}$ Caracterizar el desarrollo de la alfabetización en una muestra de niños preescolares.

$\boldsymbol{\nabla}$ Analizar la contribución de variables involucradas en el desarrollo de la alfabetización en niños preescolares (edad, habilidades lingüísticas en el lenguaje oral, escolaridad de los padres, materiales y actividades de lectura en el hogar, conductas de madres y maestras durante la lectura de cuentos).

\section{Variables}

\section{Variables contextuales}

En el ambiente familiar

\section{Escolaridad de los padres}

Se computaron ciclos terminados. Para determinar el dato que se incluiría en el análisis se promedió la escolaridad de padre y madre (cuando en el resultado se encontraba una fracción de .5, se computó el número inmediato superior).

Los niveles de esta variable son:

1. Ninguna; 2. Primaria; 3. Secundaria; 4. Carrera técnica; 5. Preparatoria;

6. Licenciatura; 7. Posgrado. 
Materiales de lectura al alcance del niño en el hogar

Se pretende indagar qué materiales de lectura y escritura se encuentran cotidianamente al alcance del niño, ya que según Saint Laurent, Giasson y Couture (1997) el ambiente debe permitir la manipulación de material escrito para promover el desarrollo de la alfabetización.

Frecuencia y tipo de actividades relacionadas con la lectura en el hogar

Según diversos autores (Teale y Sulzby,1989; Saint-Laurent, Giasson y Couture, 1997; Barrath-Pugh, 2000) las actividades cotidianas permiten a los padres modelar y estimular las actividades relacionadas con el lenguaje escrito, así como el gusto por la lectura, por lo que se identifican las actividades relacionadas con la lectura y la frecuencia con que se realizan cotidianamente. Estas dos primeras variables se midieron mediante el Cuestionario de actividades relacionadas con la lectura que se llevan a cabo en el hogar (Vega, 2001).

\section{Lectura de cuentos por las madres / padres}

Este aspecto se refiere a las actividades que realizan los padres antes, durante y después de la lectura de cuentos y que están encaminadas a estimular tanto la comprensión, como el desarrollo de la alfabetización en los niños. Estas actividades fueron identificadas mediante la Lista cotejable para la lectura de cuentos en el hogar (Vega, 2001).

En el ambiente de instrucción escolar

\section{Lectura de cuentos por las maestras}

Se refiere a las conductas que presenta la maestra antes, durante y después de la lectura de cuentos y que están encaminadas a estimular tanto la comprensión como el desarrollo de la alfabetización en los niños. Estas conductas fueron observadas mediante la Lista cotejable para la lectura de cuentos en la escuela (Vega, 2001).

\section{Variables en el niño}

\section{Edad del niño}

Se decidió considerar esta variable en virtud de que, teóricamente, a mayor desarrollo de los niños se espera mayor desarrollo de la alfabetización. La edad de los niños se computó en meses cumplidos a la fecha de la primera aplicación de los instrumentos. 


\section{Habilidades lingüísticas orales}

Definida como la extracción y producción de significado a través del uso de claves fonéticas y semánticas. Incluye:

Conciencia fonológica: Definida como la habilidad para escuchar los sonidos y comprenderlos en el lenguaje oral (Soderman, Gregory y O’Neill, 1999, p. 29).

Codificación semántica: Uso de palabras, frases y oraciones para codificar información significativa (Vellutino y Scanlon, 1982).

Esta variable fue medida mediante el Instrumento para evaluar las habilidades precurrentes para la lectura, EPLE (Vega, 1991).

\section{Desarrollo de la alfabetización}

Definida como "los primeros signos de habilidades y conocimiento con respecto del lenguaje escrito, el periodo entre el nacimiento y el momento en que los niños reciben instrucción convencional en lectura y escritura" (Sulzby y Teale, 1991 cit. en Saint-Laurent, Giasson y Couture, 1997, p. 7). Incluye los siguientes aspectos:

\section{A. Conocimiento del lenguaje escrito}

Se pretende identificar los conocimientos que los niños han logrado construir acerca de la lectura y la escritura sin haber sido alfabetizados convencionalmente. En este componente se evaluaron los siguientes subcomponentes: 1) Identificación de letras; 2) El conocimiento de conceptos relacionados con el texto impreso, por ejemplo, dónde se inicia la lectura, la dirección de la lectura; 3) Vocabulario de escritura, el número de palabras convencionales que el niño escribe espontáneamente; 4) Muestra de escritura. Mediante el análisis de la escritura del niño se toman en cuenta tres aspectos: a) El nivel de lenguaje, b) la calidad del mensaje, c) el conocimiento de los principios direccionales de la escritura. 5) Dictado. Para la definición de la subprueba de dictado, se utilizó la secuencia de desarrollo de la escritura propuesta por Fields y Spangler en 2000. Para la calificación, se ubicó a cada niño en el nivel que le correspondía de acuerdo a las características de su escritura y éste fue el puntaje obtenido. Se presentan las características de cada uno de los niveles propuestos: 


\begin{tabular}{|c|c|}
\hline NIVEL & CARACTERÍSTICAS \\
\hline 1. Garabatos & $\begin{array}{l}\text { Marcas al azar que no permiten diferenciar en- } \\
\text { tre dibujo y escritura. }\end{array}$ \\
\hline 2. Dibujo & La ilustración cuenta la historia. \\
\hline 3. Repetitivo-lineal & $\begin{array}{l}\text { Las marcas siguen una línea uniforme en tama- } \\
\text { ño y forma (parece letra cursiva). }\end{array}$ \\
\hline 4. Imita escritura convencional & $\begin{array}{l}\text { Puede o no ser lineal, pero contiene elementos } \\
\text { de palabras reales. }\end{array}$ \\
\hline 5. Formas memorizadas & $\begin{array}{l}\text { Escribe nombres frecuentes e importantes para } \\
\text { él (ej. mamá, papá, su nombre). }\end{array}$ \\
\hline 6. Formas que parecen letras & $\begin{array}{l}\text { Contiene elementos de letras reales. No más de } \\
2 \text { formas similares seguidas. }\end{array}$ \\
\hline $\begin{array}{l}\text { 7. Letras que corresponden a pa- } \\
\text { labras }\end{array}$ & $\begin{array}{l}\text { Cada letra que escribe representa una palabra. } \\
\text { No hay correspondencia de sonido. }\end{array}$ \\
\hline 8. Principios cuantitativos & $\begin{array}{l}\text { El número de letras es significativo, representa } \\
\text { hipótesis acerca del número de letras necesario } \\
\text { para una palabra. Las cosas grandes tienen nom- } \\
\text { bres grandes. }\end{array}$ \\
\hline 9. Inicio de deletreo inventado & $\begin{array}{l}\text { Refleja hipótesis de que las letrashacen el soni- } \\
\text { do de su nombre. Nombres de letas como soni- } \\
\text { dos. }\end{array}$ \\
\hline 10. Fonética simplificada & $\begin{array}{l}\text { Una letra por palabra o por sílaba, sólo sonidos } \\
\text { principales, pocas vocales. }\end{array}$ \\
\hline 11. Deletreo inventado avanzado & $\begin{array}{l}\text { Intenta regularizar la relación sonido-símbolo, } \\
\text { usa vocales. Empieza a poder leerse. }\end{array}$ \\
\hline 12. Deletreo estándar & $\begin{array}{l}\text { Autocorrección para igualar los modelos del de- } \\
\text { letreo estándar. }\end{array}$ \\
\hline
\end{tabular}

Tabla 1. Características de cada uno de los niveles en el desarrollo de la escritura (Fields y Spangler, 2000).

Este componente de la variable fue evaluado mediante el Instrumento de observación de los logros de la lectoescritura inicial (Escamilla, Andrade, Basurto y Ruiz, 1996).

\section{B. Desempeño durante la lectura de cuentos}

Según Sulzby (1985) los niños que aprenden a leer antes de recibir instrucción formal, a menudo son descritos como autodidactas a partir de sus cuentos favoritos, intentando leerlos para sí mismos, para sus hermanos, muñecas o mascotas. 
La lectura de cuentos por parte del niño revela información respecto de lo que conocen y cómo actúan con relación al lenguaje escrito y según Sulzby existe una secuencia de desarrollo en esta actividad.

Para evaluar cómo leen los pequeños y en qué nivel de este proceso se encuentran, en este estudio se utilizó la clasificación propuesta por Sulzby (1985) y retomada por Valencia y Sulzby (1991).

Esta clasificación considera los siguientes niveles:

\section{INTENTOS GOBERNADOS POR ILUSTRACIONES}

\section{A. Historias no formadas}

1. Etiquetar y comentar

El niño señala el objeto en la ilustración y da su nombre o descripción, acompañado de muchos gestos y movimientos. Puede proporcionar información adicional sobre el objeto.

\section{Seguir la acción}

Los intentos se centran en la acción que se representa en cada ilustración, puede realizar físicamente la acción o señalar la acción con los dedos. Los tiempos verbales utilizados son presente y gerundio. Hay mucho acompañamiento de efectos de sonido.

\section{B. Historias formadas}

a) Como en el lenguaje oral

\section{Narración creando un diálogo}

El escucha puede inferir una historia a partir de segmentos de la narración aun cuando no esté totalmente formada. El niño crea la historia a partir de un diálogo con el escucha o entre los personajes. A diferencia del nivel anterior, se dirige al adulto, pero sin dejar de ver el libro. Ya usa pasado y futuro, además de presente y gerundio.

\section{Narración mediante monólogo}

El escucha puede comprender la historia completa. El niño narra la historia como si la platicara y la narración depende absolutamente de las ilustraciones, asumiendo que niño y adulto las observan simultáneamente. Las frases y la sintaxis utilizadas son las que se usan cuando se narra "cara a cara", aun cuando la historia sea narrada como monólogo. 
b) Como en el lenguaje escrito

5. Lectura y narración mezcladas

Es una transición entre el lenguaje oral y el escrito. El niño intercala partes que suenan como lenguaje escrito (en entonación, palabras o ambas) con partes que continúan sonando como lenguaje oral. La historia puede diferir de la historia original, pero hay conciencia de que hay audiencia. Contiene grandes segmentos descontextualizados o suficientemente especificados para entenderse sin las ilustraciones.

6. Historia similar a la historia original

El lenguaje del niño es descontextualizado y la entonación es como de lectura. El niño crea patrones como los del libro o libros similares. Ve las ilustraciones, pero su entonación es como de lectura oral expresiva que muestra prosodia e inflexiones de lectura oral.

7. Historia similar a lectura literal

Muestra conciencia y memoria parcial de segmentos del texto. Algunos niños recitan historias completas casi literalmente. Muestra conductas de auto-corrección que indican que está tratando de "recuperar" la historia.

\section{INTENTOS GOBERNADOS POR EL TEXTO}

8. Negativa a leer basada en la conciencia de lo impreso

Se niega a leer porque ha aprendido que el texto y no las ilustraciones es lo que la gente lee. Explica "no conozco las letras", "no puedo leer todavía", "necesito que me ayudes a leer las palabras", "No puedo leer, sólo simulaba hacerlo".

9. Lectura basada en algunos aspectos del texto impreso

El niño se centra en uno o dos aspectos del texto impreso excluyendo otros. Puede centrarse en algunas palabras conocidas o en algunas letras y sus sonidos asociados, o bien en alguna parte del texto que recuerde. Su lectura parece retroceder, al igual que en el estadio anterior, de tal suerte que el niño que "leía" textos completos con entonación de lectura puede recitar sólo las palabras que reconoce en el texto.

10. Lectura con estrategias desbalanceadas

Se parece más a la lectura independiente que la lectura basada en algunos intentos del texto, pero aún no está lo suficientemente integrada ni es flexible estratégicamente. 
Omite excesivamente palabras desconocidas, sustituye palabras desconocidas por palabras que ya conoce, no corrige las palabras sin sentido que pronuncia, depende más del texto que recuerda o del que puede predecir que de lo que lee.

\section{Lectura independiente}

Se distingue de la anterior por la cantidad de autorregulación que el niño exhibe y la flexibilidad con la que hace auto-correcciones.

El niño que lee independiente puede leer correctamente o equivocarse, cuando se equivoca hace más auto-correcciones adecuadas y muestra conciencia de más conocimiento. Puede sustituir algunas palabras que se le dificultan por alguna frase como "lo que sea", puede inferir el significado de una palabra que desconoce. Hay clara evidencia de predicción y confirmación de estrategias.

De acuerdo a las características que el niño presenta durante la lectura, se le ubica en el nivel que corresponde.

\section{Método}

\section{Participantes}

La selección de los participantes se realizó mediante un muestreo no probabilístico intencional (Padua, 1987).

83 niños (31 niñas y 52 niños) de 3 a 6 años 3 meses de edad, que asisten a dos centros de desarrollo y educación infantil de la Ciudad de México.

A continuación se presenta la distribución de la muestra:

\begin{tabular}{|c|c|c|c|}
\hline RANGO DE EDAD & GRUPO & NÚMERO DE NIÑOS & PORCENTAJE \\
\hline $\begin{array}{l}3 \text { años a } 3 \text { años } 11 \\
\text { meses } \\
\text { (36 a } 47 \text { meses) }\end{array}$ & Maternal C & 21 & 25.3 \\
\hline $\begin{array}{l}4 \text { años a } 4 \text { años } 11 \\
\text { meses } \\
\text { (48 a } 59 \text { meses) }\end{array}$ & Preescolar 1 y 2 & 40 & 48.2 \\
\hline $\begin{array}{l}5 \text { años a } 6 \text { años } 3 \\
\text { meses } \\
\text { (60 a } 75 \text { meses })\end{array}$ & Preescolar 3 & 22 & 26.5 \\
\hline Total & & 83 & 100.0 \\
\hline
\end{tabular}

Tabla 2. Descripción del número de niños por grupo de edad. 
Las escuelas de donde se tomaron los participantes son dos escuelas públicas de la Ciudad de México. La primera de ellas corresponde a una estancia infantil del ISSSTE y la segunda es un centro de desarrollo infantil que se encuentra dentro de un centro comunitario de la Delegación Coyoacán.

Los niños ingresan a ambas escuelas desde los 45 días de nacidos y pueden permanecer ahí hasta los 6 años de edad. De esta manera, los niños de Maternal C llevan en promedio 3 años de escolarización, los de Preescolar 1 y 2, 4 años de escolarización y los de Preescolar 3, 5 años de escolarización.

En la Estancia Infantil del ISSSTE, las acciones pedagógicas se guiaban por el Programa Integral Educativo (1992).

En el centro de desarrollo infantil del Centro comunitario de la Delegación Coyoacán, los niños llevaban el programa de Educación Preescolar de la SEP $(1992)^{5}$.

70 padres / madres de estos niños. De estos 70 padres, 59 contestaron los cuestionarios y 47 permitieron que se les observara leyendo el cuento a sus hijos.

De los 47 padres a quienes se pudo observar: 11 correspondían a las edades de 3 años a 3 años 11 meses; 25 correspondían de 4 años a 4 años 11 meses y 11 correspondían de 5 años a 6 años 3 meses.

La distribución de la escolaridad de los padres se presenta en la siguiente tabla:

\begin{tabular}{|l|c|c||}
\hline \multicolumn{1}{|c|}{ ESCOLARIDAD } & NÚMERO DE PADRES & PORCENTAJE \\
\hline Ninguna & 1 & 1.4 \\
\hline Primaria & 5 & 7.2 \\
\hline Secundaria & 15 & 21.4 \\
\hline Carrera técnica & 11 & 15.7 \\
\hline Preparatoria & 24 & 34.3 \\
\hline Licenciatura & 13 & 18.6 \\
\hline Especialización & 1 & 1.4 \\
\hline Total & 70 & 100.0 \\
\hline
\end{tabular}

Tabla 3. Descripción del número de padres por nivel de escolaridad.

${ }^{5}$ En la actualidad, ambas escuelas aplican el programa de Educación Preescolar (SEP, 2004). Al momento del estudio aplicaban los programas mencionados. 
La escolaridad se computó en ciclos terminados, promediando la escolaridad de padre y madre para obtener el nivel de escolaridad de los padres (ver definición en método).

El nivel socioeconómico de la muestra es medio y la escolaridad promedio de los padres es de bachillerato. La mediana fue de 5, es decir, el 50\% o menos de los padres de la muestra tiene escolaridad de preparatoria, encontrándose el percentil 25 en secundaria y el percentil 75 también en preparatoria.

5 maestras de educación preescolar, cuyos datos de formación y antigüedad se presentan a continuación:

\begin{tabular}{||l|l|c||}
\hline \multicolumn{1}{|c|}{$\begin{array}{c}\text { MAESTRA Y GRUPO } \\
\text { QUE ATIENDE }\end{array}$} & \multicolumn{1}{|c||}{ FORMACIÓN } & ANTIGÜEDAD \\
\hline $\begin{array}{l}\text { 1. Maternal C } \\
\text { años a } 3 \text { años } 11 \text { meses }\end{array}$ & $\begin{array}{l}\text { Puericultista, segundo semestre } \\
\text { de Licenciatura en Psicología }\end{array}$ & 12 años \\
\hline $\begin{array}{l}\text { 2. Preescolar } 1 \text { y } 2 \\
\text { años a } 4 \text { años } 11 \text { meses }\end{array}$ & $\begin{array}{l}\text { Lic. en Pedagogía, sexto semes- } \\
\text { tre de Licenciatura en Psicología }\end{array}$ & 15 años \\
\hline $\begin{array}{l}\text { 3. Preescolar } 3 \\
\text { años a } 6 \text { años } 3 \text { meses }\end{array}$ & Educadora & 28 años \\
\hline $\begin{array}{l}\text { 4. Maternal C } \\
\text { años a } 3 \text { años } 11 \text { meses }\end{array}$ & $\begin{array}{l}\text { Niñera (curso de capacitación } \\
\text { del DIF) }\end{array}$ \\
\hline $\begin{array}{l}\text { 5. Preescolar } 1,2 \text { y } 3 \\
\text { años a } 6 \text { años } 3 \text { meses }\end{array}$ & Asistente educativa (DIF) & 21 años \\
\hline
\end{tabular}

Tabla 4. Descripción de la formación y antigüedad de las maestras.

La antigüedad promedio en el servicio es de 19 años. Las tres primeras maestras corresponden a la Estancia Infantil del ISSSTE y las dos últimas al Centro Comunitario.

\section{Escenarios}

Las aplicaciones de los instrumentos a los niños se hicieron en sus salones de clases, en el área de iniciación a la lectura.

A los padres se les observó en el cubículo de psicología en la Estancia Infantil y en el salón de inglés en el Centro Comunitario. Ambos libres de interrupciones.

Las maestras fueron observadas en sus salones de clases. 


\section{Instrumentos y materiales}

Cuestionario de actividades de lectura en el hogar (Vega, 2001)

Este cuestionario incluye preguntas respecto de las características socioeconómicas de los padres (ingresos, egresos y escolaridad) así como solicitud de autorización para observarlos durante la lectura de cuentos. Asimismo a través de él se identifican los materiales de lectura. Para su calificación se cuenta el número de materiales mencionados. El puntaje máximo posible es el número de materiales citados por los padres.

En la tercera sección del cuestionario se identifican las actividades que se realizan cotidianamente en el hogar y que pueden promover la adquisición de la lectura y la escritura.

Para su calificación se cuenta la frecuencia de cada actividad que se realiza en el hogar y que se incluye en el cuestionario. A mayor frecuencia se le da mayor puntaje, siendo 6 el puntaje máximo para cada reactivo y un total de 15 reactivos. El puntaje máximo posible para las actividades es de 90. (Anexo 1)

Lista cotejable para la lectura de cuentos en el hogar (Vega, 2001)

Esta lista cotejable incluye las actividades que los padres realizan antes, durante y después de la lectura y que según la literatura pueden promover el desarrollo de conocimiento, habilidades relacionadas con la lectura en los años preescolares. Se cuenta el número de conductas presentes durante la actividad. El puntaje máximo posible es de 40. (Anexo 2)

Lista cotejable para la lectura de cuentos en la escuela (Vega, 2001)

Esta lista cotejable es similar a la anterior, pero se adapta al escenario de salón de clases y a la lectura a grupos de niños. El puntaje máximo posible es de 44. (Anexo 3)

Instrumento para Evaluar Habilidades Precurrentes para la Lectura, EPLE (Vega, 1991a)

Fue utilizado para evaluar las habilidades lingüísticas orales. El objetivo del instrumento consiste en determinar el nivel de desarrollo lingüístico midiendo una serie de habilidades que según la literatura y la evidencia empírica están relacionadas directamente con la adquisición de la lectura (Vega, 1991b; Vega, 1998). 
Este instrumento consta de 10 subpruebas, cada una de las cuales mide un aspecto diferente relacionado con a) La conciencia fonológica: 1) Pronunciación correcta de los sonidos del habla; 2) Discriminación de sonidos verbales; 3) Análisis auditivo; 4) Síntesis auditiva; y b) La codificación semántica: 4) Reconocimiento de nombres ante la presentación de láminas; 5) Seguimiento de instrucciones; 6) Conocimiento del significado de las palabras; 7) Sinónimos, antónimos y palabras supraordinadas; 8) Repetición de un cuento; 9) Diferencia entre dibujo y texto; 10) Expresión espontánea.

La aplicación del EPLE es individual en aproximadamente 20 minutos por niño. Los puntajes totales y por subprueba se pueden convertir a porcentajes, por lo que, una vez hecha esta conversión, el puntaje máximo posible para cada subprueba y total es de 100 y se puede obtener un perfil de desempeño del niño que permite ubicar aquellas habilidades que requieren estimularse. El Anexo 4 incluye una descripción más amplia del contenido del EPLE, así como de sus características psicométricas.

Instrumento de Observación de los Logros de la Lectoescritura Inicial (Escamilla, Andrade, Basurto y Ruiz, 1996)

Este instrumento es la versión en español del Observational Survey of Early Literacy Achievement (Clay, 1993). Se utilizó para evaluar el conocimiento que los niños han construido respecto del lenguaje escrito sin haber recibido instrucción en lectura y escritura convencionales.

Consta de las siguientes subpruebas: 1) Identificación de letras; 2) Prueba de palabras; 3) Conceptos de texto impreso; 4) Vocabulario de escritura; 5) Muestra de escritura; 6) Dictado. En el Anexo 5 se presenta una descripción del contenido, así como de las características psicométricas del instrumento.

Cabe aclarar que en el presente estudio no se tomó en consideración el resultado de la prueba de palabras en la obtención del puntaje total, en virtud de que ningún niño de la muestra pudo identificar palabra alguna. Por otra parte, la calificación del dictado se realizó de acuerdo a la secuencia propuesta por Fields y Spangler (2000) descrita en la sección de "variables".

Adicionalmente a los instrumentos de evaluación utilizados para cada variable se ocuparon los protocolos de las pruebas, cuentos para los niños, una grabadora de audio para grabar la lectura de cuentos realizada por los niños y una cámara de video para filmar la lectura de cuentos por parte de madres y maestras. 
Los cuentos que los niños leyeron fueron seleccionados por ellos de los que existían cotidianamente en el salón de clases. Se les pidió que seleccionaran el cuento que más les gustara de los que conocían, es decir, que ya habían leído antes.

A las madres se les pidió que llevaran a la evaluación el cuento favorito de su hijo, aquél que con mayor frecuencia les pedía que le leyeran.

Los cuentos que leyeron las maestras fueron seleccionados por los niños, a solicitud de las maestras, de los que existían cotidianamente en el salón de clases.

\section{Procedimiento}

Se seleccionaron los instrumentos para la medición de las habilidades lingüísticas y el conocimiento del lenguaje escrito. Se elaboró el cuestionario para evaluar los materiales y actividades de lectura en el hogar, así como las listas cotejables para la lectura de cuentos por parte de madres y maestras. El contenido del cuestionario y el de las listas cotejables se basó en la bibliografía revisada.

Se realizó un estudio piloto con el fin de determinar la aplicabilidad de instrumentos y procedimientos. Con base en el estudio piloto se realizaron las modificaciones pertinentes a instrumentos y procedimientos (se describen en la sección de resultados). Se determinaron los indicadores de validez y confiabilidad de los instrumentos.

Se seleccionaron las escuelas participantes con base en un muestreo no probabilístico intencional.

Se capacitó a las dos aplicadoras de los instrumentos. Para la aplicación de los instrumentos se contó con dos estudiantes, una de maestría y una de licenciatura. La capacitación consistió en la lectura y discusión de los procedimientos de aplicación y calificación y en la aplicación supervisada con retroalimentación, así como en la calificación conjunta de varios protocolos.

Se realizó una entrevista con las autoridades de cada institución para explicar los objetivos y procedimientos del proyecto y obtener su autorización para la realización del mismo. Se tuvo una reunión con los padres de familia y maestras de cada institución con los mismos propósitos.

En la reunión con los padres se les distribuyó un cuestionario con el fin de conocer el tipo y frecuencia de las actividades relacionadas con la lectura que se realizan en el hogar, así como los materiales de lectura al alcance del niño y solicitar su autorización para video grabarlos leyendo un cuento a su hijo(a). 
Se tuvo un periodo de adaptación con los niños para que se familiarizaran con las investigadoras y se procedió a la aplicación de los instrumentos a los niños en dos sesiones por niño de aproximadamente 20 minutos cada una En una tercera sesión se pidió a cada niño que leyera su cuento favorito a la investigadora. Esta sesión se audio grabó.

Se programaron las sesiones de lectura de cuentos con los padres que accedieron a ello. Se realizó la lectura de cuentos por parte de los padres en una sesión por niño. Esta sesión se video grabó.

Se video grabó a las maestras leyendo un cuento a su grupo, una sesión para cada grupo.

Se seleccionó al azar a seis niños de cada escuela para realizar una segunda (dos meses después) y tercera evaluación (cuatro meses después), con el fin de tener datos longitudinales para describir el desarrollo de los niños en esta área.

De los doce niños elegidos, se seleccionó al azar a tres para ilustrar el desarrollo mediante muestras de sus producciones en los tres momentos de la evaluación. Por supuesto, también se tienen datos transversales en virtud de que se tomaron datos niños de diferentes edades.

Se procedió a la calificación de los instrumentos, la elaboración del archivo de datos y el análisis de los mismos.

Finalmente, se presentó un reporte de los resultados, verbal mediante una plática, e impreso, a autoridades, personal y padres de las instituciones participantes: y se entregaron sugerencias impresas a padres y maestras para promover el desarrollo de la alfabetización. 

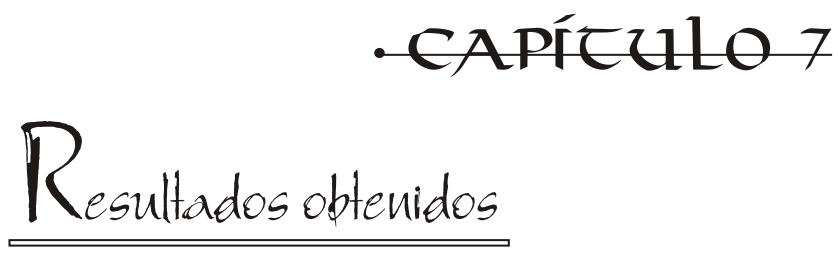

\section{Análisis realizados}

Se obtuvieron estadísticos descriptivos de la muestra total y por edad para el desarrollo de la alfabetización y para las habilidades lingüísticas orales. De la misma manera, se obtuvieron los estadísticos descriptivos para las variables del hogar y de la escuela.

Se realizó un Análisis de Varianza en una sola dirección (Kerlinger y Lee, 2002) con el fin de indagar las diferencias entre los grupos de edad, para las habilidades lingüísticas en el lenguaje oral y un análisis de varianza de Kruskall Wallis (Siegel, 1985) para el desarrollo de la alfabetización.

Se realizó una prueba t para muestras independientes con el fin de indagar diferencias por sexo en las habilidades lingüísticas orales y una U de Mann Whitney con el fin de indagar diferencias por sexo en el desarrollo de la alfabetización.

Se realizó un análisis de correlación entre todas las variables, obteniéndose así la matriz de correlación.

Se realizó un análisis de regresión múltiple, con el fin de determinar la contribución de cada una de las variables independientes a la variable dependiente.

Se realizó un análisis cualitativo de los resultados, mediante la observación de la lectura de cuentos por madres y maestras. Se realizó la descripción de las conductas de madres y maestras antes, durante y después de la lectura tendientes a estimular la comprensión de la historia y de la características del lenguaje escrito. 
Se realizó la descripción de las conductas de los niños al leer los cuentos así como la descripción de sus respuestas tanto verbales como escritas que evidencian conocimiento del lenguaje escrito con el fin de complementar la información proporcionada por los análisis cuantitativos, en virtud de que los datos numéricos no permiten dar cuenta de las diferencias individuales encontradas tanto en el desempeño de los niños como el de madres / padres y maestras.

A continuación se presentan los resultados obtenidos:

I. Se presentan en primer lugar los resultados que se refieren al primer objetivo: caracterizar el desarrollo de la alfabetización en una muestra de niños preescolares.

II. Posteriormente se presentan los resultados descriptivos de las habilidades lingüísticas orales y las variables contextuales.

III. Finalmente, se presentan los resultados que responden al segundo objetivo: analizar la contribución de variables involucradas en el desarrollo de la alfabetización en niños preescolares.

\section{Caracterizar el desarrollo de la alfabetización en una muestra de niños preescolares}

\section{A. CONOCIMIENTO DEL LENGUAJE ESCRITO}

Este componente de la variable se evaluó mediante el Instrumento de Observación de los Logros de la Lectoescritura Inicial (Escamilla y cols., 1996).

Las tareas que se aplicaron fueron: identificación de letras, prueba de palabras, conceptos de texto impreso, vocabulario de escritura, dictado y muestra de escritura. Se obtuvo un puntaje total sumando los puntajes para cada uno de estos aspectos y dividiéndolo entre el total de aspectos, el cual se denomina total y proporciona la medida del conocimiento del lenguaje escrito.

Cabe aclarar que la tarea prueba de palabras se eliminó del resultado total de la prueba ya que ninguno de los niños fue capaz de identificar palabra alguna de la lista de palabras presentada.

De la misma manera, la tarea de dictado se calificó de acuerdo a la secuencia de desarrollo propuesta por Fields y Spangler (2000), (Ver descripción de cada uno de los niveles en la definición de la variable dependiente en método) pues ninguno de los niños fue capaz de escribir un solo grafema que correspondiera al fonema dictado, lo cual servía de base para la calificación en los criterios originales. 
La tabla siguiente muestra las medianas y cuartiles para cada una de las tareas realizadas.

\begin{tabular}{||c|c|c|c|c||}
\hline \multicolumn{1}{|c|}{ TAREAS } & N & PERC 25 & MEDIANA & PERC 75 \\
\hline $\begin{array}{l}\text { Identificación } \\
\text { de letras }\end{array}$ & 83 & 1 & 4 & 8 \\
\hline $\begin{array}{l}\text { Conceptos de } \\
\text { texto impreso }\end{array}$ & 83 & 3 & 6 & 8 \\
\hline $\begin{array}{l}\text { Vocabulario } \\
\text { de escritura }\end{array}$ & 82 & 0 & 1 & 5 \\
\hline $\begin{array}{l}\text { Muestra de } \\
\text { escritura }\end{array}$ & 82 & 2 & 4 & 6 \\
\hline \begin{tabular}{l} 
Dictado \\
\hline $\begin{array}{l}\text { Total lenguaje } \\
\text { escrito }\end{array}$
\end{tabular} & 83 & 1.75 & 4.2 & 6 \\
\hline
\end{tabular}

Tabla 5. Resultados obtenidos en las áreas que componen el conocimiento del lenguaje escrito. Muestra total.

La gráfica que se presenta a continuación permite visualizar los puntajes promedio obtenidos por los niños.

CONOCIMIENTO DEL LENGUAJE ESCRTO

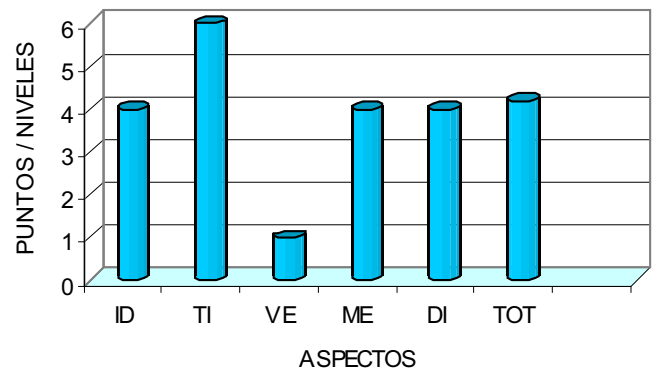

Gráfica 1. Puntajes promedio de los niños en cada uno de los aspectos que componen el conocimiento del lenguaje escrito.

Como puede observarse en la gráfica 1, los niños son capaces de identificar en promedio 4 letras (ID). Con frecuencia son las letras que se encuentran en su nombre o en el de sus compañeros de clase, por ejemplo, Sofía afirma conocer la $A$ y la $F$ porque están en su nombre, la $K$ porque es de Karla y la $V$ porque es de Víctor. Ocurre lo mismo con las letras mayúsculas y minúsculas. 
En lo que se refiere a los conceptos de texto impreso (TI), los niños manejan en promedio 6 de ellos. Ejemplos de los conceptos que manejan son: La parte de enfrente del libro, el texto impreso lleva el sentido y no la ilustración, la parte de abajo de la ilustración, en qué parte del texto se inicia la lectura, hacia dónde se sigue, la identificación de una letra. Algunos de los conceptos que los niños no manejan son: El inicio y el fin de un texto, la dirección completa de la lectura (¿Dónde inicio, hacia dónde me sigo, y luego para dónde me voy?) no son capaces de identificar si se cambia el orden de las líneas, las palabras o las letras en un texto y tampoco conocen el uso de los signos de puntuación, aunque muchos de ellos afirman que sirven para leer. Esta tarea se realiza mediante la lectura de un cuento incluido en el instrumento en el que se van formulando las preguntas conforme se va leyendo el cuento al niño.

En el vocabulario de escritura (VE), los niños pueden escribir en promedio una palabra escrita de manera convencional, que en muchos casos es su nombre. Otros niños escriben el nombre de sus padres, o bien, papá, mamá o el de sus compañeros.

En cuanto a la muestra de escritura (ME) el puntaje promedio obtenido fue de 4. En esta tarea, se otorgaba el puntaje sumando los puntos que obtenía el niño en cada uno de los tres aspectos evaluados (Ver descripción en la definición de la variable).

Se obtuvo la confiabilidad para los puntajes otorgados seleccionando diez muestras al azar y pidiendo a un observador independiente que otorgara los puntajes para cada aspecto evaluado para cada niño. Se obtuvo una confiabilidad de $80 \%$. La confiabilidad se obtuvo dividiendo el total de acuerdos entre el total de observaciones.

Por ejemplo, Liliana obtiene un punto en nivel de lenguaje, pues escribe letras, un punto en calidad del mensaje pues muestra tener el concepto de signos y 2 puntos en principios direccionales, pues muestra parte de ellos (escribe de izquierda a derecha). Esto le da un total de 4 puntos en muestra de escritura.

Se presenta a continuación la muestra de escritura de Liliana que se ha descrito en el párrafo precedente.

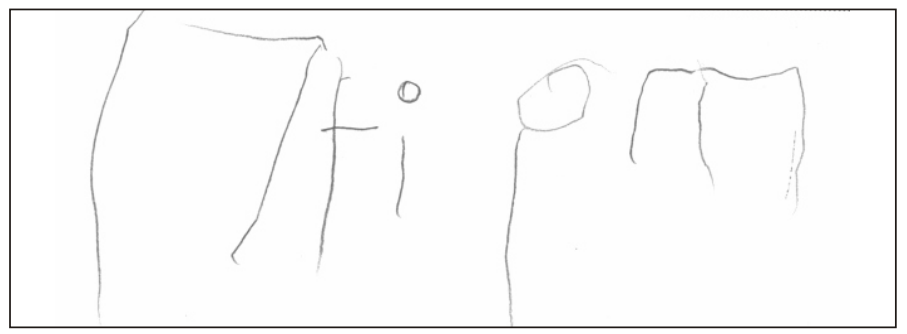

Figura 1. Muestra de escritura de Liliana (42 meses) que obtuvo 4 puntos. 
Finalmente, se dictaba a los niños un par de enunciados proporcionados también por el instrumento y se les pedía que los escribieran, los puntajes se otorgaron considerando el nivel en la clasificación de Fiels y Spangler (2000), de acuerdo a las características que presentaba la escritura de los niños.

Se obtuvo la confiabilidad de los niveles en que se situó a los niños seleccionando al azar una muestra de 20 niños y pidiendo a un observador independiente que los situara en el nivel correspondiente de acuerdo a las características presentadas por la escritura de los niños. Se obtuvo una confiabilidad de $82 \%$, dividiendo el total de acuerdos entre el total de observaciones.

Como la gráfica 1 muestra, se obtuvo un promedio de 4, es decir, el 50\% o menos de los niños se ubicaron en este nivel que corresponde a imitar la escritura convencional, conteniendo elementos de palabras reales.

Se presenta un ejemplo de escritura que corresponde a esta categoría.
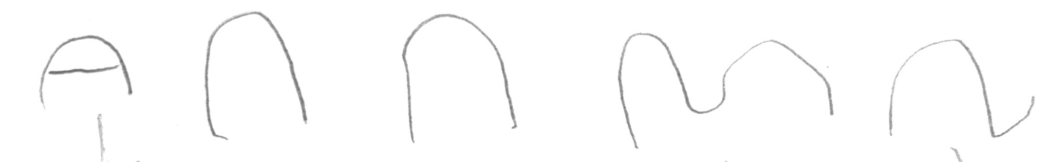

Figura 2. Ejemplo del nivel 4 de dictado, imita escritura convencional. Paola (50 meses) escribió "Tengo un perro en mi casa. Lo llevo al parque conmigo".

El puntaje total de conocimiento del lenguaje escrito se obtuvo sumando los puntajes obtenidos en cada uno de los aspectos evaluados y dividiendo la suma entre el total de aspectos, es decir, se obtuvo un promedio. El puntaje total promedio de conocimiento del lenguaje escrito fue de 4.2 como se observa en la gráfica 1.

\section{B. DESEMPEÑO DE LOS NIÑOS DURANTE LA LECTURA DE CUENTOS}

Este componente del desarrollo de la alfabetización se evaluó pidiendo a cada niño que leyera su cuento favorito de los que existían en el salón. Se hizo mucho hincapié en que los pequeños seleccionaran un cuento que ya conocían. Esta tarea se audio grabó.

Los puntajes se otorgaron con base en la clasificación propuesta por Sulzby en 1985 y retomada por Valencia y Sulzby en 1991 y que se describió en la definición de este componente de la variable (Ver Método). El puntaje otorgado corresponde al nivel en que se ubicó al niño de acuerdo las características que presentaba al leer el cuento y que correspondían a alguna de las categorías propuestas por Sulzby. 
Se obtuvo la confiabilidad de las calificaciones otorgadas mediante un observador independiente que escuchó la grabación de 15 niños seleccionados al azar y los ubicó en los niveles correspondientes. La confiabilidad obtenida fue de $87 \%$.

La gráfica siguiente muestra el número de niños que se ubicaron en cada uno de los niveles.

\section{DESEMPEÑO DE LOS NIÑOS DURANTE LA LECTURA DE CUENTOS MUESTRA TOTAL}

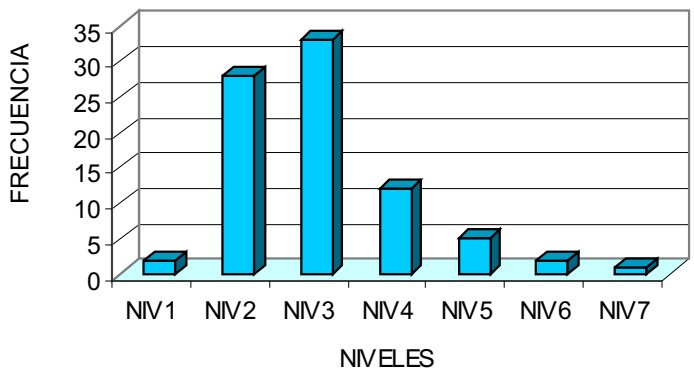

Gráfica 2. Número de niños en cada nivel de la lectura de cuentos.

La frecuencia mayor se obtuvo en el nivel 3 (33 niños), en el cual los niños narran la historia basándose totalmente en las ilustraciones, sin formar completamente la historia. La narración se basa en un diálogo que el niño realiza con el adulto o bien entre los personajes del cuento. Incluye pasado y futuro, además del presente y gerundio que utiliza en el nivel 2.

Se transcribe un ejemplo de este nivel en la narración.

P. Una vez un nene y había un castillo. Una reina estaba acostado, la mala ya encontró al bebé, entonces la mala estaba enojada. Y la hada madrina se lo quiso llevar.

E. ¿Al bebé?

P. Ajá. Entonces había un ratón japonés. (Silencio)

E. ¿Y luego que pasó Paulita?

P. Se encuentra a una vieja hada "husando" la espuma, pero la bella durmiente le dio miedo, entonces se murió. La princesa durmiente se murió. Entonces, el príncipe llegó rápido por la reina, entonces el príncipe llegó a las escaleras. El gato se durmió, (Silencio)

E. Y ¿qué más pasó Paola?

P. Entonces el príncipe llegó a rescatarla, le dio un beso, ya se fueron juntos. Se despertaron, ya no tenían miedo y las hadas ya vinieron y colorín colorado, este cuento se ha acabado.

Cuadro 1. Ejemplo del nivel 3 de lectura de cuentos. Narración mediante diálogo.

Paola (50 meses) leyó “La Bella Durmiente”. P. Paola E. Experimentadora 
El nivel que sigue en frecuencia es el nivel 2 (28 niños), en el que el niño sólo describe la acción que ocurre en cada ilustración sin formar historia alguna. En este nivel, los tiempos verbales que se utilizan son el presente y el gerundio. Aunque el niño del ejemplo, utiliza el pasado.

A continuación se muestra un ejemplo de este tipo de narración.

T. Pinocho iba caminando y encontró a un viejito.

Después se cayó al agua, el viejito también

Pinocho y el abuelito estaban dentro de una boca

Este pinocho otra vez se cayó al agua y salió una ballena

Pinocho estaba platicando con un niño, con un caballo

Después, una señora con su varita mágica puso a Pinocho en una jaula

Este pinocho ya estaba colgado en la ... en la...

E. ¿En la qué Toñito?

T. En la jaula

Después un señor quería que se subiera a su carro

Y un lobo y un gato lo estuvieron empujando

El lobo, el gato y el Pinocho iban formados caminando

También el abuelito le dio a Pinocho una manzana

Después una hormiguita estaba parado

Después la señora que tenía el gorro y la varita lo iba persiguiendo, pero parado.

El abuelito hizo a Pinocho de madera y ya.

Cuadro 2. Ejemplo del nivel 2 de la lectura de cuentos. Narra la acción” Toñito (51 meses) leyó "Pinocho". Leyó todo el cuento del fin al inicio. T. Toñito E. Experimentadora

El nivel menos frecuente es el nivel 7, (sólo un niño) en el que el niño recita la historia casi literalmente. Muestra conductas de auto corrección que indican que está tratando de recuperar la historia. Su entonación es como de lectura oral.

Se transcribirá la lectura de esta niña al presentar los resultados individuales de los niños seleccionados para ilustrar el desarrollo de la alfabetización de manera longitudinal.

Todos los niños de la muestra basaron su narración en las ilustraciones, sin embargo, algunos de ellos, aun cuando leían el cuento basándose en las ilustraciones iban siguiendo el texto con el dedo lo que permite afirmar que sabían que el texto es el que lleva el mensaje y no la ilustración. Esta afirmación, de hecho, se corrobora con los resultados obtenidos en la tarea de conceptos de texto impreso del conocimiento de lenguaje escrito. 
A continuación se presentan resultados que permiten tener una visión de las diferencias encontradas con relación al desarrollo de los niños, es decir, se presentan los resultados para los diferentes grupos de edad.

Se presentan los resultados para conocimiento del lenguaje escrito y posteriormente para el desempeño de los niños durante la lectura de cuentos.

\section{A. CONOCIMIENTO DEL LENGUAJE ESCRITO}

La gráfica muestra los resultados obtenidos por los niños en cada una de las tareas que constituyeron este componente del desarrollo de la alfabetización.

CONOCIMIENTO DE LENGUAJE ESCRTOO

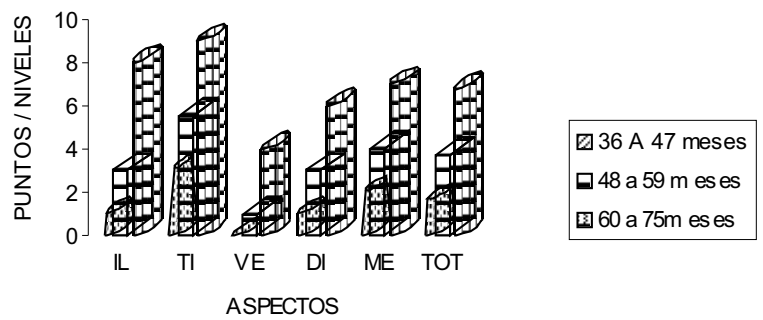

Gráfica 3. Puntajes promedio por grupo de edad en los aspectos que conforman el conocimiento del lenguaje escrito.

En la gráfica se observa una clara progresión en los resultados por grupo de edad.

Se puede observar que los niños mayores pueden identificar en promedio 9 letras (IL) en tanto que los más pequeños sólo una. Se observó que los niños de 36 a 47 meses, reconocen sólo alguna de las vocales, por ejemplo, Liliana reconoce la o mayúscula y la o y u minúsculas. Los niños de 48 a 59 meses reconocen también las vocales y además las letras que componen su nombre o el de sus compañeros, por ejemplo Karla reconoce la $A$ de Aimé, la $F$ de Fernanda, la $J$ de juego, la $Y$ de Yussif, y finalmente los niños de 60 a 75 meses reconocen las vocales tanto mayúsculas como minúsculas y algunas consonantes por su nombre, por ejemplo, Erick reconoce 21 letras entre mayúsculas y minúsculas por ejemplo, la $A, F, K, P, H, O, U, C, Q, M, N, E$ y $W$.

En cuanto a los conceptos sobre el texto impreso, los niños de 36 a 47 meses reconocen que el texto y no la ilustración es la que lleva el mensaje, la parte de enfrente del libro y la parte de abajo de la ilustración; los de 48 a 59 meses, ya identifican además por dónde inicia 
el texto, que la página izquierda se lee antes que la derecha y pueden identificar una letra aislada; los de 60 a 75 meses pueden además seguir toda la dirección de la lectura (de izquierda a derecha y regresar a la izquierda) dónde inicia y termina el texto, identificar una y dos letras y la primera y última letra de una palabra.

En cuanto al vocabulario de escritura, los niños de 36 a 47 meses no escriben palabra alguna, los de 48 a 59 meses, una, que generalmente es su nombre y los de 60 a 75 meses pueden escribir su nombre y el de sus hermanos o padres.

En cuanto al dictado, los niños de 36 a 47 meses se ubican en promedio en el nivel 1, que consiste en escribir garabatos, los de 48 a 59 en el nivel 3, que consiste en hacer marcas repetidas que siguen una línea, y los niños de 60 a 75 meses se ubican en promedio en el nivel 6 que consiste en escribir formas que parecen letras.

Se presentan a continuación ejemplos de cada uno de estos niveles.

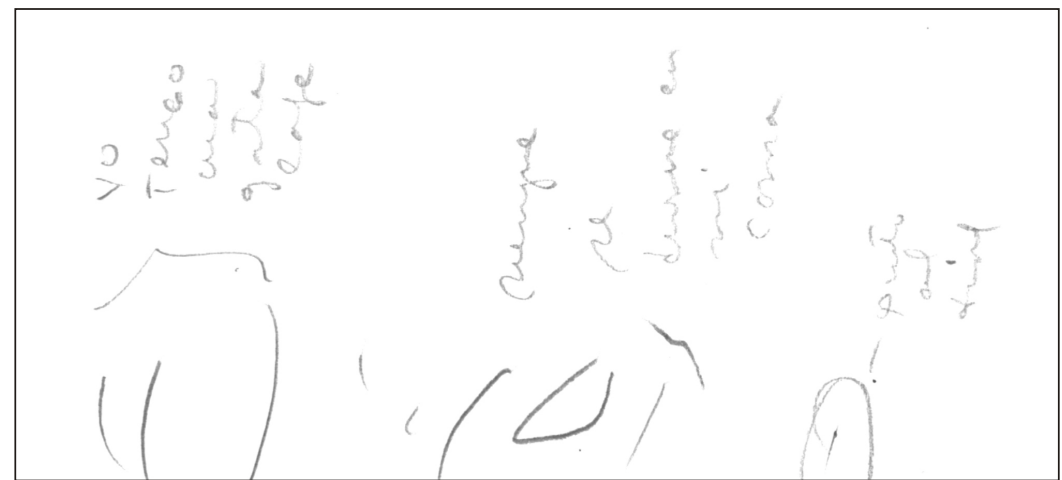

Figura 3. Ejemplo del nivel 1 de dictado, garabatos. André (46 meses) escribió: "Yo tengo una gata café. Siempre se duerme en mi cama." y agregó: "punto al final".

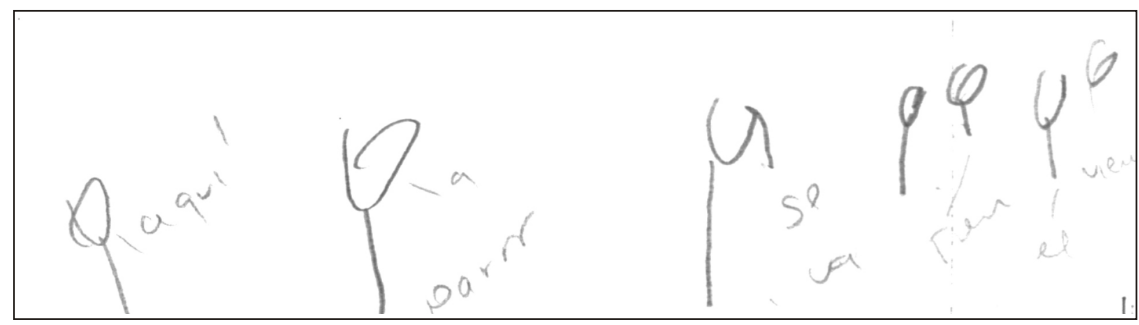

Figura 4. Ejemplo del nivel 3 de dictado, repetitivo-lineal. Judith (55 meses) escribió: "Ya viene el tren. Se va a parar aquí. Nos vamos a subir." 


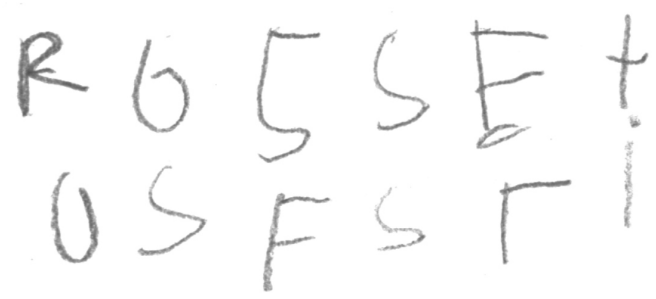

Figura 5. Ejemplo del nivel 6 de dictado, formas que parecen letras. Jessica (67 meses) escribió: "Papá está en casa. Dice que vamos a jugar a la pelota."

En muestra de escritura, los niños de 36 a 47 meses obtuvieron un puntaje promedio de 2 puntos, los de 48 a 59 meses un puntaje de 4 puntos y los de 60 a 75 meses, un puntaje de 7 puntos.

Por ejemplo, Frida (47 meses) obtiene 0 puntos en nivel de lenguaje pues todavía no usa letras, 1 punto en calidad del mensaje pues ya intenta escribir signos y 1 punto en principios direccionales, pues no hay evidencia de ellos.

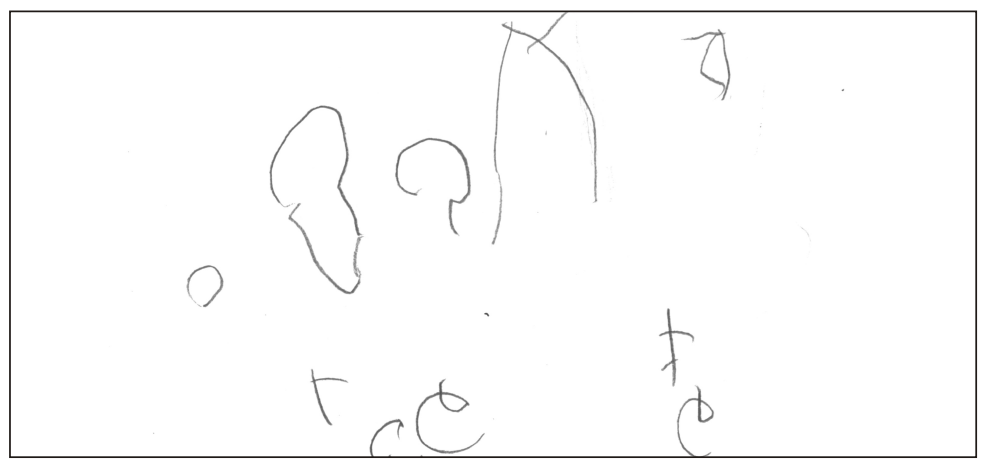

Figura 6. Muestra de escritura de Frida que obtuvo dos puntos.

Eva Paula (64 meses) obtuvo 3 puntos en nivel de lenguaje pues escribió una combinación de dos palabras, 2 puntos en calidad del mensaje pues muestra evidencia de saber que el mensaje lleva significado y 2 puntos en principios direccionales pues escribió de izquierda a derecha.

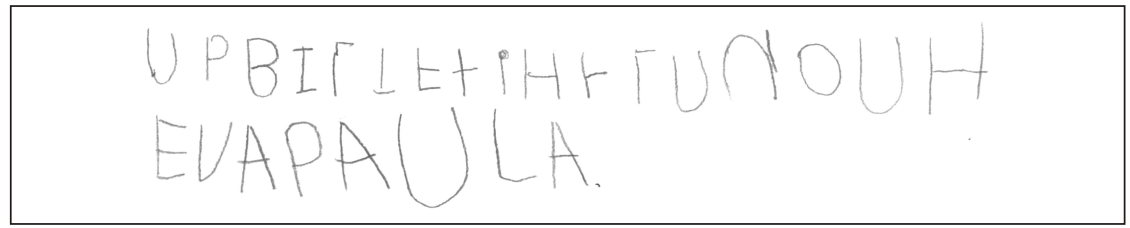

Figura 7. Muestra de escritura de Eva Paula que obtuvo 7 puntos. 
La secuencia presentada en cada uno de los aspectos que se evaluaron como parte del conocimiento del lenguaje escrito evidencia un mayor desarrollo de este conocimiento relacionado a un mayor desarrollo general, y esto se refleja también en el puntaje total de este componente de la variable dependiente. En los puntajes totales también se muestra una progresión conforme los niños avanzan en edad, obteniendo los siguientes puntajes promedio: 36 a 47 meses, 1.6; 48 a 59 meses, 3.7; 60 a 75 meses, 6.8. El puntaje mínimo alcanzado en el total fue de .40 y el máximo de 15 .

Se presentan a continuación, los resultados del otro componente de la variable desarrollo de la alfabetización.

\section{B. DESEMPEÑO DE LOS NIÑOS DURANTE LA LECTURA DE CUENTOS}

La gráfica siguiente muestra el número de niños de cada edad que se ubicaron en los diferentes niveles de este componente de la variable (Ver niveles en la definición de la variable dependiente en método).

DESEMPEÑO DE LOS NIÑNOS DURANTELA LECTURA DE CUENTOS

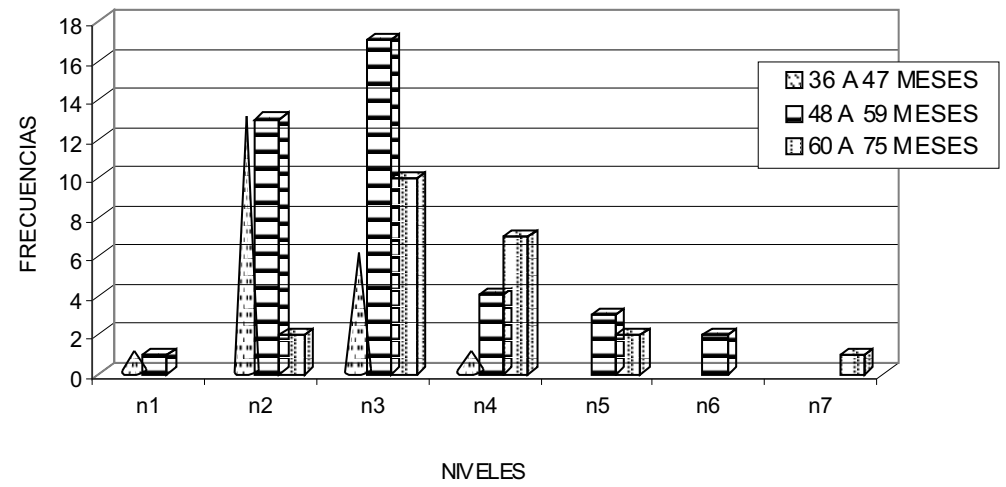

Gráfica 4. Número de niños en cada nivel de la lectura de cuentos, por edad.

En la gráfica se puede apreciar que la mayoría de los niños de 39 a 47 meses (3 a 3.11 años) se ubican en el nivel 2 (13), en el que los niños sólo describen la acción de cada ilustración, la mayoría de los niños de 48 a 59 meses se ubican en el nivel 3 (17), al igual que los niños de 60 a 75 meses (10).

Los niños de 60 a 75 meses se ubican en segundo lugar en el nivel 4 (7), que consiste en narrar la historia basado en las ilustraciones, pero mediante un monólogo. En esta narración ya se presenta una historia que el escucha puede comprender casi completa. Se presenta un ejemplo. 
D. Erase una vez... ¿Cuándo se me graba?

E. Cuentámelo, cuando termines de contarlo escuchamos lo que me contaste, iSale?

D. Erase una vez un rey que tenía siete hijas que cuando nacieron se volvieron unas sirenas. Una la llamó Ariel, la otra Malena, la otra Estrella, la otra Jessica, la otra Diana y la otra... la llamó tortuguita.

Un marino quiso aplastar a Ariel, la mayor de todas, cuando vio ella se dirigió a un barco. Mira, que parecía una calavera.

E. Es cierto, parece una calavera.

D. Se dirigió a un barco que daba mucha luz, cuando vio que una ola arrastró el barco, vio que venían muchos pasajeros.

Entonces, una señora la convirtió en muchacha, pero sin voz.

Cuando ella se enteró que se iba a casar el príncipe, sus hermanas le dieron un cuchillo, entonces la sirenita trató de agarrar el cuchillo, bajándose por una ventana, pero se cayó y al pobre sirenita vivió muy feliz.

E. ¿En dónde Diana?

D. En su mar.

Cuadro 3. Ejemplo del nivel 4 de lectura de cuento. Narración mediante monólogo.

Diana Laura (57 meses) leyó "La Sirenita".

D. Diana E. Experimentadora

Se obtuvo la significancia de las diferencias entre los grupos de edad para cada uno de los componentes del desarrollo de la alfabetización mediante un análisis de varianza no paramétrico en una sola dirección de Kruskall-Wallis. Todas las diferencias resultaron significativas con una probabilidad menor a .001.

También se obtuvo la significancia de las diferencias por sexo, mediante una U de Mann Whitney, no obteniéndose diferencias significativas en ninguno de los componentes del desarrollo de la alfabetización.

Los resultados descritos muestran los promedios obtenidos por los pequeños en cada uno de los componentes de la variable.

En la siguiente sección, se describen los resultados obtenidos por los doce niños seleccionados al azar para hacer una descripción longitudinal del desarrollo de la alfabetización.

Se mostrarán primero los cambios en puntajes observados en los niños en las tres evaluaciones realizadas, la primera de ellas se realizó en los meses de octubre y noviembre, la segunda en enero y febrero y la tercera en mayo y junio. Posteriormente, se presentan los resultados de tres niños, seleccionados al azar de los doce originales, uno de cada edad, que ilustran los cambios observados. 


\section{CONOCIMIENTO DEL LENGUAJE ESCRITO}

En la tabla se muestra el promedio de los puntajes obtenidos en las cinco tareas aplicadas. La edad que se incluye es la edad que tenían los niños al momento de la primera evaluación.

\begin{tabular}{|c|c|c|c|c|}
\hline NIÑO & $\begin{array}{l}\text { EDAD EN } \\
\text { MESES }\end{array}$ & $\begin{array}{l}\text { PRIMERA } \\
\text { EVALUACIÓN }\end{array}$ & $\begin{array}{c}\text { SEGUNDA } \\
\text { EVALUACIÓN }\end{array}$ & $\begin{array}{c}\text { TERCERA } \\
\text { EVALUACIÓN }\end{array}$ \\
\hline 1. Jorge & 45 & 2 & 2.8 & 5.8 \\
\hline 2. Ulises & 44 & 6 & 6.4 & 7 \\
\hline 3. Liliana & 42 & 1.4 & 2.6 & 3 \\
\hline 4. Alan & 43 & 2.6 & 2.2 & 1.8 \\
\hline 5. Karla & 52 & 2 & 4.2 & 6.3 \\
\hline 6. Sofía & 51 & 7.2 & 12.8 & 15.8 \\
\hline 7. Diana & 49 & 2 & 2.8 & No hay datos \\
\hline 8. Frida & 49 & 4 & 4.6 & 5 \\
\hline 9. Erick Dan & 60 & 9 & 9.4 & 12.6 \\
\hline 10. Ángel & 60 & 7.6 & 6.8 & 11 \\
\hline 11. José Erick & 62 & 4.6 & 3.8 & 5.2 \\
\hline 12. Jessica & 67 & 5 & 6.6 & 7.2 \\
\hline
\end{tabular}

Tabla 6. Resultados obtenidos por los 12 niños seleccionados para ilustrar el desarrollo del conocimiento del lenguaje escrito.

Se puede observar en la mayoría de los casos una progresión en su desempeño, siendo el caso más notable el de Sofía, quien tuvo un gran incremento de la primera a la segunda evaluación, principalmente el conocimiento de las letras del abecedario, mayúsculas y minúsculas (de 9 a 31). Para la tercera evaluación, Sofía ya conocía casi todas las letras del abecedario (47) y también hubo muchos cambios en su conocimiento de los conceptos del texto impreso (de 7 en la primera a 15 en la tercera). Es el caso también de Jorge, quien tuvo una progresión importante de la segunda a la tercera evaluación, principalmente por los conceptos del texto impreso que maneja (de 4 a 13). Erick Dan y Angel también tuvieron un incremento importante de la segunda a la tercera evaluación, en ambos casos se incrementó el conocimiento de las letras, siendo más notorio en el caso de Angel (de 8 a 32). 
Llama la atención el caso de Alan, quien en cada evaluación obtuvo un puntaje ligeramente menor.

\section{LECTURA DE CUENTO POR PARTE DEL NIÑO}

\begin{tabular}{|c|c|c|c|}
\hline NIÑO & $\begin{array}{l}\text { PRIMERA } \\
\text { EVALUACIÓN }\end{array}$ & $\begin{array}{l}\text { SEGUNDA } \\
\text { EVALUACIÓN }\end{array}$ & $\begin{array}{l}\text { TERCERA } \\
\text { EVALUACIÓN }\end{array}$ \\
\hline $\begin{array}{l}\text { Jorge } \\
45 \text { meses }\end{array}$ & 2. Sigue la acción & 2. Sigue la acción & $\begin{array}{l}\text { 3. Narración me- } \\
\text { diante diálogo }\end{array}$ \\
\hline $\begin{array}{l}\text { Ulises } \\
44 \text { meses }\end{array}$ & 2. Sigue la acción & $\begin{array}{l}\text { 3. Narración me- } \\
\text { diante diálogo }\end{array}$ & $\begin{array}{l}\text { 3. Narración me- } \\
\text { diante diálogo }\end{array}$ \\
\hline $\begin{array}{l}\text { Liliana } \\
42 \text { meses }\end{array}$ & $\begin{array}{l}\text { 4. Narración me- } \\
\text { diante monólogo }\end{array}$ & $\begin{array}{l}\text { 4. Narración me- } \\
\text { diante monólogo }\end{array}$ & $\begin{array}{l}\text { 4. Narración me- } \\
\text { diante monólogo }\end{array}$ \\
\hline $\begin{array}{l}\text { Alan } \\
43 \text { meses }\end{array}$ & $\begin{array}{l}\text { 3. Narración me- } \\
\text { diante diálogo }\end{array}$ & $\begin{array}{l}\text { 3. Narración me- } \\
\text { diante diálogo }\end{array}$ & $\begin{array}{l}\text { 3. Narración me- } \\
\text { diante diálogo }\end{array}$ \\
\hline $\begin{array}{l}\text { Karla } \\
52 \text { meses }\end{array}$ & 2. Sigue la acción & 2. Sigue la acción & $\begin{array}{l}\text { 3. Narración me- } \\
\text { diante diálogo }\end{array}$ \\
\hline $\begin{array}{l}\text { Sofía } \\
51 \text { meses }\end{array}$ & $\begin{array}{l}5 \text {. Lectura y narra- } \\
\text { ción mezcladas }\end{array}$ & $\begin{array}{l}5 \text {. Lectura y narra- } \\
\text { ción mezcladas }\end{array}$ & $\begin{array}{l}\text { 6. Narración similar } \\
\text { a la historia original }\end{array}$ \\
\hline $\begin{array}{l}\text { Diana } \\
49 \text { meses }\end{array}$ & $\begin{array}{l}\text { 3. Narración me- } \\
\text { diante diálogo }\end{array}$ & $\begin{array}{l}5 . \text { Lectura y narra- } \\
\text { ción mezcladas }\end{array}$ & No hay datos \\
\hline $\begin{array}{l}\text { Frida } \\
49 \text { meses }\end{array}$ & $\begin{array}{l}\text { 3. Narración me- } \\
\text { diante diálogo }\end{array}$ & $\begin{array}{l}\text { 3. Narración me- } \\
\text { diante diálogo }\end{array}$ & $\begin{array}{l}5 . \text { Lectura y narra- } \\
\text { ción mezcladas }\end{array}$ \\
\hline $\begin{array}{l}\text { Erick Dan } \\
60 \text { meses }\end{array}$ & $\begin{array}{l}\text { 3. Narración me- } \\
\text { diante diálogo }\end{array}$ & $\begin{array}{l}5 . \text { Lectura y narra- } \\
\text { ción mezcladas }\end{array}$ & $\begin{array}{l}5 \text {. Lectura y narra- } \\
\text { ción mezcladas }\end{array}$ \\
\hline $\begin{array}{l}\text { Ángel } \\
60 \text { meses }\end{array}$ & $\begin{array}{l}5 \text {. Lectura y narra- } \\
\text { ción mezcladas }\end{array}$ & $\begin{array}{l}5 \text {. Lectura y narra- } \\
\text { ción mezcladas }\end{array}$ & $\begin{array}{l}\text { 6. Narración similar } \\
\text { a la historia original }\end{array}$ \\
\hline $\begin{array}{l}\text { José Erick } \\
62 \text { meses }\end{array}$ & $\begin{array}{l}\text { 3. Narración me- } \\
\text { diante diálogo }\end{array}$ & $\begin{array}{l}\text { 3. Narración me- } \\
\text { diante diálogo }\end{array}$ & $\begin{array}{l}\text { 3. Narración me- } \\
\text { diante diálogo }\end{array}$ \\
\hline $\begin{array}{l}\text { Jessica } \\
67 \text { meses }\end{array}$ & $\begin{array}{l}\text { 3. Narración me- } \\
\text { diante diálogo }\end{array}$ & $\begin{array}{l}\text { 6. Narración similar } \\
\text { a la historia original }\end{array}$ & $\begin{array}{l}\text { 6. Narración similar } \\
\text { a la historia original }\end{array}$ \\
\hline
\end{tabular}

Tabla 7. Resultados en la lectura del cuento en las tres evaluaciones. Ver descripción de las características de cada nivel en la definición de la variable dependiente en la sección de método. 
En este componente no se observa tanta progresión como ocurre con el conocimiento del lenguaje escrito. Se observa que la mayoría de los niños permanecen en el mismo nivel o bien avanzan uno, salvo en el caso de Diana que pasa del tercer al quinto nivel en la segunda evaluación, pero ya no se tienen los datos de la tercera, pues la niña se dio de baja y el de Jessica que pasa del tercer nivel al sexto.

A continuación se describirá el desarrollo de tres de estos doce niños en cada uno de los componentes de la variable dependiente. Estos tres niños fueron elegidos al azar, tomándose un niño por cada grupo de edad. Se describen previamente, para cada niño, las características en las variables contextuales en el hogar y la escuela.

\section{ULISES (45 MESES)}

\section{Variables contextuales}

La escolaridad del padre de Ulises es de profesional técnico y la de su madre licenciatura. Los padres de Ulises acostumbran tener en casa libros y revistas tanto para niños como para adultos, enciclopedias, periódicos y propaganda diversa, así como lápices, crayolas, material didáctico gráfico-plástico y papel para escribir o dibujar.

Acostumbran leer a Ulises más de una vez a la semana, así como permitirle que él lea. Diariamente le leen el contenido de instructivos y de objetos de uso cotidiano, así como mensajes y letreros que se encuentran en el camino a casa. También acostumbran jugar a dibujar y manipular letras o palabras. Una vez al mes van a la librería o a la biblioteca.

Al leer el cuento, la mamá de Ulises mira el libro y las ilustraciones con él antes de iniciar la lectura y discute el posible contenido del libro.

Durante la lectura, la señora lee señalando las ilustraciones y sigue con el dedo el texto impreso, haciendo énfasis en que las palabras son las que cuentan la historia. Hace comentarios y preguntas respecto del texto y estimula a Ulises a hacer predicciones. Hace muchas inflexiones y aprovecha las interrupciones del niño para estimular la comprensión.

Al finalizar la lectura pregunta a Ulises si le gustó la historia y le pide que la cuente con sus propias palabras.

La maestra lee la historia mostrando las ilustraciones a los niños. Antes de leer muestra el título y el nombre del autor, mira las ilustraciones con los niños y discute el posible contenido con ellos. También relaciona las experiencias cotidianas de los niños con el posible contenido del cuento. 
Durante la lectura señala las ilustraciones al leer, hace comentarios y preguntas respecto de la historia, explicando los que los niños no comprenden, pregunta los nombres de los personajes y hace conexiones entre el texto y los eventos cotidianos para los niños. Estimula a los niños a hacer comentarios y el intercambio de experiencias entre ellos, así como la elaboración de inferencias, conclusiones y la predicción del final de la historia. Promueve la participación de los niños y aprovecha las interrupciones para estimular la comprensión.

Al finalizar la lectura pregunta a los niños si les gustó la historia, hace comentarios respecto de ella, relaciona lo acontecido con las experiencias cotidianas de los niños, aprovecha la comprensión de los niños para reforzar la comprensión de otros niños y pide a los niños que relean la historia, dando la oportunidad de hacerlo a diferentes niños.

\section{Desarrollo de la alfabetización}

Conocimiento del lenguaje escrito

En la primera evaluación Ulises identificaba cinco letras, las cuales eran las cinco vocales mayúsculas. Para la segunda evaluación, identificaba además la $m$ mayúscula y minúscula y para la tercera evaluación y la $o$, la $e$, y la $i$ minúsculas, en total 10 letras.

En la primera evaluación Ulises manejaba los siguientes conceptos de texto impreso: El texto es quien lleva el sentido y no la ilustración, dónde empezar a leer, que la página izquierda se lee antes de la derecha y la parte de abajo del libro. Para la segunda evaluación, además sabía dónde se termina de leer , podía aislar una y dos letras en el texto y podía identificar una letra mayúscula. Finalmente, para la tercera evaluación sabía además en que dirección se sigue después de que se ha iniciado la lectura. En total 8 conceptos de texto impreso.

En el vocabulario de escritura, Ulises no escribió palabra alguna en ninguna de las tres evaluaciones, escribió sólo letras, que en la primera y segunda evaluación fueron la $i$ y la $e$, mayúsculas en la primera y minúsculas en la segunda. En la tercera evaluación escribió además la $A$, la $O$ y la $M$.

En cuanto al dictado, se incluye a continuación la muestra de lo que escribió Ulises cuando se le dictaron las oraciones en cada evaluación. 


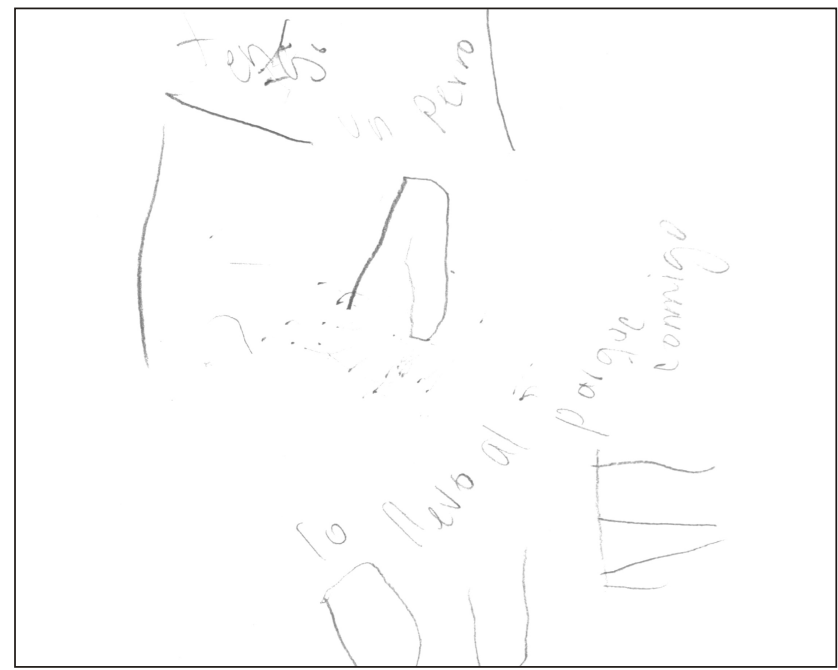

Figura 8. Dictado de Ulises en la primera evaluación. Nivel 4. Imita escritura convencional. Ulises escribió: “Tengo un perro en la casa. Lo llevo al parque conmigo.”

En la segunda evaluación, Ulises quedó ubicado en el mismo nivel. Finalmente en la tercera evaluación, Ulises de ubicó en el nivel 6. Formas que parecen letras.

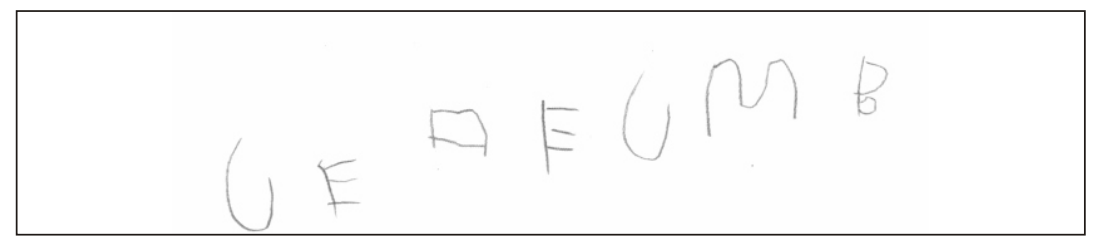

Figura 9. Dictado de Ulises en la tercera evaluación. Ulises escribió. "Tengo un perro en la casa. Lo llevo al parque conmigo."

En cuanto a la muestra de escritura, en la primera evaluación, Ulises obtuvo 3 puntos, ya que escribe letras (1) (reales o inventadas), tiene el concepto de signos (1) y no hay evidencia de principios direccionales (1). En la segunda y tercera evaluaciones obtuvo 5 puntos, pues nuevamente escribe letras (1) , tiene el concepto de que el mensaje expresa algo (2) y hay evidencia de parte de los principios direccionales (2).

\section{Lectura de cuento}

En la primera evaluación, únicamente describía la acción representada en cada ilustración, sin formar una historia. Para la segunda y tercera evaluaciones, Ulises ya narraba la historia, que si bien no estaba completamente formada, ya podía ser inferida por el adulto. 
A continuación se transcriben fragmentos de la primera y tercera evaluaciones.

\section{PRIMERA EVALUACIÓN}

U. El señor estaba construyendo un muñeco de madera (Silencio)

E. ¿Y luego qué pasó Ulises?

U. El hada tocó a Pinocho (Silencio)

E. ¿Y qué pasó con Pinocho?

U. Se movió

Aquí se iba a la escuela

Aquí lo subieron... iA cuál?

E. A una carreta

U. Después lo encerraron en una jaula

Y luego le creció la nariz

Y luego se convirtieron en burros

A Pinocho le están creciendo las orejas de burro

Después se fue al agua

Después se lo tragó

La ballena estornudó

Y después están bailando

Ya no es un niño de madera. Otro, quiero otro.

\section{TERCERA EVALUACIÓN}

U. Tú primero

E. No, tú primero y luego yo

U. Sí

Gepetto construyó un títere de madera. Entonces el hada vino y lo convirtió en... ¿En qué?

E. En un muñequito que se podía mover y caminar y hablar

U. En un muñequito que podía hablar y caminar y mover sus brazos. Entonces le dio una manzana su papá a Pinocho. Entonces un gato y lobo lo siguieron y caminó con ellos, entonces un muchacho lo metió en una jaula. Entonces le creció la nariz y le dio una oportunidad. Entonces vio un carro y entonces se subió en él y se convirtió en burro, entonces fue a nadar y había una ballena que se llamaba monstruo. Entonces el papá murió.

E. No, sólo estaba desmayado.

U. Entraron a su boca y Pinocho salió despertado y su papá desmayado (Ininteligible) se pusieron feliz y a nadar y entonces la hada lo convirtió en un niño de a verdad.

Cuadro 4. Lectura de Ulises en la primera y tercera evaluaciones. Ubicándose en los niveles 2 y 3 respectivamente. Ulises leyó "Pinocho". 


\section{SOFIA (51 MESES)}

\section{Variables contextuales}

La escolaridad de los padres de Sofía es de licenciatura. Ellos acostumbran tener en casa libros y revistas para niños y adultos, cuentos para niños, periódicos, lápices, crayolas, plumones y papel para escribir y dibujar.

Leen a Sofía una vez por semana y ella los observa leer más de una vez a la semana, ofreciéndole un libro mientras leen y papel y lápiz cuando ellos escriben. Una vez por semana le leen el contenido de instructivos y objetos de uso cotidiano, así como el contenido de mensajes enviados por alguien y letreros y mensajes en la calle. Diariamente realizan actividades que requieren dibujar y manipular letras o palabras y también dibujan y escriben con la niña y hacen comentarios a los textos escritos por ella. Van a la biblioteca y a la librería una vez al mes.

Con respecto a la lectura del cuento la mamá de Sofía no realiza actividad alguna antes de iniciar.

Durante la lectura lee la historia señalando las ilustraciones, hace comentarios y preguntas respecto del texto, preguntando sobre el contenido de la historia, así como detalles de la misma. Hace conexiones entre el contenido y los eventos cotidianos, estimula la elaboración de conclusiones, responde a las preguntas de Sofía y aprovecha las interrupciones para estimular la comprensión.

Después de la lectura, pregunta a la niña si le gustó la historia, haciendo comentarios respecto de la misma y le pide que cuente la historia.

La maestra de Sofía muestra el título y el nombre del autor antes de iniciar la lectura, mira el libro y las ilustraciones con los niños y discute con ellos el posible contenido.

Durante la lectura lee la historia señalando las ilustraciones, hace pausas para cuestionar a los niños sobre el contenido de la historia, los nombres de los personajes y detalles al interior. Hace conexiones entre el libro y los eventos cotidianos y explica lo que los niños no comprenden o desconocen. Estimula que los niños hagan comentarios, predicciones e inferencias y elaboren conclusiones. Explica el significado de las palabras que los niños desconocen y aprovecha las interrupciones para estimular la comprensión. Responde a las preguntas de los niños. Hace inflexiones y modula la voz de acuerdo a la trama y las características de los personajes. 
Después de la lectura la maestra pregunta a los niños si les gustó la historia, hace comentarios respecto de ella y preguntas sobre la trama y nombres y características de los personajes, promoviendo la elaboración de conclusiones y relacionando lo acontecido con las experiencias cotidianas de los niños.

\section{Desarrollo de la alfabetización}

\section{Conocimiento del lenguaje escrito}

Identificación de letras. En la primera evaluación, Sofía conocía la $F, P, O$, $L$ de Luis, $S$ de Sofía, $V$ de Víctor, $f$, o, $s$ por sonido, para la segunda evaluación este conocimiento se incrementó considerablemente. Ahora conocía, además de las anteriores, la $A, K$ de Karla, $B, H, J, U, C, Y, M, N, S, X, I, E, R$, $a, f, k, o, j, c, i, a, v, m$. Todas por su nombre. Para la tercera evaluación, además conocía: $L l, Z, Q, D, G, T, p, z, y, x, t, r r, g$ (47 letras en total).

En cuanto a los conceptos de texto impreso, en la primera evaluación, Sofía identificaba la parte de enfrente del libro, sabía que el texto impreso es el que lleva el mensaje y no la ilustración, dónde seguir la lectura, que había que regresarse a la izquierda al iniciar el segundo renglón, la parte de abajo del libro, Dónde se empieza a leer cuando las letras están de cabeza, que la página izquierda se lee antes que la derecha, identificaba una y dos letras, así como una y dos palabras. Para la segunda evaluación, sabía dónde iniciar la lectura, seguía el texto con el dedo mientras se le leía, conocía el significado del punto, podía encontrar dos letras minúsculas correspondientes a dos mayúsculas que se le señalan en el texto y podía ubicar la primera y la última letra en una palabra. En la tercera evaluación tenía exactamente los mismos conceptos que en la segunda.

En el vocabulario de escritura, Sofía no escribió palabra alguna en la primera evaluación, en la segunda escribió casi completo su nombre y dos palabras que copió de los adornos del salón, en la tercera evaluación, escribió su nombre y papá, mamá, o, i, y.

En el dictado, Sofía alcanzó en las tres ocasiones el nivel 7, Letras que no corresponden a los sonidos de las palabras, una letra por palabra.

Se incluye una muestra del dictado de Sofía.

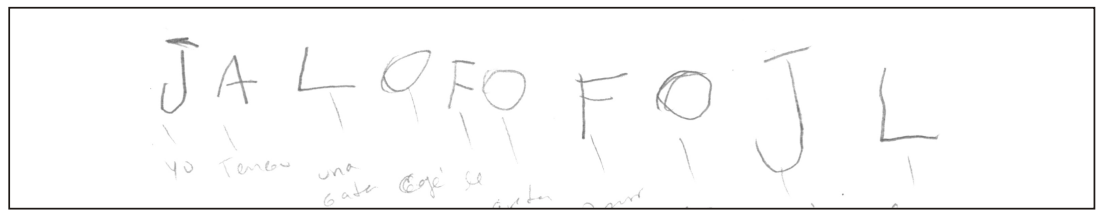

Figura 10. Muestra de dictado de Sofía. Nivel 7. Una letra por palabra, que no corresponde a los sonidos de las palabras. Sofía escribió: "Yo tengo una gata café. Le gusta dormir en mi cama." 
Finalmente, en muestra de escritura, Sofía obtuvo 5 puntos en la primera evaluación, ya que escribía letras (1), tenía el concepto de que el mensaje expresa algo (2) y mostraba evidencia de parte de los principios direccionales (2).

En la segunda y tercera evaluaciones Sofía además escribió palabras (2) y mostró evidencia de la totalidad de los principios direccionales.

Se muestra como ejemplo la segunda evaluación.

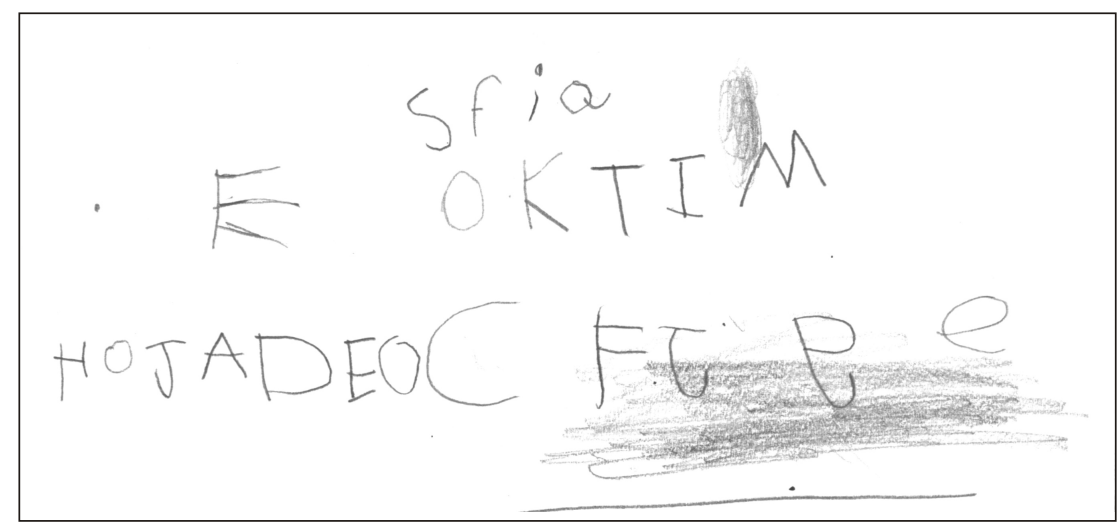

Figura 11. Ejemplo de la muestra de escritura de Sofía que obtuvo 8 puntos.

\section{Lectura de cuento}

En la primera y segunda evaluaciones, Sofía se ubicó en el nivel 5, lectura y narración mezcladas que consiste en que partes de la narración se escuchan como si la niña estuviera leyendo y partes como lenguaje oral. La niña tiene plena conciencia de que hay audiencia escuchando su narración y el escucha comprende perfectamente la historia sin las ilustraciones.

En la tercera evaluación, Sofía se ubicó en el nivel 7. En este nivel, la entonación es como de lectura y la historia es muy similar a la historia original que se está narrando. 
Se muestran ejemplos de ambos niveles.

\section{PRIMERA EVALUACIÓN}

S. Había una vez un bebé y los reyes querían tener una hija, la tuvieron, pero como no invitaron a la bruja, ella les dijo "Cuando llegue a cumplir 18 años, se pinchará el dedo". Entonces le dijo "¿Quieres salvar a mi hija? Y la salvó, pero estaba la viejita cosiendo con un huso y un hilo. Entonces tocó el huso y se desmayó. El hada durmió a todos. ¿Este, por qué bosteza?

E. Porque todavía no se queda bien dormido.

S. La hada despertó a todos y el príncipe llegó al país y vio que todos estaban dormidos y entonces se desmayó y le dio un beso y los despertó a todos y fueron felices para siempre y este cuento se ha acabado.

\section{TERCERA EVALUACION}

S. Había una vez un palacio donde vivía una bella muchacha y su rey. Estaban decepcionados por tener una hija. La más mayor era la más linda. Para celebrar el bautizo de la bebé pusieron una mesa con cosas lindas. La vieja dijo: " ¿Por qué no me invitaron a mí?. Yo quería invitarme también". Y la vieja se puso un disfraz de mujer buena y quería hacerle un hechizo a la bebé, la bebé tan feliz estaba viendo cómo estaban platicando. "Al pasar muchos años - dijo la bruja - al crecer 8 años, 28 años, se pinchará el dedo en el huso de una rueca y morirá". El rey mandó a quemar todos los husos para que la hija no se picara, eso es lo que estaban haciendo. La princesita fue creciendo y a ella le gustaba mucho visitar a los vecinos. La viejecita estaba cosiendo un suéter. Dijo la viejecita a la princesa: "Ven, acércate". La princesa se pinchó y para nunca se desmayó. Sus padres la pusieron en una camita muy comodita y la princesa se durmió. La hada llegó y hizo con su varita que todos los del mundo se durmieran. El príncipe llegó y con su espada cortó todas las ramas y fue al séptimo correr donde estaba la princesa y juntos se enamoraron y tan tan.

Cuadro 5. Primera y tercera lectura de Sofía, ubicándose en los niveles 5 y 7 respectivamente. Sofía leyó "La Bella Durmiente".

\section{ANGEL (60 MESES)}

\section{Variables contextuales}

La escolaridad del padre de Angel es de primaria y la de su madre de profesional técnico. Ellos tienen en casa libros para niños y adultos, revistas para niños y adultos, cuentos para niños, enciclopedias, propaganda diversa, lápices, crayolas y papel para escribir y dibujar.

Las actividades que realizan diario son leer al niño, leerle el contenido de objetos de uso cotidiano, leerle letreros cuando van por la calle y realizar actividades que requieran manipular o dibujar letras o palabras. Más de una vez por semana Angel lee a sus padres, le ofrecen lápiz y papel cuando escriben, le leen el contenido de instructivos, le explican los diferentes usos de la lectura y la escritura, dibujan con él 
y hacen comentarios sobre los textos escritos por Ángel. Una vez por semana los observa leer y le leen mensajes enviados por alguien ajeno a la familia. Una vez al mes lo llevan a la librería y menos de una vez al mes le dan un libro mientras ellos leen y lo llevan a la biblioteca.

Al leer el cuento, la mamá de Ángel no realiza actividad alguna antes de la lectura.

Durante la lectura la señora lee la historia señalando las ilustraciones. Hace comentarios respecto del texto.

Después de la lectura pregunta al niño si le gustó la historia, hace comentarios respecto de la historia, relaciona lo acontecido con las experiencias cotidianas, pide a Ángel que intente leer la historia y lo instiga para que cuente la totalidad de la historia, sin centrarse sólo en algunas ilustraciones y le hace preguntas respecto de la trama.

La maestra de Ángel mira el libro y las ilustraciones con los niños antes de iniciar la lectura, discute con ellos y relaciona las experiencias cotidianas con el posible contenido.

Durante la lectura, la maestra lee la historia señalando las ilustraciones, hace comentarios respecto del texto, hace preguntas sobre el contenido de la historia, pregunta el nombre y características de los personajes, así como detalles de la historia. Estimula a los niños a hacer comentarios, predicciones, inferencias y a predecir el final del texto. Responde a las preguntas de los niños, aprovecha las interrupciones para estimular la comprensión y promueve que los todos los niños participen.

Después de la lectura pregunta a los niños si les gustó la historia, hace comentarios respecto de la misma, pide a los niños que cuenten al historia con sus palabras, los estimula para que se refieran a la totalidad de la historia, aprovecha la comprensión de algunos niños para reforzar la comprensión de los demás. Los niños eligen representar la historia en los espacios recreativos del salón.

\section{Desarrollo de la alfabetización}

\section{Conocimiento del lenguaje escrito}

En la identificación de letras, en la primera evaluación, Angel identificaba la $A, P, O, C, X, E, a, o, e$. En la segunda identificó las mismas letras, menos la $X$ y en la tercera evaluación identificó la $A, L l, Z, O$, $U, L, M, S, e, a, z, o, u, l, m, n, s, x, i, a, e$ (21 letras en total). 
En los conceptos de texto impreso, en la primera evaluación, Angel conocía la parte de enfrente del libro, que el texto impreso lleva el sentido, dónde empezar a leer, dónde seguir, que se debe regresar a la izquierda al cambiar de renglón, dónde se inicia y dónde se termina de leer en un párrafo, la parte de abajo de la ilustración, que la página izquierda se lee antes que la derecha, pudo aislar una y dos letras y la primera y la última letra de una palabra (11). En la segunda evaluación, Ángel, además de lo anterior, pudo identificar una letra mayúscula (12). En la tercera evaluación, además pudo seguir con el dedo lo que se le leía, conocía el significado del punto y pudo aislar una y dos palabras. En total 14 conceptos.

En cuanto al vocabulario de escritura, en la primera evaluación Angel escribió su nombre, hoja (que copió del protocolo) y la $O$. En la segunda evaluación escribió su nombre y todas las vocales y en la tercera evaluación escribió Ángel, mamá, todas las vocales y algunas consonantes (E, $V, C, D, L l, Z, M)$ y los números 2 y 3.

En cuanto al dictado, se ubicó en el nivel 6, Formas que parecen letras, en las tres evaluaciones. Se muestra en ejemplo.

\section{OrelaOuahmeahouUOUAKIILUU}

Figura 12. Ejemplo del dictado de Angel. Se ubicó en el nivel 6, Formas que parecen letras. Angel escribió: "Yo tengo una gata café. Le gusta dormir en mi cama."

Finalmente, en la muestra de escritura obtuvo un puntaje de 6 en la primera evaluación, pues escribió palabras (2), mostró evidencia de saber que el texto significa algo (2) y mostró conocimiento parcial de los principios direccionales (2).

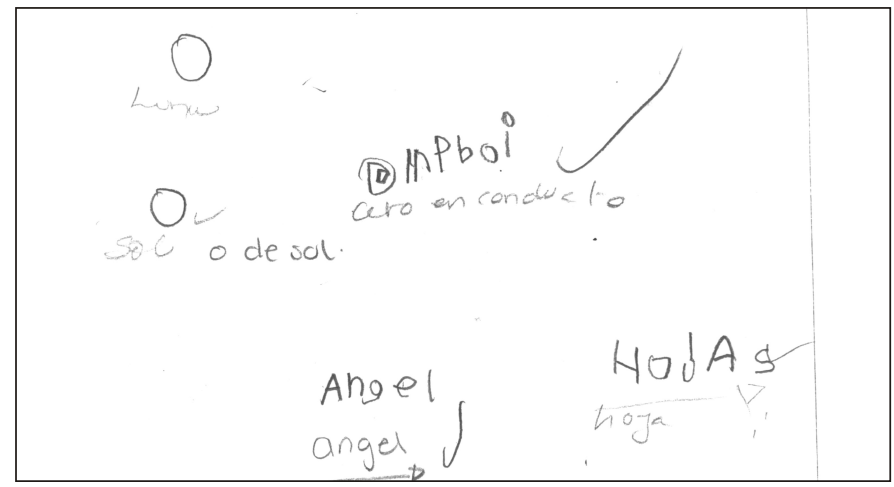

Figura 13. Muestra de escritura de Ángel en la primera evaluación, que obtuvo seis puntos. 
En la tercera evaluación, obtuvo 8, pues escribió palabras (2), mostró evidencia de saber que el mensaje expresa algo (2) y utilizó todos los principios direccionales (izquierda-derecha y regresar a la izquierda) (4).

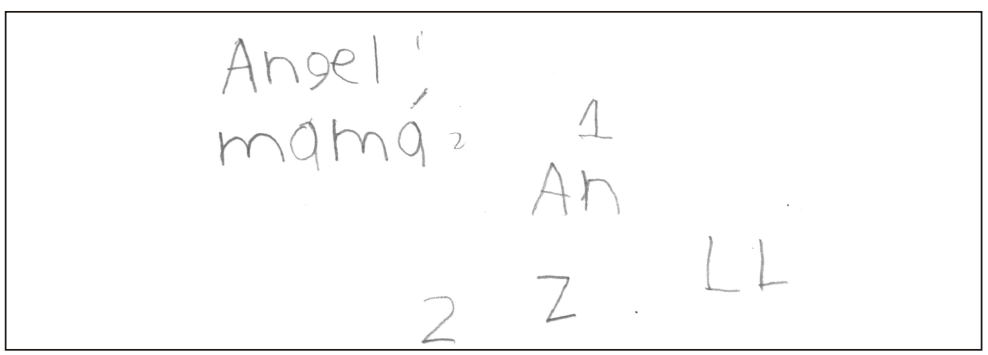

Figura 14. Muestra de escritura de Angel, tercera evaluación, que obtuvo 8 puntos.

\section{Lectura de cuento}

Al igual que Sofía, Ángel se ubicó en el nivel 5, lectura y narración mezcladas en la primera y segunda evaluaciones. En la tercera evaluación, se ubicó en el nivel 6, lectura similar a la historia original. Se transcriben fragmentos de la primera y tercera evaluaciones.

\section{PRIMERA EVALUACIÓN}

A. Un día era el abuelito, entonces pintó a un niño de madera y después le compró útiles y cuadernos con todo el dinero que tenía y después dijo: "Ven al circo de la risa y entonces que ya fueron y Pepe Grillo le dijo" no vayas" y entonces le empezó a crecer la nariz y después se le hizo un nido y le llegaron los pájaros, ji,ji,ji y después estaban en la feria y a Pinocho se le empezó a hacer cola de burro y orejas de burro...

E. ¿Por qué?

A. Pues porque no había obedecido a su papá que fuera a la escuela. Entonces un día había una ballena y se los tragó y se le apareció su papá y después Pinocho hizo que estornudara la ballena y zuum, se salieron y se terminó. Fin.

\section{TERCERA EVALUACION}

A. Un día, el abuelo estaba haciendo un muñeco de madera, entonces apareció la hada y lo convirtió en... para que se moviera, entonces, Pepe Grillo lo iban a llevar a la escuela y entonces su papá con todo el dinero que tenía le compró útiles y cuadernos y le llevó una manzana a la maestra y que se encontró a un gato y a un lobo y entonces le dijeron que lo iban a llevar a los juegos y entonces lo encerraron en una jaula y Pepe grillo se opuso a entrar y entonces le creció la nariz y la hada madrina se enojó. Entonces después estaban en los juegos y le creció las orejas como burro y una cola como burro y entonces que ya su papá estaba allí, entonces el... el... lo tragó y le dijo que cabían muchas cajas, entonces lo picó para que estornudara, entonces salió el abuelo y...

E. Pinocho.

A. Pinocho y ya acabó.

Cuadro 6. Primera y tercera lecturas de Ángel, ubicándose en los niveles 5 y 6 respectivamente. Ángel leyó "Pinocho". 
Los resultados mostrados hasta el momento responden al primer objetivo de la investigación: Caracterizar el desarrollo de la alfabetización en los niños preescolares.

A continuación se presentan los resultados descriptivos de las variables independientes, que se relacionarán con la variable dependiente para dar respuesta al segundo objetivo de la investigación.

\section{Resultados descriptivos de las variables contextuales y lingüísticas orales}

Los resultados de las variables independientes se presentan en el siguiente orden:

\section{Contextuales}

$\nabla$ Escolaridad de los padres

จ Número de materiales de lectura al alcance del niño en el hogar

$\boldsymbol{\nabla}$ Actividades relacionadas con la lectura en el hogar

$\boldsymbol{\nabla}$ Lectura de cuento por parte de las madres

$\boldsymbol{\nabla}$ Lectura de cuento por parte de las maestras

En el niño

$\nabla$ Edad

$\boldsymbol{\nabla}$ Habilidades lingüísticas en el lenguaje oral

Se presentan en primer lugar los resultados de la muestra total y después los resultados por grupo de edad.

\section{Variables Contextuales}

En el ambiente familiar

\section{Escolaridad de los padres}

Los resultados de esta variable ya se presentaron en la sección en la que se describió la muestra. Como se recordará la mediana fue de 5 , es decir, el 50\% o menos de los padres de la muestra tiene escolaridad de preparatoria, encontrándose el percentil 25 en secundaria y el percentil 75 también en preparatoria.

Materiales al alcance del niño relacionados con la lectura en el hogar Esta variable se midió a través del Cuestionario de Actividades Relacionadas con la Lectura en el Hogar, que se describe en el método en este mismo trabajo y que se presenta como anexo al final (Anexo 1). 
Se obtuvieron 59 cuestionarios contestados por los padres. En promedio, los padres reportaron tener una variedad de 9 materiales relacionados con la lectura al alcance del niño. El percentil 25 se ubicó en 7 materiales y el percentil 75 en 11 materiales. El puntaje máximo para esta variable fue el número de materiales que los padres mencionaran. Originalmente se sugieren 15 en el cuestionario; pero los padres pueden agregar aquellos que sí tienen en el hogar y que no están mencionados en el cuestionario. Los materiales que se mencionaron con mayor frecuencia fueron cuentos, libros y revistas para niños, papel para escribir o dibujar y crayolas o colores; los menos mencionados fueron historietas (cómics), circulares y catálogos. Es importante mencionar que estos dos últimos y la propaganda diversa, en general no eran considerados por los padres como materiales que pudieran ser útiles para promover el conocimiento del lenguaje escrito en sus hijos, ya que prácticamente no fueron mencionados.

Los padres añadieron a la lista original materiales como: computadora, películas para niños, acuarelas, letras de plástico, pizarrón y libros de otros niveles educativos como primaria, secundaria, preparatoria y psicología.

\section{Actividades relacionadas con la lectura en el hogar}

Esta variable se midió a través del cuestionario de actividades relacionadas con la lectura en el hogar (Ver Anexo 1).

En él se incluían 15 actividades que según la literatura revisada pueden realizarse de manera cotidiana para estimular el desarrollo de la alfabetización en los pequeños (cada actividad constituía un reactivo). Cada reactivo tenía seis opciones de respuesta, siendo 6 el puntaje máximo para cada reactivo y 90 el puntaje máximo posible.

Se realizó un análisis de los reactivos mediante una $\quad{ }^{2}$ (Ji cuadrada) para cada reactivo comparando las frecuencias obtenidas para cada opción de respuesta contra las frecuencias esperadas por azar. De esta manera se eliminaron el reactivo 6, "Papá, mamá u otros miembros de la familia leen el contenido de instructivos de juguetes u otros objetos al niño" y el reactivo 9, "Papá, mamá u otros miembros de la familia explican al niño los diferentes usos de la lectura y la escritura" ya que las frecuencias obtenidas para cada opción no fueron significativamente diferentes de las que se esperarían por azar ( $\mathrm{P}=.287$ y .095, respectivamente).

Como resultado de este análisis, para la obtención del puntaje total del cuestionario se consideraron 13 reactivos en total, siendo el puntaje máximo posible de 78. 
Se obtuvieron los siguientes resultados:

\begin{tabular}{|c|c|}
\hline Percentil 25 & 45 \\
\hline Mediana & 53 \\
\hline Percentil 75 & 58 \\
\hline
\end{tabular}

Como se puede observar, el 50\% de los padres se ubica en o por debajo del puntaje 53, habiendo muy poca diferencia entre el puntaje debajo del cual se ubica el $50 \%$ de los padres y el puntaje por debajo del cual se ubica el $75 \%$ de los padres (58), en tanto que el $25 \%$ de los padres se ubica por debajo del puntaje 45. Cabe mencionar que existe un rango muy amplio en el puntaje obtenido por los padres en esta variable ya que el puntaje mínimo fue de 7 y el máximo de 75 .

Las actividades que se realizaron con mayor y menor frecuencia, se obtuvieron sumando las frecuencias para la opción 1 "diario" y la opción 2 , "más de una vez por semana".

La tabla siguiente muestra las actividades más frecuentes y las menos frecuentes realizadas por los padres.

\begin{tabular}{||c|l|c||}
\hline \hline REACTIVO & \multicolumn{1}{|c||}{ ACTIVIDAD } & FRECUENCIA \\
\hline ACTIVIDADES MÁS FRECUENTES & $\begin{array}{l}\text { Papá, mamá u otros miembros de la } \\
\text { familia ofrecen al niño lápiz y papel } \\
\text { cuando ellos escriben. }\end{array}$ & $48 / 36$ en la primera opción \\
\hline 5 & $\begin{array}{l}\text { Papá, mamá u otros miembros de la } \\
\text { familia leen al niño letreros y men- } \\
\text { sajes que se encuentran en el cami- } \\
\text { no cuando van por la calle. }\end{array}$ & $48 / 32$ en la primera opción \\
\hline 10 & $\begin{array}{l}\text { Papá, mamá u otros miembros de la } \\
\text { familia realizan con el niño activi- } \\
\text { dades que requieran manipular o di- } \\
\text { bujar letras o palabras. }\end{array}$ \\
\hline 12 & $\begin{array}{l}\text { Papá, mamá u otros miembros de la } \\
\text { familia dibujan o escriben con el niño. }\end{array}$ & \multicolumn{2}{||}{42} \\
\hline
\end{tabular}




\begin{tabular}{|c|c|c||}
\hline REACTIVO & \multicolumn{1}{|c||}{ ACTIVIDAD } & FRECUENCIA \\
\hline ACTIVIDADES MENOS FRECUENTES & 6 \\
\hline 15 & $\begin{array}{l}\text { Papá, mamá u otros miembros de la } \\
\text { familia acuden a la librería con el pro- } \\
\text { pósito de comprar libros para el niño. }\end{array}$ & 3 \\
\hline 14 & $\begin{array}{l}\text { Algún miembro de la familia visita } \\
\text { la biblioteca con el niño. }\end{array}$ & \\
\hline
\end{tabular}

Tabla 8. Actividades más frecuentes y menos frecuentes relacionadas con la lectura en el hogar.

Como se puede observar, las actividades más frecuentes se refieren a actividades que requieren escribir o dibujar con el niño y la actividad cotidiana de leer los letreros cuando van por la calle, la cual ha sido señalada como una actividad que contribuye de manera importante al desarrollo de la alfabetización (Saint Laurent, Giasson y Couture, 1997; Ferreiro, 1998).

Existen actividades que se presentaron con menor frecuencia y que algunos de los padres comentaron que no se podían realizar porque su hijo "no sabe leer". Como ejemplo de ellas tenemos: "Papá, mamá $\mathrm{u}$ otros miembros de la familia ofrecen al niño un libro para leer, mientras ellos leen" (24 sumando la primera y segunda opciones y 7 para la primera opción); y “El niño lee a papá, mamá u otros miembros de la familia” (28 sumando la primera y segunda opciones y 7 para la primera opción).

\section{Conductas de las madres / padres durante la lectura de cuentos}

Se obtuvieron en total 47 observaciones de la lectura de cuentos por parte de las madres / padres. En esta actividad participaron 42 madres, 4 padres y en un caso ambos padres.

Esta actividad se video grabó con el fin de poder obtener un producto permanente que permitiera un análisis posterior.

Se pidió a los padres que llevaran el cuento favorito de sus hijos ("el que más les piden que les lean”). La mayoría de los libros seleccionados por los padres eran textos narrativos: cuentos clásicos, como Pinocho, La Bella Durmiente, La Cenicienta, Los Tres Cochinitos, La Bella y la Bestia. Igualmente, los libros que llevaban los padres eran libros con poco texto, letra grande y muchas ilustraciones, aunque en un caso un padre llevó un libro que no tenía ilustraciones. Cuando los padres no llevaban cuento, la investigadora les proporcionó cuentos similares a éstos y de la serie "Manchitas" (Trillas, 1983). 
Los registros de la lectura de cuentos por parte de los padres se realizaron mediante la observación de las grabaciones a través de una lista cotejable que se diseñó para ese fin (Ver Anexo 2). Se registraba si la madre o el padre realizaban cada conducta, independientemente de la frecuencia. El puntaje máximo posible es de 40.

Como resultado del estudio piloto este instrumento sufrió algunas modificaciones que a continuación se mencionan: Se cambió la redacción de algunos reactivos que no estaban claros, por ejemplo, en lugar de modela, se incluyó promueve. Se agregaron algunas categorías que originalmente no estaban incluidas y que se observaron en el estudio piloto, por ejemplo, hace preguntas descriptivas (detalles al interior de la historia). Se incluyó una misma categoría en diferentes momentos, por ejemplo Explica lo que el niño no comprende o desconoce que estaba antes de la lectura se introdujo también durante y después de la lectura.

Para obtener la confiabilidad entre observadores, se seleccionaron al azar los registros de 10 padres para ser calificados por un observador independiente, obteniéndose una confiabilidad promedio de $94 \%$, con un rango de $85 \%$ a $100 \%$. La confiabilidad se obtuvo dividiendo el total de acuerdos entre el total de observaciones, para cada caso (Bakeman y Gottman, 1989).

A continuación se presentan los resultados obtenidos por las madres / padres.

\begin{tabular}{|c|c|}
\hline Percentil 25 & 7 \\
\hline Mediana & 11 \\
\hline Percentil 75 & 14 \\
\hline
\end{tabular}

Como se puede observar, 7 es el puntaje debajo del cual se ubica el $25 \%$ de las madres, 11 el puntaje debajo del cual se ubica el 50\% y 14 , el $75 \%$ de las madres. Si se considera que el puntaje total posible es de 40, pudiera parecer que al leer cuentos las madres realizan pocas conductas que pueden estimular el desarrollo de la alfabetización.

Se seleccionó al azar una muestra de 10 registros de las madres para hacer un análisis más fino de la lectura del cuento.

Con base en los resultados de esta muestra, a continuación se hace una descripción de las conductas de las madres antes, durante y después de la lectura de cuentos. 
Antes. La conducta más frecuente de las madres antes de la lectura de cuentos fue mirar las ilustraciones con el niño (6 madres) y la que no se presentó fue explicar lo que el niño desconoce. Relacionar las experiencias cotidianas del niño con el posible contenido del cuento se presentó solo en un caso.

Se presenta un ejemplo de las conductas de las mamás antes de la lectura.

M. Vamos a leer, ¿Cómo se llama?

N. Pinocho

M. Al niño que le crece la qué

N. (No responde)

M. Mira, es Gepetto, y aquí está construyendo a Pinocho.

M. Mira, dice....

Cuadro 7. Madre 1 antes de la lectura. M. madre N. niño

Otra mamá inició de esta manera:

M. ¿Te acuerdas cómo se llama este cuento?

N. Margarito hace berrinches

M. Ay, Margarito, no hagas berrinches iPor qué no debemos hacer berrinches?

N. Porque nuestros papás no nos dan lo que queremos

M. Si, porque hay otras maneras de pedir las cosas, vamos a ver quéle pasó a Margarito...

Cuadro 8. Madre 2 antes de la lectura. M. madre N. niño

Durante la lectura, la mayoría de las madres leyó la historia (9), es decir, leían el texto, no narraban la historia, apoyándose en las ilustraciones (8). 6 madres hacían comentarios respecto del texto y señalaban con el dedo lo que leían. Ninguna de las madres estimuló al niño a predecir el final de la historia, promovió que el niño intentara identificar palabras o lo estimuló para que intentara leer. Una madre promovía que el niño conociera los convencionalismos de la lectura, señalando con el dedo y diciendo continuamente "mira, aquí dice", "aquí empieza", "aquí termina”. 
Se presenta un ejemplo de un padre que leyó una historia sobre vampiros.

P... Dicen que los vampiros no se reflejan en el espejo, así los puedes reconocer tú y no les gusta el ajo ¿Por qué crees que no les gusta el ajo?

N. Huele feo

P. Fíjate, luego dice: Cómo deshacerse de él. Enterrándoles una estaca. iSabes lo que es una estaca?

N. No

P. Es un palo que tiene filo. Dice: O deja que se consuma a la luz del sol. Ellos no pueden ver la luz, por eso salen de noche. Pero sí existen iTú crees que existan?

N. Son murciélagos

P. Aquí dice: Sí existen, son murciélagos de América del Sur, como tú dices...

P. Mira, (Señala la ilustración) este es un murciélago, un vampiro...

Cuadro 9. Un padre durante la lectura. P. padre N. niño

Después de la lectura hubo poca actividad, sólo tres madres preguntaron a los niños si les gustó la historia, hicieron comentarios respecto de la misma, relacionaron lo acontecido en el cuento con las experiencias cotidianas de los niños o pidieron al niño que contara el cuento con sus propias palabras. Sólo dos madres los estimularon a que intentaran leer la historia.

El mismo padre, terminó así la historia:

P. ¿Te gustó? ¿Le entendiste o no?

N. (Asiente con la cabeza)

P. ¿Sabes cuáles son los vampiros?. Mira, así los pintan (Señala la ilustración). Así dice la leyenda que son, pero no se ha visto un ser humano que tenga esas características.

P. Tú tienes un disfraz, ino? De vampiro iy te gusta?

N. (Asiente con la cabeza)

P. iTe cuento otro o ya no? iLe puedo contar otro?

Cuadro 10. El mismo padre después de la lectura. P. padre N. niño

Otra mamá terminó así:

M. ... Y colorín, colorado, este cuento se ha acabado. Ahora tú léelo. A ver...

N. Al mediodía estaba regando

M. Y luego, ¿qué pasó?

N. Y le salió una semillita. A mediodía la flor, nació una niña...

N.... Se casó con un pequeño príncipe que era tan pequeño como ella y colorín, colorado, este cuento se ha acabado

Cuadro 11. Una madre después de la lectura. M. madre N. niño 
Como puede observarse, la mayor parte de la actividad por parte de las madres se presenta durante la lectura del cuento y está encaminada básicamente a lograr la comprensión de la historia, más que pretender que los niños conozcan los convencionalismos que se utilizan durante la lectura o intenten identificar palabras o leer por sí mismos, es decir, interactuar con el texto.

\section{Conductas de las maestras durante la lectura de cuentos}

La lectura de los cuentos por las maestras se realizó en sus salones de clases en los horarios que ellas consideraron apropiados.

Las maestras pidieron a los niños que seleccionaran los libros que se leyeron, dichos libros eran textos narrativos. En tres casos la historia se refería a alguna enseñanza respecto de conductas apropiadas de los niños en el ambiente social inmediato, en dos casos eran cuentos clásicos (La Bella Durmiente y Los Tres Cerditos). Todos los cuentos incluían muchas ilustraciones y poco texto.

Cada sesión de lectura de cuentos se videograbó con el fin de tener producto permanente que permitiera un análisis posterior.

Los resultados de la lectura de cuentos por las maestras se obtuvieron a través de una lista cotejable diseñada para ese fin (Ver Anexo 3). Se contaba si se presentaba la conducta en cuestión sin importar la frecuencia de cada una. El puntaje total posible era de 44. Como resultado del estudio piloto esta lista sufrió modificaciones similares a la lista de las madres.

La lista se confiabilizó mediante un observador independiente, obteniéndose una confiabilidad promedio de $87 \%$, con un rango de 80 a 98\%. La confiabilidad para cada registro se obtuvo dividiendo el número de acuerdos entre el total de observaciones.

Los resultados obtenidos en la lectura de cuentos por las maestras son los siguientes:

\begin{tabular}{|c|c|}
\hline Percentil 25 & 8 \\
\hline Mediana & 21 \\
\hline Percentil 75 & 30 \\
\hline
\end{tabular}

Como puede observarse, en o debajo del puntaje 8 se ubican el 25\% de las maestras (1), en o debajo del 21 el 50\% (2) y debajo del puntaje 30 el $75 \%$ (4). 
En la siguiente gráfica se pueden observar los puntajes totales para cada una de las educadoras.

Los números que identifican a cada maestra corresponden a los números presentados en la tabla que describe su formación y antigüedad (Ver Método).

CONDUCTAS DELAS MAESTRAS DURANTE LA LECTURA DE CUENTOS

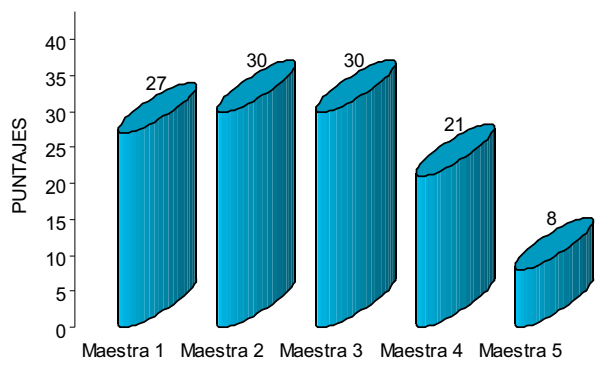

MAESTRAS

Gráfica 5. Puntajes totales de las maestras al leer los cuentos.

Puede observarse que el desempeño de las tres primeras maestras es muy similar y el de la maestra 4 es un poco menor. Sin embargo, el de la maestra 5 se encuentra muy por debajo de sus compañeras.

Se explicará con más detalle lo que hacían las maestras antes, durante y después de la lectura.

Antes de la lectura. Todas las maestras pidieron a los niños que seleccionaran el cuento. Sólo una mostró el título y el nombre del autor. Cuatro de ellas discutieron el posible contenido del libro con los niños y les modelaron cómo se usa, les enseñaron la portada, dónde inicia, les explicaban que tenían que pasar la página, mostraban las ilustraciones y dónde empezaban a leer.

Durante la lectura. Todas las maestras leyeron la historia y señalaron las ilustraciones. Todas ellas hicieron comentarios y preguntas respecto del texto, 4 de ellas explicaron lo que los niños no comprenden o desconocen, los estimularon a hacer comentarios y predicciones, respondieron a las preguntas de los niños y aprovecharon las interrupciones de los niños para estimular la comprensión.

Ninguna de las maestras narró la historia, siguió con el dedo el texto impreso, estimuló a los niños a anticipar el final de la historia, permitió a los niños intentar leer, promovió la identificación de palabras o el conocimiento de los convencionalismos de la lectura. Dos de las maestras modularon la voz e hicieron inflexiones de acuerdo al contenido del texto. 
Después de la lectura. 4 de las maestras preguntaron a los niños si les gustó la historia, 3 de ellas hicieron comentarios respecto de la misma, sólo una pidió a los niños que representaran la historia por medio de dibujos o palabras y sólo una les pidió que la releyeran y le dio oportunidad de hacerlo a diferentes niños y sólo una pidió a los niños que contaran la historia con sus propias palabras.

Las maestras 1, 2 y 3 hicieron muchos comentarios respecto de la historia después de la lectura del cuento.

Se presenta la lectura de una maestra para ilustrar las conductas antes, durante y después de la lectura, $M$ se refiere a la maestra y $N$ a los niños.

\section{ANTES}

M. ¿Cómo se llama este cuento? ¿Cómo creen que se llama?

N. El burrito

M. iEl burrito? ¿Este es un burrito?. Esta es una cabra. Y estos son unos...

N. Perritos

M. Perritos, son unos perritos. ¿Cuántos perritos hay?

M y N. Uno, dos... seis

M. Aquí dice seis, seis cachorritos traviesos. Vamos a ver el cuento.

\section{DURANTE}

M. Dice: Doña perra pinta tiene seis cachorros...

M. ... Los cachorros saben que cuando su mamá trabaja, ellos pueden divertirse haciendo travesuras. De esto es de lo que se trata el cuento. Vamos a ver qué travesuras hacen mientras su mamá trabaja...

M. ... iTremendos, verdad? ¿A quién se parecen?

N. A nosotros

M. ¿Por qué se parecen a ustedes?

N. Porque somos muy latosos

M. ... Y los cachorros ladran y persiguen a los pollitos iY qué les pasará a los pollitos?

N. Se mueren

M. ¿Se mueren?. Cuando ladran los perritos tras ellos, qué sienten los pollitos

N. Se asustan

M.... Ven a dos terneros pastando en la llanura. iSi saben qué son los terneros?

N. No

M. Son los bebés de las vacas. Estos son los terneros (Señala la ilustración) vean qué cara tienen los terneros. ¿Qué cara tienen los terneros?

N. De susto 
M. ... Llega la señora vaca (sic) y qué le preguntará a la señora gata

N. Si no ha visto a sus perritos

M. ¿Y qué le dice la señora gata?

N. Que no sabe dónde están

M. ¿Qué creen que haya hecho la señora cabra con los perritos?

N. Los castigó

M. Veamos qué hizo la señora cabra con los perritos. Sofía, qué crees que haya hecho la señora cabra con los cachorritos

S. Los metió en una canasta

M. Ya viste la figura que sigue. Sí, efectivamente...

M. Y colorín, colorado...

\section{DESPUÉS}

M. ¿Quiénes son estos personajes?

M y N. Mamá perra, sus hijitos, señora cabra...

M. Díganme, cómo se duermen los perritos

N. En una canasta

M. ¿Qué les hicieron, los arrullaron, les contaron un cuento?

N. Cuento

M. ¿Qué les gusta más, que les contaran un cuento o que los arrullaran?

N. Que les contaran un cuento

M. ¿Así les gusta dormir a ustedes?

N. Movimientos de cabeza indicando afirmación

M. ¿Les gustó el cuento?

N. Síiı́

M. Bueno. Colorín, colorado

N. Este cuento se ha acabado.

Cuadro 12. Conductas de las maestras antes, durante y después de la lectura. M. maestra N. niños S. Sofía

Hubo una maestra (la maestra 1) quien creó un espacio de discusión respecto de la historia al final de la lectura, les hizo preguntas respecto de la trama, les pidió sacar conclusiones y hacer inferencias y relacionó las experiencias cotidianas de los pequeños con la enseñanza que trasmitía el cuento.

Se presenta un fragmento de esta interacción. Es un cuento que trata de un cachorrito que se escondió de su mamá en el supermercado y realmente se perdió. 
M. ¿Les gustó? ¿Qué piensan de este cuento?

N. Que se perdió

M. Pero ustedes creen que hizo bien Puchi en esconderse de su mamá?

N. No

M. ¿No, verdad?. Como broma está muy pesada, ¿O no, Camila, tú te esconderías de tu mamá?

C. (Dice que no con un movimiento de cabeza)

M. ¿Por qué creen que perjudicó a Puchi esconderse?

N. (Silencio)

M. Porque la mamá empezó a caminar en el supermercado. Ella se fue alejando de Puchi y entonces se hizo realidad. Se perdió Puchi. Pero tuvo varias experiencias, icomo cuáles Jorge?

N. (Silencio)

M. ¿Quién se acercó a ofrecerle un pedazo de pan?

N. Una niña

M. ¿Pero no aceptó, verdad? ¿Por qué creen que no aceptó ninguna de las cosas que le estaban ofreciendo? Ya nos explicó Ulises por qué no debemos tomar cosas de gente extraña. ¿Qué te pueden hacer?

U. Te pueden maltratar

M. Ulises, muy bien. Te pueden maltratar, te pueden robar. Lo que nos quiere decir este cuento de Puchi, Cuchi, se llama Cuchi, es que no debemos hacer este tipo de bromas a mamá y aparte obedecer y NO tomar nunca cosas de gente extraña...

M. ... Entonces, muy importante que no nos separemos ide quién?

N. De mamá

M. De mamá. Bueno, iles gustó?

N. A mí me gustó por el perrito.

M. El perrito está bien bonito iverdad? ¿Quieren verlo?. Se los voy a ir pasando (Pasa el cuento). Ahorita que termines, André, se lo pasas a Camila para que ella vea a Cuchi. Mañana escogen ustedes el cuento, nada más me recuerdan.

La maestra sigue haciendo comentarios mientras los niños se pasan el cuento.

Cuadro 13. Una maestra después de la lectura del cuento.

M. maestra N. niños U. Ulises

La maestra 3 pidió a los niños que reprodujeran el cuento mediante una representación dramática pidiendo a los niños que personificaran los personajes del cuento, y la maestra 5 pidió a uno de los pequeños que contara la historia con sus propias palabras "pues estuvo jugando todo el tiempo".

La mayor actividad de las maestras, al igual que la de las madres se llevó a cabo durante la lectura del cuento, sin embargo, a diferencia de las primeras, las maestras también tuvieron mucha actividad después de la lectura del mismo. En el caso particular de la lectura del cuento al 
grupo de niños, las experiencias y comentarios de unos y otros niños pueden ser aprovechadas para promover el conocimiento y comprensión del contenido del texto y de los convencionalismos del lenguaje escrito (Dickinson, 2001).

\section{Variables en el niño}

\section{Habilidades lingüísticas orales (Muestra Total)}

Se presentan a continuación los puntajes promedio obtenidos por los niños en cada una de las habilidades evaluadas mediante el instrumento que se utilizó para medir esta variable independiente (Anexo 4).

\begin{tabular}{|c|c|c|}
\hline HABILIDAD & $\begin{array}{l}\text { PUNTAJE } \\
\text { PROMEDIO }\end{array}$ & MIN / MAX \\
\hline \multicolumn{3}{|l|}{ CONCIENCIA FONOLÓGICA } \\
\hline Pronunciación correcta de los sonidos del habla & 66.92 & $0 / 100$ \\
\hline Discriminación de sonidos & 65.05 & $0 / 100$ \\
\hline Análisis y síntesis auditivas & 43.01 & $0 / 100$ \\
\hline \multicolumn{3}{|l|}{ CODIFICACIÓN SEMÁNTICA } \\
\hline $\begin{array}{l}\text { Reconocimiento de nombres ante la presentación } \\
\text { de láminas }\end{array}$ & 57.59 & $0 / 100$ \\
\hline Seguimiento de instrucciones & 94.94 & $10 / 100$ \\
\hline Conocimiento del significado de las palabras & 46.93 & $0 / 80$ \\
\hline Sinónimos, antónimos y palabras supraordinadas & 26.57 & 0/85 \\
\hline $\begin{array}{l}\text { Repetición de un cuento captando las ideas prin- } \\
\text { cipales y los detalles }\end{array}$ & 40.96 & 0/90 \\
\hline Diferencia entre dibujo y texto & 78.67 & $0 / 100$ \\
\hline Expresión espontánea & 64.10 & $0 / 100$ \\
\hline Puntaje total de habilidades lingüísticas & 54 & $15 / 86$ \\
\hline
\end{tabular}

Tabla 9. Puntajes promedio obtenidos por los niños en cada una de las habilidades lingüísticas evaluadas. El puntaje máximo posible para cada habilidad y total es de 100. $\mathrm{N}=83$ 
En la gráfica que se presenta a continuación se pueden visualizar los resultados presentados en la tabla 9 .

HABILIDADES LINGÜISTICAS ORALES

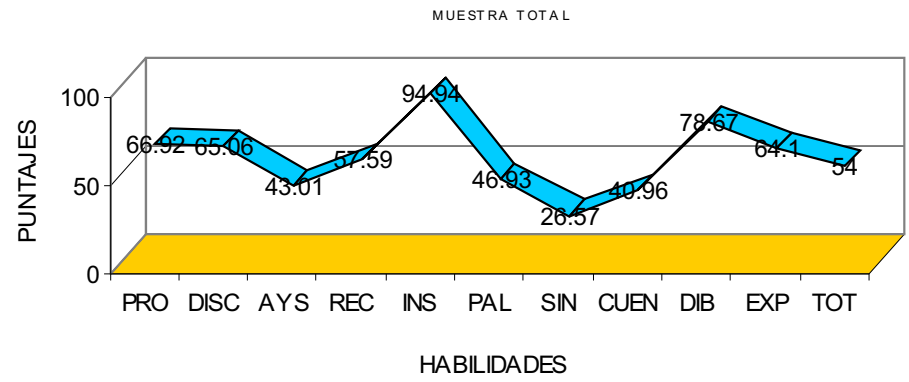

Gráfica 6. Puntajes promedio en cada una de las habilidades lingüísticas orales.

Se puede observar que la mayoría de los puntajes se sitúan por debajo del $80 \%$.

En aquellas habilidades que se refieren a la conciencia fonológica, el puntaje más bajo se obtuvo en lo que se refiere a la realización de análisis y síntesis auditiva (AYS), ya que fue difícil para muchos niños descomponer palabras en sus unidades, en tanto que dependiendo de la edad, la pronunciación de los fonemas (PRO) y la discriminación de sonidos (DISC) fueron más fáciles de realizar.

En cuanto a las variables que se refieren a la obtención de significado mediante claves semánticas (codificación semántica), la tarea más fácil para los niños la constituyó el poder seguir instrucciones (INS), en tanto que la más difícil consistió en poder proporcionar sinónimos y antónimos de las palabras (SIN), así como el poder proporcionar la palabra supraordinada que subyace a dos conceptos (ej. animales cuando se le pregunta qué son un perro, un gato y un ratón), que se evalúa en esta misma subprueba.

También por debajo del 60\% se ubican el reconocimiento de nombres ante la presentación de láminas (REC), el poder proporcionar una descripción que permita saber si el niño conoce el significado de la palabra (PAL) y el poder repetir un cuento captando las ideas principales y los detalles (CUEN). 
En cuanto a la expresión espontánea, (EXP) este fue uno de los puntajes más altos, ya que los niños fueron capaces de narrar un acontecimiento común, usando un vocabulario de cerca de 50 palabras en promedio, con adecuada concordancia entre género y número de sustantivos y adjetivos, verbos y adverbios, etc., una adecuada secuenciación de ideas y mediante el uso de diferentes categorías gramaticales (sustantivos, adjetivos, verbos, adverbios, pronombres, preposiciones, conjunciones), aun cuando este último aspecto y el de la concordancia fue menos manejado por los niños más pequeños, como se verá en los resultados por edad.

El puntaje total (TOT) en el desarrollo de las habilidades lingüísticas en el lenguaje oral fue de 54 .

\section{Habilidades lingüísticas orales (Por grupo de edad)}

Los resultados obtenidos mediante la evaluación de las habilidades lingüísticas se obtuvieron también para cada grupo de edad. Las edades de los niños se computaron en meses cumplidos a la fecha de la primera aplicación, pero para fines descriptivos, se dividió a los niños en tres grupos de edad: 1) de 3 años cumplidos a 3 años 11 meses cumplidos (36 a 47 meses); 2) de 4 años cumplidos a 4 años 11 meses cumplidos ( 48 a 59 meses) y 3 ) de 5 años cumplidos a 6 años, 3 meses (60 a 75 meses). A continuación se presentan los puntajes promedio obtenidos por cada uno de estos tres grupos de edad en las habilidades lingüísticas orales.

\begin{tabular}{|l|c|c|c||}
\hline \multicolumn{1}{|c|}{ HABILIDAD } & $\begin{array}{c}\text { PUNTAJE } \\
\text { PROMEDIO } \\
\text { 36 A 47 } \\
\text { MESES }\end{array}$ & $\begin{array}{c}\text { PUNTAJE } \\
\text { PROMEDIO } \\
\text { 48 A 59 } \\
\text { MESES }\end{array}$ & $\begin{array}{c}\text { PUNTAJE } \\
\text { PROMEDIO } \\
60 \text { A 75 } \\
\text { MESES }\end{array}$ \\
\hline & N=21 & N=40 & N=22 \\
\hline CONCIENCIA FONOLÓGICA \\
\hline $\begin{array}{l}\text { Pronunciación correcta de los } \\
\text { sonidos del habla }\end{array}$ & 52.90 & 68.93 & 76.64 \\
\hline Discriminación de sonidos & 54.29 & 65.75 & 74.09 \\
\hline Análisis y síntesis auditivas & 23.10 & 46.88 & 55 \\
\hline
\end{tabular}




\begin{tabular}{|c|c|c|c|}
\hline \multirow[t]{2}{*}{ HABILIDAD } & $\begin{array}{c}\text { PUNTAJE } \\
\text { PROMEDIO } \\
36 \text { A } 47 \\
\text { MESES }\end{array}$ & $\begin{array}{c}\text { PUNTAJE } \\
\text { PROMEDIO } \\
48 \text { A } 59 \\
\text { MESES }\end{array}$ & $\begin{array}{c}\text { PUNTAJE } \\
\text { PROMEDIO } \\
60 \text { A } 75 \\
\text { MESES }\end{array}$ \\
\hline & $\mathrm{N}=21$ & $\mathrm{~N}=40$ & $\mathrm{~N}=22$ \\
\hline \multicolumn{4}{|l|}{ CODIFICACIÓN SEMÁNTICA } \\
\hline $\begin{array}{l}\text { Reconocimiento de nombres } \\
\text { ante la presentación de láminas }\end{array}$ & 41.43 & 59.50 & 69.55 \\
\hline Seguimiento de instrucciones & 89.52 & 95.75 & 98.64 \\
\hline $\begin{array}{l}\text { Conocimiento del significado } \\
\text { de las palabras }\end{array}$ & 39.29 & 47.63 & 52.95 \\
\hline $\begin{array}{l}\text { Comprensión de sinónimos, antó- } \\
\text { nimos y palabras supraordinadas }\end{array}$ & 17.14 & 22.50 & 42.95 \\
\hline $\begin{array}{l}\text { Repetición de un cuento captando } \\
\text { las ideas principales y los detalles }\end{array}$ & 27.62 & 42 & 51.82 \\
\hline Diferencia entre dibujo y texto & 62.38 & 80 & 91.82 \\
\hline Expresión espontánea & 55.24 & 66.25 & 68.64 \\
\hline Total de habilidades lingüísticas & 41.76 & 55.08 & 63.73 \\
\hline
\end{tabular}

Tabla 10. Puntajes promedio obtenidos por cada grupo de edad en cada una de las habilidades lingüísticas evaluadas. El puntaje máximo posible para cada subprueba y total es de 100.

A continuación se presenta una gráfica que permite visualizar estos resultados:

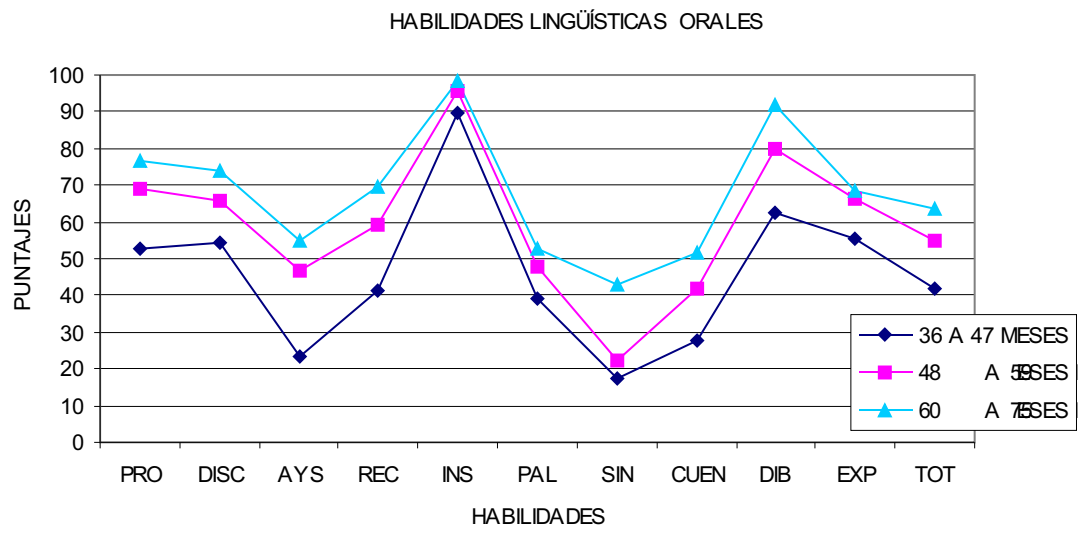

Gráfica 7. Puntajes promedio en las habilidades lingüísticas orales por grupo de edad. 
Se observa que el perfil de desempeño es similar para los tres grupos de edad en todos los aspectos evaluados, siendo mayor el desempeño de los niños de 60 a 75 meses que el de sus compañeros y menor el de los niños de 36 a 47 meses que el de los otros dos grupos de edad. Es decir, se observa una clara secuencia de desarrollo en estos resultados.

Al igual que en los resultados grupales, en la conciencia fonológica, el desempeño inferior se encuentra en al análisis y síntesis auditivos (AYS), siendo esto claramente más complicado para los más pequeñitos. Se observó al interior de la evaluación de este aspecto, que es más fácil para los niños "juntar" palabras que se les presentan separadas que separar palabras que se les presentan juntas (por ejemplo, es más fácil juntar "ca-rre-ta", que separar "anteojos"). Hay mucha similitud también en los resultados que se presentan en la pronunciación de los sonidos del habla (PRO) y en la discriminación auditiva (DISC). Conforme los niños avanzan en edad son más hábiles para pronunciar sonidos dentro de las palabras y poder identificar dos palabras que suenan igual o diferente, por ejemplo “ pan-ban”, día-tía”.

En cuanto a las habilidades relacionadas con la codificación semántica, nuevamente el puntaje más bajo se obtuvo en la identificación de los sinónimos, antónimos y palabras supraordinadas (SIN), siendo muy similar el desempeño de los niños de 36 a 47 meses y el de los niños de 48 a 60. En esta tarea en particular, se observa que los niños de 60 a 75 meses superan claramente a sus compañeros. Se observó también que es más difícil para los niños encontrar una palabra que "sea lo mismo que...." que una que sea lo contrario.

Por otra parte, en la repetición de un cuento captando las ideas principales y los detalles (CUEN) se observó que es más difícil para los niños recordar las características de los personajes del mismo que las ideas principales, por ejemplo, la mayoría de los niños recuerda que Héctor quiere mucho a su oso; pero muy pocos mencionan que el oso es negro.

En la descripción de los objetos que evidencian un conocimiento del significado de las palabras (PAL), también se observa una progresión, aunque los puntajes son muy similares. Esto puede deberse a que los niños más pequeños mencionan características muy concretas de los objetos que no permiten diferenciarlos claramente de otros. Por ejemplo, los más niños pequeños dicen que "una flor es una bolita con un palito” y algunos de los más grandes ya la ubican en una categoría más general, diciendo que "es una planta".

En la diferenciación entre el dibujo y el texto, los niños de 60 a 75 meses ( 5 a 6.3 años) se ubican cerca de un puntaje perfecto. Esto se debe a que la mayoría ya tienen muy claro que el texto impreso es el que lleva el mensaje 
y no la ilustración que se les muestra de manera simultánea, por ejemplo, muchos de ellos dicen que la ilustración "no dice nada, porque no tiene letras" (algunos dicen: "porque no tiene números").

En el puntaje total de las habilidades lingüísticas orales se observa de manera clara una progresión entre los tres grupos de edad, por lo que estos resultados sugieren que a mayor desarrollo de los niños, mayor desarrollo de las habilidades lingüísticas en el lenguaje oral. De acuerdo a la literatura revisada (Garton y Pratt, 1991; Goodman, 1986b; Fields y Spangler, 2000) que habla de una clara relación entre el lenguaje oral y el lenguaje escrito, esta variable (habilidades lingüísticas orales) fue considerada como variable independiente para analizar su contribución en el desarrollo de la alfabetización de la muestra estudiada.

Se obtuvo la significancia de estas diferencias mediante un análisis de varianza en una sola dirección, tomando como variable independiente la edad de los niños y como variables dependientes las habilidades lingüísticas orales.

\begin{tabular}{|c|c|c|}
\hline HABILIDAD & $\mathrm{F}$ & POST HOC (Tukey) \\
\hline $\begin{array}{l}\text { 1. Pronunciación correcta de los sonidos } \\
\text { del habla }\end{array}$ & $5.252 * *$ & $\begin{array}{l}3 \text { у } 1 \\
3 \text { у } 2\end{array}$ \\
\hline 2. Discriminación de sonidos verbales & $4.544 *$ & 3 у 1 \\
\hline 3. Análisis y síntesis auditivas & $5.516 * *$ & $\begin{array}{l}3 \text { у } 1 \\
2 \text { y } 1\end{array}$ \\
\hline $\begin{array}{l}\text { 4. Reconocimiento de nombres ante la pre- } \\
\text { sentación de láminas }\end{array}$ & $11.199 * *$ & $\begin{array}{l}3 \text { у } 1 \\
2 \text { y } 1\end{array}$ \\
\hline 5. Seguimiento de instrucciones & $4.042 *$ & 3 y 1 \\
\hline 6. Conocimiento del significado de las palabras & $3.149 *$ & 3 у 1 \\
\hline $\begin{array}{l}\text { 7. Comprensión de sinónimos, antónimos y } \\
\text { palabras supraordinadas }\end{array}$ & $11.670 * *$ & $\begin{array}{l}3 \text { у } 1 \\
3 \text { y } 2\end{array}$ \\
\hline $\begin{array}{l}\text { 8. Repetición de un cuento captando las } \\
\text { ideas principales y los detalles }\end{array}$ & $9.462 * * *$ & $\begin{array}{l}3 \text { у } 1 \\
2 \text { y } 1\end{array}$ \\
\hline 9. Diferencia entre dibujo y texto & $8.864 * * *$ & 3 y 1 \\
\hline 10. Expresión espontánea & $3.348 *$ & 2 y 1 \\
\hline TOTAL & $15.286^{* *}$ & $\begin{array}{l}3 \text { у } 1 \\
3 \text { y } 2\end{array}$ \\
\hline
\end{tabular}

Tabla 11. Significancia de las diferencias por edad obtenidas en las habilidades lingüísticas orales. ${ }^{*} \mathrm{P}<.05 \quad * * \mathrm{P}=.01 * * * \mathrm{P}<.001$ 
En el análisis post hoc se presenta primero el grupo que tuvo media mayor. Como puede observarse, todas las diferencias resultaron significativas a favor del grupo de 60 a 75 meses, siendo esta diferencia mayor en el puntaje total y en dos de las habilidades que se relacionan con la obtención de significado a través de claves semánticas, como son el reconocimiento de nombres (conceptos) y la comprensión de sinónimos, antónimos y palabras supraordinadas (relaciones entre conceptos).

Finalmente, se obtuvo la significancia de las diferencias por sexo, mediante una prueba t para muestras independientes no obteniéndose diferencias significativas para ninguna de las habilidades lingüísticas evaluadas.

A continuación se presentarán los resultados de los análisis correspondientes al segundo objetivo de la investigación.

III. Analizar la contribución de variables involucradas en el desarrollo de la alfabetización en niños preescolares (edad, habilidades lingüísticas orales, escolaridad de los padres, materiales y actividades de lectura en el hogar, conductas de madres / padres y maestras durante la lectura de cuentos).

En primer lugar se realizó un análisis de correlación para establecer la relación entre las variables independientes entre sí y con la variable dependiente.

Posteriormente, se realizó un análisis de regresión con el fin de ubicar la contribución de cada variable independiente y de todas en conjunto al desarrollo de la alfabetización.

\section{A. ESTABLECIMIENTO DE LA RELACIONES ENTRE LAS VARIABLES}

La tabla a continuación muestra los coeficientes obtenidos entre las variables independientes y la variable dependiente, así como la correlación entre las variables independientes. Las variables independientes fueron:

$\nabla$ La escolaridad de los padres

$\boldsymbol{\nabla}$ Los materiales de lectura al alcance del niño en el hogar

$\boldsymbol{\nabla}$ Las actividades de lectura en el hogar

$\mathbf{v}$ La lectura de cuentos por parte de madres/ padres

$\boldsymbol{\nabla}$ La lectura de cuentos por parte de las maestras

$\nabla$ La edad de los niños

$\boldsymbol{\nabla}$ Las habilidades lingüísticas del niño en el lenguaje oral

La variable dependiente fue el desarrollo de la alfabetización, que tiene dos componentes: conocimiento del lenguaje escrito y lectura de cuento por parte del niño. Para obtener el puntaje de desarrollo de la alfabetización se obtuvo un puntaje compuesto promediando el puntaje obtenido en el conocimiento del lenguaje escrito y el obtenido en la lectura del cuento. 
RESULTADOS

OBTENIDOS

\begin{tabular}{|c|c|c|c|c|c|c|c|c|}
\hline 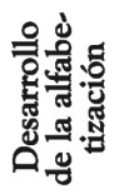 & $\stackrel{\stackrel{*}{*}}{\stackrel{*}{\dagger}}$ & $\stackrel{\dddot{\vartheta}}{\because}$ & ธิ & 导 & $\stackrel{\infty}{\rightleftharpoons}$ & 啇 & గ్రై & $\underset{-}{8}$ \\
\hline 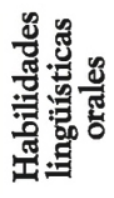 & 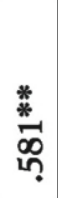 & $\begin{array}{l}\text { \%ั. } \\
\text { तุ }\end{array}$ & $\tilde{o}$ & 웅 & $\underset{\text { స̦ }}{\mathbb{N}}$ & ষ্ণ & $\underset{-}{8}$ & \\
\hline 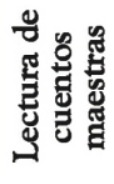 & సָ & 营 & 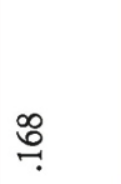 & 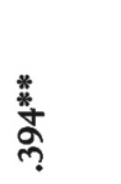 & $\stackrel{\infty}{\rightleftharpoons}$ & $\underset{-}{8}$ & & \\
\hline 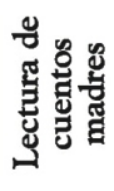 & סू & ఝ్య & 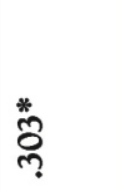 & $\stackrel{\circ}{\stackrel{\circ}{\hookrightarrow}}$ & $\underset{-}{8}$ & & & \\
\hline 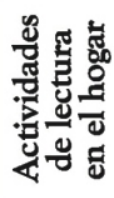 & సุ & 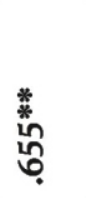 & 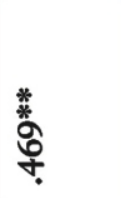 & $\underset{-}{8}$ & & & & \\
\hline 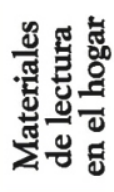 & ণ্ণ & 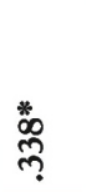 & ن․ & & & & & \\
\hline 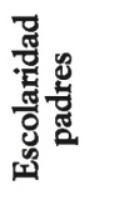 & 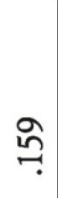 & $\underset{-}{8}$ & & & & & & \\
\hline 蛋 & $\underset{-}{8}$ & & & & & & & \\
\hline & 胥 & 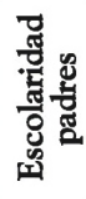 & 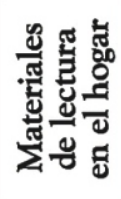 & 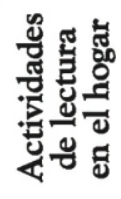 & 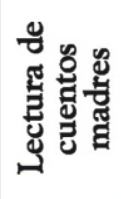 & 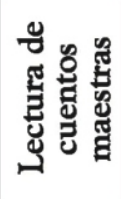 & 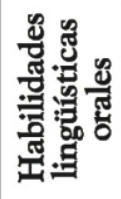 & 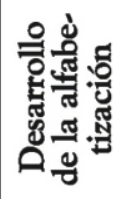 \\
\hline
\end{tabular}

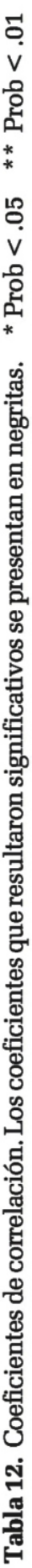


En la tabla 12, se puede observar que la edad de los niños correlaciona significativamente con el desarrollo de la alfabetización. Por otra parte, esta variable correlaciona con la lectura de cuentos por parte de las maestras.

La escolaridad de los padres no correlacionó de manera significativa con la variable dependiente, pero sí lo hizo con las habilidades lingüísticas en el lenguaje oral y con los materiales de lectura al alcance de los niños y las actividades de lectura que se realizan en el hogar.

Los materiales de lectura al alcance de los niños guardan relación con las actividades de lectura que se realizan en el hogar, lo cual es hasta cierto punto evidente y con la lectura de cuentos por parte de las madres. Cabe aclarar que esta es la única variable con la que la lectura de cuentos por parte de las madres / padres tuvo correlación significativa.

Las actividades de lectura correlacionaron positivamente con la lectura de cuentos por parte de las maestras. Llama la atención una posible relación entre la escolaridad de los padres, las actividades de lectura en el hogar y la lectura de cuento por parte de las maestras.

Resumiendo, la edad fue la variable independiente que correlacionó más alto con el desarrollo de la alfabetización, seguida por las habilidades lingüísticas orales y la lectura de cuentos por las maestras.

\section{B. ESTABLECIMIENTO DEL PODER PREDICTIVO DE LAS VARLABLES INDEPENDIENTES}

Una vez establecidos los coeficientes de correlación de las variables independientes entre sí y con la variable dependiente se procedió a la realización de un análisis de regresión para determinar la contribución de todas las variables independientes en conjunto y de cada una por separado al desarrollo de la alfabetización en los niños preescolares.

Las variables independientes (Predictoras) que se consideraron son las siguientes:

$\boldsymbol{\nabla}$ Escolaridad de los padres

$\boldsymbol{\nabla}$ Materiales de lectura en el hogar al alcance del niño

$\boldsymbol{\nabla}$ Actividades de lectura en el hogar

$\nabla$ Lectura de cuentos por parte de las madres

$\boldsymbol{\nabla}$ Lectura de cuentos por parte de las maestras

$\nabla$ Edad del niño

จ Habilidades lingüísticas orales del niño 
Como variable dependiente se consideró el desarrollo de la alfabetización. El método utilizado para realizar el análisis de regresión fue el método paso a paso (stepwise), utilizándose como criterio de inclusión de las variables independientes al modelo de regresión, el que el incremento en $\mathrm{R}^{2}$ fuera significativo al menos al .05 y para eliminarla del modelo, que la probabilidad fuera de .10.

A continuación se presentan los resultados del análisis realizado.

\begin{tabular}{|c|c|c|c|c|c|c|}
\hline $\begin{array}{c}\text { VARIABLE } \\
\text { INDEPENDIENIE }\end{array}$ & $\mathrm{R}^{2}$ & $\begin{array}{c}\mathrm{R}^{2} \\
\text { ajustada }\end{array}$ & $\begin{array}{l}\text { CAMBIO } \\
\text { EN R }^{2}\end{array}$ & $\begin{array}{l}\text { SIGNIFICAN- } \\
\text { CIA DEL } \\
\text { CAMBIO }\end{array}$ & BETA & $\begin{array}{l}\text { PROBA- } \\
\text { BILIDAD }\end{array}$ \\
\hline Edad & .509 & .498 & .509 & .000 & .305 & .036 \\
\hline $\begin{array}{l}\text { Habilidades } \\
\text { lingüísticas } \\
\text { orales }\end{array}$ & .587 & .568 & .079 & .006 & .494 & .000 \\
\hline $\begin{array}{l}\text { Lectura de } \\
\text { cuento por las } \\
\text { maestras }\end{array}$ & .639 & .614 & .052 & .018 & .276 & .018 \\
\hline
\end{tabular}

Tabla 13. Resultados del Análisis de Regresión, tomando como variable dependiente el desarrollo de la alfabetización.

En la tabla 13 se puede observar que las tres variables que cumplieron con los requisitos para ser incluidas en el modelo de regresión fueron la edad de los niños, las habilidades lingüísticas orales y la lectura del cuento por parte de las maestras. En conjunto estas variables explican el 61 \% de la varianza en el desarrollo de la alfabetización en los niños $\left(\mathbf{R}^{2}\right.$ ajustada $\left.=.614\right)$.

Los Coeficientes de Regresión Estandarizados obtenidos (Beta) indican que al incrementarse en una unidad la edad, el desarrollo de la alfabetización se incrementa en .30, al incrementarse en un punto el puntaje en las habilidades lingüísticas orales, el desarrollo de la alfabetización se incrementa en .49 y al incrementarse en un punto la lectura de cuentos por las maestras, el desarrollo de la alfabetización se incrementa en .28.

El valor que se obtuvo para la constante (a) fue de 2. 46, esto es, es lo que valdría la variable dependiente cuando todas las variables independientes valen cero.

La ecuación de regresión se presenta como sigue:

Desarrollo de la alfabetización $=2.46+.30$ (edad) +.49 (habilidades lingüísticas orales) +.28 (lectura de cuentos por la maestra) 
Se obtuvieron también las correlaciones parciales y semi-parciales entre las variables independientes incluidas en el modelo y la variable dependiente.

La tabla siguiente muestra los valores obtenidos.

\begin{tabular}{|l|c|c|c||}
\hline $\begin{array}{c}\text { VARIABLES } \\
\text { INDEPENDIENTES }\end{array}$ & CORRELACIÓN & $\begin{array}{c}\text { CORRELACIÓN } \\
\text { PARCIAL }\end{array}$ & $\begin{array}{c}\text { CORRELACIÓN } \\
\text { SEMIPARCIAL }\end{array}$ \\
\hline Edad & .713 & .317 & .201 \\
\hline $\begin{array}{l}\text { Habildades } \\
\text { lingüísticas orales }\end{array}$ & .656 & .506 & .352 \\
\hline $\begin{array}{l}\text { Lectura de cuentos } \\
\text { por la maestra }\end{array}$ & .353 & .355 & .228 \\
\hline
\end{tabular}

Tabla 14. Correlaciones simples, parciales y semiparciales de las variables independientes y el desarrollo de la alfabetización.

Como se observa en estos resultados, las correlaciones de orden cero (simples) indican que la edad es la variable que tiene mayor correlación con el desarrollo de la alfabetización. Sin embargo, al controlar los efectos de las otras variables independientes sobre la variable independiente en cuestión (correlación semiparcial) el panorama cambia, ya que el coeficiente de correlación de la edad con el desarrollo de la alfabetización disminuye a .201, el de las habilidades lingüísticas en el lenguaje oral disminuye de .656 a .352 y el de la lectura de cuentos por parte de la maestra disminuye de .353 a .328. Como resultado de este análisis, la edad pasó de ser la variable más importante a la tercera en importancia.

Al realizar la correlación parcial, esto es, controlar los efectos de las otras variables independientes sobre ambas, variable independiente y dependiente se observa que la variable que más se relaciona con el desarrollo de la alfabetización son las habilidades lingüísticas orales (.506), en segundo lugar, la lectura del cuento por parte de las maestras (.355) y por último la edad (.317) que como se puede verificar como resultado de este último análisis existen efectos de multicolinealidad por su relación con las otras variables independientes.

Como resultado de los análisis realizados, las tres variables independientes que cumplieron los requisitos para ser incluidas en el modelo son la edad de los niños, las habilidades lingüísticas en el lenguaje oral y la lectura del cuento por parte de las maestras, contribuyendo las tres a un $61 \%$ de la varianza en el desarrollo de la alfabetización. 
Con base en los resultados obtenidos en las correlaciones parciales y semiparciales se observa que las habilidades lingüísticas en el lenguaje oral es la variable que más se relaciona con el desarrollo de la alfabetización, seguida por la lectura de cuentos por parte de las maestras y finalmente la edad de los niños. En la sección de discusión se abundará sobre las relaciones encontradas y el papel de las variables independientes que no fueron incluidas en el análisis de regresión.

Para corroborar estos resultados se realizó el análisis de regresión, incluyendo las mismas variables independientes excepto la edad y como variable dependiente el desarrollo de la alfabetización. El método utilizado fue el mismo (stepwise) y los criterios de inclusión $(\mathrm{p}=.05)$ y exclusión $(\mathrm{p}=.10)$ de las variables al modelo fueron los mismos. Los resultados obtenidos fueron los siguientes:

\begin{tabular}{||c|c|c|c|c|c|c||}
\hline \multicolumn{1}{|c|}{$\begin{array}{c}\text { VARIABLE } \\
\text { INDEPENDIENIE }\end{array}$} & $\mathrm{R}^{2}$ & $\mathrm{R}^{2}$ \\
ajustada & $\begin{array}{c}\text { CAMBIO } \\
\text { EN R }\end{array}$ & $\begin{array}{c}\text { SIGNIFICAN } \\
\text { CIADEL } \\
\text { CAMBIO }\end{array}$ & BETA & $\begin{array}{c}\text { PROBA- } \\
\text { BILIDAD } \\
\text { DE BETA }\end{array}$ \\
\hline $\begin{array}{l}\text { Habilidades lin- } \\
\text { güísticas orales }\end{array}$ & .430 & .417 & .430 & .000 & .691 & .000 \\
\hline $\begin{array}{l}\text { Lectura de } \\
\text { cuentos por la } \\
\text { maestra }\end{array}$ & .599 & .580 & .169 & .000 & .412 & .000 \\
\hline
\end{tabular}

Tabla 15. Resultados del Análisis de Regresión, excluyendo al edad y tomando como variable dependiente el desarrollo de la alfabetización.

En la tabla 15 se puede observar que nuevamente las variables que cumplieron con los requisitos para ser incluidas en el modelo fueron las habilidades lingüísticas en el lenguaje oral y la lectura de cuentos por las maestras, explicando ambas el 58\% de la varianza en el desarrollo de la alfabetización $\left(\mathbf{R}^{2}\right.$ ajustada $\left.=.580\right)$.

Los Coeficientes de Regresión Estandarizados obtenidos (Beta) indican que al incrementarse las habilidades lingüísticas en una unidad, el desarrollo de la alfabetización se incrementa en .69. Al incrementarse la lectura de cuentos por la maestra en una unidad, el desarrollo de la alfabetización se incrementa en .41.

El valor que se obtuvo para la constante (a) fue de 1.67, esto es, es lo que valdría la variable dependiente cuando todas las variables independientes valen cero. 
La ecuación de regresión se presenta como sigue:

Desarrollo de la alfabetización $=1.67+.69$ (habilidades lingüísticas orales) +.41 (lectura de cuentos por la maestra)

En este análisis también se obtuvieron las correlaciones parciales y semiparciales entre las variables independientes incluidas en el modelo y la variable dependiente. La tabla siguiente muestra los valores obtenidos.

\begin{tabular}{||c|c|c|c||}
\hline $\begin{array}{c}\text { VARIABLES } \\
\text { INDEPENDIENTES }\end{array}$ & CORRELACIÓN & $\begin{array}{c}\text { CORRELACIÓN } \\
\text { PARCIAL }\end{array}$ & $\begin{array}{c}\text { CORRELACIÓN } \\
\text { SEMIPARCIAL }\end{array}$ \\
\hline $\begin{array}{l}\text { Habilidades } \\
\text { lingüísticas orales }\end{array}$ & .656 & .736 & .689 \\
\hline $\begin{array}{l}\text { Lectura de cuento } \\
\text { por la maestra }\end{array}$ & .353 & .544 & .411 \\
\hline
\end{tabular}

Tabla 16. Correlaciones simples, parciales y semiparciales de las variables independientes, excluyendo la edad, y el desarrollo de la alfabetización

Como se observa en estos resultados, las correlaciones de orden cero (simples) son congruentes con las correlaciones parciales y semiparciales al observarse que las habilidades lingüísticas orales están más correlacionadas con el desarrollo de la alfabetización que la lectura de cuentos por la maestra. Siendo las correlaciones parciales de .736 y .544 respectivamente, esto es, la relación entre cada una de las variables independientes incluidas en el modelo y la variable dependiente al controlar los efectos de las otras variables independientes sobre variable dependiente e independiente.

Estos resultados corroboran los obtenidos en el análisis de regresión en el que se incluyó la edad, por lo que las variables que permiten predecir el desarrollo de la alfabetización en la muestra estudiada son: las habilidades lingüísticas orales, la lectura de cuentos por la maestra y la edad de los niños.

Se presenta como anexo una tabla que resume los resultados obtenidos al realizar el análisis de regresión tomando como variables independientes a las mismas variables consideradas en los análisis que se han reportado y como variable dependiente a cada uno de los componentes del desarrollo de la alfabetización (Anexo 6). 


\section{ANÁLISIS DE REGRESIÓN PARA CADA GRUPO DE EDAD}

Finalmente, se realizó un análisis de regresión por cada grupo de edad tomando como variables independientes las mismas variables que para el análisis general (escolaridad de los padres, materiales de lectura al alcance del niño, actividades de lectura en el hogar, lectura de cuentos por las madres, lectura de cuentos por las maestras y habilidades lingüísticas orales) y como variable dependiente el desarrollo de la alfabetización, utilizando el mismo método y los mismos criterios para la inclusión de las variables independientes al modelo de regresión. Se presentan los resultados obtenidos.

\section{A 47 MESES}

La única variable que cumplió con los criterios fue las habilidades lingüísticas orales, obteniéndose una $\mathrm{R}^{2}$ ajustada de .494. Es decir, que el desarrollo en las habilidades lingüísticas orales explica un $49 \%$ de la varianza en el desarrollo de la alfabetización para los niños de 36 a 47 meses. El coeficiente Beta fue de .735, por lo que se puede afirmar que en los niños de esta edad, al incrementarse las habilidades lingüísticas orales en un punto, el desarrollo de la alfabetización se incrementa en .73 y finalmente, la correlación parcial obtuvo el valor de .735.

\section{A 59 MESES}

Las variables que se incluyeron en el modelo fueron las habilidades lingüísticas orales y la lectura de cuentos por la maestra, lo cual coincide con los resultados generales. Se obtuvo una $\mathrm{R}^{2}$ ajustada de .456, es decir que para los niños de esta edad, las dos variables explican el $47 \%$ de la varianza en el desarrollo de la alfabetización. Los coeficientes de regresión estandarizados (Beta) fueron de .665 y .372, respectivamente, por lo que se puede decir que al incrementarse el puntaje en las habilidades lingüísticas en un punto, el desarrollo de la alfabetización se incrementa en .66 y al incrementarse el valor de la lectura de la maestra en un punto, el desarrollo de la alfabetización se incrementa en .37. Finalmente, las correlaciones parciales fueron de .681 para las habilidades lingüísticas orales y de .462 para la lectura de cuento por parte de la educadora. 
60 A 75 MESES

Para esta edad, la variable que cumplió con el criterio para ser incluida en el modelo fue los materiales de lectura al alcance del niño, obteniéndose una $\mathrm{R}^{2}$ de .500 , una beta de .750 y una correlación parcial de .75. Por lo que se puede afirmar que para los niños de esta edad, los materiales de lectura a su alcance explican un 50\% de la varianza en el desarrollo de la alfabetización y que al incrementarse los materiales de lectura en un punto, el desarrollo de la alfabetización se incrementa en .75.

Se analizará la relación de estos resultados con los resultados generales en la sección de comentarios finales y conclusiones. 


\section{. capículos}

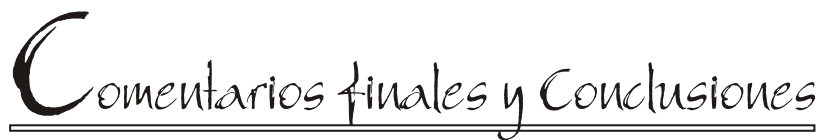

\section{Comentarios finales}

El primer objetivo de este trabajo fue:

Caracterizar el desarrollo de la alfabetización en una muestra de niños preescolares.

Los resultados obtenidos han permitido constatar dos aspectos principales con respecto de este objetivo:

1) Los niños han construido conocimiento respecto del lenguaje escrito aun sin haber accedido a la instrucción formal en lectura y escritura.

2) Los niños de diferentes edades tienen conocimientos y niveles de desarrollo diferentes.

Se discutirá cada uno de estos aspectos:

1) Los niños han construido conocimiento respecto del lenguaje escrito aun sin haber recibido instrucción formal.

Este hallazgo resulta congruente con el concepto de desarrollo de la alfabetización que sirvió de marco de referencia para el presente trabajo y que establece que los niños construyen conocimiento y desarrollan habilidades relacionadas con el lenguaje escrito sin recibir instrucción directa (Clay, 1989; Dixon-Krauss, 1997; Justice y Kaderaveck, 2002). Los salones preescolares con los que interactúan cotidianamente promueven este conocimiento y habilidades ya que están repletos de muestras de lenguaje escrito, tal como lo sugiere Morrow (2001). 
Los conocimientos que los niños han construido respecto de los conceptos relacionados con el texto impreso se pueden observar tanto en sus respuestas a los aspectos que componen esta subprueba, como en su desempeño como lectores de cuentos. En ellos se puede observar que los niños saben que el texto es quien lleva el mensaje y no la ilustración, que tienen conocimiento del uso del libro, esto es, la parte de enfrente, pasar las páginas en el orden correcto, que la página izquierda se lee antes que la derecha. Estas observaciones se corroboran con la prueba de diferencia entre dibujo y texto del EPLE. Los autores revisados en el marco teórico de este trabajo coinciden en que estos aspectos se aprenden a través de la interacción cotidiana con el lenguaje escrito (Clay, 1989; Ferreiro, 1998).

La escritura de los niños también muestra los conocimientos que han construido respecto del lenguaje escrito. Se observa nuevamente el conocimiento de los principios direccionales, como se ve en la escritura de Liliana (resultados, fig.1) quien muestra evidencia de conocer que se escribe de izquierda a derecha, de que se escriben letras, las cuales si bien no son letras convencionales, sí son un intento de representar el significado mediante signos. La escritura de Liliana refleja sus intentos por tratar de representar las letras que observa en el ambiente con el que interactúa de manera cotidiana, una vez que ha descubierto que la escritura, a diferencia del dibujo, no representa la forma de los objetos (Fields y Spangler, 2000).

Un aspecto que resulta particularmente interesante, como evidencia de la construcción que realizan los niños a partir de las experiencias cotidianas, se refiere a la identificación de letras. Muchos de ellos las identificaban porque forman parte de su nombre, o bien del de algunos de sus compañeros. Esto se relaciona directamente con los letreros que las maestras tienen en el salón de clases y que contienen los nombres de los niños, lo que les permite asociar estos aspectos impresos con las letras en cuestión. Por ejemplo, en una de las escuelas se acostumbra que los niños pasen a los rincones de juego, tomando un gafete que tiene impreso su nombre. En esta actividad los niños tienen la oportunidad de relacionar el lenguaje escrito con una situación cotidiana y útil y además identificar uno de los usos de la lectura. Esta actividad y otras similares les permiten saber que el texto lleva el mensaje y algunas particularidades de la escritura del texto como la dirección de la misma. (Dahl y Freepon, 1995; Nielsen y Monson, 1996). Las actividades de este tipo, que se realizan cotidianamente en los salones preescolares informan a los niños, al igual que las que se realizan en el hogar, de los usos y particularidades del 
lenguaje escrito y el conocimiento que los niños van construyendo se nutre de la interacción que tiene con ambos ambientes, tal como se postula en las perspectivas teóricas revisadas en este trabajo.

Dado que el instrumento utilizado se aplica también a niños que están iniciando el aprendizaje de la lectura y la escritura convencionales, se espera que sean capaces de identificar palabras, lo que por supuesto, estos niños preescolares no son capaces de hacer. Sin embargo, sus respuestas mostraron evidencia de conocimiento tácito de la palabra como unidad de significado, ya que al pedírseles que trataran de leerlas, muchos de los niños daban como respuesta a cada una de las palabras presentadas, otra palabra cualquiera que se les ocurría en el momento, que si bien no correspondía al estímulo impreso, si correspondía en el sentido de que ofrecían la misma unidad lingüística (una palabra) como respuesta a la petición de lectura. Roberts (1992) encontró que los niños van construyendo un conocimiento tácito de la palabra como unidad de significado, primero en el lenguaje oral y luego en el escrito. Este conocimiento inicia su desarrollo en el periodo preoperacional, de acuerdo a Piaget, que corresponde a esta etapa preescolar.

Existen algunos conocimientos que los niños en promedio no manejan, por ejemplo, el uso de los signos de puntuación. Este conocimiento parece estar más relacionado con la instrucción formal ya que requiere el conocer reglas muy específicas de uso en el lenguaje escrito. En un estudio realizado con niños de primero a sexto de primaria, Díaz (1995) encontró que la instrucción respecto de los signos de puntuación inicia con el punto en segundo grado y que los niños siguen una serie de etapas en la construcción de su conocimiento que no termina para todos los signos al terminar la primaria. El grado de conocimiento que los niños construyen depende de la complejidad del signo y de las circunstancias de su uso. En la muestra estudiada en la presente investigación, aun cuando los niños no conocían el uso de dichos signos, muchos de ellos contestaban que sirven "para leer", lo cual evidencia las hipótesis que construyen respecto de las particularidades del texto impreso. Los niños reconocen que esos signos son útiles en el lenguaje escrito; pero aún no son capaces de asignarles su función, e incluso, algunos resultados parecen evidenciar un conocimiento tácito de sus funciones. Por ejemplo, André de 46 meses, al escribir el enunciado que se le dictó, escribió: "punto al final" (fig. 3, resultados). Estos resultados son congruentes con los encontrados por Díaz y corresponderían a la primera etapa identificada por este autor y que denominó “generalización”. 
Los niños preescolares construyen su conocimiento del lenguaje escrito a partir de la observación y la participación en actividades cotidianas relacionadas con la lectura y la escritura (McGee y Richgels, 1990; Dahl y Freepon, 1995; Ferreiro, 1998). En el caso de la muestra estudiada, esto se pone de manifiesto en virtud de que en ninguna de las dos escuelas existe un programa encaminado a enseñar a los niños la lectura o la escritura de manera convencional, ni propositiva. Sin embargo, en los reportes de las madres a través de los cuestionarios contestados, se observa que en los hogares de los niños se realizan cotidianamente actividades relacionadas con la lectura y la escritura, siendo las más frecuentes: leer los letreros cuando van por la calle y escribir y dibujar con el niño.

La importancia de estas actividades para promover el desarrollo de la alfabetización en los niños preescolares ha sido señalada por diversos autores (Purcell-Gates, 1996; Saint Laurent, Giasson y Couture, 1997; Bauman y Thomas, 1997; Ferreiro, 1998) por lo que los conocimientos construidos por los niños de la muestra pueden estar relacionados con su realización. De la misma manera, si bien la enseñanza del lenguaje escrito no se realiza de manera propositiva en el contexto escolar, sí se realizan actividades cotidianas que tienen que ver con el lenguaje escrito, como la lectura de cuentos y el pasar a los rincones de juego mediante un gafete que tiene impreso el nombre de cada niño.

2) Los niños de diferentes edades tienen conocimientos y niveles de desarrollo diferentes:

En cuanto al desempeño de los niños de acuerdo a su nivel de desarrollo, se observa que el patrón de desempeño es muy semejante, es decir, los aspectos que más se conocen son los mismos en los tres grupos de edad y corresponden al manejo de conceptos del texto impreso, que se evidencian tanto en su respuesta a esta prueba, como en sus producciones escritas y en la identificación de letras.

Estos resultados confirman el hecho de que el desarrollo de la alfabetización es un proceso continuo que inicia muy temprano en la vida del niño, y que va dando como resultado mayor conocimiento en la medida en que su propio desarrollo le haya dado mayor oportunidad de interactuar con la lectura y la escritura y cuestionarse respecto de su naturaleza (Barratt Pugh, 2000). 
Al igual que en el caso de la muestra total, en el caso de la lectura de cuentos por los niños por edades, se pudo obtener información del conocimiento que han logrado construir respecto del lenguaje escrito. Esta información evidencia que existen diferencias relacionadas con el nivel de desarrollo general de los niños (gráfica 4). Sin embargo, en esta tarea no se observan diferencias tan notables como en las tareas correspondientes al instrumento de observación de los logros de la lectoescritura inicial, en el que las diferencias se observan primordialmente en lo que se refiere al conocimiento de las letras y al vocabulario de escritura (gráfica 3).

Esto puede deberse a que, si bien no se tienen datos sistemáticos, se observó incidentalmente que en los dos escenarios preescolares se tiene la concepción de que a medida que los niños se acercan al momento en que deberán recibir instrucción formal en lectura se les debe dar este tipo de instrucción. Esta concepción sería acorde a la aproximación de aprestamiento que se ha mencionado en el presente trabajo (Dahl y Freepon, 1995; Nielsen y Monson, 1996; Smith,2001), por lo que las maestras del grupo de tercero de preescolar (sobre todo en uno de los escenarios) llevan a cabo actividades de identificación de fonemas y asociación de los mismos con los grafemas correspondientes. Este tipo de actividad, aunado al conocimiento que los niños han logrado construir debido a su nivel de desarrollo y su interacción con el lenguaje escrito en el hogar y en la escuela, podría dar como resultado el mayor conocimiento de aspectos formales, tales como el conocimiento de las letras por su nombre y sonido, que se observó en los niños de 5 años a 6 años, 3 meses. Los niños de los otros dos grupos identifican las letras porque forman parte de palabras conocidas y algunas por su nombre. Purcell Gates (1996) enfatiza que el conocimiento del lenguaje escrito se construye tanto en el hogar, como en la escuela y que un aspecto crítico lo constituye la relación que se establece entre el conocimiento informal construido en el hogar y el conocimiento que se construye en la escuela debido a la instrucción. La interrelación de estos dos aspectos podría dar como resultado el mayor conocimiento de los nombres de las letras de los niños de 5 años a 6 años 3 meses.

Los datos longitudinales obtenidos a través de la submuestra de doce niños permiten constatar la progresión del desarrollo que se observó a través de los datos transversales. Los resultados de esta submuestra permitieron ubicar de manera más precisa los conocimientos que hacen la diferencia en los diferentes niveles de edad. 
Por ejemplo, en la lectura de cuentos se puede ver que los niños más pequeños hacen una narración que se relaciona básicamente con lo que es evidente en las ilustraciones y que en su mayoría las características de su narración corresponden al lenguaje oral (diálogo con el escucha, palabras y entonación utilizados). Los niños mayores (2 niños de 48 a 60 y todos los de 60 a 75 meses) incluyen en su narración aspectos que caracterizan a la lectura, por ejemplo, lectura como monólogo y entonación que se usa en la lectura (Sulzby, 1985; Valencia y Sulzby, 1991).

Las muestras de escritura de estos niños permiten identificar también los diferentes niveles de desarrollo de acuerdo a su edad. Los niños más pequeños tienen la idea de que el lenguaje expresa algo y pretenden escribir signos y los niños más grandecitos aúnan a esto una aproximación más cercana a la escritura convencional y el conocimiento de la dirección de la escritura (Goodman, 1986; Tolchinsky y Levin, 1986; Escamilla, Andrade, Basurto y Ruiz, 1996; Fields y Spangler, 2000).

Las descripciones que se realizaron del desarrollo de tres niños complementan la información presentada, ya que en ellos se observa claramente que el desarrollo de la alfabetización es un proceso gradual que permite un mayor nivel de dominio a medida que se avanza en él.

Esto se observa en su progresión del conocimiento de las letras: Angel pasó de 9 a 21, Sofía de 7 a 47 y Ulises de 5 a 10. Se observa también en su manejo de los conceptos del texto impreso, lo cual se evidencia en el caso de Angel quien incluso ya conocía el uso del punto. Sus producciones escritas también evidencian este desarrollo y en el caso de Sofía y Angel, escriben ya palabras comunes y pretenden representar el significado mediante las letras que conocen. Evidencian ya una idea de que los grafemas se asocian al lenguaje hablado, aun cuando no son todavía capaces de establecer la relación grafema-fonema que está más relacionada con la enseñanza convencional.

La lectura de los cuentos también evidencia esta situación, ya que los tres niños muestran un manejo adecuado de los libros: inician por la portada, pasan las páginas, leen primero la página izquierda y después la derecha, observándose en Ulises una progresión de la simple descripción de las ilustraciones al intento de narrar una historia y en el caso de Sofía y Angel al conocimiento de algunos de los convencionalismos al leer, como son la entonación y la conciencia de que existe audiencia. 
Las diferencias individuales dentro de los grupos de edad, pudieran deberse al ambiente de alfabetización en el hogar, ya que los niños que obtienen los puntajes más altos en cada grupo de edad (Ulises, Sofía y Erick Dan) son también aquellos niños en cuyos hogares, de acuerdo a los resultados de los cuestionarios, tienen mayor cantidad de materiales de lectura al alcance del niño y se realizan más actividades relacionadas con la lectura en el hogar. Barrath-Pugh (2000) explica que lo que los niños aprenden respecto del lenguaje escrito depende de sus interacciones con eventos relacionados con él y que éstas son diferentes de familia a familia.

De igual manera, durante la lectura de cuentos por las madres de estos tres niños, se observó una interacción que estimulaba la elaboración de predicciones, conclusiones e inferencias, que aprovechaba las interrupciones para estimular la comprensión, que relaciona el contenido del texto con los eventos cotidianos en la vida de los niños y que les solicita la reconstrucción de la historia. Autores como De Temple (2000) y Dickinson (2001) mencionan que es este tipo de interacción el que promueve en mayor medida el desarrollo de la alfabetización.

Adicionalmente, se observa que, para cada grupo de edad, los dos niños que tienen los puntajes más altos proceden del mismo salón de clases. Este hecho podría corroborar el papel del ambiente escolar en el desarrollo de la alfabetización, el cual complementa al hogar como promotor de dicho desarrollo. Collins, Oakar y Hurt (2002) identificaron una serie de variables que hacen que una maestra sea efectiva para promover el desarrollo de la alfabetización. En el caso de las maestras de niños preescolares su papel predominante es el de guía, utilizar la exploración para estimular la curiosidad acerca del lenguaje escrito y relacionar las experiencias de la casa y la escuela.

En la presente investigación no se tomaron datos sistemáticos del ambiente y las actividades del salón de clases; pero la observación de la lectura de cuentos permite identificar algunas de las características de la interacción de las maestras y los niños que pudieran ser responsables de estos resultados. Por ejemplo, la maestra del grupo de niños de 36 a 47 meses estableció un espacio de discusión al final de la lectura con el fin de que los niños reflexionaran sobre el contenido del cuento. La maestra de los niños de 48 a 59 meses tuvo una interacción muy activa con los niños durante la lectura del cuento, estimulándolos a hacer comentarios, predicciones, conclusiones e inferencias y relacionando el contenido del cuento con los eventos cotidianos en la vida de los niños. La maestra de los niños de 60 a 75 meses tuvo también una interacción muy rica durante la lectura del 
cuento, refiriéndose más al aquí y ahora; pero al final pidió a los niños que reprodujeran la historia y ellos eligieron hacerlo mediante una representación dramática. En esta representación, la maestra fungió como guía y los niños organizaron y realizaron la actividad.

Los resultados analizados hasta el momento permiten responder al primer objetivo ya que muestran evidencia de que el conocimiento y habilidades respecto de la alfabetización se construyen sin haber recibido instrucción forma en lectura y escritura, que los niños tienen un gran bagaje de conocimientos respecto de esta área y que el desarrollo que se va presentando está muy relacionado con el nivel de desarrollo general de los niños.

Los resultados también permitieron constatar que existe un patrón similar de desarrollo para los tres grupos de edad analizados y que existen diferencias en términos del nivel de desarrollo, dependiendo de la edad de los niños. Parece haber relación entre el conocimiento respecto del lenguaje escrito al interior de los grupos de edad, las actividades de lectura en el hogar y las características del salón al que los niños pertenecen.

La discusión realizada hasta el momento responde al primer objetivo de la investigación que consistió en caracterizar el desarrollo de la alfabetización en una muestra de niños preescolares. A continuación se discutirán los resultados que se relacionan con el segundo objetivo:

Analizar la contribución de variables involucradas en el desarrollo de la alfabetización en niños preescolares (edad, habilidades lingüísticas en el lenguaje oral, escolaridad de los padres, materiales y actividades de lectura en el hogar, conductas de madres / padres y maestras durante la lectura de cuentos).

Con relación a este objetivo se obtuvieron los siguientes hallazgos:

1) Las variables independientes que contribuyeron al desarrollo de la alfabetización en la muestra estudiada fueron:

- Las habilidades lingüísticas orales.

- La lectura de cuentos por las maestras.

- La edad de los niños.

2) No se encontraron relaciones estadísticamente significativas entre las variables del hogar (escolaridad de los padres, materiales de lectura al alcance del niño en el hogar, actividades de lectura y lectura de cuentos por las madres) y el desarrollo de la alfabetización, aun cuando esta relación está muy fundamentada en la literatura. 
3) Existen algunas relaciones entre las variables independientes que merecen ser discutidas.

Por ejemplo, la escolaridad de los padres se relaciona con las habilidades lingüísticas orales, con los materiales y actividades relacionados con la lectura en el hogar y con la lectura de cuentos por las maestras.

Las actividades de lectura que se llevan a cabo en el hogar se relacionan con la lectura de cuentos por las maestras.

4) Los resultados de los análisis de regresión realizados, sin tomar en cuenta la edad y para cada grupo de edad, corroboran la contribución de las habilidades lingüísticas y la lectura de cuentos por las maestras.

Se procederá a discutir cada uno de estos hallazgos:

1) Las variables que contribuyen más a la varianza en el desarrollo de la alfabetización fueron: habilidades lingüísticas orales, lectura de cuentos por las maestras y edad de los niños.

Los resultados de las correlaciones simples entre las variables presentan evidencia de esta situación, ya que la variable edad fue la que tuvo la correlación significativa más alta, seguida por las habilidades lingüísticas orales y finalmente la lectura de cuentos por las maestras.

$\mathrm{Al}$ realizarse el análisis de regresión, se conserva este orden, observándose que las tres variables en conjunto explican el 61\% de la varianza en el desarrollo de la alfabetización.

Al obtenerse las correlaciones parciales el panorama cambia, ya que se observa que las habilidades lingüísticas orales es la variable que tiene la correlación más alta, lo que concuerda con los enfatizado por los autores revisados en el presente trabajo en lo que se refiere a la estrecha relación entre el lenguaje oral y el lenguaje escrito (Goodman, 1986b; Garton y Pratt, 1991; Fields y Spangler, 2000). Según Glazer (1989) este desarrollo del lenguaje oral es un vehículo para el desarrollo del lenguaje escrito y ayuda al niño a utilizar su conocimiento del lenguaje en todas sus actividades relacionadas con la lectura y la escritura.

Específicamente, en esta investigación se estableció la relación entre la conciencia fonológica, medida a través de las tres primeras subpruebas de EPLE, y el desarrollo de la alfabetización. La importancia de esta habilidad ha sido enfatizada por varios autores, quienes han establecido que se requiere una buena habilidad para identificar y manipular los componentes de las palabras (sílabas y fonemas) para poder acceder con éxito al aprendizaje de la lectura (Jiménez, 
1992; Soderman, Gregory y O’Neill, 1999; Morrow, 2000). En el caso de la muestra estudiada, básicamente se pidió a los niños que identificaran sonidos aislados al inicio y dentro de las palabras (subprueba 2), y que identificaran sílabas y palabras aisladas, es decir, las tareas que realizaron se ubicaron en el nivel fonético, silábico y léxico. Autores como Nation y Hulme (1997) y Vernon (1998) han evidenciado que el nivel más fácil de lograr es el léxico, seguido por el silábico y finalmente el fonético.

Otra habilidad lingüística que se analizó en el presente trabajo fue la codificación semántica (Vellutino y Scanlon, 1982) medida por las últimas siete subpruebas del EPLE, la cual parece ser también responsable de las varianza en el desarrollo de la alfabetización. Esta habilidad de extraer significado a través del propio significado de palabras, frases y oraciones puede deberse a un buen manejo del vocabulario, tanto receptivo (subprueba 4) como expresivo (subprueba 6). La importancia de la riqueza de vocabulario en el desarrollo de la alfabetización ha sido establecida por Dickinson (2001). El manejo de las relaciones entre conceptos y de las palabras supraordinadas (subprueba 7) ha sido enfatizado por Jordan, Snow y Porsche (2000). Curtis (1980) ha enfatizado la comprensión de lo que se escucha (subpruebas 5 y 8) y autores como Fields y Spangler (2000) han enfatizado la importancia de que los niños sean capaces de diferenciar entre el dibujo y la escritura (subprueba 9). Finalmente mediante la expresión espontánea (subprueba 10) los niños proporcionan evidencia tanto de su vocabulario expresivo, como de su manejo de los aspectos fonológicos, semánticos y sintácticos en el lenguaje oral.

El conocimiento y habilidad de los niños con el lenguaje oral les permitirán, entre otras cosas, tener una mejor comprensión de los aspectos que se refieren a las habilidades de decodificación del texto impreso y que tienen que ver con el establecimiento de la correspondencia grafema-fonema. Estas habilidades se desarrollarán una vez que accedan a la instrucción formal en lectura y escritura (generalmente a su ingreso a la primaria).

La segunda variable en importancia, después de la obtención de las correlaciones parciales y semiparciales la constituye la lectura de cuentos por parte de las maestras, enfatizando así el papel que juega el ambiente de instrucción escolar. El papel de esta variable puede estar relacionado con lo que afirma Barratt Pugh (2000) respecto de la homogeneidad del ambiente escolar para promover aquellas conductas relacionadas con el desarrollo de la alfabetización que son valoradas en un contexto alfabetizado en particular. 
Adicionalmente, se ha enfatizado la relación entre cierto tipo de interacción durante la lectura de cuentos y el desarrollo de la alfabetización (De Temple, 2001; Dickinson, 2001; Rocha y Vega, 2002). En el caso de las maestras de la muestra estudiada, tendieron a solicitar a los niños que elaboraran conclusiones, así como inferencias y predicciones y a relacionar el contenido del cuento con sus experiencias cotidianas. Ejemplo de ello es el extracto presentado en el cuadro 13 de los resultados, en donde la maestra aprovechó el cuento para hacer reflexionar a los niños respecto del peligro de alejarse de mamá y aceptar cosas de extraños. Este tipo de interacción es el que más contribuye al desarrollo de la alfabetización según los autores citados.

Esta variable enfatiza la importancia que tiene el contexto preescolar y en particular la interacción que se da entre las maestras y los niños en relación con el lenguaje escrito. Como ya se mencionó, en la etapa preescolar el papel predominante de la maestra es el de guía, promoviendo la exploración y relacionado las experiencias de la casa y la escuela (Collins, Oakar y Hurt, 2002).

Finalmente, la edad es la tercera variable que da cuenta de las relaciones entre las variables independientes y la variable dependiente. La edad es una variable que representa importancia por su relación con otros aspectos. El tener mayor edad representa, en principio, un mayor nivel de desarrollo, por lo que se puede establecer que efectivamente el nivel de desarrollo de los niños, y en particular el desarrollo del lenguaje oral, es una variable importante en el desarrollo de la alfabetización. Por otra parte, el tener mayor edad representa la oportunidad de haber sido expuesto durante más tiempo a la interacción con el lenguaje escrito, y si esta interacción ha podido promover mayor familiaridad con el mismo, se esperaría un mayor desarrollo de la alfabetización.

2) No se encontraron relaciones estadísticamente significativas entre las variables del hogar (escolaridad de los padres, materiales de lectura al alcance del niño en el hogar, actividades de lectura y lectura de cuentos por las madres) y el desarrollo de la alfabetización aun cuando esta relación está muy fundamentada en la literatura.

Ninguna de las variables mencionadas tuvo una correlación significativa, aunque en términos de la fuerza de la relación, la lectura de cuentos realizada por las madres es la variable que tiene la correlación más alta y esta relación ha sido ampliamente considerada en la literatura (Reese y Cox, 1999; Jordan, Snow y Porsche, 2000; Neuman, 2000; Burges, 2002). 
En este caso, habría que establecer si la sola lectura es suficiente para estimular el desarrollo de la alfabetización o si esta lectura debe tener ciertas características que la hagan más efectiva en el sentido de la promoción de ciertas conductas y habilidades en el niño más relacionadas con dicho desarrollo. Autores como De Temple (2001), Dickinson (2001), Rocha y Vega (2002) establecen que son ciertos tipos de interacción durante la lectura de los cuentos los que hacen más probable un mayor desarrollo de la alfabetización en los niños.

En general, son aquellas interacciones que estimulan la formación de inferencias y predicciones y que relacionan el contenido del texto con las experiencias cotidianas de los niños las que favorecen más el desarrollo de la alfabetización. Las madres de la presente muestra tendieron a establecer interacciones más relacionadas con el aquí y ahora, pidiendo a los niños respuestas descriptivas respecto de características de los personajes o detalles de la historia. Hubo algunos casos, como el del padre que se presenta en el extracto del cuadro 9 de los resultados, en el que sí existen cuestionamientos que permiten al niño reflexionar sobre el contenido de la historia. El papel del tipo de interacción se corrobora al analizarse los resultados de los niños que se utilizaron para obtener datos longitudinales del desarrollo de la alfabetización, ya que como se mencionó anteriormente, las madres de los niños que tuvieron los puntajes más altos en el desarrollo de la alfabetización tendían a tener el tipo de interacción que más promueve este desarrollo.

Los materiales y actividades relacionados con la lectura en el hogar no tuvieron relación con la misma. Esto puede deberse a que si bien se reporta la realización de estas actividades, no se tuvo la oportunidad de observar si efectivamente se llevan a cabo como se reportan y por otra parte y muy importante, no se tuvo evidencia del grado de participación de los niños en estas actividades. Este aspecto en particular ha sido considerado fundamental por los autores que establecen la relación entre las actividades en el hogar y el desarrollo de la alfabetización (Mc Gee y Richgels, 1991; Dahl y Freepon, 1995; Purcell-Gates, 1996; Jordan, Snow y Porsche, 2000; Morrow, 2001; Britto, 2001). Hubiera sido necesario realizar observaciones en el hogar para establecer si es la sola presencia de estas actividades la que se relaciona con el desarrollo de la alfabetización o además de ella, el nivel de participación de los niños. Sin embargo, a través de las actividades más y menos frecuentes que se observan en los cuestionarios se puede identificar que las actividades de lectura consisten en leerle y modelarle actividades de lectura; pero no en hacerlo par- 
ticipar activamente, por ejemplo, pidiéndole que lea o comentando sus lecturas. Por otra parte, las actividades incluidas en el cuestionario se basaron en la literatura revisada; pero no pueden representar toda la gama de actividades que se realizan cotidianamente y que pueden estimular el desarrollo de la alfabetización.

3) Existen algunas relaciones entre las variables independientes que merecen ser discutidas.

Se observa una alta correlación entre la edad de los niños y las habilidades lingüísticas en el lenguaje oral, lo cual es hasta cierto punto esperado, ya que los niños más grandes deben tener un mayor desarrollo del lenguaje al haber tenido mayor oportunidad de interactuar con él. La edad de los niños también correlaciona significativamente con la lectura de cuentos por parte de las maestras lo cual puede querer decir que, a medida que los niños son mayores, las maestras ponen mayor énfasis en los aspectos que hacen distintivo al lenguaje escrito durante la lectura de los cuentos. Esto se observa comparando la lectura de las maestras de los niños maternales y de las de tercero de preescolar, ya que en el caso de las primeros, la lectura se parece más a la narración y de las última a la lectura.

La escolaridad de los padres se relaciona también de manera significativa con la lectura de cuentos por las maestras, y a su vez esta última con las actividades de lectura que se realizan en los hogares, lo que puede querer decir que los padres de mayor escolaridad se interesan más en tener intercambios con las educadoras, que les permitan conocer las actividades que realizan sus hijos en la escuela y tratar de complementarlas mediante actividades relacionadas con la lectura en el hogar. Burges (2002) menciona que el nivel socioeconómico de los padres representa un conglomerado de actitudes, actividades y oportunidades que se relacionan con el interés que se tiene por la lectura y la manera de promoverla en los niños.

La escolaridad de los padres tiene relación con los materiales y las actividades de lectura que se llevan a cabo en el hogar. Lo que significa que a mayor escolaridad los padres tienen mayor interés en proveer a sus hijos de materiales que les permitan interactuar con el lenguaje escrito. Igualmente llevan a cabo más actividades relacionadas con el mismo e incluso pueden ellos mismos servir como modelos. La relación entre la escolaridad de los padres y la frecuencia y variedad de actividades de lectura ha sido establecida por Baker, Soneschein, Serpell y Scher (1996); Sanders, Gerson, Huffman y Mendoza (2000) y Castillo y Luna (2002). 
$\mathrm{Al}$ analizar los resultados descriptivos respecto de estas variables se puede ver que en los hogares de los padres entrevistados existe una variedad de materiales de lectura al alcance de los niños en el hogar y que los materiales que se encuentran con mayor frecuencia son los que tradicionalmente se considera que pueden proveer el conocimiento del lenguaje escrito (cuentos, libros y revistas para niños y papel, crayolas y colores) en tanto que los materiales de uso cotidiano no fueron mencionados por los padres como materiales que permiten promover este desarrollo. En la concepción del desarrollo de la alfabetización, cualquier material impreso de uso cotidiano puede ser utilizado para favorecer el conocimiento del lenguaje escrito (Goodman, 1986b; Saint Laurent, Giasson y Couture, 1997).

Por otra parte, las actividades más frecuentes relacionadas con la lectura en el hogar consideran actividades de lápiz y papel como dibujar y escribir con el niño manipulando letras o palabras (es decir, nuevamente actividades que se parecen a las actividades escolarizadas, en una aproximación de habilidades (Dahl y Freepon, 1995; Nielsen y Monson, 1996; Baker, Sonneschein, Serpell y Scher, 1996; Sonnenschein, Baker, Sarpell y Schmidt, 2000). La segunda actividad más frecuente, leer letreros por la calle, ha sido señalada como una actividad que efectivamente es muy útil para promover el desarrollo de la alfabetización ya que permite al niño conocer tanto las características del lenguaje escrito como su utilidad y su relación con la vida cotidiana (Ferreiro, 1998; Saint Laurent, Giasson y Couture, 1997).

La escolaridad de los padres también correlaciona significativamente con el desarrollo de las habilidades lingüísticas orales, lo que puede relacionarse con un discurso más completo y variado en los hogares de los padres que tienen mayor escolaridad y esto a su vez, relacionarse con el desarrollo de las habilidades lingüísticas (Snow, Tabors y Dickinson, 2001). Además, la correlación significativa de la escolaridad de los padres con los materiales y actividades de lectura en el hogar y a su vez con las habilidades lingüísticas pudiera querer decir que los padres, a través de los materiales y actividades de lectura están estimulando el desarrollo del lenguaje oral en sus hijos, promoviendo así el desarrollo de la alfabetización (Mc Gee y Richgels, 1990; Soderman, Gregory y O’Neill, 1999; Snow, Tabors y Dickinson, 2001) y que esto ocurre más a medida que los padres tienen mayor escolaridad. 
4) Los resultados de los análisis de regresión realizados, eliminando la edad y para cada grupo de edad, corroboran la contribución de las habilidades lingüísticas y la lectura de cuentos por las maestras.

Al realizarse el análisis de regresión, excluyendo a la edad de los niños como variable independiente se puede observar nuevamente que las variables responsables de la varianza en el desarrollo de la alfabetización se conservan, esto es, las habilidades lingüísticas orales y la lectura de cuentos por la maestra siguen siendo las variables que permiten predecir el desarrollo de la alfabetización.

Las variables incluidas en el modelo de regresión en el análisis general se conservan al hacerse el análisis por edades. Para los niños más pequeños se conservó la variable habilidades lingüísticas orales y para los niños de 48 a 60 meses se conservó tanto esta variable como la lectura de cuentos por la maestra. Para los de 60 a 75 meses la variable responsable fue los materiales de lectura en el hogar. Este panorama puede evidenciar la aproximación que los niños van teniendo a la instrucción en la lectura, lo que podría relacionarse con una concepción tradicional de padres y maestras de la adquisición de la lectura y con el hecho de que los padres se involucran más en las actividades de alfabetización a medida que los niños se aproximan a la alfabetización convencional. Adicionalmente, puede ser que los niños tengan mayor facilidad para acceder a los materiales de lectura en virtud de que dado su nivel de desarrollo es más fácil relacionarse con ellos y manipularlos.

\section{Conclusiones}

Se lograron los objetivos de la investigación al establecerse:

$\boldsymbol{\nabla}$ Las características por edad en la progresión en el desarrollo de la alfabetización de los niños de la muestra estudiada.

$\boldsymbol{\nabla}$ La contribución de cada una de las variables analizadas al desarrollo de la alfabetización, así como la contribución de las variables en su conjunto.

El patrón de desempeño en las habilidades lingüísticas en el lenguaje oral es el mismo para todas las edades, y se observa una secuencia de desarrollo en dichas habilidades. 
Los niños han logrado construir conocimiento acerca del lenguaje escrito aun sin haber recibido instrucción formal y también se observa una secuencia de desarrollo en este desempeño.

El desarrollo de la alfabetización se hace evidente tanto en los conceptos que los niños manejan acerca del texto impreso, como en el manejo de los convencionalismos del lenguaje escrito que se observan a través de la lectura de cuentos y de sus producciones escritas.

Las variables que contribuyen a la varianza en el desarrollo de la alfabetización, en la muestra estudiada fueron:

$\mathbf{v}$ Las habilidades lingüísticas orales (fonológicas y semánticas).

$\boldsymbol{\nabla}$ La lectura de cuentos por parte de las educadoras.

$\boldsymbol{\nabla}$ La edad de los niños, que se relaciona con su nivel de desarrollo general.

La escolaridad de los padres se relaciona con los materiales y actividades de lectura al alcance de los niños en el hogar y con las habilidades lingüísticas orales, lo que puede querer decir que a través de estos materiales los padres estimulan el desarrollo del lenguaje oral y dada la estrecha relación entre los dos sistemas de lenguaje, el desarrollo de la alfabetización.

Es necesario examinar con mayor detalle la relación de los materiales y actividades de lectura en el hogar con el desarrollo de la alfabetización, ya que las técnicas utilizadas en la investigación que aquí se reporta no permitieron identificar aquellos aspectos de estas variables responsables de la relación que se reporta en la literatura.

Por otra parte, se requiere realizar un análisis más preciso de la relación existente entre el tipo de interacción que se produce durante la lectura de cuentos en el hogar y el desarrollo de la alfabetización en los niños, ya que aunque los resultados individuales proporcionaron indicios de esta relación, no se estableció como relación significativa.

Es preciso aclarar que los resultados obtenidos son aplicables a la muestra estudiada y que se requiere replicar el estudio con otras muestras de niños, padres y maestros cuyas características sean diferentes para poder establecer la posibilidad de generalización de los resultados, aunque los resultados obtenidos se encuentran documentados en la literatura, por ejemplo: el papel del lenguaje oral, la construcción de conocimientos respecto del lenguaje escrito, el papel del escenario preescolar. 
Con base en estos resultados, se puede concluir que los programas encaminados a la promoción del desarrollo de la alfabetización, en principio, deberían promover las habilidades lingüísticas orales en los niños, así como la lectura de cuentos en los escenarios preescolares y en el hogar, privilegiando una interacción que vaya más allá del aquí y ahora, promoviendo en los niños la elaboración de predicciones, conclusiones e inferencias y relacionando sus experiencias cotidianas con el contenido de los cuentos.

\section{Limitaciones}

Las limitaciones de la presente investigación se refieren básicamente al tamaño y la representatividad de la muestra. Dado que el muestreo fue intencional, los resultados no pueden generalizarse a la población de niños preescolares. Sin embargo, estos resultados corroboran lo encontrado en el estudio piloto que se instrumentó para probar los instrumentos y procedimientos a utilizar. En este estudio (Macotela y Vega, 2005) se obtuvo como resultado la identificación de las mismas variables como responsables de la mayor parte de la varianza en el desarrollo de la alfabetización.

Adicionalmente, los padres que permitieron que se les observara durante la lectura de cuentos pueden tener características que los hagan diferentes al resto de la población en virtud de su participación voluntaria en el estudio. Estos padres pueden estar más interesados en promover el desarrollo de la alfabetización de sus niños que los padres que no aceptaron ser observados, o bien, pueden estar más acostumbrados a dicha lectura o pueden querer recibir asesoría como producto de su participación en el estudio, que de hecho ocurrió mediante una plática en la que se presentaron los resultados a personal y padres de la dos instituciones y se repartieron sugerencias por escrito tanto a las maestras como a los padres. Adicionalmente, se entregó un reporte por escrito a cada institución.

No se realizaron observaciones sistemáticas que permitieran constatar el ambiente ni las actividades de alfabetización en el salón de clases, aunque se posee información incidental ya que se trabajó dentro de los salones. No se realizaron observaciones en el hogar que permitieran corroborar y complementar la información proporcionada en los cuestionarios y el grado de participación de los niños en las actividades relacionadas con la lectura en el hogar. 


\section{Aportaciones}

Considerando las limitaciones mencionadas, este trabajo aporta datos empíricos acerca de la relación del desarrollo de la alfabetización con el desarrollo en el lenguaje oral y las variables del hogar, así como el papel de la lectura de cuentos por madres y maestras.

Los resultados encontrados permiten constatar algunas de las relaciones establecidas previamente, tanto por los fundamentos teóricos, como por la evidencia empírica que sirvió de marco de referencia al presente trabajo: La estrecha relación entre el lenguaje oral y el lenguaje escrito, la relación entre las actividades en el hogar y el lenguaje oral, el papel de la interacción de maestras y niños durante la lectura de cuentos en el desarrollo de la alfabetización y la estrecha relación entre el desarrollo del niño y su desarrollo de la alfabetización.

Otros resultados, que no ocurrieron conforme a lo esperado, permiten constatar que las relaciones entre las variables son más complejas de lo que pudiera concluirse a partir de la literatura. Estos hallazgos plantean la necesidad de identificar aspectos más específicos, por ejemplo, en la relación entre las variables del hogar y el desarrollo de la alfabetización.

Los resultados obtenidos plantean la necesidad de investigación futura, que permita:

Replicar este estudio con otras muestras para determinar si las relaciones encontradas se corroboran.

Esclarecer el papel de la participación de los niños en las actividades relacionadas con la lectura y la escritura en el hogar. Así como identificar una mayor variedad de actividades relacionadas con la lectura en el hogar.

Analizar el tipo de relación que se presenta durante la lectura de cuentos y su relación con el desarrollo de la alfabetización, tanto en general, como con aspectos específicos del mismo.

Establecer la relación entre la estimulación que se da al desarrollo del lenguaje oral en el hogar y el desarrollo de la alfabetización.

Analizar la relación entre el ambiente en la escuela y el hogar que permita que se complementen para la creación de un ambiente rico en experiencias que promueva un desarrollo más exitoso.

Este estudio aporta elementos que permiten esclarecer la relación entre las variables estudiadas y el desarrollo de la alfabetización en los niños preescolares. Esta aportación permitirá, en principio, considerar los aspectos que acentuarse al realizarse acciones encamina- 
das a promover el desarrollo de la alfabetización en niños preescolares. Con base en los resultados presentados, los aspectos a enfatizar se refieren a la promoción del desarrollo en el lenguaje oral, enfatizándose la conciencia fonológica y la codificación semántica y la promoción de la lectura de cuentos en los escenarios preescolares, considerando el tipo de interacción que promueve el desarrollo de la alfabetización.

Las acciones que se realicen, fundamentadas en los resultados de la investigación revisten un valor preventivo muy importante al hacer más probable que el desempeño en la lectura y escritura convencionales sea exitoso. 


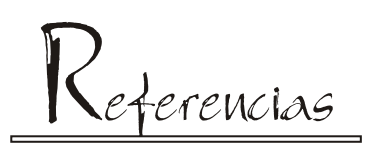

Ary, D., Jacobs, L. y Razavieh, A. (1993). Introducción a la investigación pedagógica (2a ed.). México: Mc Graw Hill.

Athey, I. (1983). Language development factors related to reading development. Journal of Educational Research, 76 (4), 197-203.

Ball, E. y Blachman, B. (1991). Does phoneme awareness training in kindergarten make a difference in early word recognition and developmental spelling? Reading Research Quarterly, 25 (3), 49-66.

Baker, L., Sonnenschein, S., Serpell, R. y Scher, D. (1996). Early literacy at home: Children's experiences and parents' perspectives. The Reading Teacher, 50 (1), 70-74.

Bakerman, R. y Gottman, J. M. (1989). Observación de la interacción. Introducción al análisis secuencial. Madrid, España: Morata.

Barratt-Pugh, C. (2000). The sociocultural context of literacy learning. En C. Barrath-Pugh y M. Rohl (Eds.), Literacy learning in the early years. Philadelphia, PA, EE. UU.: Open University Press.

Baumann, J. F. y Thomas, D. (1997). "If you can pass momma's tests, then she knows you are getting your education": A case study of support for literacy learning within an African American family. The Reading Teacher, 51 (2), 108-120. 
Britto, P. R. (2001). Family literacy environments and young children's emergent literacy skills. Reading Research Quarterly, 36 (4), 346-348.

Burgess, S. (2002). Shared reading correlates of early reading skills. Reading Online, 5 (7). Extraido de: http://www.readingonline.org/articles/art_index.asp?HREF $=$ burgess/index.html

Castillo, A. Y. y Luna, A. J. (2002). La lectura y el contacto con libros en etapas tempranas (Estudio con familias de niños de uno a cuatro años de diferentes medios socioculturales). Memorias del VII Congreso Latinoamericano para el Desarrollo de la Lectura y la Escritura (pp. 397-402). México: SEP.

Clay, M. (1989). Prólogo a D. S. Strickland y L. M. Morrow (Eds.), Emergent literacy: Young children learn to read and write. Newark, NJ, EE. UU.: International Reading Association.

Clay, M. (1991). Becoming Literate: The construction of inner control. Portsmouth, NH, : Heinemann.

Clay, M. (1993). An observation survey of early literacy achievement. Portsmouth, NH, : Heinemann.

Coles, G. (1989). Excerpts from the learning mystique: A critical look at learning disabilities. Journal of Learning Disabilities, 22, 267-277.

Collins, C., Oakar, M. y Hurt, N. (2002). The expertise of literacy teachers: A continuum from preschool to grade 5. Reading Research Quarterly, 37 (2), 178-197.

Corley, P. (1988). A developmental analysis on sentences comprehension abilities in good and poor readers. Educational Psychologist, 23 (1), 57-75.

Curtis, M. (1980). Development of components of reading skill. Journal of Educational Psychology, 72 (5), 656-669.

Dahl, K. y Freepon, P. (1995). A comparison of innercity children's interpretations of reading and writing instruction in the early grades in skills based and whole language classrooms. Reading Research Quarterly, 30 (1), 50-74.

De Temple, J. (2001). Parents and children reading books together. En D. K. Dickinson y P. O. Tabors (Eds.), Beginning literacy with language. Baltimore, MD, EE. UU.: Paul H. Brookes. 
Díaz, R. (1995). La puntuación en la escritura de los niños de educación primaria. Un estudio psicogenético. Tesis de Maestría en Educación. Facultad de Pedagogía, Universidad de Colima.

Dickinson, D. K. (2001). Book reading in preschool classrooms: Is recommended practice common. En D. K. Dickinson y P. O. Tabors (Eds.), Beginning literacy with language. Baltimore, MD, EE.UU.: Paul H. Brookes.

Dickinson, D. K. y Smith, M. W. (1994). Long-term effects of preschool teachers' book readings on low income children's vocabulary and story comprehension. Reading Research Quarterly, 29 (2), 104-122.

Dixon-Krauss, L. (1997). Vigotsky in the classroom. Mediated literacy instruction and assessment. EE. UU.: Longman.

Durkin, D. (1980). Teaching young children to read (3a ed.). Boston, MA, EE. UU.: Allyn and Bacon.

Ehri, L. C., Nunes, S., Willows, D. M., Schuster, B. V., Zadeh, Z. Y. y Shanan, T. (2001). Phonemic awareness instruction helps children learn to read: Evidence from National Reading Panel's meta-analysis. Reading Research Quarterly, 36 (3), 250-287.

Escamilla, K., Andrade, A., Basurto, A. y Ruiz, O. (1996). Instrumento de observación de los logros de la lectoescritura inicial. Portsmouth, NH, : Heinemann.

Favila, A. y Seda, I. (2006). Efectos de un programa de entrenamiento en conciencia fonológica para niños con retraso lector. En L. Vega y cols. (Eds.), Alfabetización: Retos y perspectivas (pp. 197-209). México: UNAM.

Ferreiro, E. (1998). Alfabetización. Teoría y práctica (3a ed.). México: Siglo XXI.

Ferreiro, E. y Teberosky, A. (1987). Los sistemas de escritura en el desarrollo del niño. México: Siglo XXI.

Fields, M. y Spangler, K. (2000). Let's begin reading right. A developmental approach to emergent literacy ( $4^{\mathrm{a}}$ ed.). Upper Saddle River, NJ, EE. UU.: Prentice Hall.

Gárate, M. (1994). La comprensión de cuentos en los niños. Un enfoque cognitivo y sociocultural. Madrid, España: Siglo XXI.

Garton, A. y Pratt, C. (1991). Aprendizaje y proceso de alfabetización. El desarrollo del lenguaje hablado y escrito. Barcelona, España: Paidós. 
Gillet, J., Temple, C. (1994). Understanding reading problems (4 ed.). New York, NY, EE. UU.:Harper Collins.

Glazer, S. M. (1989). Oral language and literacy development. En D. S. Strickland y L. S. Morrow (Eds.), Emergent literacy: Young children learn to read and write. Newark, NJ, EE. UU.: International Reading Association.

Goldrine, T. y Vega, L. (1999). Evolución de las habilidades precurrentes de lectura en niños preescolares. Memorias del XIX Foro Nacional de Educación Preescolar (pp. 1-12). México: Trillas.

Göncü, A. y Katsarou, E. (2000). Constructing sociocultural approaches to literacy education. En K. A. Roskos y J. F. Christie (Eds.), Play and literacy in early childhood. Research from multiple perspectives. Hillsdale, NJ, EE. UU.: Lawrence Erlbaum Associates.

Goodman, K. (1986a). El proceso de lectura: Consideraciones a través de las lenguas y el desarrollo. En E. Ferreiro y M. Gómez (Comp.), Nuevas perspectivas sobre los procesos de lectura y escritura (4a ed.). México: Siglo XXI.

Goodman, K. (1986b). El lenguaje integral. Buenos Aires, Argentina: Aique.

Goodman, Y. (1986). El desarrollo de la escritura en niños muy pequeños. En E. Ferreiro y M. Gómez (Comp.), Nuevas perspectivas sobre los procesos de lectura y escritura ( $4^{\mathrm{a}}$ ed.). México: Siglo XXI.

Hall, N. (1987). The emergence of literacy. Portsmouth, NH, EE. UU.: Heinemann.

Harste, J. C., Woodward, V. A y Burke, C. L. (1984). Language stories and literacy lessons. Portsmouth, $\mathrm{NH}$, : Heinemann.

Hernández, I. y Jiménez, J. (2001). Conciencia fonémica y retraso lector: ¿Es determinante la edad en la eficacia de la intervención? Infancia y Aprendizaje, 20 (3), 379- 395.

Huba, M., Robinson, S. y Kontos, S. (1989). Prereaders understanding of the purposes of print and subsequent reading achievement. Journal of Educational Research, 82 (4), 210-215.

International Reading Association y National Association for the Education of Young Children. (1998). Learning to read and write: Developmentally appropiate practices for young children. Young Children. EE. UU.:Autores. 
Instituto de Seguridad y Servicios Sociales para los Trabajadores del Estado. (1984). Programa integral educativo. México: Autor.

Jacobo, H. M., Velázquez, M. L., Martínez, M. S., Mendoza, M. J. y Verdugo, I. (2002). La reflexión metalingüística y la construcción de la conciencia fonológica como prerrequisito para el aprendizaje de la lectoescritura. Un programa de intervención pedagógica para niños y niñas preescolares. Memorias del VII Congreso Latinoamericano para el Desarrollo de la Lectura y la Escritura (pp. 161-165). México: SEP.

Jiménez, J. (1992). Metaconocimiento fonológico. Estudio descriptivo sobre una muestra de niños prelectores en edad preescolar. Infancia y Aprendizaje, 57, 49-65.

Jordan, G. E., Snow, C. E., y Porsche, M. V. (2000). Project EASE: The effect of a family literacy project on kindergarten students' early literacy skills. Reading Research Quarterly, 35 (4), 524-546.

Justice, L. M. y Kadaraveck, J. (2002). Using shared storybook to promote emergent literacy. Council for Exceptional Children, 34 (4), 8-14.

Katz, D. (1953). Los estudios de campo. En L. Festinger y D. Katz (Comp.), Los métodos de investigación en ciencias sociales. Barcelona, España: Paidós.

Kerlinger, F. y Lee, H. (2002). Investigación del comportamiento. Métodos de investigación en ciencias sociales ( $4^{\text {a }}$ ed.). México: McGraw Hill.

Levin, I. y Tolchinsky, L. (1989). Becoming literate: referential and phonetic strategies in early reading and writing. International Journal of Behavioural Development, 12 (3), 369-384.

Lozada, R. y Vega, L. (2002, octubre) Estimulación de la narrativa oral en niños preescolares. Ponencia presentada en el X Congreso Mexicano de Psicología. Acapulco, México.

Macotela, S., Bermúdez, P. y Castañeda, I. (1991). Inventario de Ejecución Académica (IDEA) [Versión revisada]. México: Facultad de Psicología, UNAM.

Mason, J. A. (1980). When do children begin to read: An exploration of four year old children's letter and word reading competencies. Reading Research Quarterly, 15, 203-225.

McGee, L. y Richgels, D. (1990). Literacy's beginnings. Supporting young readers and writers. Boston, MA, EE. UU.: Allyn and Bacon. 
Miller, W. (2000). Strategies for developing emergent literacy. EE. UU.: McGraw Hill.

Morrow, L. M. (2001). Literacy development in the early years. Helping children read and write ( $4^{\mathrm{a}}$ ed.). Boston, MA, EE. UU.: Allyn and Bacon.

Morrow, L. M., O'Connor, E. M. y Smith, J. K. (1990). Effects of a storyreading program on the literacy development of at-risk kindergarten children. Journal of Reading Behavior, XXII (3), 255-275.

Nation, K. y Hulme, C. (1997). Phonemic segmentation, not one set rime segmentation predicts early reading and spelling skills. Reading Research Quarterly, 32 (2), 154-167.

Neuman, S. B. (2000). Social contexts for literacy development: A family literacy program. En K. A. Roskos y J. F. Christie (Eds.), Play and literacy in early childhood. Research from multiple perspectives. New Jersey, NY, EE. UU.: Lawrence Erlbaum.

Nielsen, D. y Monson, D. (1996). Effects of literacy environment on literacy development of kindergarten children. Journal of Educational Research, 89 (5), 259-271.

Nunnally, J. C. (1987). Teoría psicométrica. México: Trillas.

Nunnally, J. C. y Bernstein, I. J. (1995). Teoría psicométrica (3ª ed.). México: McGraw Hill.

Padua, J. (1987). Técnicas de investigación aplicadas a las ciencias sociales. México: FCE.

Papalia, D. E., Olds, S. W., Feldman, R. D. (2001). Psicología del desarrollo (8a ed.). Bogotá, Colombia: McGraw Hill.

Peters, S. J. (1993). Where have the children gone? Storyreading in kindergarten and prekindergarten classes. Early child development and care, 88, 1-15.

Phillips, L., Walker, L. (1987). Three views of language and their influence on instruction in reading and writing. Educational Theory, 37 (2), 135-143.

Pintado, J. (1999). El proceso de construcción de la lectoescritura en el niño preescolar. Mecanograma. México: Facultad de Psicología, UNAM. 
Purcell-Gates, V. (1996). Stories, coupons and the TV Guide. Relationships between home literacy and emergent literacy knowledge. Reading Research Quarterly, 20 (4), 406-428.

Reese, E. y Cox, A. (1999). Quality of adult book reading affects children's emergent literacy. Developmental Psychology, 35 (1), 20-28.

Reitsma, P. (1984). Sound priming in beginning readers. Child Development, 55, 406-423.

Rivalland, J. (2000). Linking literacy learning across diferent contexts. En C. Barrath-Pugh y M. Rohl (Eds.), Literacy learning in the early years. Philadelphia, PA, EE. UU.: Open University Press.

Roberts, B. (1992). The evolution of the child's concept of word as a unit of spoken and written language. Reading Research Quarterly, 20 (4), 124-138.

Rocha, G., y Vega, L. (2002, octubre). Capacitación a maestras en estrategias para el desarrollo de habilidades de prelectura en niños preescolares. Ponencia presentada en el X Congreso Mexicano de Psicología. Acapulco, México.

Rogoff, B. (1993). Aprendices del pensamiento: El desarrollo cognoscitivo en el contexto social. Barcelona, España: Paidós.

Rohl, M. (2000). Learning about words, sounds and letters. En C. Barrath-Pugh y M. Rohl (Eds.), Literacy learning in the early years. Philadelphia, PA, EE. UU.: Open University Press.

Rosenhouse, J., Feitelson, D., Kita, B., Goldstein, Z. (1997). Interactive readings to Israeli first graders: Its contribution to literacy development. Reading Research Quarterly, 32 (2), 168-183.

Rubin, A. (1980). A theoretical taxonomy of the differences between oral and written language. En R. Spiro, B. Bertram y W. Brewer (Eds.), Theoretical issues in reading comprehension. Perspectives from cognitive psychology, linguistics, artificial intelligence and education. Hillsdale, NJ, EE. UU.: Lawrence Erlbaum Associates.

Rumelhart, D. E. (1980). Schemata: The building blocks of cognition. En R. Spiro, B. Bertram y W. Brewer (Eds.), Theoretical issues in reading comprehension. Perspectives from cognitive psychology, linguistics, artificial intelligence and education. Hillsdale, NJ, EE. UU.: Lawrence Erlbaum Associates. 
Saint-Laurent, L., Giasson, J. y Couture, C. (1997). Parents + Children + Reading activities $=$ Emergent literacy. Teaching Exceptional Children, 30 (2), 52-59.

Sanders, L., Gershon, T., Huffman, L. y Mendoza, F. (2000). Prescribing books for immigrant children: A pilot study to promote emergent literacy among the children of Hispanic immigrants. Archives of Pediatric and Adolescent Medicine, 154 (8), 771-777.

Secretaría de Educación Pública. (1992). Programa de educación preescolar. México: Autor.

Secretaría de Educación Pública. (2001). Programa nacional de educación 2001-2006. México: Autor.

Secretaría de Educación Pública. (2004). Programa de educación preescolar. México: Autor.

Seda, I. (1996). Lengua escrita: evolución teórica desde Piaget. Pedagogía, XI (6), 4-13.

Seda, I. y Pearson, D. (1991). Interviews to assess learners' outcomes. Reading Research and Instruction, 31 (1), 22-32.

Serie "Manchitas". (1983). México: Trillas.

Schnikedanz, J. A. (1989). The place of specific skills in preschool and kindergarten. En D. S. Strickland y L. M. Morrow (Eds.), Emergent literacy: Young children learn to read and write. Newark, NJ, EE. UU.: International Reading Association.

Sheridan, C. (2000). Children's literature and literacy learning. En C. Barratt-Pugh y M. Rohl (Eds.), Literacy learning in the early years. Philadelphia, PA, EE. UU.: Open University Press.

Siegel, S. (1985). Estadística no paramétrica. México: Trillas.

Smith, M. (2001). Children's experiences in preschool. En D. K. Dickinson y P. O. Tabors (Eds.), Beginning literacy with language. Baltimore, MD, EE. UU.: Paul H. Brookes.

Soderman, A. K., Gregory, K. M. y O’Neill, L. T. (1999). Scaffolding emergent literacy. A child-centered approach for preschool trough grade 5. Boston, MA, EE. UU.: Allyn and Bacon.

Sonnenschein, S., Baker, L., Serpell, R. y Schmidt, D. (2000). Reading is a source of entertainment: The importance of the home perspective for children's literacy development. En K. A. Roskos y J. F. Christie (Eds.), Play and literacy in early childhood. 
Research from multiple perspectives. Hillsdale, NJ, EE. UU.: Lawrence Erlbaum Associates.

Snow, C. E., Tabors, P. O. y Dickinson, D. K. (2001). Language development in the preschool years. En D. K. Dickinson y P.O. Tabors (Eds.), Beginning literacy with language. Baltimore, MD, EE. UU.: Paul H. Brookes.

Strickland, D. S. y Taylor, D. (1989). Family storybook reading: Implications for children, families and curriculum. En D. S. Strickland y L. M. Morrow (Eds.), Emergent literacy: Young children learn to read and write. Newark, NJ, EE. UU.: International Reading Association.

Sulzby, E. (1985). Children's emergent reading of favorite storybooks: A developmental study. Reading Research Quarterly, 20 (4), 458-481.

Sulzby, E., Barnhart, J. y Hiesima, J. (1990). Forms of writing and reading from writing: A preliminary report. En J. Mason (Comp.), Reading and writing connections. Boston, MA, EE. UU.: Allyn and Bacon.

Tabors, P., Snow, C. y Dickinson, D. (2001). Homes and schools together. Supporting language and literacy development. En D. K. Dickinson y P.O. Tabors (Eds.), Beginning literacy with language. Baltimore, MD, EE. UU.: Paul H. Brookes.

Teale, W. H. y Sulzby, E. (1989). Emergent literacy: New perspectives. En D. S. Strickland y L. M. Morrow (Eds.), Emergent literacy: Young children learn to read and write. Newark, NJ, EE. UU.: International Reading Association.

Thorndike, R. L. y Hagan, E. P. (1989). Medición y evaluación en psicología y educación. México: Trillas.

Tolchinsky, L. y Levin, I. (1987). Writing in four to six-year-olds: Representation of semantic and phonetic similarities and differences. Journal of Child Language, 14, 127-144.

Tummer, W. E., Herriman, M. L. y Nesdale, A. R. (1988). Metalinguistic abilities and beginning reading. Reading Research Quarterly, XXIII (2), 134-157.

Vacc, N. y Ritter, S. (1995). Assessment of preschool children. Eric Digests (071). Extraido de: http://ericae.net/edo/ED389964.htm 
Valencia, S. (1997). Authentic classroom assessment of early reading. Alternatives to standardized tests. Preventing School Failure, 41 (2). 63-71.

Valencia, S. y Sulzby, E. (1991). Assessment of emergent literacy: Storybook reading. The Reading Teacher, 4 (7), 498-500.

Vega, L. (1991a). Instrumento para evaluar habilidades precurrentes de lectura [Manual inédito]. México: Facultad de Psicología, UNAM.

Vega, L. (1991b). Proposición y prueba de un instrumento para evaluar habilidades precurrentes de lectura. Tesis de Maestría en Psicología. Facultad de Psicología, UNAM.

Vega, L. (1998). Instrumento para evaluar habilidades precurrentes de lectura (EPLE). Reporte de su elaboración y análisis psicométrico. Integración. Educación y Desarrollo Psicológico, 10, 9-19.

Vega, L. (2001). Evaluación del desarrollo de la alfabetización en niños preescolares. Alternativas a las pruebas de aprestamiento. Integración: Educación y Desarrollo Psicológico, 15/16, 29-36.

Vega, L. (2002). Análisis del desarrollo de la alfabetización en niños preescolares. Memorias del VII Congreso Latinoamericano para el Desarrollo de la Lectura y la Escritura (pp. 22-28). México: SEP.

Vega, L. (2006). Los años preescolares: Su importancia para promover la competencia lectora y el gusto por la lectura. En L. Vega y cols. (Eds.), Alfabetización: Retos y perspectivas (pp. 13-39). México: UNAM.

Vega, L. y Reyes, J. L. (1998, abril). Habilidades precurrentes de lectura y su relación con el desempeño académico en niños de primaria. Ponencia presentada en el IV Congreso Internacional de Educación. UDLA Puebla, Puebla, México.

Vega, L., Reyes, J. L. y Azpeitia, L. V. (1999). Habilidades precurrentes de lectura en niños de primaria con desempeño normal y con necesidades educativas especiales. Integración: Educación y Desarrollo Psicológico, 11, 67-77.

Vega, L. y Macotela, S. (2005). Alfabetización en niños preescolares: Factores que inciden en su desarrollo. Estudio piloto. Lectura y Vida. XXVI (4), 18-29. 
Vellutino, F. y Scanlon, A. (1982). Verbal processing in poor and normal readers. En C. Brainerd y M. Presley (Eds.), Verbal processes in children. Progress in cognitive development research. New York, NY, EE. UU.: Springer Verbal.

Vernon, S. (1998). Escritura y conciencia fonológica en niños hispano parlantes. Infancia y Aprendizaje, 81, 105-120.

Vigotsky, L. S. (1934/1979). Pensamiento y lenguaje. Teoría del desarrollo cultural de las funciones psíquicas. México: Quinto Sol.

Vukelich, C. (1997). Assessing young children's literacy: Documenting growth and informing practice. The Reading Teacher, 50 (5), 430-434. 


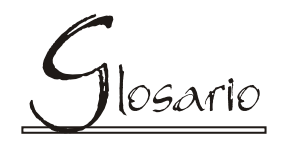

Análisis de Correlación. Análisis estadístico que permite examinar la magnitud y la dirección de la relación que existe entre dos o más variables.

Análisis de Regresión. Procedimiento de análisis estadístico que permite predecir los valores en una variable dependiente, denominada criterio a partir de los valores obtenidos en una variable independiente, denominada predictora.

Análisis de Regresión Múltiple. Permite predecir los valores de una variable dependiente a partir de dos o más variables independientes.

Análisis de Varianza. Procedimiento de análisis estadístico que permite identificar diferencias significativas entre dos o más grupos de personas en algún atributo o característica (variable) de interés.

Análisis de Varianza Paramétrico. Análisis de varianza, que se basa en la suposición de las medidas (parámetros) de la población de la que proceden los participantes en una investigación.

Análisis de Varianza No Paramétrico. Análisis de varianza que no se basa en los parámetros (medidas) de la población de la que proceden los participantes en un estudio o investigación.

Aprestamiento para la lectura: Aquellas habilidades necesarias para que una persona inicie el proceso de aprender a leer.

Codificación semántica: Uso de palabras, frases y oraciones para codificar información significativa. 
Coeficientes de Regresión. Coeficiente obtenido en el análisis de regresión que indica el incremento esperado en la variable dependiente cuando la variable independiente se incrementa en una unidad.

Conciencia de las Palabras. Conciencia que los niños van adquiriendo respecto de las palabras como unidades lingüísticas diferentes a los fonemas y a las frases.

Conciencia Fonológica: Habilidad para escuchar e identificar los sonidos y comprenderlos en el lenguaje oral.

Conciencia metalingüística. Capacidad del niño para reflexionar sobre aspectos del lenguaje que se desarrolla antes de que se enfrente a la instrucción en lectura.

Conciencia sintáctica. Conciencia de la gramática de las oraciones.

Confiabilidad de una lista cotejable. Porcentaje de acuerdo entre dos observadores independientes observando simultáneamente la misma conducta o conjunto de conductas.

Coeficiente de Correlación. Coeficiente que expresa, en un valor numérico, la magnitud y la dirección de la relación entre dos variables.

Coeficiente de Correlación Múltiple ( $\left.\mathbf{R}^{2}\right)$. Coeficiente que indica, en el análisis de regresión la magnitud de la relación entre dos o más variables predictoras (independientes) y una variable criterio (dependiente).

Correlación negativa. Relación entre dos variables, cuya tendencia indica que al incrementarse el valor de una de ellas, disminuye el valor de la otra.

Correlación positiva. Relación entre dos variables, cuya tendencia indica que al incrementarse el valor de la primera, se incrementa el valor de la segunda y viceversa.

Correlación significativa. Valor obtenido en un análisis de correlación, cuya probabilidad de ocurrencia es menor de .05.

Correlación parcial. El grado de relación entre dos variables una vez que se han controlado los efectos de una (o más) tercera(s) variable(s) sobre ambas.

Correlación semiparcial. El grado de relación entre dos variables una vez que se han controlado los efectos de una (o más) tercera(s) variable(s) sobre una de ellas. 
Desarrollo de la Alfabetización: Todos los intentos de los niños por interpretar símbolos, así como para comunicarse mediante ellos, independientemente de que sean texto impreso, garabatos o dibujos. Definida también como: El conocimiento y la conducta de los niños relacionados con la lectura y la escritura cuando aún no son alfabetizados convencionalmente.

Diferencia Significativa. Valor de la diferencia entre dos o más resultados cuya probabilidad de ocurrencia es menor a una probabilidad prefijada por el investigador. Permite concluir que la probabilidad de ocurrencia de los resultados es menor a lo que se hubiera esperado por azar.

Ecuación de Regresión. Ecuación cuya resolución permite obtener cada valor predicho en la variable dependiente, a partir de cada valor de la variable independiente.

Esquema. Estructura que permite representar los conceptos genéricos almacenados en la memoria, de tal manera que contiene la red de interrelaciones que subyacen al concepto en cuestión.

Estudio Piloto. Estudio que se realiza previamente al estudio formal con participantes y procedimientos similares a lo definitivos, con el fin de detectar posibles adecuaciones a los procedimientos de evaluación o de realización del estudio.

Habilidades lingüísticas orales. Definida como la extracción y producción de significado a través del uso de claves fonéticas y semánticas.

Instrucción formal. Instrucción directa sobre los convencionalismos del lenguaje escrito, impartida generalmente al ingreso a la escuela primaria.

Lista cotejable. Listado que permite identificar la ocurrencia y sucesión de las conductas, definidas teórica o empíricamente, necesarias, para llevar a cabo una actividad.

Matriz de correlación. Matriz que muestra las relaciones, en parejas, de todas las variables analizadas.

Media. Promedio de las puntuaciones de un grupo de personas. Suma de los puntajes dividida entre el número de los mismos.

Mediana. Promedio de las puntuaciones de un grupo de personas que indica el puntaje por debajo del cual se ubica el 50\% de los participantes.

Muestreo no probabilístico intencional. Selección de los participantes porque poseen alguna característica deseable para incluirlos en la investigación (Ej. Ser niños preescolares de escuelas públicas). 
Percentil. Cada una de las 100 partes iguales en que puede ser dividida la totalidad de los puntajes. Indica el valor debajo del cual cae un porcentaje dado de los datos.

Selección al azar. Método de selección de los participantes en el que todos los miembros de la población de origen tienen la misma probabilidad de ser seleccionados.

T para muestras independientes. Procedimiento de análisis estadístico que permite identificar diferencias significativas entre dos grupos de personas en alguna propiedad o característica (variable) de interés.

Variable. Propiedad o característica observable de algo que puede fluctuar y cuya variación es susceptible de medirse. Suele representarse mediante un símbolo al que se le asignan valores o números.

Variable Dependiente. Variable en una investigación, que es medida para determinar los efectos de la variable independiente.

Variable Independiente. Variable en una investigación, que es controlada o manipulada de forma sistemática por el investigador. En un análisis predictivo es la variable a partir de la cual se predicen los valores de la variable dependiente. 
Anexos 


\section{ANEXO 1 \\ CUESTIONARIO DE ACTIVIDADES RELACIONADAS CON LA LECTURA QUE SE REALIZA EN EL HOGAR}

(Vega, 2001)

Estimado(a) padre y/o madre de familia:

El presente cuestionario tiene la finalidad de identificar aquellas actividades relacionadas con la lectura que se llevan a cabo en el hogar.

Le rogamos contestar con absoluta veracidad ya que sus respuestas serán absolutamente confidenciales y servirán sólo para fines de investigación.

Agradecemos su colaboración.

NOMBRE DEL NIÑO

GRADO FECHA

CONTESTA EL CUESTIONARIO: PADRE ( ) MADRE ( )

NOMBRE DE QUIEN CONTESTA

\section{INFORMACIÓN SOCIOECONÓMICA}

ESCOLARIDAD DEL PADRE

ESCOLARIDAD DE LA MADRE

INGRESOS

PROMEDIO

MENSUALES

EGRESOS PROMEDIO MENSUALES

\section{MATERIALES DE LECTURA}

Por favor marque aquellos materiales de lectura que se encuentran en su hogar y que están a disposición del niño.

( ) Libros para niños

( ) Libros para adultos

( ) Enciclopedias

( ) Revistas para niños 
( ) Revistas para adultos

( ) Cuentos para niños

( ) Cómics

( ) Catálogos

( ) Periódicos

( ) Circulares

( ) Propaganda diversa

( ) Papel para escribir o dibujar

( ) Lápices

( ) Crayolas o colores

( ) Otros

Especificar:

\section{ACTIVIDADES DE LECTURA}

Marque el número que corresponda en su caso, a la frase que se presenta a la izquierda.

\section{QUÉ SIGNIFICA CADA NÚMERO:}

\section{Diario}

2. Más de una vez por semana

3. Una vez por semana
4. Cada quince días

5. Una vez al mes

6. Menos de una vez al mes

\begin{tabular}{|l|llllll||}
\hline 1. Papá, mamá u otros miembros de la familia leen al niño. & 1 & 2 & 3 & 4 & 5 & 6 \\
\hline 2. El niño lee a papá, mamá u otros miembros de la familia. & 1 & 2 & 3 & 4 & 5 & 6 \\
\hline $\begin{array}{l}\text { 3. El niño observa leer a papá, mamá u otros miembros de la } \\
\text { familia. }\end{array}$ & 1 & 2 & 3 & 4 & 5 & 6 \\
\hline $\begin{array}{l}\text { 4. Papá, mamá u otros miembros de la familia ofrecen al } \\
\text { niño un libro para leer, mientras ellos leen. }\end{array}$ & 1 & 2 & 3 & 4 & 5 & 6 \\
\hline $\begin{array}{l}\text { 5. Papá, mamá u otros miembros de la familia ofrecen al } \\
\text { niño un lápiz y papel cuando ellos escriben. }\end{array}$ & 1 & 2 & 3 & 4 & 5 & 6 \\
\hline $\begin{array}{l}\text { 6. Papá, mamá u otros miembros de la familia leen el conte- } \\
\text { nido de instructivos de juguetes u otros objetos al niño. }\end{array}$ & 1 & 2 & 3 & 4 & 5 & 6 \\
\hline $\begin{array}{l}\text { 7. Papá, mamá u otros miembros de la familia leen al niño el } \\
\text { nombre o contenido de alimentos, medicamentos, u } \\
\text { otros objetos de uso cotidiano. }\end{array}$ & 1 & 2 & 3 & 4 & 5 & 6 \\
\hline $\begin{array}{l}\text { 8. Papá, mamá u otros miembros de la familia leen al niño el } \\
\text { contenido de mensajes enviados por alguno de ellos o } \\
\text { una persona ajena a la familia (Ej. la maestra). }\end{array}$ & 1 & 2 & 3 & 4 & 5 & 6 \\
\hline
\end{tabular}




\begin{tabular}{||l|cccccc||}
\hline $\begin{array}{l}\text { 9. Papá, mamá u otros miembros de la familia explican al } \\
\text { niño los diferentes usos de la lectura y escritura. }\end{array}$ & 1 & 2 & 3 & 4 & 5 & 6 \\
\hline $\begin{array}{l}\text { 10. Papá, mamá u otros miembros de la familia leen al niño } \\
\text { letreros y mensajes que se encuentran en el camino } \\
\text { cuando van por la calle. }\end{array}$ & 1 & 2 & 3 & 4 & 5 & 6 \\
\hline $\begin{array}{l}\text { 11. Papá, mamá u otros miembros de la familia realizan acti- } \\
\text { vidades con el niño que requieran manipular o dibujar } \\
\text { letras o palabras. }\end{array}$ & 1 & 2 & 3 & 4 & 5 & 6 \\
\hline $\begin{array}{l}\text { 12. Papá, mamá u otros miembros de la familia dibujan o es- } \\
\text { criben con el niño. }\end{array}$ & 1 & 2 & 3 & 4 & 5 & 6 \\
\hline $\begin{array}{l}\text { 13. Papá, mamá u otros miembros de la familia leen y co- } \\
\text { mentan los textos escritos por el niño. }\end{array}$ & 1 & 2 & 3 & 4 & 5 & 6 \\
\hline $\begin{array}{l}\text { 14. Algún miembro de la familia visita la biblioteca con el } \\
\text { niño. }\end{array}$ & 1 & 2 & 3 & 4 & 5 & 6 \\
\hline $\begin{array}{l}\text { 15. Papá, mamá u otros miembros de la familia acuden a la } \\
\text { librería con el propósito de comprar libros para el niño. }\end{array}$ & 1 & 2 & 3 & 4 & 5 & 6 \\
\hline
\end{tabular}

IV.

Si usted estuviera de acuerdo en permitir que se le observe en una actividad de lectura de cuentos con su hijo, por favor marque la opción de acuerdo.

( ) De acuerdo
( ) En desacuerdo

Si contestó de acuerdo, por favor especifique el horario (dentro del horario habitual de clases del niño). 


\section{ANEXO 2}

\section{LISTA COTEJABLE PARA LA LECTURA DE CUENTOS POR PARTE DE LOS PADRES}

(Vega, 2001)

NOMBRE DEL NIÑO
EDAD $\quad$ ESCUELA
GRADO_ FECHA
LEE: PADRE ( ) MADRE ( ) OTRA PERSONA
APLICADOR

\begin{tabular}{||l|l||}
\hline \multicolumn{1}{|c||}{ ACTIVIDADES DEL PADRE } & RESPUESTA DEL NIÑO \\
\hline ANTES DE LA LECTURA & \\
\hline Mira el libro y las ilustraciones con el niño. & \\
\hline Modela el uso del libro. & \\
\hline $\begin{array}{l}\text { Discute con el niño el posible contenido del libro, } \\
\text { estimulándolo a hacer predicciones. }\end{array}$ & \\
\hline $\begin{array}{l}\text { Relaciona las experiencias cotidianas del niño con } \\
\text { el posible contenido del cuento. }\end{array}$ & \\
\hline Explica lo que el niño desconoce. & \\
\hline DURANTE LA LECTURA & \\
\hline Narra la historia. & \\
\hline Lee la historia. & \\
\hline Señala las ilustraciones. & \\
\hline $\begin{array}{l}\text { Al leer, sigue con el dedo el texto impreso enfati- } \\
\text { zando qué las palabras son las que cuentan la his- } \\
\text { toria y la dirección de la lectura. }\end{array}$ & \\
\hline $\begin{array}{l}\text { Hace pausas para cuestionar al niño respecto de } \\
\text { palabras conocidas. }\end{array}$ & \\
\hline Hace comentarios y /o preguntas respecto del texto. & \\
\hline
\end{tabular}




\begin{tabular}{|c|c|}
\hline \multicolumn{2}{|l|}{$\begin{array}{l}\text { Hace conexiones entre el texto y los eventos coti- } \\
\text { dianos que el niño conoce. }\end{array}$} \\
\hline Explica lo que el niño no comprende o desconoce. & \\
\hline Estimula al niño a hacer comentarios. & \\
\hline $\begin{array}{l}\text { Hace preguntas sobre el contenido de la historia } \\
\text { (trama). }\end{array}$ & \\
\hline Pregunta los nombres de los personajes. & \\
\hline Pregunta características de los personajes. & \\
\hline $\begin{array}{l}\text { Hace preguntas descriptivas (respecto de los de- } \\
\text { talles al interior de la historia). }\end{array}$ & \\
\hline Se apoya en las ilustraciones. & \\
\hline Muestra el uso del texto (señalando lo que lee). & \\
\hline Estimula al niño a hacer predicciones. & \\
\hline Estimula al niño a anticipar el final de la historia. & \\
\hline Estimula la elaboración de inferencias. & \\
\hline Estimula la predicción del final del texto. & \\
\hline Estimula la elaboración de conclusiones. & \\
\hline Permite al niño que intente leer. & \\
\hline Estimula al niño para que intente leer. & \\
\hline $\begin{array}{l}\text { Explica el significado de las palabras que el niño } \\
\text { desconoce. }\end{array}$ & \\
\hline Responde a las preguntas del niño. & \\
\hline Promueve que el niño intente identificar palabras. & \\
\hline $\begin{array}{l}\text { Promueve que el niño conozca los convenciona- } \\
\text { lismos de la lectura. }\end{array}$ & \\
\hline $\begin{array}{l}\text { Cuando el niño interrumpe, aprovecha las inte- } \\
\text { rrupciones para estimular la comprensión. }\end{array}$ & \\
\hline DESPUÉS DE LA LECTURA & \\
\hline Pregunta al niño si le gustó la historia. & \\
\hline Hace comentarios respecto de la historia. & \\
\hline
\end{tabular}




\begin{tabular}{|l|l||}
\hline $\begin{array}{l}\text { Al comentar la historia, relaciona lo acontecido } \\
\text { en ella con las experiencias cotidianas del niño. }\end{array}$ & \\
\hline $\begin{array}{l}\text { Pide al niño que cuente la historia en sus propias } \\
\text { palabras. }\end{array}$ & \\
\hline $\begin{array}{l}\text { Si al contar la historia el niño se centra sólo en } \\
\text { una o algunas ilustraciones, le instiga por medio } \\
\text { de preguntas o comentarios para que se refiera a } \\
\text { la totalidad de la historia. }\end{array}$ & \\
\hline Pide al niño que relea la historia. & \\
\hline Estimula los intentos del niño por releer la historia. & \\
\hline Si el niño rehúsa leer, lo estimula para que lo intente. & \\
\hline TOTAL & \\
\hline
\end{tabular}




\section{ANEXO 3 \\ LISTA COTEJABLE PARA LA LECTURA DE CUENTOS EN LA ESCUELA}

(Vega, 2001)

\begin{tabular}{|c|c|c|}
\hline ESCUELA & $-c$ & \\
\hline MAESTRA & \multirow{3}{*}{\multicolumn{2}{|c|}{$\begin{array}{l}\text { FECHA } \\
\\
\text { INICIO _ FIN }\end{array}$}} \\
\hline NÚMERO DE NIÑOS PRESENTES & & \\
\hline APLICADOR & & \\
\hline
\end{tabular}

\begin{tabular}{|l|l||}
\hline \multicolumn{1}{|c||}{ ACTIVIDADES DE LA MAESTRA } & \multicolumn{1}{c||}{ RESPUESTA DEL NIÑO } \\
\hline ANTES DE LA LECTURA & \\
\hline $\begin{array}{l}\text { Pide a los niños que seleccionen el libro que les } \\
\text { gustaría que les leyeran. }\end{array}$ & \\
\hline Muestra el título del libro y el nombre del autor. & \\
\hline Mira el libro y las ilustraciones con los niños. & \\
\hline Modela el uso del libro. & \\
\hline $\begin{array}{l}\text { Discute con los niños el posible contenido del li- } \\
\text { bro, estimulándolos a hacer predicciones. }\end{array}$ & \\
\hline $\begin{array}{l}\text { Relaciona las experiencias cotidianas de los niños } \\
\text { con el posible contenido del cuento. }\end{array}$ & \\
\hline Explica lo que los niños desconocen. & \\
\hline DURANTE LA LECTURA & \\
\hline Narra la historia. & \\
\hline Lee la historia. & \\
\hline Señala las ilustraciones. & \\
\hline $\begin{array}{l}\text { Al leer, sigue con el dedo el texto impreso enfati- } \\
\text { zando que las palabras son las que cuentan la his- } \\
\text { toria y la dirección de la lectura. }\end{array}$ & \\
\hline $\begin{array}{l}\text { Hace pausas para cuestionar a los niños respecto } \\
\text { de palabras conocidas. }\end{array}$ & \\
\hline
\end{tabular}




\begin{tabular}{|c|c|}
\hline Hace comentarios y/o preguntas respecto del texto. & \\
\hline $\begin{array}{l}\text { Hace conexiones entre el texto y los eventos coti- } \\
\text { dianos que los niños conocen. }\end{array}$ & \\
\hline $\begin{array}{l}\text { Explica lo que los niños no comprenden o des- } \\
\text { conocen. }\end{array}$ & \\
\hline $\begin{array}{l}\text { Hace preguntas sobre el contenido de la historia } \\
\text { (trama). }\end{array}$ & \\
\hline Pregunta los nombres de los personajes. & \\
\hline Pregunta características de los personajes. & \\
\hline $\begin{array}{l}\text { Hace preguntas descriptivas (respecto de los de- } \\
\text { talles al interior de la historia). }\end{array}$ & \\
\hline Estimula a los niños a hacer comentarios. & \\
\hline Estimula a los a niños a hacer predicciones. & \\
\hline Estimula a los niños a anticipar el final de la historia. & \\
\hline $\begin{array}{l}\text { Estimula el intercambio de experiencias entre los } \\
\text { niños. }\end{array}$ & \\
\hline Estimula la elaboración de inferencias. & \\
\hline Estimula la predicción del final del texto. & \\
\hline Estimula la elaboración de conclusiones. & \\
\hline Permite a los niños que intenten leer. & \\
\hline Estimula a los niños para que intenten leer. & \\
\hline $\begin{array}{l}\text { Explica el significado de las palabras que los niños } \\
\text { desconocen. }\end{array}$ & \\
\hline Responde a las preguntas de los niños. & \\
\hline $\begin{array}{l}\text { Promueve que los niños intenten identificar pa- } \\
\text { labras. }\end{array}$ & \\
\hline $\begin{array}{l}\text { Promueve que los niños conozcan los convencio- } \\
\text { nalismos de la lectura. }\end{array}$ & \\
\hline $\begin{array}{l}\text { Cuando los niños interrumpen, aprovecha las in- } \\
\text { terrupciones para estimular la comprensión. }\end{array}$ & \\
\hline Promueve que todos los niños participen. & \\
\hline
\end{tabular}




\begin{tabular}{|l|l||}
\hline DESPUÉS DE LA LECTURA \\
\hline Pregunta a los niños si le gustó la historia. & \\
\hline Hace comentarios respecto de la historia. & \\
\hline $\begin{array}{l}\text { Al comentar la historia, relaciona lo acontecido en } \\
\text { ella con las experiencias cotidianas de los niños. }\end{array}$ & \\
\hline $\begin{array}{l}\text { Pide a los niños que representen por medio de di- } \\
\text { bujos o palabras lo acontecido en la historia. }\end{array}$ & \\
\hline $\begin{array}{l}\text { Pide a los niños que cuenten la historia en sus } \\
\text { propias palabras. }\end{array}$ & \\
\hline $\begin{array}{l}\text { Si al contar los niños se centran sólo en una o al- } \\
\text { gunas ilustraciones, les instiga por medio de pre- } \\
\text { guntas o comentarios para que se refieran a la to- } \\
\text { talidad de la historia. }\end{array}$ & \\
\hline $\begin{array}{l}\text { Aprovecha la participación de los niños que han } \\
\text { comprendido la historia para reforzar la compren- } \\
\text { sión de los niños que no lo han hecho. }\end{array}$ & \\
\hline $\begin{array}{l}\text { Pide a los niños que relean la historia, dando la } \\
\text { oportunidad de hacerlo a diferentes niños. }\end{array}$ & \\
\hline $\begin{array}{l}\text { Estimula los intentos de los niños por releer la his- } \\
\text { toria. }\end{array}$ & \\
\hline $\begin{array}{l}\text { Si los niños rehúsan leer, los estimula para que lo } \\
\text { intenten. }\end{array}$ & \\
\hline TOTAL & \\
\hline
\end{tabular}




\section{ANEXO 4 \\ CONTENIDO Y CARACTERÍSTICAS PSICOMÉTRICAS DEL INSTRUMENTO PARA EVALUAR HABILIDADES PRECURRENTES PARA LA LECTURA, EPLE}

(Vega, 1991)

\section{Contenido}

\begin{tabular}{|c|c|c|c|}
\hline SUBPRUEBA & DESCRIPCIÓN & REACTIVOS & PUNTOS \\
\hline \multicolumn{4}{|c|}{ CONCIENCIA FONOLÓGICA } \\
\hline $\begin{array}{l}\text { 1. Pronunciación } \\
\text { correcta de } \\
\text { los sonidos } \\
\text { del habla. }\end{array}$ & $\begin{array}{l}\text { Se presenta al niño una serie de } \\
\text { palabras y se le pide que las repita. } \\
\text { Se evalúa la pronunciación co- } \\
\text { rrecta de los fonemas en posi- } \\
\text { ción inicial y final. }\end{array}$ & 15 & 15 \\
\hline $\begin{array}{l}\text { 2. Discriminación } \\
\text { de sonidos } \\
\text { verbales. }\end{array}$ & $\begin{array}{l}\text { Se presentan } 10 \text { pares de palabras } \\
\text { (un par a la vez) que tienen soni- } \\
\text { do igual o bien se diferencian por } \\
\text { sólo uno de los fonemas pronun- } \\
\text { ciados y se pide al niño que diga si } \\
\text { suenan igual o diferente. } \\
\text { Se cuenta el número de respues- } \\
\text { tas correctas. }\end{array}$ & 10 & 10 \\
\hline $\begin{array}{l}\text { 3.1. Análisis } \\
\text { auditivo. }\end{array}$ & $\begin{array}{l}\text { Se presenta } 10 \text { palabras com- } \\
\text { puestas de uso común (una a la } \\
\text { vez) y se pide al niño que las des- } \\
\text { componga en sus componentes. } \\
\text { Se cuenta el número de respuestas } \\
\text { correctas. }\end{array}$ & 10 & 10 \\
\hline $\begin{array}{l}\text { 3.2. Síntesis } \\
\text { auditiva. }\end{array}$ & $\begin{array}{l}\text { Esta prueba constituye una mis- } \\
\text { ma con la anterior. } \\
\text { Se presentan al niño } 10 \text { palabras } \\
\text { compuestas que el experimenta- } \\
\text { dor pronuncia separadas en síla- } \\
\text { bas y el pequeño debe repetirlas } \\
\text { completas. } \\
\text { Se cuenta el número de respues- } \\
\text { tas correctas. }\end{array}$ & 10 & 10 \\
\hline
\end{tabular}




\begin{tabular}{|c|c|c|c|}
\hline SUBPRUEBA & DESCRIPCIÓN & REACTIVOS & PUNTOS \\
\hline \multicolumn{4}{|c|}{ CODIFICACIÓN SEMÁNTICA } \\
\hline $\begin{array}{l}\text { 4. Reconocimien- } \\
\text { to de nombres } \\
\text { ante la presenta- } \\
\text { ción de láminas. }\end{array}$ & $\begin{array}{l}\text { Se presenta una lámina con una } \\
\text { escena familiar común (padre, } \\
\text { madre y niños en la sala) y se le } \\
\text { pide que identifique objetos que } \\
\text { se encuentran en ella (se le se- } \\
\text { nala y se le pregunta qué es } \\
\text { esto). } \\
\text { Se cuenta el número de objetos } \\
\text { identificados. }\end{array}$ & 10 & 10 \\
\hline $\begin{array}{l}\text { 5. Seguimiento } \\
\text { de instrucciones. }\end{array}$ & $\begin{array}{l}\text { Se pide al pequeño que realice } \\
\text { una serie de instrucciones sen- } \\
\text { cillas que se van encadenando. } \\
\text { Se cuenta el número de instruc- } \\
\text { ciones realizadas. }\end{array}$ & 10 & 10 \\
\hline $\begin{array}{l}\text { 6. Conocimiento } \\
\text { del significado } \\
\text { de las palabras. }\end{array}$ & $\begin{array}{l}\text { Se le presentan una serie de pa- } \\
\text { labras comunes y se le pregunta } \\
\text { qué es o cómo es. } \\
\text { Para calificar esta subprueba se } \\
\text { otorgan dos puntos si el niño da } \\
\text { cualquiera de las siguientes res- } \\
\text { puestas: una característica princi- } \\
\text { pal que permita diferenciar clara- } \\
\text { mente al objeto, la mención de la } \\
\text { categoría a la que pertenece el ob- } \\
\text { jeto, dos o más características que } \\
\text { en conjunto den una idea clara } \\
\text { del significado, un sinónimo. } \\
\text { Se otorga un punto si el niño: } \\
\text { menciona alguna característica } \\
\text { que no permita diferenciar cla- } \\
\text { ramente al objeto que se está } \\
\text { definiendo, dos ó más caracte- } \\
\text { rísticas demasiado concretas o } \\
\text { poco relevantes, un uso que no } \\
\text { sea principal. } \\
\text { Se otorgan cero puntos por res- } \\
\text { puestas erróneas o demasiado } \\
\text { vagas. }\end{array}$ & 10 & 20 \\
\hline
\end{tabular}




\begin{tabular}{|c|c|c|c|}
\hline SUBPRUEBA & DESCRIPCIÓN & REACTIVOS & PUNTOS \\
\hline $\begin{array}{l}\text { 7. Comprensión } \\
\text { de sinónimos, } \\
\text { antónimos y } \\
\text { palabras su- } \\
\text { praordinadas. }\end{array}$ & $\begin{array}{l}\text { Esta subprueba consta de tres } \\
\text { partes. } \\
\text { En la primera de ellas se presen- } \\
\text { tan al niño cinco palabras, una } \\
\text { a una y se le pide que diga otra } \\
\text { palabra que sea lo mismo que... } \\
\text { Se cuenta el número de res- } \\
\text { puestas correctas. } \\
\text { En la segunda parte se le pre- } \\
\text { senta al pequeño una palabra } \\
\text { común y se le pide que diga una } \\
\text { palabra que sea lo contrario. En } \\
\text { esta parte se proporciona una } \\
\text { ayuda adicional al niño, al dár- } \\
\text { sele pistas verbales para instigar } \\
\text { la respuesta. Se cuenta el nú- } \\
\text { mero de respuestas correctas. } \\
\text { En la tercera parte se le dicen } \\
\text { tres palabras que pertenecen a } \\
\text { la misma categoría y se le pide al } \\
\text { niño que diga qué son o en qué } \\
\text { se parecen. Se otorgan dos pun- } \\
\text { tos si el niño contesta un concep- } \\
\text { to general que incluya a ambas } \\
\text { palabras, un punto si menciona } \\
\text { propiedades o características que } \\
\text { sean compartidas por ambas, cero } \\
\text { puntos si menciona características } \\
\text { específicas de cada concepto. }\end{array}$ & 15 & 20 \\
\hline $\begin{array}{l}\text { 8. Repetición } \\
\text { de un cuento } \\
\text { captando las } \\
\text { ideas princi- } \\
\text { pales y los } \\
\text { detalles. }\end{array}$ & $\begin{array}{l}\text { Se le lee un cuento y se le pide } \\
\text { que lo repita. } \\
\text { Se cuenta el número de ideas } \\
\text { principales (5) y detalles (5) que } \\
\text { el niño recuerda. }\end{array}$ & 10 & 10 \\
\hline $\begin{array}{l}\text { 9. Diferencia } \\
\text { entre dibujo } \\
\text { y texto. }\end{array}$ & $\begin{array}{l}\text { Se presentan al niño } 5 \text { láminas, } \\
\text { una a la vez, que contienen una } \\
\text { ilustración y un texto referente } \\
\text { a la ilustración y se le pregunta } \\
\text { "señálame dónde dice..." "señá- } \\
\text { lame dónde hay...". } \\
\text { Se cuenta el número de respues- } \\
\text { tas correctas. }\end{array}$ & 10 & 10 \\
\hline
\end{tabular}




\begin{tabular}{||c|l|c|c||}
\hline SUBPRUEBA & \multicolumn{1}{|c||}{ DESCRIPCIÓN } & REACTIVOS & PUNTOS \\
\hline $\begin{array}{c}\text { 10. Expresión } \\
\text { espontánea. }\end{array}$ & $\begin{array}{l}\text { Se pregunta al niño qué estaba } \\
\text { haciendo antes de ir al escena- } \\
\text { rio de evaluación y se registra su } \\
\text { respuesta o bien se aprovecha la } \\
\text { iniciativa del niño al comentar } \\
\text { algún acontecimiento. } \\
\text { En esta subprueba se califican } \\
\text { cinco aspectos: } \\
\text { Uso adecuado de sustantivos, } \\
\text { verbos, adverbios, pronombres } \\
\text { y palabras relacionales. } \\
\text { Vocabulario rico en términos } \\
\text { de número. } \\
\text { Vocabulario rico en términos } \\
\text { de diversidad. } \\
\text { Elaboración gramatical adecuada. } \\
\text { Adecuada secuenciación de ideas. }\end{array}$ & 5 & 10 \\
\hline TOTAL EPLE & \multicolumn{2}{|c||}{115} & 135 \\
\hline
\end{tabular}

Tabla 1. Subpruebas del EPLE, habilidades que miden, reactivos y puntajes posibles.

\section{Confiabilidad}

La confiabilidad del EPLE se determinó mediante el índice Alpha de Cronbach, obteniéndose los siguientes coeficientes:

\begin{tabular}{|c|c|}
\hline SUBPRUEBA & COEFICIENTE ALPHA \\
\hline 1.Pronunciación correcta de los sonidos del habla. & .47 \\
\hline 2. Discriminación de sonidos verbales. & .59 \\
\hline 3.1. Análisis auditivo. & .91 \\
\hline 3.2. Síntesis auditiva. & .91 \\
\hline $\begin{array}{l}\text { 4. Reconocimiento de nombres ante la presentación } \\
\text { de láminas. }\end{array}$ & .48 \\
\hline 5. Seguimiento de instrucciones. & .50 \\
\hline 6. Conocimiento del significado de las palabras. & .49 \\
\hline $\begin{array}{l}\text { 7. Comprensión de sinónimos, antónimos y palabras } \\
\text { supraordinadas. }\end{array}$ & .73 \\
\hline
\end{tabular}




\begin{tabular}{|l|c|}
\hline $\begin{array}{l}\text { 8. Repetición de un cuento captando las ideas prin- } \\
\text { cipales y los detalles. }\end{array}$ & .16 \\
\hline 9. Diferencia entre dibujo y texto. & .83 \\
\hline 10. Expresión espontánea. & .63 \\
\hline TOTAL EPLE & \\
\hline
\end{tabular}

Tabla 2. Coeficientes de confiabilidad para cada subprueba del EPLE. Algunos de los coeficientes de confiabilidad son bajos (menores a .60), por lo que habría que considerar esto al interpretar los resultados.

\section{Validez}

Se determinó la validez de contenido mediante un procedimiento de validación por jueces (10 psicólogos, 10 pedagogos, 10 maestras de tercero de preescolar y 10 maestras de primero de primaria) para la inclusión de las habilidades que constituyen el instrumento (11) seleccionándose aquéllas que hubieran sido escogidas como indispensables por al menos el $70 \%$ de los jueces, de un total de 23 habilidades incluidas originalmente como resultado de la revisión bibliográfica realizada.

Se obtuvo la validez de criterio (concurrente) a través de su correlación con la subprueba de lectura del Inventario de Ejecución Académica (Macotela, Bermúdez y Castañeda, 1991), obteniéndose una correlación de .76 ( $\mathrm{p}<.001)$ entre los puntajes totales de ambos instrumentos.

Se obtuvo la validez predictiva mediante un análisis de regresión, tomando como variables predictoras los puntajes obtenidos por los niños en cada subprueba y en el puntaje total del EPLE y como variable dependiente el puntaje obtenido por los niños en la prueba de lectura del IDEA. El Coeficiente de Correlación Múltiple (R) fue de .917 y el coeficiente de determinación $\left(\mathrm{R}^{2}\right)$ ajustado fue de .78.

Se obtuvo la validez de constructo mediante la aplicación de un programa instruccional que promovía el desarrollo de las habilidades lingüísticas medidas por el EPLE en un grupo de niños de puntajes bajos y se tuvieron dos grupos control, un grupo de niños de puntaje medio y un grupo de niños de puntaje alto (Thorndike y Hagan, 1989; Nunnally, 1987; Nunnally y Bernstein, 1995). Al finalizar el programa se realizó un análisis de covarianza, tomándose como variable independiente la pertenencia a cada uno de los grupos, como covariable el puntaje en el EPLE en pretest y como variable dependiente el puntaje del IDEA en postest, obteniéndose diferencias significativas en los grupos ( $\mathrm{F}=4.941, \mathrm{p}=.02)$ debidas al entrenamiento en las habilidades lingüísticas y no a los puntajes en pretest. 
Los datos de validez y confiabilidad se obtuvieron de una muestra de 60 niños de la Ciudad de México que cursaban el primer grado de primaria. Las evaluaciones se realizaron al inicio y al final del año escolar. Adicionalmente, existen evidencias empíricas de su aplicabilidad a niños preescolares (Goldrine y Vega, 1999) niños de primero a sexto grado de primaria (Vega y Reyes, 1998) y niños con necesidades educativas especiales (Vega, Reyes y Azpeitia, 1999) y niños preescolares de uno de los escenarios de la presente investigación (Vega y Macotela, 2005)ํ․

\footnotetext{
${ }^{1}$ Para mayor información respecto de esta prueba consultar Vega (1991b) y Vega (1998).
} 


\section{ANEXO 5}

\section{CONTENIDO Y CARACTERÍSTICAS PSICOMÉTRICAS DEL INSTRUMENTO DE OBSERVACIÓN DE LOS LOGROS DE LA LECTOESCRITURA INICIAL}

(Escamilla, Andrade, Basurto y Ruiz, 1996)

A continuación se presenta una tabla que describe cada una de las subpruebas del instrumento.

\begin{tabular}{||l|l|c|c||}
\hline SUBPRUEBA & \multicolumn{1}{|c|}{ DESCRIPCIÓN } & REACTIVOS & $\begin{array}{c}\text { PUNTAJE } \\
\text { MÁXIMO }\end{array}$ \\
\hline $\begin{array}{l}\text { Identificación } \\
\text { de letras }\end{array}$ & $\begin{array}{l}\text { En esta prueba se le presenta } \\
\text { una página que contiene to- } \\
\text { das las letras del abecedario, } \\
\text { mayúsculas y minúsculas, y se } \\
\text { le pide que diga si conoce } \\
\text { cada una por su nombre, so- } \\
\text { nido o conoce alguna palabra } \\
\text { que la contenga. Antes de } \\
\text { que empiece a identificar las } \\
\text { letras, se le pregunta "iQué } \\
\text { son éstas?". } \\
\text { Se cuenta el número de letras } \\
\text { identificado. }\end{array}$ & 61 \\
\hline $\begin{array}{l}\text { Prueba de } \\
\text { palabras }\end{array}$ & $\begin{array}{l}\text { Se presenta un listado de pa- } \\
\text { labras y se pide al niño que } \\
\text { diga qué dice cada una. } \\
\text { Se cuenta el número de pala- } \\
\text { bras identificado. }\end{array}$ & 20 & 20 \\
\hline & & & \\
\hline
\end{tabular}




\begin{tabular}{|c|c|c|c|}
\hline SUBPRUEBA & DESCRIPCIÓN & REACTIVOS & $\begin{array}{l}\text { PUNTAJE } \\
\text { MÁXIMO }\end{array}$ \\
\hline $\begin{array}{l}\text { Conceptos de } \\
\text { texto impreso }\end{array}$ & $\begin{array}{l}\text { Se le presenta al niño un cuen- } \\
\text { to (incluido en los materiales } \\
\text { del instrumento) y se le hacen } \\
\text { preguntas conforme se van pa- } \\
\text { sando las hojas. } \\
\text { Las preguntas que se hacen in- } \\
\text { dagan el conocimiento de los } \\
\text { siguientes aspectos: uso ade- } \\
\text { cuado de los libros, conoci- } \\
\text { miento de que es el texto el } \\
\text { que transmite el mensaje, prin- } \\
\text { cipios de dirección en la lectu- } \\
\text { ra, concepto de letra, concepto } \\
\text { de palabra, conocimiento de } \\
\text { los signos de puntuación, de- } \\
\text { codificación del mensaje. } \\
\text { Se cuenta el número de res- } \\
\text { puestas correctas. }\end{array}$ & 25 & 25 \\
\hline $\begin{array}{l}\text { Vocabulario de } \\
\text { escritura }\end{array}$ & $\begin{array}{l}\text { En el vocabulario de escritura } \\
\text { se pide al niño que escriba to- } \\
\text { das las palabras que conoce y } \\
\text { se le dan diez minutos para } \\
\text { hacerlo. } \\
\text { Se cuenta el número de pala- } \\
\text { bras escritas por el niño. }\end{array}$ & & $\begin{array}{l}\text { El número de } \\
\text { palabras que el } \\
\text { niño escribe. }\end{array}$ \\
\hline
\end{tabular}




\begin{tabular}{|c|c|c|c|}
\hline SUBPRUEBA & DESCRIPCIÓN & REACTIVOS & $\begin{array}{l}\text { PUNTAJE } \\
\text { MÁXIMO }\end{array}$ \\
\hline $\begin{array}{l}\text { Muestra de } \\
\text { escritura }\end{array}$ & $\begin{array}{l}\text { Se analizan los productos per- } \\
\text { manentes. En el caso de esta } \\
\text { investigación se tomó el voca- } \\
\text { bulario de escritura y el dicta- } \\
\text { do para la observación de la } \\
\text { muestra de escritura. } \\
\text { En esta subprueba se conside- } \\
\text { ran tres aspectos: } \\
\text { Nivel de lenguaje: Que se refie- } \\
\text { re al nivel de organización lin- } \\
\text { güística utilizado por el niño, } \\
\text { que puede ser: 1) letras, 2) pa- } \\
\text { labras, 3) frases de dos pala- } \\
\text { bras, 4) oración, 5) dos o más } \\
\text { oraciones, 6) dos temas. } \\
\text { Calidad del mensaje: Incluye } \\
\text { los siguientes niveles: 1) El } \\
\text { niño usa letras o las inventa, } \\
\text { 2) Tiene el concepto de que el } \\
\text { mensaje expresa algo, 3) Co- } \\
\text { pia un mensaje, 4) Usa patro- } \\
\text { nes repetitivos como: Este es } \\
\text { un..., 5) Intenta registrar sus } \\
\text { propias ideas, 6) Completa una } \\
\text { composición. } \\
\text { Principios direccionales: Inclu- } \\
\text { ye los siguientes niveles: 1) } \\
\text { No muestra evidencia de co- } \\
\text { nocimiento de los principios } \\
\text { direccionales, 2) Muestra evi- } \\
\text { dencia de algún principio di- } \\
\text { reccional, por ejemplo escribe } \\
\text { de izquierda a derecha, o ini- } \\
\text { cia en la esquina superior iz- } \\
\text { quierda, 3) Muestra reversión } \\
\text { del patrón direccional (escri- } \\
\text { be de derecha a izquierda y re- } \\
\text { gresa a la derecha 4) Utiliza } \\
\text { correctamente el patrón di- } \\
\text { reccional, 5) Utiliza correcta- } \\
\text { mente el patrón direccional y } \\
\text { además los espacios entre las } \\
\text { palabras, 6) Escribe un texto } \\
\text { extenso sin dificultades en la } \\
\text { dirección y el espacio. } \\
\text { En cada uno de los aspectos } \\
\text { se torna el nivel más alto al } \\
\text { que llegó el niño. }\end{array}$ & 3 & 18 \\
\hline
\end{tabular}




\begin{tabular}{||l|l|c|c||}
\hline \hline SUBPRUEBA & \multicolumn{1}{|c||}{ DESCRIPCIÓN } & REACTIVOS & $\begin{array}{c}\text { PUNTAJE } \\
\text { MÁXIMO }\end{array}$ \\
\hline Dictado & $\begin{array}{l}\text { Se le dicta un enunciado senci- } \\
\text { llo, elegido al azar de cuatro po- } \\
\text { sibles y se le pide que lo escriba. } \\
\text { Se cuenta el número de grafe- } \\
\text { mas que el niño escribe y que } \\
\text { corresponden a cada uno de } \\
\text { los fonemas dictados. }\end{array}$ & 39 & 39 \\
\hline TOTAL & $\begin{array}{l}\text { Esta prueba no arroja un pun- } \\
\text { taje total, para el presente es- } \\
\text { tudio se computó un puntaje } \\
\text { compuesto, sumando los pun- } \\
\text { tos obtenidos en cada sub- } \\
\text { prueba y dividiéndolo entre el } \\
\text { total de subpruebas. Es decir, } \\
\text { se obtuvo un promedio. }\end{array}$ & $\begin{array}{l}\text { Promedio } \\
\text { de puntos } \\
\text { obtenidos. }\end{array}$ & \\
\hline
\end{tabular}

Tabla 3. Subpruebas del instrumento de Observación de los Logros de la Lectoescritura Inicial, aspectos que miden reactivos y puntajes posibles.

Los resultados del instrumento pueden traducirse a porcentajes, excepto para el vocabulario de escritura en dónde no existe un puntaje máximo posible. Los resultados también pueden convertirse a estaninas, basadas en población hispano parlante de Estados Unidos de América.

El instrumento ofrece los siguientes índices de confiabilidad y validez.

\begin{tabular}{||l|c|c|c|c||}
\hline SUBPRUEBA & \multicolumn{3}{|c|}{$\begin{array}{c}\text { CONFIABLIDAD } \\
\text { ALPHA DE CRONBACH }\end{array}$} & $\begin{array}{r}\text { VALIDEZDE CRITERIO } \\
\text { (CONCURRENTE) CON } \\
\text { APRENDA SPANISH READING } \\
\text { ACHIEVEMENT TEST }\end{array}$ \\
\hline $\begin{array}{l}\text { Otoño } \\
1991\end{array}$ & $\begin{array}{c}\text { Primavera } \\
1992\end{array}$ & $\begin{array}{c}\text { Otoño } \\
1991\end{array}$ & $\begin{array}{c}\text { Primavera } \\
1992\end{array}$ \\
\hline $\begin{array}{l}\text { Identificación } \\
\text { de letras }\end{array}$ & .94 & .96 & .60 & .66 \\
\hline $\begin{array}{l}\text { Prueba de } \\
\text { palabras }\end{array}$ & .95 & .97 & .72 & .75 \\
\hline $\begin{array}{l}\text { Conceptos de } \\
\text { texto impreso }\end{array}$ & .69 & .82 & .53 & .51 \\
\hline $\begin{array}{l}\text { Vocabulario } \\
\text { de escritura* }\end{array}$ & .95 & .87 & .66 & .65 \\
\hline Dictado & .96 & .95 & .70 & .60 \\
\hline
\end{tabular}

Tabla 4. Confiabilidad y validez del Instrumento de Observación de los Logros de la Lectoescritura Inicial. * La confiabilidad se obtuvo mediante test- retest 
Los datos que se presentan en esta tabla fueron obtenidos de una muestra de 282 niños en otoño de 1991 y 202 en la primavera de 1992, de comunidades urbanas-hispano parlantes de Arizona, Texas e Illinois (Escamilla, 1992 cit. en Escamilla y cols., 1996) ${ }^{2}$.

${ }^{2}$ Para mayor información sobre esta prueba consultar Escamilla y cols. (1996). 


\section{ANEXO 6 \\ RESULTADOS DEL ANÁLISIS DE REGRESIÓN POR TAREAS DE DESARROLLO DE LA ALFABETIZACIÓN}

El método que se utilizó para cada análisis fue el método paso a paso (stepwise). Se tuvo como criterio para en el modelo a cada variable independiente el que la probabilidad del cambio en $\mathrm{R}^{2}$ fuera menor a .05 y para eliminarla el que fuera mayor de .10.

\begin{tabular}{|c|c|c|c|c|}
\hline $\begin{array}{c}\text { VARIABLE } \\
\text { DEPENDIENTE }\end{array}$ & $\begin{array}{c}\text { VARIABLES } \\
\text { INDEPENDIENTES }\end{array}$ & $\mathrm{R}^{2}$ & BETA & $\begin{array}{c}\text { CORRELACIÓN } \\
\text { PARCIAL }\end{array}$ \\
\hline $\begin{array}{l}\text { Identificación de } \\
\text { letras }\end{array}$ & Edad & $.233 * * *$ & $.500 *$ & .500 \\
\hline $\begin{array}{l}\text { Conceptos de } \\
\text { texto impreso }\end{array}$ & $\begin{array}{c}\text { Edad } \\
\text { Habilidades } \\
\text { lingüísticas orales }\end{array}$ & $\begin{array}{l}.430 * * * \\
.352 * *\end{array}$ & $\begin{array}{l}.376 * * \\
.377 * *\end{array}$ & .375 \\
\hline $\begin{array}{l}\text { Vocabulario de } \\
\text { escritura }\end{array}$ & Edad & $.321 * * *$ & $.580 * * *$ & .580 \\
\hline Dictado & $\begin{array}{l}\text { Habilidades } \\
\text { lingüísticas orales } \\
\text { Lectura de cuentos } \\
\text { por la maestra }\end{array}$ & $\begin{array}{l}.403 * * * \\
.541 * * *\end{array}$ & $\begin{array}{l}.677 * * * \\
.383 * * *\end{array}$ & $\begin{array}{l}.714 \\
.499\end{array}$ \\
\hline $\begin{array}{l}\text { Muestra de } \\
\text { escritura }\end{array}$ & $\begin{array}{c}\text { Edad } \\
\text { Habilidades } \\
\text { lingüísticas orales }\end{array}$ & $\begin{array}{l}.439 * * * \\
.486 *\end{array}$ & $\begin{array}{l}.488 * * \\
.302 *\end{array}$ & .324 \\
\hline Cuento niño & Edad & $.181 * *$ & $.446 * *$ & .446 \\
\hline $\begin{array}{l}\text { Conocimiento } \\
\text { del lenguaje } \\
\text { escrito }\end{array}$ & $\begin{array}{c}\text { Edad } \\
\text { Habilidades } \\
\text { lingüísticas orales } \\
\text { Lectura de } \\
\text { cuento maestra }\end{array}$ & $\begin{array}{l}.535 * * \\
.575 *\end{array}$ & $\begin{array}{l}.478 * * \\
.265 *\end{array}$ & $\begin{array}{l}.476 \\
.329\end{array}$ \\
\hline
\end{tabular}

Tabla 5. Resultados del análisis de regresión realizado para cada componente del desarrollo de la alfabetización.

$$
\begin{aligned}
& * \quad \mathrm{P}<.05 \\
& * * \quad \mathrm{P}<.01 \\
& * * * \mathrm{P}<.001
\end{aligned}
$$


El libro Desarrollo de la Alfabetización en Niños Preescolares fue editado por la Facultad de Psicología de la UNAM y se terminó de imprimir en noviembre de 2007, en la Editorial Cromo Color S.A. de C.V., Miravalle Número 703, Portales, México, D.F.

Su composición se hizo en tipos Bergell LET de 18 pts. N; ZapEllipt BT de 9 y 11 pts. N, B, I.; Goudy OlSt BT de 10 pts. N, B.

La edición consta de 200 ejemplares. 


\section{$978-970-32-4945-9$}

